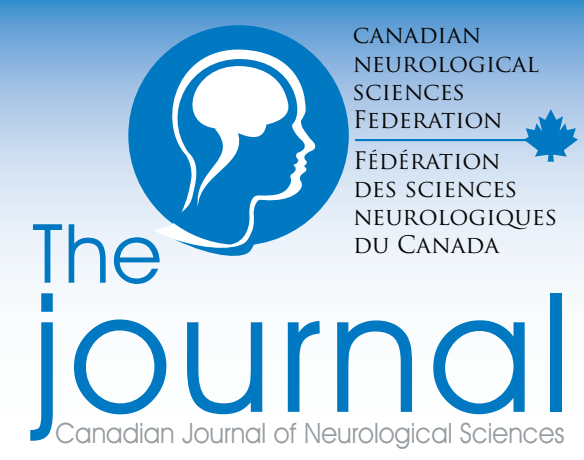

Volume 36 (Supplement 2) August 2009

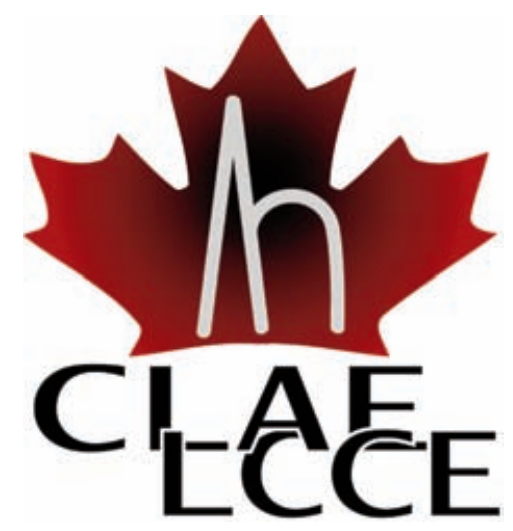

\title{
The Canadian League Against Epilepsy 2007 Conference Supplement
}

\author{
A Peer-Reviewed Supplement to \\ the Canadian Journal of Neurological Sciences
}




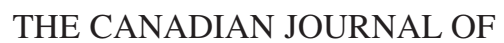 \\ Neurological Sciences

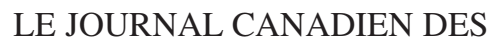 \\ Sciences Neurologiques}

Volume 36 (Supplement 2) August 2009

S1 A Tribute to Dr. Juhn Wada

Warren Blume, Lionel Carmant, Michael O. Poulter

S2 Canadian League Against Epilepsy CLAE 2007

Warren Blume

S3 Canadian League Against Epilepsy - A Brief History

Juhn A. Wada

S7 Epidemiology of Epilepsy: Prevalence, Impact, Comorbidity and Disparities

Samuel Wiebe, Peter Camfield, Nathalie Jetté,

Jorge G. Burneo

S17 Maximizing Quality of Life in People with Epilepsy

Elizabeth M.S. Sherman

S25 Is Functional Hemispheric Lateralization Guided by Structural Cerebral Asymmetry

Juhn A. Wada

S32 Kindling Session - Introductory Remarks

Dan C. McIntyre

S33 Kindling as a Model of Human Epilepsy

Dan C. McIntyre, Krista L. Gilby

S36 Kindling, Long-Term Potentiation and Spatial Memory Performance

\section{Stan Leung}

S39 Mechanisms Underlying Behavioural Co-Morbidities Associated with Kindling

G. Campbell Teskey

S41 Commentary - Epilepsy and Memory Dysfunction Mary B. Connolly

S42 "I Can't Remember": Memory Deficits in Children with Epilepsy

Mary Lou Smith

S46 The Patient's Experience of Memory Change after Elective Temporal Lobe Resection

Jaime Williams, Mora Martin, Jeannette McGlone
S51 Intracarotid Amobarbital Procedure and Etomidate Speech and Memory Test

M. Jones-Gotman, V. Sziklas, J. Djordjevic

S55 Clinical Intracranial Overview of Seizure Synchrony and Spread

Warren T. Blume

S58 Insular Cortex Epilepsy: An Overview

Dang Khoa Nguyen, Dong Bach Nguyen, Ramez Malak, Alain Bouthillier

S63 Commentary - The Catastrophic Epilepsies

Sharon Whiting

S64 Reflections on the Epileptic Encephalopathies

Kevin Farrell

S67 Metabolic Epilepsies: Approaches to a Diagnostic Challenge Sylvia Stöckler-Ipsiroglu, Barbara Plecko

S73 Vitamin $B_{6}$ Dependent Seizures

Barbara Plecko, Sylvia Stöckler

S78 Investigating Epigenetic Influences on Seizure Disposition Krista L. Gilby

S82 Extratemporal "Limbic" Seizures - Introductory Remarks R. Mark Sadler

S84 A Brief Review of the Anatomy and Physiology of the Limbic System

Richard S. McLachlan

S88 Seizures in the Intensive Care Unit Section - Introductory Remarks

G. Bryan Young

S89 Continuous EEG Monitoring in the ICU: Challenges and Opportunities

G. Bryan Young

S92 Status Epilepticus in the Pediatric ICU: State of the Art

A.N. Prasad

S99 Canadian League Against Epilepsy Abstracts 


\section{THE CANADIAN JOURNAL OF \\ Neurological Sciences

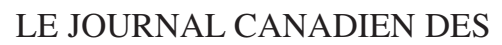 \\ Sciences Neurologiques}

Volume 36 (SupPlement 2) August 2009

\section{Editor-in-Chief/Rédacteur en chef \\ G. Bryan Young LONDON, ON}

\section{Associate Editors/Rédacteurs associés \\ J. Max Findlay EDMONTON, AB \\ Michael Shevell MONTREAL, QC \\ Timothy J. Benstead HALIFAX, NS \\ Mike Poulter LONDON, ON \\ Serge Gauthier VERDUN, QC \\ Mandar Jog LONDON, ON}

Past Editors/Anciens rédacteurs en chef

Douglas W. Zochodne CALGARY, AB

James A. Sharpe TORONTO, ON

Robert G. Lee CALGARY, AB

Robert T. Ross WINNIPEG, MB

(Emeritus Editor, Founding Editor)

\section{Editorial Board/Conseil d'éditorial}

Jorge Burneo LONDON, ON

Richard Desbiens QUEBEC CITY, QC

David Fortin SHERBROOKE, QC

Mark Hamilton CALGARY, AB

Robert Hammond LONDON, ON

Hans-Peter Hartung DUSSELDORF, GERMANY

Michael Hill CALGARY, AB

Alan C. Jackson WINNIPEG, MB

Daniel Keene OTTAWA, ON

Terence Myles CALGARY, AB

James Perry TORONTO, ON

Oksana Suchowersky CALGARY, AB

Brian Toyota VANCOUVER, BC

Brian Weinshenker ROCHESTER, MN, USA

Samuel Wiebe CALGARY, AB

Elaine Wirrell ROCHESTER, MN, USA

\section{SECTION EDITORS/CONSEIL DE RÉDACTION}

Neuroimaging Highlight/Neuroimagerie

Richard Farb TORONTO, ON

David Pelz LONDON, ON

Neuropathological Conference/Conférence sur la neuropathologie

Robert Hammond LONDON, ON

Book Review/Critiques de livres

Andrew Kirk SASKATOON, SK

Critically Appraised Topic Summaries

(CATS)

Jorge Burneo LONDON, ON

Mary Jenkins LONDON, ON
Editorial Review Board/Conseil de Revue d'éditorial

Donald Brunet KINGSTON, ON

Lionel Carmant MONTREAL, QC

Colin Chalk MONTREAL, QC

K. Ming Chan EDMONTON, AB

Robert Chen TORONTO, ON

Mary Connolly VANCOUVER, BC

Joseph Dooley HALIFAX, NS

Daryl Fourney SASKATOON, SK

Hannah Glass SAN FRANCISCO, CA, USA

Alan Goodridge ST. JOHN's, NL

Ian Grant HALIFAX, NS

Alan Guberman OTTAWA, ON

John Hurlbert CALGARY, AB

Manouchehr Javidan VANCOUVER, BC

Patrick McDonald WINNIPEG, MB

Martin McKeown VANCOUvER, BC

Joseph Megyesi LONDON, ON

Vivek Mehta EDMONTON, AB

Steven Miller VANCOUVER, BC

Neelan Pillay CALGARY, AB

Christopher Power EDMONTON, AB

Alex Rajput SASKATOON, SK

Jean Raymond MONTREAL, QC

Gary Redekop VANCOUVER, BC

Mark Sadler HALIFAX, NS

Harvey Sarnat CALGARY, AB

John Stewart VANCOUVER, BC

Jeanne Teitelbaum MONTREAL, QC

Eve Tsai OTTAWA, ON

Shannon Venance LONDON, ON

Matt Wheatley EDMONTON, AB

Jerome Yager EDMONTON, AB

\section{Journal Staff - Calgary, $A B$}

Dan Morin, Chief Executive Officer

Maggie McCallion,

Designer/Production Coordinator

Cindy Leschyshyn, Editorial Coordinator

Advertising representative/Représentant de publicité:

Brett Windle

Corporate Development Coordinator

Tel (403) 229-9575 Fax (403) 229-1661

E-mail: brett-windle@cnsfederation.org
The official journal of: / La Revue officielle de:

The Canadian Neurological Society

La Société Canadienne de Neurologie

The Canadian Neurosurgical Society

La Société Canadienne de Neurochirurgie

The Canadian Society of Clinical Neurophysiologists La Société Canadienne de Neurophysiologie Clinique The Canadian Association of Child Neurology

L'Association Canadienne de Neurologie Pédiatrique

The permanent secretariat for the four societies and the Canadian Neurological Sciences Federation is at:

Le secrétariat des quatre associations et du Fédération des sciences neurologiques du Canada est situe en permanence à: 7015 Macleod Trail SW, Suite 709, Calgary AB, Canada T2H $2 \mathrm{~K} 6$.

The Canadian Journal of Neurological Sciences is published bimonthly. The annual subscription rate for Individuals are: $\mathrm{C} \$ 120$ (Canada), C $\$ 140$ (Foreign including USA). Subscription rates for Institutions are: $\mathrm{C} \$ 150$ (Canada), $\mathrm{C} \$ 170$ (Foreign including USA). See www.cjns.org for details. Single copies C $\$ 30$ each plus postage and handling. Communications should be sent to: Canadian Journal of Neurological Sciences, 709 - 7015 Macleod Trail SW, Calgary, AB Canada T2H 2K6. Telephone (403) 229-9575; Fax (403) 2291661.E-mail: journal@cjns.org; Web: www.cjns.org COPYRIGHT 2009 by THE CANADIAN JOURNAL OF NEUROLOGICAL SCIENCES INC. All rights reserved. No part of this journal may be reproduced in any form without the prior permission of The Canadian Journal of Neurological Sciences. Mailed under Publications Mail Agreement no: 40007777; PAP Registration no: 09824. Postage paid at Calgary, Alberta. This journal is indexed by AbHyg, AgBio, BIOBASE, BiolAb, BIOSIS Prev, CABS, ChemAb CSA, CurAb, CurCont, EBSCO, Elsevier, EMBASE, ExcerpMed, HelmAb, Inpharma, JW-N, LTB, MEDLINE, MetaPress, MycolAb, NRN, NSCI, PE\&ON, PN\&I, ProtozoAb, PsycInfo, Reac, RefZh, RM\&VM, RurDevAb, SCI, SCOPUS, Swets, TDB, TOCprem.

Le Journal Canadien des Sciences Neurologiques est publié 6 fois par an. L'abonnement annuel est de 120 \$C (non-membres au Canada); 140 \$C (Etats Unis et ailleurs); l'abonnement annuel for pour les institutions est de $150 \$ C$ (non-membres au Canada); 170 \$C (Etats Unis et ailleurs); Voir www.cjns.org pour détails. Copie simple: 30 \$C plus affranchissement et manutention. Toutes les communications doivent être adressés à Journal Canadien des Sciences Neurologiques, 709 - 7015 Macleod Trail SW, Calgary, AB Canada T2H 2K6. Téléphone (403) 229-9575; Fax (403) 2291661.E-mail journal@ cjns.org; Web:www.cjns.org. DROITS D'AUTEUR@ 2009: THE CANADIAN JOURNAL OF NEUROLOGICAL SCIENCES INC. Tous droits réservés. Aucune partie de ce Journal ne peut être reproduite, sous quelque forme que ce soit, sans la l'authorisation du Journal Canadien des Sciences Neurologiques. Posté sous poste-publications: numéro de convention: 40007777; numéro d'enregistrement PAP 09824. Port payé à Calgary, Alberta. Le Journal est cité et indexé dans $A b H y g$, AgBio, BIOBASE, BiolAb, BIOSIS Prev, CABS, ChemAb, CSA, CurAb, CurCont, EBSCO, Elsevier, EMBASE, ExcerpMed, HelmAb, Inpharma, JW-N, LTB, MEDLINE, MetaPress, MycolAb, NRN, NSCI, PE\&ON, PN\&I, ProtozoAb, PsycInfo, Reac, RefZh, RM\&VM, RurDevAb, SCI, SCOPUS, Swets, TDB, TOCprem.

Printer/Imprimeur:

Unicom Graphics, 4501 Manitoba Road SE

Calgary, Alberta T2G 4B9 


\section{A Tribute to Dr. Juhn Wada}

Can. J. Neurol. Sci. 2009; 36: Suppl. 2 - S1

The 2007 Conference of the Canadian League Against Epilepsy (CLAE) celebrated the 30th anniversary of its founding by Dr. Juhn Wada. His formation of the CLAE created a forum for interchange of information among Canadian physicians and scientists interested in this common and treatable affliction. It also provided a vehicle for promotion of epilepsy as a significant health care challenge for Canadian society and its governments.

Dr. Wada's career manifests exceptional abilities in both basic and clinical neuroscience. His vision, organizing capabilities and an amusing capacity for gentle persuasion has made him an effective leader in ours and many other professional organizations.

His extraordinary perceptive ability allowed him to translate a fortuitous clinical observation into the intracarotid amytal test for language and memory. Dr. Wada has written a moving account of its inspiration and development in a recent issue of Epilepsia. Without the clarifying data of this procedure, over the years many patients would have been refused potentially beneficial epilepsy surgery or would have suffered unanticipated consequences because of it.

Citing Watanabe's kindling-like experiments published in the Japanese literature in 1936, Dr. Wada recognised the implication of Graham Goddard, Dan McIntyre and C.K. Leech's “fresh perception" of the kindling phenomenon to the neuroscience of epilepsy. Much of his subsequent career has been devoted to logically sequenced kindling studies that chart the pathways of seizure activity through the mammalian central nervous system.

Juhn Wada's achievements have earned him many honours and awards, most notably Officer of The Order of Canada in 1992 and The Order of The Sacred Treasure, Gold and Silver Star from The Emperor and Empress of Japan in 1996. Others include The Wilder Penfield Award of the CLAE, the International League Against Epilepsy (ILAE) and International Bureau for Epilepsy (IBE) Epilepsy International Gold Medal, and The Lennox Award of The American Epilepsy Society.

In his 1976 book "Kindling” Dr. Wada wrote: “.... Every discovery is made to order for the one who can look at a phenomenon with a detached eye, with perspective, and without

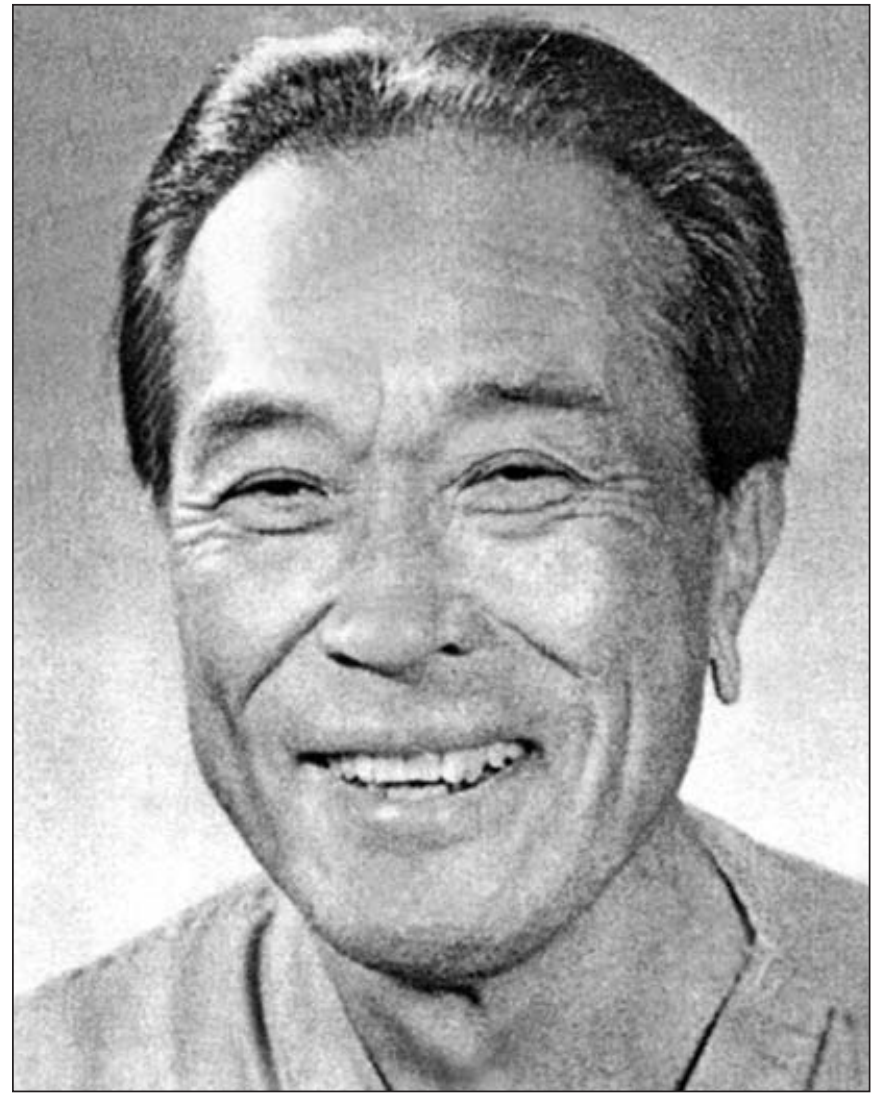

Figure: Dr. Juhn Wada

excessive immediate or categorical pre-occupation, so that one can penetrate the non-essential mossy or glossy layers covering the fact facing him." We would do well to emulate his teachings.

Warren Blume, London, Ontario Lionel Carmant, Montreal, Quebec Michael O. Poulter, London, Ontario 


\section{Canadian League Against Epilepsy CLAE 2007}

Can. J. Neurol. Sci. 2009; 36: Suppl. 2 - S2

We created this program to engage fruitful interaction among basic scientists, neurologists and neurosurgeons in the several epilepsy-related disciplines to promote effective collaborative efforts beyond the conference itself. The active participation of the Canadian Epilepsy Alliance was invited to underscore the pivotal importance of lifestyle management for our patients.

This conference was also designed to provide a window and a forum for young, potential basic and clinical neuroscientists to thereby encourage direction of their careers toward epileptology.
Hopefully our deliberations and this supplement will increase recognition of epilepsy as a common, treatable disorder and of epileptology as the vibrant science devoted to improving the lives of those so afflicted. Articles of this supplement are expanded versions of several presentations of this conference.

All of the foregoing has been made possible by the vision and exemplary career of Dr. Juhn A. Wada, CLAE founder and first president. This conference demonstrates our enduring appreciation of his accomplishments and guidance.

Warren Blume, London, Ontario 


\title{
Canadian League Against Epilepsy
}

\author{
A Brief History
}

Can. J. Neurol. Sci. 2009; 36: Suppl. 2 - S3-S6

The year 2007 has marked the 30th anniversary of the Canadian League Against Epilepsy (CLAE). The celebration of this event was a success under the leadership of the incumbent 14th CLAE president, Dr. Lionel Carmant,

The 30th anniversary represented a youthful maturation of an established organization with intrinsic growth, equipped with the wisdom and extrinsic evolution to meet future challenges. Dr. Carmant has made a timely decision to document the progress of the League since its inception. The ready availability of this historical overview and perspective is a landmark that will not only strengthen our resolve to invigorate the epilepsy movement, but also undoubtedly help to chart our future course.

\section{BACKGROUND}

Back in 1956, the stark reality was a state of general inertia on epilepsy in British Columbia (BC) as the writer arrived in Vancouver from Montreal, where a vibrant activity existed. The situation in BC at that time was probably not too different from that in other provinces and territories outside of Quebec. This realization became the driving force to search for mechanisms to invigorate the epilepsy movement in subsequent years.

As we shall see in this historical overview, the creation of CLAE was deeply rooted in the hopes of boosting the epilepsy movement in Canada through a high-profile public event. It was thus intricately intertwined with events leading to the 10th International Epilepsy Congress in 1978, held in Vancouver. It was during the planning process for this Congress that the necessity of a national professional organization capable of hosting such a world-class event surfaced in our awareness.

\section{Canada's Role in the North American Epilepsy Movement}

During the mid-twentieth century, the Montreal Neurological Institute (MNI) was a prominent centre of excellence in neurology in general and epileptology in particular. Due to the personal interest of its founding director, Dr. Wilder Penfield, Canada became the cradle of epileptology, contributing more than its share of the world's knowledge and training a number of outstanding specialists worldwide.

Historically, the North American epilepsy movement began largely in the eastern United States, to which Montreal had ready access. In 1898, the National Association for the Study of Epilepsy and the Care and Treatment of Epileptics was founded and in 1901 held its first meeting in Washington, DC. In 1909, it became the American affiliate of the International League Against Epilepsy (ILAE). In 1936, the American Branch of the ILAE was organized and the study of epilepsy naturally thrived through intimate interaction and collaboration among interested Canadian and American colleagues. The following served as presidents: Dr. William G. Lennox(1937-38), Dr. Temple Fay (1938-39), Dr. Irving McQuarrie (1939-40), Dr. Tracy J. Putnam (1940-41), Dr. H. Houston Merritt (1941-42), Dr. Wilder Penfield (1942-43), Dr. T.C. Erickson - who had earlier made a historic study on the role of corpus callosum in partial onset generalized seizure at MNI-(1943-44), Dr. C.D. Aring (194445). The first meeting following World War II took place in New York in 1946. Subsequently this date has been identified as the founding date of the American Epilepsy Society (AES) of today, and Dr. Francis McNaughton of Montreal was its first president (1948-49). The AES has served and represented the interests of both the United States and Canada without discrimination. This tradition of AES continued as reflected by the fact that four more Canadians served as its president: T. Rasmussen (1961-62), P. Robb (1965-66), P. Gloor (1975-76), and J. Wada (1988-89). It seems that there was no particular need or reason to have a separate Canadian Epilepsy Society.

However, despite what appeared to be a seamless representation of both Canadian and American interests, there was a substantial need to implement new knowledge at local and provincial levels across the vast landscape of Canada, particularly outside of Quebec. It was under such circumstances, that Dr. Wada attended quadrennial Neurological Congresses: in Vienna (1965), where he heard Dr. F. McNaughton speak eloquently on the need for an accelerated epilepsy movement at the ILAE Congress, and in New York (1969), where he met Dr. Jerome Merlis, then president of ILAE and a past president (1956-57) of the AES, who spoke on North American participation in a worldwide endeavour against epilepsy. These events provided Dr. Wada an important insight into local and national efforts within the international context and perspective. 


\section{The Genesis of CLAE}

The most critical opportunity presented itself in 1973 following the International EEG \& Clinical Neurophysiology Congress in Marseille. Dr. Wada was heading for Barcelona, where both Neurological and ILAE Congresses were to be held. At the Marseille train station, Dr. Wada found his friend Dr. David Daly as a fellow traveller to Barcelona. Dr. Daly had served as AES president (1966-1967) and was then about to become the ILAE president in Barcelona. Conversation during their train ride centred around the workings and mandates of AES and ILAE.

Attendance at subsequent ILAE-related European Epilepsy Congresses brought Dr. Wada into closer contact with not only ILAE executives but also Mrs. Ellen Grass, who represented the International Bureau for Epilepsy (IBE), a lay organization. These events nurtured Dr. Wada's vision of enhancing public awareness of research frontiers of epilepsy and changing public attitudes towards epilepsy through holding a similar high-profile meeting on Canada's Pacific Coast. At the Brussels Congress (1974), Dr. Wada discussed this possibility with Dr. Daly and Mrs. Grass. There were strong arguments in favour of this idea: there had not been any precedent of an Epilepsy Congress on the west coast of North America, Canadian provinces outside of Quebec needed an invigorated epilepsy movement, and Vancouver is strategically located for direct access from the American, European, and Asian continents. Both Dr. Daly and Mrs. Grass were highly supportive of the idea, but at the same time it became clear that the ILAE Congress would require a national professional epilepsy society to host the event. It suddenly dawned on Dr. Wada that, despite its prominence in the profession, Canada did not have its own national society, possibly due in part to its very close involvement in the AES. When the question was posed about this issue, Dr. Wada was reminded that he was also an AES member, and consequently the AES could easily host it on Canada's behalf. Despite this generous American gesture, Dr. Wada still felt very strongly that Canada must have its own national society. It was a natural response for him since he was born and educated in Japan, came to Canada via the United States, and had made a conscious decision to be an adopted son of Canada.

\section{Creation of a National Society: Canada to Host International Congress}

At the 1975 Canadian Neurological Congress in London, Ontario, Dr. Wada discussed with a number of colleagues the idea of boosting nation-wide the clinical and basic research effort on epilepsy and increasing public awareness on the research frontiers of epilepsy through developing a professional Canadian organization. Those colleagues were Dr. Norman Auckland (BC), Dr. Frederick Andermann (PQ), Dr. Warren Blume (ONT), Dr. Henry Dunn (BC), Dr. Keith Meloff (ONT), and Dr. Allan Sherwin (PQ). It was their unanimous decision to create a Canadian national epilepsy society, and they agreed to become the six founding members. Legal groundwork began immediately to incorporate the Canadian society, with assistance from lawyer Mr. Kay Collins and his associate Mr. Will Geselbracht of Vancouver. Constitution and bylaws were drawn up and the proposal was submitted to Ottawa. The Congress proposal was then submitted to ILAE at the Berlin Congress in
1975, pending admittance of our society as the Canadian Chapter of ILAE. Our Vancouver Congress proposal was formally approved at the Dublin Congress in 1976. The proposed name of our national society was initially Epilepsy Canada. However, we were informed by Ottawa that the name was already claimed by a lay organization, then the Canadian Epilepsy Association. Thus, the new national society was formally baptised as the Canadian League Against Epilepsy.

\section{Inaugural CLAE Symposium, Proceedings, and the Wilder Penfield Gold Medal}

On May 20 and 21, 1977, inauguration of the Canadian League Against Epilepsy was celebrated by holding an International Symposium in Vancouver. Greetings and support were received from both the AES (Dr. D. Purpura) and the Japan Epilepsy Society (JES, Dr. H. Akimoto). Participants included clinical and basic scientists from both Canada and the United States in addition to the presidents of both ILAE and IBE. The proceedings were published as Modern Perspectives in Epilepsy (J.A. Wada, ed., Eden Press, 1978).

In 1977, the CLAE had 171 paid-up members. The tenure of presidency was set for two years; the secretary-treasurer was chosen locally to make future efforts easier. In addition, the CLAE developed an Awards Program and engaged jeweller Henry Birks to develop the Wilder Penfield Medal. This Gold Medal was to be given for outstanding service in clinical and research accomplishments on epilepsy. (The medal was subsequently made available to MNI for its 50th Anniversary celebration but the original cast remains with CLAE). Lists of past presidents and Penfield awardees are appended at the end of this document.

\section{Preparation for the 1978 International Congress, Program, and Proceedings}

Having created our national society, an intensive race to work out the details of the Vancouver Congress began. Countless formal and informal meetings and transactions took place locally, nationally, and internationally. We found ourselves in totally unknown territory with a huge financial undertaking. Yet our spirits soared as we took the concrete steps towards achieving our ultimate goals of raising public awareness on research frontiers of epilepsy and generating a sense of urgency on epilepsy among our colleagues by hosting the International Congress in Canada.

\section{Financial and Legal Undertaking}

The most serious initial challenge was financial in nature, but this was overcome by substantial private mortgage financing from the founding president. Subsequently, a chance encounter on a plane with Senator Ray Perrault led to a successful federal grant application. Countless advice from others helped us to obtain further funding from both federal and provincial (per Professor Richard Splane, Social Work) and private (per former UBC Dean of Medicine, Dr. John McCreary, Woodward Foundation Director) sources. Since ILAE did not allow us to hire a professional accounting firm, we enlisted voluntary assistance from personal friends on the UBC campus: Faculty of Commerce (then-Dean Peter Lustzig) and Faculty of Law (Professor Ralf Loffmark). Our close ties with colleagues in a 
multi-faculty university proved to be an enormous asset as we grappled with the financial and legal implications of our undertaking.

To host the International Congress, there was a need to consolidate our national resources. Thus, the Canadian Epilepsy Association moved its headquarters to Vancouver from Toronto to maximize our national potential along with CLAE. Retrospectively, the 1978 Vancouver Congress not only created CLAE but also revitalized the lay organization, known as Epilepsy Canada.

\section{Congress Program}

Conceptually, the Vancouver Congress was unique. While it was held on Canada's Pacific Coast and hosted by the CLAE, it was considered important to join forces with professionals from other Pacific Rim regions. The outcome of this initiative was that CLAE was joined by the AES (President: F. Dreifuss), the (U.S.) Western Institute of Epilepsy (WIE, President: J. Wada), and the Japan Epilepsy Society (JES, President: H. Akimoto), in becoming the moving force while retaining their own themes within the Congress program. Additional program contributions were made by lay organizations: the British Columbia Epilepsy Society (BCES), the Canadian Epilepsy Association (CEA), and the Epilepsy Foundation of America (EFA). Thus, the major themes that evolved were AES - Intensive monitoring; CLAE New surgical treatment through experimental models; JES Natural history and prognosis; WIE- Neurotransmitters, Behaviour and Teratogenicity; ILAE - New drug testing, marketing and availability; BCES/CEA and EFA Comprehensive care. Finally, IBE supported a special lecture at which Dr. Robert Naquet of Paris spoke on "Limits and Perspective of Our Knowledge: Progress from Research." Following the Congress, a Public Seminar on "What's New on Epilepsy," with prominent participants of the Congress as speakers, was held at the University of British Columbia Hospital.

\section{Congress Registration and Media Coverage}

Over 1,200 people registered for the Congress - this was in contrast to the 150-300 registrants on previous occasions) - and Public Seminar (500 registrants). The events were successfully presented with the voluntary assistance of many local professionals and lay people. Extensive media coverage highlighted the research frontier of epilepsy and the problem of epilepsy as an important public health issue.

\section{Publication of Proceedings}

Proceedings of these events were published: ILAE: Progress in Epileptology (eds. Wada \& Penry); CLAE / WIE: EPILEPSY - Neurotransmitter, Behavior and Pregnancy (ed. Wada) and CLAE: What's New on Epilepsy (ed. Wada). The latter was reprinted in the BC Medical Journal and was widely distributed to enhance the sense of urgency among professionals.

\section{Local Consequence}

One substantial benefit was the development of a dedicated Seizure Investigation Unit. This state of the art clinical facility enabled to complement and integrate existing basic research facility at the University of British Columbia Hospital in 1979.

\section{Consolidation of National Resources}

Reflecting the subsequent increased awareness of epilepsy, there has been a remarkable proliferation of epilepsy-related groups between 1980 and 2006 such as the Canadian Epilepsy Consortium (CEC), Canadian Epilepsy Research Institute (CERI), Canadian Epilepsy Data Resource (CEDAR), and Canadian Pediatric Epilepsy Network (CPEN) within Canada, independent of the CLAE. Although these groups were all highly worthwhile, it was felt that a nation-wide integrated approach using the legally established CLAE entity would streamline various facets of the epilepsy movement. In March 2001, a suggestion was made by Dr. Peter Carlen and Dr. Warren Blume that all people interested in epilepsy get together.

Under the leadership of the 12th President, Elout Starreveld (2001-03), this issue was addressed, the aim being to broaden the perspective of the Canadian Epilepsy movement by an initiative formally linking the CLAE with other organizations and inviting representatives of the CEC (Dr. Neelan Pillay), CPEN (Dr. Lionel Carmant), CERI (Dr. Peter Carlen), Neurology/ Neurosurgery residents (Dr. Nathalie Jette), and Epilepsy Canada (Dr. Donald Weaver) to join the CLAE Board. The resulting high-spirited mutual collaboration with Epilepsy Canada (EC, President Tim Ryan) resulted in the CLAE President sitting also on the Board of Epilepsy Canada.

One substantial outcome of this initiative was an organic union with CERI. The CERI September 2001 meeting, held at the MNI, became a historic event when the more than one hundred attendees voted unanimously to join the CLAE as a section, paving the way for an organic union of basic and clinical national resources under the CLAE umbrella. With this formal link in place, the concept of an annual conference, either preceding the Canadian Congress of Neurological Sciences (CCNS) or as a stand-alone symposium in the fall was realized. Thus, the 2005 London Conference on Intractable Epilepsy was organized, with basic and clinical resources mobilized by Dr. Warren T. Blume, who ceaselessly worked towards a unified front. The proceeding of this symposium was also published (Blume et al., eds. Intractable Epilepsy: Advances in Neurology, vol. 97, 2005).

\section{Legal Status}

In the meantime, the by-laws of the CLAE were amended to accommodate the changes that had taken place and to ensure continuity of an effective Board composition and representation.

Another important issue addressed was an obvious shortcoming of the status of CLAE: as a charitable organization rather than a foundation or corporation, it was legally required to expend $80 \%$ of annual revenue. This limitation was legally rectified in subsequent years. The amended by-laws now enable the CLAE to adapt to the changing circumstances of the twentyfirst century.

\section{Awards}

It was also under Dr. Starreveld's presidency that the Mary Anne Lee Award was established to honour the late Dr. Mary Anne Lee, a highly respected epileptologist from Calgary. This award is made annually and is open to a resident in training in Neurology, Neurosurgery, or Paediatric Neurology, or to a medical or basic science student under certain criteria. (See also 
the "New Directions" section for the expansion of the awards program.)

\section{New Directions of Endeavour}

Under the leadership of the 13th President, Dr. S. Wiebe, there has been an additional intrinsic growth spurt corresponding to a new era of an extrinsic high-profile CLAE activity.

\section{National Activities}

Further promotion of CLAE as a platform for dialogue among the many Canadian epilepsy organizations resulted in the inclusion of the Canadian Epilepsy Alliance (CEA) in the CLAE Board. Membership was opened to a wider population, including allied health care workers and other interested individuals.

$\square$ Half-day Epilepsy Course on various topics are offered by the CLAE education committee under the leadership of Dr.Neelan Pillay at The Canadian Congress of Neurological Sciences.

$\square$ An endowment was established for CLAE research awards geared towards medical and basic science students, clinical fellows, and allied health personnel. These awards are part of the Mary Anne Lee Award. All four awards are made annually now since 2006.

\section{International Activities}

Provision of international leadership: the CLAE president is chairing the newly created ILAE North American Region Commission on epilepsy. The latter with representatives from Canada, Jamaica and the United States have a broad mandate to foster epilepsy care and education in North America and the Caribbean.

$\square$ New relationship with AES: participation of CLAE president in the AES Board and CLAE / AES hosting of the Biennial North American Congress, beginning in 2006.

\section{Epilogue}

The intrinsic growth and extrinsic evolution of the CLAE with an expanding role and forum will enable Canada to contribute its traditional strength more effectively to explore new horizons for further invigoration of the North American Epilepsy movement, hand-in-hand with our American and regional colleagues.

This spirit of mutual collaboration is highly reminiscent of previous AES arrangements that represented both American and Canadian interests. The future is with us here today and we are all thrilled with this dynamic transformation of the CLAE as it expands and fulfils its role more forcefully and effectively, thus escalating the North American drive as an integral part of a global campaign against epilepsy. At this time, we look forward to the 30th Anniversary Symposium in October 2007 featuring an overall review of significant topics on epilepsy relevant to Canada that will be the most prominent event in CLAE history.

\author{
Appendix \\ Past CLAE Presidents \\ 1977-79 Juhn Wada \\ 1979- 81 Norman Auckland \\ 1981- 83 Henry Dunn \\ 1983- 85 Warren Blume \\ 1985- 87 Frederick Andermann \\ 1987-89 Allan Sherwin \\ 1989-91 Joseph Bruni \\ 1991-93 Alan Guberman \\ 1993-95 Mark Sadler \\ 1995-99 Richard McLachlan \\ 1999-01 Michael Jones \\ 2001-03 Elout Starrveld \\ 2003-06 Sam Wiebe \\ 2006- Lionel Carmant

$\begin{array}{ll}\text { Wilder Penfield Gold Medal Awardees } \\ 1982 & \text { Dr. Theodore Rasmussen } \\ 1984 & \text { Dr Brenda Milner } \\ 1986 & \text { Dr Preston Robb } \\ 1987 & \text { Drs Katherine and Julius Metrakos } \\ 1988 & \text { Dr Juhn Wada } \\ 1990 & \text { Dr Pierre Gloor } \\ 1997 & \text { Dr Warren Blume } \\ 1999 & \text { Dr Frederick Andermann } \\ 2001 & \text { Dr St Hilaire } \\ 2003 & \text { Dr Peter Camfield } \\ 2005 & \text { Dr Brenda Milner } \\ 2006 & \text { Dr Jean Gotman }\end{array}$ \\ Mary Anne Lee Awardees \\ 2002 N. Jette \\ 2003 P. Tai \\ 2004 A. Kirton \\ 2005 S Hussein \\ 2006 J Wong (Resident/med student) \\ J Tellez-Zenteno (Fellow) \\ M Robertson (Allied Health) \\ P deGuzman (Grad student)
}

Juhn A Wada CLAE Founding President Vancouver, British Columbia 


\title{
Epidemiology of Epilepsy: Prevalence, Impact, Comorbidity and Disparities
}

\author{
Samuel Wiebe, Peter Camfield, Nathalie Jetté, Jorge G. Burneo
}

\begin{abstract}
This is a summary of four presentations on epidemiological aspects of Epilepsy in children and adults in Canada, given at the Canadian League Against Epilepsy 30th anniversary meeting in Vancouver, British Columbia in October 2007. Dr. S. Wiebe discusses the burden of epilepsy, Dr, P. Camfield addresses the epidemiology of epilepsy in children, Dr. N. Jetté provides an overview of comorbidity and epidemiological surveillance in epilepsy, and Dr. Burneo explores the area of disparities in epilepsy. The summary is intended as a brief overview of these aspects, with particular emphasis on available Canadian data.
\end{abstract}

RÉSUMÉ: Épidémiologie de l'épilepsie : prévalence, impact, comorbidité et disparités. Il s'agit d'un sommaire de quatre présentations portant sur les aspects épidémiologiques de l'épilepsie chez les enfants et les adultes au Canada, présentées en octobre 2007 à Vancouver en Colombie-Britannique, à l'occasion du 30e anniversaire de la Ligue canadienne contre l'épilepsie. Le Dr S. Wiebe discute du fardeau de l'épilepsie, le Dr P. Camfield présente l'épidémiologie de l'épilepsie chez les enfants, le Dr N. Jetté offre un résumé de la surveillance épidémiologique et de la comorbidité et le Dr Burneo explore les disparités dans l'épilepsie. Il s'agit donc un bref survol de ces aspects mettant en lumière les données canadiennes disponibles.

Can. J. Neurol. Sci. 2009; 36: Suppl. 2 - S7-S16

\section{THE IMPACT OF INTRACTABLE EPILEPSY Samuel Wiebe}

The concept of burden of illness is broad-ranging and includes epidemiological, socioeconomic and clinical components. In addition, this term also involves subjective perceptions by individuals about the impact of health issues on their quality of life. The term "burden of illness" can also be conceptualized as "impact of illness," and we will use the latter term in this manuscript. In the following paragraphs we will briefly touch on each of these aspects of the impact of epilepsy, emphasizing Canadian data when possible.

\section{Epidemiological Impact of Epilepsy in Canada}

Recent reports derived from data gathered in the Canadian National Health Surveys and the Canadian Community Health Surveys have provided the first epidemiological national estimates of prevalence of epilepsy in Canada. The age-adjusted point-prevalence of self-reported physician-diagnosed epilepsy in Canada is 5.6 per 1,000 (95\% CI, 5.1-6.0) according to a national epidemiological study by Tellez-Zenteno et $\mathrm{al}^{1}$. These authors also studied the prevalence of epilepsy in each province and demonstrated that this was somewhat lower in the western provinces, particularly in British Columbia $(3.6$ per 1,000), and somewhat higher in the Atlantic $(6.9$ per 1,000$)$. Overall, one in 150 people in Canada, or approximately 250,000, suffer from epilepsy according to these figures. These data are in keeping with the prevalence rates reported in the USA and in other developed countries ${ }^{2}$. The only data on the incidence of epilepsy (the number of new cases diagnosed per unit of time) in Canada pertain to the paediatric population and are discussed below ${ }^{3}$. There are no data on the incidence of epilepsy in adults in Canada.

A clearer view of the impact of epilepsy on the health of the population in general can be obtained by looking at data compiled by the World Health Organization in its 2004 Atlas of health resources ${ }^{4}$. In this document, which describes the neurological disorders most frequently reported in primary care world-wide, epilepsy emerges as the second most common condition seen in primary health care settings $(72.5 \%)$, after

From the Department of Clinical Neurosciences (SW, NJ), University of Calgary, Calgary, AB; Department of Pediatrics (PC), Dalhousie University, Halifax NS; Department of Clinical Neurological Sciences (JGB), University of Western Ontario, London, ON, Canada.

Received August 5, 2008. Final Revisions Submitted September 25, 2008. Correspondence to: Samuel Wiebe, Division of Neurology, Foothills Medical Centre, 1403-29 St NW, Calgary, Alberta T2N 2T9, Canada. 
headache (73.5\%) and before stroke (62.7\%)4 (Figure 1). According to the World Health Organization, epilepsy is the most common neurological condition seen in primary care in Africa, the Americas, the Eastern Mediterranean region and Southeast Asia ${ }^{4}$. Although some of these data are driven by the high incidence and prevalence of epilepsy in developing countries, developed countries are not immune to the impact of epilepsy. Because the incidence of epilepsy is higher in children and aging adults, as the aging population increases in developed countries, we can expect to see a higher incidence and prevalence of epilepsy in developed countries in the coming years.

\section{Economic Impact of Epilepsy}

The economic impact of epilepsy is often assessed in terms of the costs to the health care system. However, there are also important economic costs to patients, their families and society. The studies assessing the cost of epilepsy can be divided into those that explore the cost of all prevalent or of all incident cases. Costs of prevalent cases refer to the annual costs of the existing cases of epilepsy within a certain region. Costs of incident cases describe the projected lifetime costs of all new cases of epilepsy within that region. There are no direct estimates of the cost of epilepsy in Canada. However, cost estimates from industrialized countries and in those that have public health care systems can be expected to have some resemblance to those in Canada ${ }^{5}$. In industrialized countries, the cost per prevalent case per year

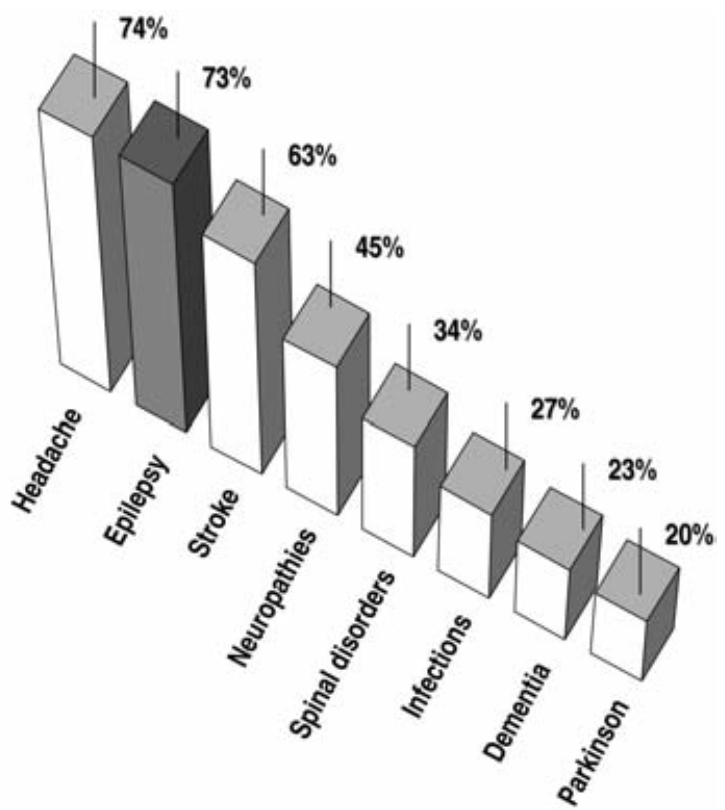

Figure 1: Neurological conditions in primary care worldwide. Percentages represent proportion of countries reporting each condition as that most commonly seen in primary care. (Source: WHO Atlas of Neurological Disorders 2004) ranges from about $\$ 1,000$ for inactive epilepsy, and $\$ 1,500$ for active epilepsy, to $\$ 3,000$ for intractable epilepsy ${ }^{5}$. In the US, the lifetime costs for incident cases nationwide is estimated at $\$ 11.1$ billion and the annual costs for all prevalent cases is estimated at $\$ 12.5$ billion $^{6}$. Of these, $87 \%$ are indirect costs, i.e. costs related to foregone earnings from morbidity and mortality. This profile of costs is a common pattern in most studies, i.e., indirect costs are responsible for the largest economic impact in epilepsy. With regards to direct medical costs, the breakdown of various aspects of medical care is as follows: hospital costs are responsible for $33 \%$, AEDs for $31 \%$, diagnostic investigations for $21 \%$, physician services for $12 \%$ and surgical treatment for $6 \%$ of all medical costs ${ }^{6}$. Patients with active epilepsy have higher costs, and those with intractable epilepsy have a disproportionately high cost. There are no direct estimates of the cost of epilepsy in Canada. However, cost estimates from countries that have public health care systems can be expected to have some resemblance to those in Canada 5 .

\section{Psychosocial Impact of Epilepsy}

The sudden, unexpected and recurrent interruption of brain function produced by seizures, the cognitive side effect of therapies, and the comorbidities associated with epilepsy all have serious psychosocial consequences for people with epilepsy. Sillanpaa et al have reported on the socioeconomic aspects of neurologically intact individuals who are in long term remission from seizures ${ }^{7}$. As compared with people without epilepsy, these individuals have a higher prevalence of low socioeconomic status, unemployment, inability to drive, limited education, nonmarried marital status and childlessness (Figure 2). Some of the psychosocial problems appear to have a direct correlation with seizure frequency. Patients without seizures for one year, those with less than one seizure per month, and those with more than one seizure per month have a corresponding gradient of ascending prevalence of psychosocial problems such as impaired social activities, inability to sustain paid work, poor self perceived health, inability to make friends, poor planning for the future, and low standards of living ${ }^{8}$. In population based Canadian studies the prevalence of injuries that are severe enough to limit activities did not differ in people with epilepsy from that in the general population (about $14 \%$ per year) ${ }^{9}$. However, people with epilepsy are three times more likely to be hospitalized following an injury than those without epilepsy ${ }^{9}$. These results differed from those that focus on selected or institutionalized patients. In the latter, the prevalence of injuries is higher than in the general population, and it exhibits a gradient which relates to the frequency of seizures ${ }^{8}$.

\section{Impact of Epilepsy on Mortality}

People with intractable epilepsy and frequent seizures have a higher mortality rate than the general population. The standardized mortality ratio (SMR) is a metric commonly used to assess the mortality rate in specific populations. It refers to the ratio of observed deaths in the population of interest to those expected in a standard population, adjusted for age and gender. Depending on the epilepsy population studied, the reported SMR is up to six or seven times higher in people with epilepsy than in controls. The highest SMRs are seen in patients with medically refractory epilepsy. There appears to be an increasing gradient in 


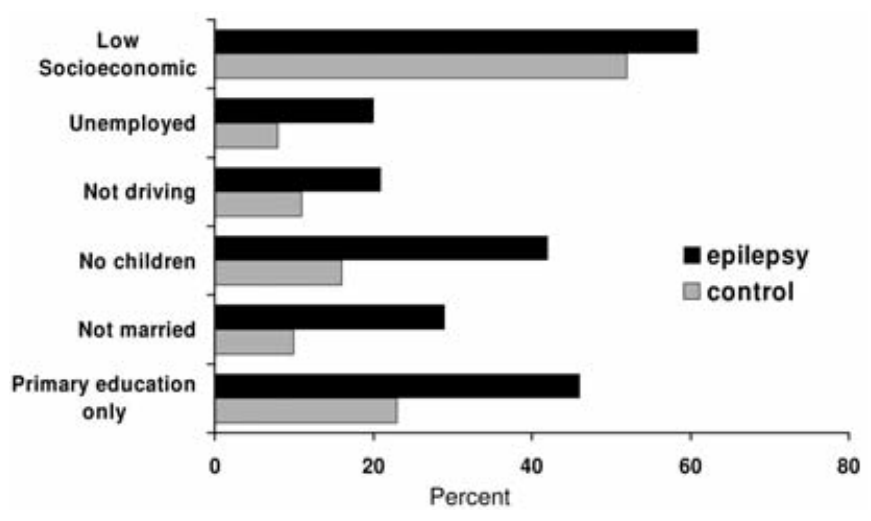

Figure 2: Long term impact of epilepsy in otherwise healthy adults diagnosed with epilepsy in childhood, as compared to controls without childhood epilepsy. (From reference 7)

the SMR corresponding to the frequency of seizures and to their severity. The SMR is 1.0 in those without seizures for one year, close to 2.5 in those with no generalized convulsions but with other seizures, 2.5 in those with generalized convulsions in the past year, and close to 4.0 in those with status epilepticus in the past year ${ }^{10}$. According to at least two reports, the excess mortality reverts to the levels of the general population in patients who undergo successful epilepsy surgery and become seizure free ${ }^{11,12}$.

\section{EPIDEMIOLOGY OF CHILDHOOD EPILEPSY Peter Camfield}

This brief review touches on five aspects of the epidemiology of childhood epilepsy - definition of seizures and epilepsy, incidence, prevalence, mortality and preventable causes.

\section{Definition}

Epilepsy in children is usually diagnosed when a child has had at least two or more unprovoked seizures. This pragmatic decision is based on the observation that in children the recurrence risk is $40-50 \%$ after a first unprovoked seizure, but after a second seizure the risk of a third increases to about $80 \%{ }^{13-}$ 15. Two unprovoked seizures then imply a recurring disorder, which is a key concept in the definition of epilepsy, ie., an enduring tendency for unprovoked recurrent seizures ${ }^{16}$.

There are many issues related to the diagnosis of epilepsy. Seizures are rarely witnessed by the diagnosing physician - they are based on historical data that may be inaccurate, as noted below. Particularly confusing are reported events that preceded the first "definite" seizure. For example if a child awoke with a small bite on his/her tongue on one occasion and on another occasion had a more definite seizure, can epilepsy be diagnosed? "Unprovoked" is not well defined. If a child was significantly sleep-deprived or an adolescent had consumed a small amount of alcohol, was the seizure unprovoked? Is it reasonable to consider
EEG epileptiform discharges in diagnosing epilepsy after a first seizure? For example, should epilepsy be diagnosed if an adolescent has a single generalized tonic-clonic seizure, and a subsequent EEG captures a few tiny myoclonic jerks associated with generalized spike and wave discharges? Finally there is a problem with assigning an epilepsy syndrome diagnosis after a first seizure. For example, a normal child may present with a first nocturnal seizure primarily involving the face and tongue, and an EEG showing typical centro-temporal spikes. The diagnosis of Benign Focal Epilepsy of Childhood with Centro-temporal Spikes can easily be made, and yet by the two unprovoked seizure rule, the child does not yet have epilepsy.

Because the diagnosis of seizures and epilepsy is based on the clinical history, there are inevitably some errors. A Dutch group of investigators studied this issue carefully ${ }^{17}$. A panel of three paediatric epilepsy experts reviewed the histories of patients presenting with a first seizure presented to other neurologists. Of 207 cases the panel found that 156 seizures were convincing while 51 were found to be disputable. During follow up, 54\% of those with a definite seizure had a recurrence to confirm the diagnosis. That means that for $46 \%$ of those with a definite first seizure there was no way to confirm the diagnosis. For the disputable group $10 \%$ had a definite seizure recurrence, $35 \%$ had a convincing non-epileptic recurrence and the remainder had no further attacks. It is likely that in a less sophisticated setting even more diagnostic errors might be made after a first seizure. Therefore all epidemiological studies of childhood epilepsy will suffer from the methodological issue that an unknown proportion of subjects do not actually have epilepsy.

\section{Incidence and Prevalence}

Since epilepsy is a chronic disorder, prevalence is higher than incidence. Most studies have found the prevalence of epilepsy to be three to four times the incidence ${ }^{18}$. On the other hand about $50 \%$ of childhood epilepsy eventually remits, therefore prevalence is usually defined as having a diagnosis of epilepsy with at least one seizure in the past one to three years, regardless of medication treatment. It is common to refer to the prevalence of "active epilepsy."

It is challenging to design satisfactory studies for establishing incidence and prevalence of epilepsy ${ }^{18}$. Databases that document the health visits and physician diagnoses for a given population are often used. A Health Maintenance Organization (HMO) might provide such data but it may have a socioeconomic bias. In Canada, a provincial physician billing visit/hospitalization database might be used but the accuracy of the diagnosis and what the physician actually enters on the billing form are potential sources of error. Pharmacare programs are tempting sources of data since most epilepsy is treated with AEDs; however, at least $50 \%$ of AED prescriptions are for non-epilepsy diagnoses. Linking pharmacare and physician visits may provide further reassurance. Electroencephalogram (EEG) laboratories may provide comprehensive data for developed countries since EEG is nearly always requested when the diagnosis of epilepsy is being considered. Obviously an EEG request can only be the gateway to finding people with epilepsy since EEG is used for many other reasons than epilepsy ${ }^{19}$. Door to door or telephone surveys have also been used. Here, the sophistication of the interviewer and respondent may be a problem and it has been 
suggested that at least $10 \%$ of people with epilepsy will hide the diagnosis is such settings.

Given all of these caveats, it is not surprising that there is a great deal of variation in published rates of incidence and prevalence of childhood epilepsy among studies of similar populations. A major review of 40 incidence studies of variable methodological quality suggested that for children from 0-14 years, the median incidence was $82 / 100,000$ with a range of 41 $840 / 100,000$. Data for adults (15-59 years) showed a median of $34.7 / 100,000$ with a range of $28-158 / 100,000$, and for the elderly ( $\geq 60$ years) the median was 39.7 with a range of 7.5$150 / 100,000^{20}$.

The Nova Scotia epilepsy study documented all children with epilepsy ( 2 or more unprovoked seizures between 1 month and 16 years of age) with onset between 1977 and $1985^{3}$. As in all similar studies, the incidence was highest in the first year of life $(118 / 100,000)$, stable between one and ten years (about $45 / 100,000)$ and then falling in adolescence to about $21 / 100,000$ suggesting that puberty does not have a significant influence on new onset epilepsy. This study found in general a lower
There is no doubt that children with epilepsy have a considerably higher mortality than the baseline population; however, it has also become clear that nearly all of this excess mortality is related to co-morbid problems ${ }^{21-23}$ (Table 1). In three large prospective studies with 5-20 years of follow up, the number of seizure-related deaths is very small - only four of the total of 1777 incidence cases died from status epilepticus or SUDEP. All of the other deaths were the result of co-morbid conditions. In the Nova Scotia cohort this was mostly from aspiration pneumonia not due to seizures but to severe bulbar dysfunction associated with cerebral palsy or other static encephalopathies. Children with symptomatic epilepsy (seizures caused by a preexisting structural or acquired brain abnormality) were 22-33 times more likely to die than those in the general population (Table 1). Those with a non-symptomatic etiology (no coexisting neurological abnormality or pre-existing structural or acquired brain abnormality) had no increase risk of death. About $60 \%$ of children with epilepsy have a non-symptomatic cause. For the majority of children with epilepsy, families can be reassured that the child's chance of dying over the next 20 years

Table 1: Mortality in childhood epilepsy

\begin{tabular}{|c|c|c|c|}
\hline & $\begin{array}{l}\text { Nova } \text { Scotia }^{22} \\
\mathrm{~N}=692 \\
\text { Follow up }=20 \text { years (average) }\end{array}$ & $\begin{array}{l}\text { Dutch } S_{\text {tudy }}{ }^{21} \\
\mathrm{~N}=472 \\
\text { Follow up }=5 \text { years (average) }\end{array}$ & $\begin{array}{l}\text { Connecticut Study }{ }^{23} \\
\mathrm{~N}=613 \\
\text { Follow up }=7.8 \text { years (average) }\end{array}$ \\
\hline All Deaths & 26 & 9 & 13 \\
\hline Seizure-related & 1 from status epilepticus & 0 & 1 from status epilepticus \\
\hline SUDEP & 1 & 0 & 1 \\
\hline $\begin{array}{l}\text { Standard mortality ratio } \\
\text { Non-symptomatic cause } \\
\text { Symptomatic cause }\end{array}$ & $\begin{array}{l}1.51(0.2-2.8) \\
22.2(8.3-59.2)\end{array}$ & $\begin{array}{l}1(0-2.2) \\
22.8(8-38)\end{array}$ & $\begin{array}{l}1.43(0.4-5.7) \\
33.5(18.5-60.4)\end{array}$ \\
\hline
\end{tabular}

incidence than many others which may reflect the fact that all cases were diagnosed by a child neurologist with provoking factors carefully excluded.

\section{Mortality}

There are two interlocking issues about death and epilepsy. First, the seizures themselves may cause death (sudden unexpected death in epilepsy or SUDEP, accidental injury from a fall or lethal aspiration during a seizure). Many parents witnessing their child's first seizure(s) fear that the child will die, especially if there is prominent cyanosis or profound post-ictal suppression. Second, there is an overall risk of death in people with epilepsy. The causes of death include death from seizures, but also death from co-existing problems and from all the expected causes of mortality, such as cancer or heart disease. is the same as that in everyone else. Apparently only very rarely do seizures directly cause death in children.

\section{Prevention of Childhood Epilepsy}

There have been few epidemiological studies that have addressed the prevention of childhood epilepsy. In the Nova Scotia study we focused on children with epilepsy plus mental retardation and assessed if their epilepsy could have been prevented with current public health or personal interventions ${ }^{24}$. There were 692 children with epilepsy in this population-based study of whom $21 \%$ had mental retardation plus epilepsy. Causes identified in this group were prenatal or genetic $(65 \%)$, perinatal $(8 \%)$ or complications of prematurity $(13 \%)$. Only $11(7 \%)$ had an acquired cause that was potentially preventable. In developing countries it is conceivable that the proportion of children with 
Table 2: Characteristics of the various Canadian Health Surveys used to estimate prevalence of epilepsy

\begin{tabular}{|c|c|c|c|}
\hline Characteristics & NPHS & CCHS & OHS \\
\hline Population & 49,026 & 130,822 & $61,239(49,164>12)$ \\
\hline Epilepsy prevalence & 5.2 per 1,000 & 5.6 per 1,000 & 5.8 per 1,000 \\
\hline Sampling method & Cluster & Cluster & Cluster \\
\hline Weighing to adjust for survey design & Yes & Yes & Yes \\
\hline $\begin{array}{l}\text { Survey administration and data collection } \\
\text { method }\end{array}$ & Computer-assisted personal & Computer-assisted personal & $\begin{array}{l}\text { Computer-assisted personal and self- } \\
\text { administered for some sections }\end{array}$ \\
\hline Ages included & All groups & 12 years and older & All ages \\
\hline Females & $51 \%$ & $54 \%$ & $53 \%$ \\
\hline Validated questionnaire & Yes & Yes & Yes \\
\hline Response rates & $89 \%$ & $85 \%$ & $\begin{array}{c}88 \% \text { (personal interviews) } \\
77 \% \text { (self-administered) }\end{array}$ \\
\hline Groups excluded & $\begin{array}{l}\text {-Indian Reserves } \\
\text {-Canadian Force Bases } \\
\text {-Some remote areas in Québec and Ontario }\end{array}$ & $\begin{array}{l}\text {-Indian Reserves or Crown Lands } \\
\text {-Clientele of institutions } \\
\text {-Canadian Armed Forces } \\
\text {-Some remote regions }\end{array}$ & $\begin{array}{l}\text {-Aboriginal people living in reserves } \\
\text {-Clientele of institutions } \\
\text {-Homeless people }\end{array}$ \\
\hline Years of the survey (examples) & $1998-1999$ & 2001 & 1990 \\
\hline
\end{tabular}

Data from Téllez-Zenteno et.al. ${ }^{1}$; NPHS = National Population Health Survey; CCHS = Canadian Community Health Survey; OHS = Ontario Health Survey

preventable epilepsy is higher as the result of more head injuries, fewer vaccinations for meningitis and high rates of cerebral infections such as neurocysticercosis.

\section{PREVALENCE, COMORBIDITY, AND SURVEILLANCE SYSTEMS FOR EPILEPSY \\ N. Jette}

Epidemiological data are crucial to understand the full impact of epilepsy on individuals and on society. For example, prevalence data can help us determine the age, gender and geographic distribution of epilepsy. Defining comorbidities associated with epilepsy is necessary in order to adequately manage this patient population, and to ensure proper resources are in place for these individuals. Ultimately, a national surveillance program for epilepsy is the solution to ensure that adequate epidemiological data are acquired and to project the future social and clinical demands imposed by epilepsy.

\section{The prevalence of epilepsy in Canada}

When interpreting epidemiological studies, the distinction between active and lifetime prevalence is essential as the lifetime prevalence rates will be higher than the active prevalence rates for the same population. The main Canadian data sources used to estimate epilepsy prevalence include the Ontario Health Survey $(\mathrm{OHS})^{25,26}$, the Canadian Community Health Survey $(\mathrm{CCHS})^{27}$ and the National Population Health Survey (NPHS) ${ }^{28}$. Table 2 provides an overview of these three Canadian population-based omnibus health surveys. Administrative data have also been used to study epilepsy prevalence in children in Manitoba ${ }^{29}$.

Table 3: Prevalence of epilepsy in different age groups (per 1,000)

\begin{tabular}{|c|c|c|c|c|c|c|}
\hline Age (yr) & $\begin{array}{c}\text { CHS }^{a} \\
\text { Weighted } \\
\text { prevalence }\end{array}$ & $\begin{array}{l}\text { CHS unweighted } \\
\text { no. of } \\
\text { cases/population } \\
\text { at risk }\end{array}$ & $\begin{array}{c}\text { NPHS }^{\mathrm{b}} \\
\text { Weighted } \\
\text { prevalence }\end{array}$ & $\begin{array}{l}\text { NPHS unweighted no. of } \\
\text { cases/population at risk }\end{array}$ & $\begin{array}{l}\text { OHS weighted } \\
\text { prevalence }\end{array}$ & $\begin{array}{c}\text { Rochester, } \\
\text { Minnesota } \\
\text { prevalence }^{67}\end{array}$ \\
\hline $0-11$ & $\begin{array}{l}\text { Not } \\
\text { evaluated }\end{array}$ & Not evaluated & $2.5(2.1-3.0)$ & $26 / 9,697$ & 3.1 & 2.6 \\
\hline $12-14$ & $2.9(1.9-4.0)$ & $25 / 6,468$ & $4.4(3.4-5.8)$ & $13 / 2,414$ & 5.7 & 6.2 \\
\hline $15-24$ & $4.8(4.2-5.5)$ & $106 / 18,658$ & $3.6(3.0-4.2)$ & $28 / 6,711$ & 4.3 & 6.2 \\
\hline $25-44$ & $6.2(5.7-6.7)$ & $324 / 44,346$ & $6.0(5.4-6.6)$ & $90 / 15,490$ & 5.9 & 7.7 \\
\hline $45-64$ & $6.5(5.9-7.1)$ & $266 / 37,133$ & $5.3(4.7-5.8)$ & $52 / 9,900$ & 4.9 & 7.6 \\
\hline$>65$ & $4.1(3.5-4.8)$ & $114 / 24,417$ & $6.9(6.0-7.8)$ & $31 / 4,723$ & 7.2 & 10.8 \\
\hline Total & $5.6(5.1-6.0)$ & $835 / 130,822$ & $5.2(4.9-5.4)$ & $241 / 49,026$ & 5.8 & 6.8 \\
\hline
\end{tabular}

Data reported in parentheses as $95 \%$ confidence interval. CHS - Community Health Survey; NPHS = National Population Health Survey; OHS = Ontario Health Survey. $a=p<0.001$ and $b=p<0.02$ for differences among strata. 
The prevalence rates of active epilepsy obtained from all Canadian surveys are similar, and range between 5.2 and 5.8 per 1,000 persons $^{1}$ (Table 2 ). These prevalence rates are very similar to those obtained with various case definitions and ascertainment methods ${ }^{18,30}$.

In one study, the prevalence of epilepsy seemed higher in Eastern provinces and lowest in the Western provinces ${ }^{1}$. However, most of the differences were not significant, with the exception of British-Columbia where the risk of having selfreported epilepsy was $30 \%$ lower than in the rest of Canada. The authors hypothesized that the lower prevalence rate in British Columbia may be due to socio-demographic differences, genetic differences or cultural differences leading to variations in selfreporting ${ }^{1}$. The prevalence of epilepsy in Canada has also been examined by age group ${ }^{1,30}$. Table 3 compares the Canadian findings with those in classic US epidemiological studies. The results obtained from the CCHS and NPHS are consistent with those obtained in the OHS and in the Rochester studies, showing a higher prevalence in the older age groups ${ }^{1,30}$.

The role of social determinants on the prevalence of epilepsy has also been examined in Canada ${ }^{1}$. No gender differences were found in the rates of self-reported epilepsy. However, selfreported epilepsy was more prevalent in people with the lowest income and educational level. It was also highest in those who were unemployed, consistent with prior studies. Interestingly, Kozyrskyj and Prasad recently reported the same trend in prevalence in an urban Canadian paediatric population ${ }^{29}$. They speculated that the higher prevalence of seizure disorders among children of low-income neighbourhoods may be due to environmental factors (e.g. exposure to infection, head trauma or injury).

\section{Comorbidity of epilepsy - Canadian studies}

Originally coined by Feinstein, the term "comorbidity" is used to refer to the greater than coincidental association of two conditions in the same individual ${ }^{31}$. Understanding the psychiatric and medical comorbidities associated with epilepsy has important clinical and therapeutic implications. The CCHS and NPHS have both been used to study epilepsy comorbidities in Canada $^{32,33}$. Tellez-Zenteno et al compared the national prevalence of chronic somatic conditions in those with epilepsy compared with the general population ${ }^{32}$. A higher prevalence of most conditions is found in those with epilepsy compared to the general population. Conditions with a particularly high prevalence in epilepsy (prevalence ratio greater than two) include: stomach/intestinal ulcers, stroke, urinary incontinence, bowel disorders, migraine, Alzheimer disease and chronic fatigue. The findings are consistent in the two largest surveys and reveal that people with epilepsy have a two- to five-fold risk of somatic comorbid conditions compared to the general population. This is in concordance with other international studies which have also reported an increased rate of somatic comorbidity in those with epilepsy compared to those without epilepsy ${ }^{34-36}$.

The psychiatric comorbidity of epilepsy was assessed in a recent Canadian study using cycle 1.2 of the $\mathrm{CCHS}^{32}$. A sample of 36,984 subjects was administered the World Mental Health Composite International Diagnostic Interview, a validated instrument that provides psychiatric diagnoses based on DSM-
IV criteria. The study found that individuals with epilepsy are more than twice as likely than individuals without epilepsy to report lifetime anxiety disorders [odds ratio (OR) 2.4 with $95 \%$ confidence interval $(95 \% \mathrm{CI}) 1.5-3.8)]$ or suicidal ideation (OR 2.2, 95\% CI 1.4-3.3). Logistic regression analyses found that lifetime major depression was significantly more common in people with epilepsy as compared to those without epilepsy. These findings are consistent with prior studies showing an increased risk of psychiatric comorbidity in those with epilepsy $^{37}$.

\section{Epidemiological Surveillance of Epilepsy in Canada}

Surveillance is the ongoing systematic collection, analysis and interpretation of health data ${ }^{38}$. There are many purposes of surveillance, such as estimating the magnitude of a health problem, determining the geographic distribution of a condition, portraying the natural history of a condition, generating hypotheses, evaluating programs and control measures, detecting changes in health practises and behaviours and facilitating planning.

Administrative data are used increasingly by health researchers and planners for chronic disease surveillance. Advantages of using administrative data include their large samples, ready data availability in electronic format, costeffectiveness, representativeness because of their inclusion of broad based populations and settings, and the lower rate of loss to follow-up as compared to other systems. The first coordinated Canadian effort to use administrative data for public health surveillance is the National Diabetes Surveillance System $(\text { NDSS })^{39}$. The NDSS uses a validated diabetes case definition based on the International Classification of Diseases (ICD) coding from the World Health Organization. The NDSS can assess the prevalence, incidence, and outcomes of diabetes over time nationally and regionally; it can also compare health outcomes and use of health services in those with and without diabetes. Thus, the NDSS is a prototype of enhanced capacity and infrastructure to support the development of surveillance systems for other diseases and conditions use health care administrative databases.

Using administrative databases requires assessing the accuracy of disease coding systems. Few studies have assessed this important aspect. The validity of ICD-9-CM and ICD-10CA epilepsy coding was recently assessed in the Calgary Health Region inpatient and emergency databases (ER $)^{40,41}$. Epilepsy coding was equally good regardless of hospital setting (community or teaching site, adult or paediatric site) or ICD classification. The sensitivity and specificity for epilepsy in ICD9-CM data were $84 \%$ and $97 \%$ respectively, and for ICD-10-CA data were $76 \%$ and $94 \%$ respectively. Excluding the code for isolated convulsions (used for convulsions not associated with epilepsy), the sensitivity was $98 \%$ in ICD-9-CM and $99 \%$ in ICD-10-CA. Agreement in coding between the epileptologist and the professional coders was excellent for ICD-9-CM with a Kappa value of 0.83 , and substantial for ICD-10-CA with a Kappa value of 0.71 . It was concluded that ER and inpatient administrative data have accurately coded epilepsy. However some epilepsy cases may be missed due to miscoding as non epilepsy convulsions. Validation of outpatient data through physician claims databases will be required if these databases are 
to be used as a tool for future population-based surveillance programs.

\section{DISPARITIES IN EPILEPSY CARE Jorge G. Burneo}

\section{What is Health Disparity?}

Little is known about disparities in epilepsy. Therefore, this discussion will focus on methodological challenges in assessing disparities, as well as a brief description of ongoing efforts to assess this problem.

The term "Health Disparity" is almost exclusively used in the United States, and terms like "health inequity" and "health inequality" are more commonly used outside the United States to denote the same construct. It is important to define these terms to allow readers to understand subsequent statements and comments. Most dictionaries define disparity as inequality: "lack of similarity or equality; a disparity in age; disparity in rank" Inequality is similarly defined as "the quality of being unequal or uneven" 43 . Inequity, though, signifies an ethical judgment: "an instance of injustice or unfairness" $"$. More recent dictionaries include this ethical judgment in definitions of disparity: "a lack of equality and similarity, especially in a way that is not fair" 45 . Disparity in the context of public health and social science has begun to take on the implications of injustice. A health disparity should be viewed as a chain of events signified by a difference in environment, access to, utilization of, and quality of care, health status, or a particular health outcome that deserves scrutiny. Such differences should be evaluated in terms of both inequality and inequity, since what is unequal is not necessary inequitable $\mathrm{e}^{46}$.

The bases for inequalities may reside in one or more of the many determinants of health. Health Canada considers 12 factors as determinants of health: 1) income and social status, 2) social support networks, 3) education, 4) employment and working conditions, 5) social environments, 6) physical environments, 7) personal health practices and coping skills, 8) healthy child development, 9) biology and genetic endowment, 10) health services, 11) gender, and 12) culture ${ }^{46,47}$. Some determinants of health can be modified and some cannot. The determination of what can or cannot be modified through an intervention relies on medical knowledge, resource availability, public acceptance, and ideology ${ }^{46}$. For example, age cannot be modified, but a healthdamaging behaviour like smoking can. Once the evidence shows that a health determinant can be modified, the question is: would that be just? In other words, if an inequality is avoidable, then a judgment ensues as to whether it is unjust, and thus whether an inequity is present.

\section{Measuring disparities}

The Rockeller Foundation has suggested a five-step process when measuring or assessing health inequalities: 1) define which aspects of health or health outcomes to measure; 2) identify the relevant population groups across which to compare health status; 3 ) choose a reference group against which to compare the health of different groups; 4) decide whether to measure inequality using the absolute or relative difference in health status between population groups; and, 5) select among alternative 'social weights' for preferences that are built into health measures ${ }^{46,48}$. Before measuring the gap in a health outcome, one must be clear as to what is being measured and compared and to use standard methods as much as possible ${ }^{46}$. Although there are more than ten definitions of health outcome comparisons in the literature, the more widely used are those of the NIH and the 'Healthy People 2010'46. The common denominator is the inclusion of comparisons of health aspects between the non-minority or majority populations and the general population, and among segments of the population ${ }^{46}$.

\section{Disparities in epilepsy care}

Recent efforts of the North American Commission (NAC) of the International League Against Epilepsy (ILAE) have focused on the evaluation of disparities in epilepsy. A task force dedicated to this effort has embarked in a systematic review of the literature to identify and evaluate what is known about disparities in epilepsy, and what needs to be done to address gaps in knowledge. Disparities in five specific areas are being evaluated: Access to medical and surgical treatment, outcomes following medical and surgical treatment, attitudes and knowledge about epilepsy, epidemiology, and disability. The systematic review will not only focus on North America, but also the geographic areas described in the available literature. It is expected that the information gained will result in a call to action to address disparities.

Preliminary results of this review point to a scarcity of data. For example, efforts evaluating access to surgical care, are limited to a study from Alabama reporting that African Americans who are candidates for epilepsy surgery are less likely to have surgery than Non-Hispanic Caucasians ${ }^{49}$. This finding was not related to differences in health insurance, socioeconomic status, and educational level of the population studied $^{49}$. In terms of 'access to medical care', the literature points to four major obstacles to equality: limited financial resources, lack of knowledge about epilepsy, poor patientprovider communication, and lack of social support. Lack of social support encompasses inability to purchase medications, lack of health insurance, poor adherence to medical treatment, and impediments in transportation. Furthermore, lack of knowledge, misinformation and poor communication with physicians have been identified as contributors to the social stigma of epilepsy ${ }^{50,51}$.

Psychosocial and behavioural outcomes following medical treatment in children were dependent on the family's socioeconomic status in one study ${ }^{52}$. On the other hand, outcomes following surgical treatment in adults were related to race/ethnicity in a preliminary study ${ }^{53}$, but not in a larger study including two patient populations from New York and Alabama. In this study, socioeconomic status did not appear to influence outcomes, although there was a non-significant trend towards women having a worse outcome in terms of seizure recurrence ${ }^{54}$. An intriguing finding from a different study suggests that women who became seizure free after surgery have a higher divorce rate than men $^{55}$. These findings require substantiation by further research.

Some studies also suggest that knowledge and attitudes about epilepsy are inadequate among some teachers and college students, and that these can be improved with simple educational interventions $^{56,57}$. In terms of disability, there is higher unemployment rate and lower educational status in patients with 
epilepsy than in other comparison groups, but little is known about subgroups of patients with epilepsy ${ }^{30}$. The same applies to reports about a higher incidence and prevalence of epilepsy among people with low socioeconomic status and low educational level, but no internal comparisons exist within subgroups of epilepsy patients ${ }^{58}$. Although it has been postulated for some time that the incidence and prevalence of epilepsy is higher in rural than in urban areas in some countries, significant variations within the same area have been also been reported, which may point to methodological differences ${ }^{59}$.

With regard to the Canadian population, the only data available pertain to the population surveys described above (Surveillance, Prevalence and Comorbidity). A study describing the burden of epilepsy in the province of Ontario revealed a lower quality of life, family function, and worse social support in persons with epilepsy, compared to the general population ${ }^{30}$. The study on the burden of seizure in Manitoba found higher rates of seizures in children of low socioeconomic status ${ }^{29}$. Among the few internal comparisons available in those studies the salient findings suggested a lower prevalence of epilepsy among immigrant populations in $\mathrm{Canada}^{1}$. Finally, a recent analysis of administrative data in the Calgary Health Region identifies statistically significant disparities in use of health resources among people with epilepsy ${ }^{60}$. These authors found that younger patients were more likely to see a neurologist $(\mathrm{OR}=1.7,95 \% \mathrm{CI}$ 1.3-2.3), visit the $\mathrm{ER}(\mathrm{OR}=4.9,95 \% \mathrm{CI} 3.2-7.4)$, or be hospitalized $(\mathrm{OR}=2.9,95 \%$ CI 2.0-4.3), and females were less likely to see a general practitioner but more likely to see a neurologist. Aboriginals were more likely than non-aboriginals to visit the $\mathrm{ER}(\mathrm{OR}=2.3,95 \% \mathrm{CI} 1.1-5.0)$ or be hospitalized $(\mathrm{OR}=2.8,95 \% \mathrm{CI} 1.5-5.1)$ but less likely to see a neurologist $(\mathrm{OR}=0.3,95 \%$ CI 0.2-0.6)60. Similarly, data from the Ontario Health Survey suggest that among people with epilepsy, women had more hospitalizations, those in remote areas used more emergency services, and barriers to care were less frequently reported in more heavily populated areas ${ }^{30}$. In addition, people with epilepsy living in urban areas were significantly more frequent users of psychological/social work services, experienced more barriers to health care and described poorer quality of life ${ }^{30}$. Importantly, quality of life was better in people with epilepsy living in households with healthy family relations, and higher educational levels were associated with healthier families ${ }^{30}$.

\section{Future Directions in Disparities}

In an effort to address health disparities in epilepsy, a panel of investigators assembled in Rockville, Maryland, in November 2002. They concluded that additional information on disparities in epilepsy is important for the development of effective intervention programs or campaigns ${ }^{61}$. Subsequently two review papers were published addressing disparities and arriving at similar conclusions ${ }^{62,63}$. Furthermore, a study assessing the quality of reporting of race/ethnicity in clinical trials in epilepsy in high-impact journals specializing in neurology and epilepsy found that only $6.6 \%$ of clinical trials reported the race/ethnicity of study participants, and only $1.9 \%$ tried to analyze possible differences ${ }^{64}$. The National Institutes of Health $(\mathrm{NIH})$ in the USA, and the CIHR in Canada now require that clinical researchers demonstrate adequate representation of minorities and diverse ethnic groups in study samples to examine epidemiological characteristics and differential effects of various therapies.

In conclusion, research in disparities is scarce, and awareness among clinical researchers needs to be raised. Disparities in health care exist not only between developed and developing countries, but also within developed countries like Canada. Universal access is enshrined in the Canadian Health Care Act, yet reports are accumulating about important health care disparities in some clinical conditions, based on age, gender, socioeconomic status and other factors ${ }^{65}$. This raises questions about equality and equity and require further exploration in epilepsy ${ }^{66}$.

\section{Conclusions}

The prevalence of epilepsy in Canada is about 6/1,000 and is similar to that of other industrialized countries. The impact of epilepsy is broad ranging, affecting health status, psychosocial, quality of life and economic aspects. World wide, epilepsy is the second most common neurological condition seen in general clinical practice. The risk of death is higher in people with epilepsy than in the general population and appears to be associated with the frequency and severity of epilepsy. In children, methodological differences have resulted in a wide range of incidence rates in the literature (range of 41 to 840 per 100,000 population). The incidence in Canada appears to be lower than in many studies, ranging from 118/100,000 in the first year of life, to $21 / 100,000$ in adolescence. The risk of seizure related death is very low in children; and mortality is usually associated to severe comorbid conditions. The prevention of epilepsy in children in the Canadian population poses significant challenges. Only about $7 \%$ of children have an identifiable preventable cause of epilepsy. In the majority the cause is not identified or it cannot be modified. Surveillance systems in epilepsy are important to gauge the health of the population, to assess health resource use and to plan for health care delivery. Initial studies looking at the health of people with epilepsy in the general population in Canada have found substantial somatic and psychiatric comorbidity. Common chronic conditions occur more frequently in people with epilepsy than in the general population. People with epilepsy are more than twice as likely as individuals without epilepsy to report lifetime anxiety disorders or suicidal ideation, and lifetime major depression occurs significantly more frequently as well. Disparities in epilepsy, like in other chronic conditions, potentially involve a large number of domains such as access to care, health resource use, outcomes, education and psychosocial aspects. Disparities occur not only in developing countries, but also within industrialized societies like Canada. Initial Canadian data point to disparities in health resource utilization by age, gender, rural/urban residence and racial/ethnic factors in Canada and in the USA. Much work needs to be done in this area, as reflected by the remarkable under-reporting in scientific journals of issues related to disparities. 


\section{REFERENCES}

1. Tellez-Zenteno JF, Pondal-Sordo M, Matijevic S, Wiebe S. National and regional prevalence of self-reported epilepsy in Canada. Epilepsia. 2004;45:1623-9.

2. Hauser WA, Hesdorffer DC. Incidence and Prevalence. In: Hauser WA, Hesdorffer DC, editors. Epilepsy: frequency, causes and consequences. 1st edition. New York: Demos; 1990. p. 1-51.

3. Camfield CS, Camfield PR, Gordon K, Wirrell E, Dooley JM. Incidence of epilepsy in childhood and adolescence: A population-based study in Nova Scotia from 1977 to 1985. Epilepsia. 1996;37:19-23.

4. World Health Organization, World Federation of Neurology. Atlas: Country resources for neurological disorders 2004. Geneva, Switzerland: World Health Organization; 2004.

5. Begley CE, Beghi E. The economic cost of epilepsy: a review of the literature. Epilepsia. 2002;43 Suppl 4:3-9.

6. Begley CE, Famulari M, Annegers JF, Lairson DR, Reynolds TF, Coan S, et al. The cost of epilepsy in the United States: an estimate from population-based clinical and survey data. Epilepsia. 2000;41:342-51.

7. Sillanpaa M, Jalava M, Kaleva O, Shinnar S. Long-term prognosis of seizures with onset in childhood. N Engl J Med. 1998;338: 1715-22.

8. Baker GA, Jacoby A, Buck D, Stalgis C, Monnet D. Quality of life of people with epilepsy: a European study. Epilepsia. 1997;38: 353-62.

9. Tellez-Zenteno JF, Hunter G, Wiebe S. Injuries in people with selfreported epilepsy: a population-based study. Epilepsia. 2008;49: 954-61.

10. Strauss DJ, Day SM, Shavelle RM, Wu YW. Remote symptomatic epilepsy: does seizure severity increase mortality? Neurology. 2003;60:395-9.

11. Salanova V, Markand O, Worth R. Temporal lobe epilepsy surgery: outcome, complications, and late mortality rate in 215 patients. Epilepsia. 2002;43:170-4.

12. Sperling MR, Feldman H, Kinman J, Liporace JD, O'Connor MJ. Seizure control and mortality in epilepsy. Ann Neurol. 1999; 46:45-50.

13. Camfield PR, Camfield CS, Dooley JM, Tibbles JA, Fung T, Garner B. Epilepsy after a first unprovoked seizure in childhood. Neurology. 1985;35:1657-60.

14. Shinnar S, Berg AT, O'Dell C, Newstein D, Moshe SL, Hauser WA. Predictors of multiple seizures in a cohort of children prospectively followed from the time of their first unprovoked seizure. Ann Neurol. 2000;48:140-7.

15. Hauser WA, Rich SS, Lee JR, Annegers JF, Anderson VE. Risk of recurrent seizures after two unprovoked seizures. N Engl J Med. 1998;338:429-34.

16. Fisher RS, Harding G, Erba G, Barkley GL, Wilkins A. Photic- and pattern-induced seizures: a review for the Epilepsy Foundation of America Working Group. Epilepsia. 2005;46:1426-41.

17. Stroink H, Brouwer OF, Arts WF, Geerts AT, Peters AC, van Donselaar CA. The first unprovoked, untreated seizure in childhood: a hospital based study of the accuracy of the diagnosis, rate of recurrence, and long term outcome after recurrence. Dutch study of epilepsy in childhood. J Neurol Neurosurg Psychiatry. 1998;64:595-600.

18. Hauser WA, Hesdorffer DC. Epilepsy: frequency, causes, and consequences. Maryland: Demos 1990; 273-96.

19. Camfield P, Camfield C. Childhood epilepsy: what is the evidence for what we think and what we do? J Child Neurol. 2003;18: $272-87$

20. Kotsopoulos IA, van MT, Kessels FG, De Krom MC, Knottnerus JA. Systematic review and meta-analysis of incidence studies of epilepsy and unprovoked seizures. Epilepsia. 2002;43:1402-9.

21. Callenbach PM, Westendorp RG, Geerts AT, Arts WF, Peeters EA, van Donselaar CA, et al. Mortality risk in children with epilepsy: the Dutch study of epilepsy in childhood. Pediatrics. 2001;107: 1259-63.

22. Camfield CS, Camfiels PR, Veugelers PJ. Death in children with epilepsy: a population-based study. Lancet. 2002;1:1891-5.
23. Berg AT, Shinnar S, Testa FM, Levy SR, Smith SN, Beckerman B. Mortality in childhood-onset epilepsy. Arch Pediatr Adolesc Med. 2004;158:1147-52.

24. Camfield C, Camfield P. Preventable and unpreventable causes of childhood-onset epilepsy plus mental retardation. Pediatrics. 2007;120:e52-5

25. Ontario Ministry of Health. Ontario Health Survey 1990: Highlights. Toronto, Ontario: 1992.

26. Ontario Ministry of Health. Ontario Health Survey 1990. Documentation: User's Guide. 1st Edition. Toronto, Ontario: 1993.

27. Statistics Canada. Canadian Community Health Survey - Cycle 1.1.2001., 2003

28. Statistics Canada. National Population Health Survey: cycle 4 (2001-2002), 2000

29. Kozyrskyj AL, Prasad AN. The burden of seizures in Manitoba children: a population-based study. Can J Neurol Sci. 2004;31:48-52.

30. Wiebe S, Bellhouse DR, Fallahay C, Eliasziw M. Burden of epilepsy: the Ontario Health Survey. Can J Neurol Sci. 1999;26: 263-70.

31. Feinstein AR. The pretherapeutic classification of comorbidity in chronic disease. J Chronic Dis. 1970;23:455-68.

32. Tellez-Zenteno JF, Matijevic S, Wiebe S. Somatic comorbidity of epilepsy in the general population in Canada. Epilepsia. 2005;46: 1955-62.

33. Tellez-Zenteno JF, Patten SB, Jette N, Williams J, Wiebe S. Psychiatric comorbidity in epilepsy: a population-based analysis. Epilepsia. 2007;48:2336-44.

34. Kobau R, DiIorio CA, Price PH, Thurman DJ, Martin LM, Ridings DL, et al. Prevalence of epilepsy and health status of adults with epilepsy in Georgia and Tennessee: Behavioral Risk Factor Surveillance System, 2002. Epilepsy Behav. 2004;5:358-66.

35. Gaitatzis A, Carroll K, Majeed A, Sander W. The epidemiology of the comorbidity of epilepsy in the general population. Epilepsia. 2004;45:1613-22.

36. Strine TW, Kobau R, Chapman DP, Thurman DJ, Price P, Balluz LS. Psychological distress, comorbidities, and health behaviors among U.S. adults with seizures: results from the 2002 National Health Interview Survey. Epilepsia. 2005;46:1133-9.

37. Kobau R, Gilliam F, Thurman DJ. Prevalence of self-reported epilepsy or seizure disorder and its associations with selfreported depression and anxiety: results from the 2004 Health Styles Survey. Epilepsia. 2006;47:1915-21.

38. Overview of public health surveillance, CDC 2007; 1-64.

39. Responding to the challenge of diabetes in Canada. First report of the National Diabetes Surveillance System (NDSS), 2003; 1125 .

40. Jette N, Reid A, Quan H, Hill MD, Wiebe S. Using administrative databases for research in epilepsy: Validation of ICD - 9 epilepsy codes. Epilepsia. 2007;48(S6):87.

41. Reid AY, Jette N, Quan H, Hill MD, Wiebe S. Using administrative databases for research in epilepsy: Validation of ICD - 10 epilepsy codes. Epilepsia. 2007;48(S6):87.

42. Dictionary.com. Dictionary.com Unabridged v 1.1, 2007 Edition. 2007; Available from: http://dictionary.reference.com

43. Merriam-Webster. Merriam-Webster's online dictionary, 2007 Edition. 2008; Available from: http://www.merriamwebster.com/dictionary

44. Britannica. Encyclopedia Britannica Online, 2007 Edition. 2007; Available from: http://www.britannica.com/

45. Cambridge. Cambridge Dictionaries Online, 2007 Edition. 2007; Available from: http://dictionary.cambridge.org/

46. Carter-Pokras O, Baquet C. What is a "health disparity"? Public Health Rep. 2002;117:426-34.

47. Health-Canada. Determinants of Health Working Group Synthesis Report, 2007 Edition. 2007; Available from: http://hcsc.gc.ca/hcs-sss/pubs/renewal-renouv/1997-nfoh-fnssv2/legacy_heritage4_e.html

48. Rockefeller-Foundation, Swedish-International-DevelopmentCooperation-Agency. Challenging inequities in health: from ethics to action, 2007 Edition. 2002; Available from: http://www.rockfound.org 
49. Burneo JG, Black L, Knowlton RC, Faught E, Morawetz R, Kuzniecky RI. Racial disparities in the use of surgical treatment for intractable temporal lobe epilepsy. Neurology. 2005;64:50-4.

50. Asawavichienjinda T, Sitthi-Amorn C, Tanyanont W. Compliance with treatment of adult epileptics in a rural district of Thailand. J Med Assoc Thai. 2003;86:46-51.

51. Paschal AM, Ablah E, Wetta-Hall R, Molgaard CA, Liow K. Stigma and safe havens: a medical sociological perspective on African-American female epilepsy patients. Epilepsy Behav. 2005;7:106-15.

52. Mitchell WG, Scheier LM, Baker SA. Psychosocial, behavioral, and medical outcomes in children with epilepsy: a developmental risk factor model using longitudinal data. Pediatrics. 1994;94:471-7.

53. Burneo JG, Knowlton RC, Martin R, Faught RE, Kuzniecky RI. Race/ethnicity: a predictor of temporal lobe epilepsy surgery outcome? Epilepsy Behav. 2005;7:486-90.

54. Burneo JG, Black L, Martin R, Devinsky O, Pacia S, Faught E, et al. Race/ethnicity, sex, and socioeconomic status as predictors of outcome after surgery for temporal lobe epilepsy. Arch Neurol. 2006;63:1106-10.

55. Carran MA, Kohler CG, O'Connor MJ, Cloud B, Sperling MR. Marital status after epilepsy surgery. Epilepsia. 1999;40: 1755-60.

56. Young GB, Derry P, Hutchinson I, John V, Matijevic S, Parrent L, et al. An epilepsy questionnaire study of knowledge and attitudes in Canadian college students. Epilepsia. 2002;43:652-8.

57. Bekiroglu N, Ozkan R, Gurses C, Arpaci B, Dervent A. A study on awareness and attitude of teachers on epilepsy in Istanbul. Seizure. 2004;13:517-22.

58. Hesdorffer DC, Tian H, Anand K, Hauser WA, Ludvigsson P, Olafsson E, et al. Socioeconomic status is a risk factor for epilepsy in Icelandic adults but not in children. Epilepsia. 2005;46:1297-303.
59. Burneo JG, Tellez-Zenteno J, Wiebe S. Understanding the burden of epilepsy in Latin America: a systematic review of its prevalence and incidence. Epilepsy Res. 2005;66:63-74.

60. Jette N, Quan H, Faris P, Dean S, Li B, Fong A, et al. Health resource use in epilepsy: Significant disparities by age, gender, and aboriginal status. Epilepsia. 2008;49:586-93.

61. NIH. Health Disparities in Epilepsy Panel, 2002; Available from: http://www.ninds.nih.gov/news_and_events/proceedings/epileps y_panel_2002.htm\#iv.

62. Szaflarski M, Szaflarski JP, Privitera MD, Ficker DM, Horner RD. Racial/ethnic disparities in the treatment of epilepsy: what do we know? What do we need to know? Epilepsy Behav. 2006;9: 243-64.

63. Theodore WH, Spencer SS, Wiebe S, Langfitt JT, Ali A, Shafer PO, et al. Epilepsy in North America: a report prepared under the auspices of the global campaign against epilepsy, the International Bureau for Epilepsy, the International League Against Epilepsy, and the World Health Organization. Epilepsia. 2006; 47:1700-22.

64. Burneo JG, Martin R. Reporting race/ethnicity in epilepsy clinical trials. Epilepsy Behav. 2004;5:743-5.

65. Fowler RA, Sabur N, Li P, Juurlink DN, Pinto R, Hladunewich MA, et al. Sex-and age-based differences in the delivery and outcomes of critical care. Can Med Assoc J. 2007;177:1513-9.

66. Baxter NN. Equal for whom? Addressing disparities in the Canadian medical system must become a national priority. Can Med Assoc J. 2007;177:1522-3.

67. Hauser WA, Hesdorffer DC. Incidence and prevalence. In: Hauser WA, Hesdorffer DC, editors. Epilepsy: frequency, causes and consequences. New York: Demos; 1990. p. 1-51. 


\title{
Maximizing Quality of Life in People Living with Epilepsy
}

\author{
Elisabeth M.S. Sherman
}

\begin{abstract}
Improving quality of life is now seen as a major challenge facing people with epilepsy. Can research on human happiness shed light on why it is that the wellbeing and quality of life of people with epilepsy is worse than the condition's clinical and medical prognosis would predict? Empirical research on subjective wellbeing and happiness in healthy people indicates that there are a small number of key factors that are related to wellbeing, including employment, social interactions, family relationships, and experiential activities. This paper reviews these crucial components of wellbeing, discusses how each factor applies to people living with epilepsy, and identifies epilepsy-specific factors such as stigma and comorbidity that contribute to low quality of life. Lastly, this review provides a list of program-based approaches to improving quality of life, as well as practical recommendations for use by practitioners and people living with epilepsy.
\end{abstract}

RÉSUMÉ: Maximiser la qualité de vie chez les épileptiques. On considère maintenant que l'amélioration de la qualité de vie est un défi majeur auquel les épileptiques sont confrontés. La recherche sur le bonheur humain peutelle nous renseigner sur ce qui fait que le bien-être et la qualité de vie des individus atteints d'épilepsie sont pires qu'on pourrait le prédire selon le pronostic clinique et médical de cette pathologie? La recherche empirique sur le bien-être subjectif et le bonheur chez les individus en bonne santé indique qu'il existe un petit nombre de facteurs clés qui sont reliés au bien-être dont l'emploi, les interactions sociales, les relations familiales et les activités expérientielles. Dans cet article, nous revoyons ces composantes cruciales du bien-être et nous discutons de la façon dont chaque facteur s'applique aux individus atteints d'épilepsie. Nous identifions les facteurs propres à l'épilepsie comme la stigmatisation et la comorbidité qui contribuent à la faible qualité de vie et nous proposons une liste d'approches basées sur des programmes destinés à améliorer la qualité de vie ainsi que des recommandations pratiques à l'intention des praticiens et des individus atteints d'épilepsie.

Can. J. Neurol. Sci. 2009; 36: Suppl. 2 - S17-S24

\section{Quality of Life, Life Satisfaction and Wellbeing: Researching the Components of Happiness}

What is quality of life? Quality of life refers to life satisfaction and subjective wellbeing. It is a term that is now commonplace in literature on epilepsy; epilepsy researchers and practitioners study quality of life so that they can minimize obstacles for people who live with epilepsy, and to expand the aims of treatment beyond traditional medical indicators such as seizure frequency and medications. The science of studying, measuring and promoting quality of life in people with epilepsy is relatively new, but to most people, attaining a high degree of subjective wellbeing and life satisfaction is simply commonsense: quality of life matters to people with epilepsy, and it matters to everyone else as well. Nevertheless, the view that quality of life - or wellbeing, life satisfaction and happiness - could be a subject worthy of scientific study is a very recent development.
Historically, modern mental health research had an overwhelming focus on psychopathology, abnormal/ dysfunctional coping mechanisms, and negative emotional states and disorders such as depression, paranoia, anxiety, and neuroses. In contrast, the study of wellbeing and happiness focuses on positive mental states such as resiliency, optimism, courage, agreeableness, openness, and resourcefulness. Scientific interest in these concepts has prompted the development of an entirely new branch of psychology, Positive

\footnotetext{
From the Alberta Children's Hospital and University of Calgary, Calgary, AB, Canada Received SePtember 8, 2008. Final Revisions Submitted September 18, 2008. Correspondence to: Elisabeth M.S. Sherman, Neurosciences Program, Alberta
} Children's Hospital, 2888 Shaganappi Trail NW, Calgary, Alberta, T3B 6A8, Canada. 
Psychology, which is a nascent scientific discipline focused on the study of subjective wellbeing. ${ }^{1,2}$ Interestingly, models of subjective wellbeing from psychology research are uncannily similar to models of quality of life in the health literature. Subjective wellbeing is thought to consist of a component defined by global life satisfaction, as well as satisfaction with specific sub-components of wellbeing such as work, education, personal relationships, and importantly, health. ${ }^{3}$

Specifically, Positive Psychology research informs us that health conditions do affect life satisfaction. For example, catastrophic conditions such as quadriplegia or cancer tend to be associated with an immediate drop in subjective wellbeing. However, over time, happiness levels tend to return to just below baseline levels, suggesting that while important for happiness, health may only have a minor effect on subjective wellbeing. ${ }^{1}$ Thus, the impact of most health conditions is not long-term or permanent; most people recover to a significant degree in terms of wellbeing. Interestingly, while acquired health conditions may temporarily decrease happiness, happiness itself appears to predict longevity. A now classic longitudinal study of catholic nuns indicates that positive emotions expressed in autobiographies when participants were in their early 20 s predicted longevity (and thus health) 60 years later. ${ }^{4}$

Because health is only one component of wellbeing, does that mean that having epilepsy should have only a negligible effect on overall wellbeing? Jacoby, Snape and Baker ${ }^{5}$ point out that "epilepsy is a generally benign disorder with excellent clinical prognosis", largely due to the fact that a substantial majority (70 to $80 \%$ ) of patients are controlled on medication. This would suggest that like most health conditions, epilepsy has only a mild effect on subjective wellbeing, and that it may even have a lesser effect than health conditions that are incurable or disabling. However, the authors go on to state that, "epilepsy is not just a clinical disorder but a social label... the social prognosis of epilepsy may be less optimistic than the clinical one". As most of us know, studies documenting a low quality of life in people with epilepsy are now legion, and low quality of life is now seen as a major challenge facing people with epilepsy. Can research on human happiness shed light on why it is that the wellbeing and quality of life of people with epilepsy is so much worse than the condition's clinical prognosis would predict?

Empirical research on subjective wellbeing and happiness in healthy people indicates that there are a small number of key factors that are related to wellbeing. Below, we will review these crucial components of wellbeing. Next, we will discuss how these specific factors apply to people living with epilepsy, and whether there are additional factors that might serve to explain the often-reported lower quality of life of people with epilepsy. Lastly, we will attempt to translate these factors into an optimal treatment plan and into practical recommendations for people living with epilepsy, for use by practitioners and people with epilepsy.

\section{What Specific Factors are Associated with Happiness? \\ Money, Work and Income}

When basic necessities are not met, money matters. For example, living below the poverty line is associated with poor subjective wellbeing, and happiness levels do improve when socioeconomic levels increase to cover basic needs. However, wealth itself is only a weak predictor of wellbeing; while the very rich tend to report slightly higher happiness levels than average people ${ }^{6}$, this effect is relatively small. Thus, additional money (and related increases in the standard of living and more consumer goods) does not necessarily make people happier. However, relative wealth does appear to matter: the income distribution in people's home community affects subjective wellbeing such that individuals who find themselves below the modal income (regardless of the mean level of income in that particular community) report lower levels of wellbeing. Thus, there is a social comparison effect that reduces subjective wellbeing when negative comparisons to others occur; this effect may be modifiable by changing the reference group to which people compare themselves. ${ }^{7}$ Interestingly, spending money on others tends to increase happiness levels, whereas spending on oneself does not ${ }^{8}$; money may therefore be one venue for expressing prosocial behavior through giving to others, which is itself associated with higher subjective wellbeing.

Generally speaking, having a job that is enjoyable is more important than the actual amount of wealth the job generates. However, unemployment decreases life satisfaction. ${ }^{9}$ Notably, the effect of unemployment is stronger in people who have a lower baseline life satisfaction, and has negligible effects at high happiness levels; unemployment has therefore been seen as a factor that exacerbates pre-existing inequality in subjective wellbeing. ${ }^{10}$ Conversely, happier people are less likely to end up unemployed, and may be re-hired more quickly after unemployment ${ }^{11}$, indicating a two-way relationship between wellbeing and work.

\section{Socializing}

Spending time with friends boosts wellbeing, and social supports act as buffers for difficult life events. The effect of socializing on human happiness is robust, leading some to conclude that social relationships are the single most important factor in human happiness. Thus, "social capital" is a strong determinant of well-being, through social ties related to marriage, family, friends, neighbours, co-workers, and engagement in community, and this positively impacts both health and quality of life..$^{12}$

\section{Marriage and Family}

Partnered and/or married people live longer and report better health and wellbeing. ${ }^{13}$ The effect of marriage on happiness is robust and has been reported in many studies, but it is not clear what happens first: are married people happier to begin with, and thus more likely to attract mates ${ }^{1}$ At its most basic level, however, marriage and cohabitation increase social interactions de facto through daily interactions with a spouse, but also extend the social network to a larger pool combined from both partners. Living alone has been associated with lower wellbeing overall, and while having young children is a factor that adversely affects wellbeing, the establishment of a family unit, however defined, is an almost universal component of people's perception of a satisfying life ${ }^{2}$. 


\section{Experiencing}

Activities like travel, exercising and hobbies are important for happiness. While material possessions and materialism do not increase wellbeing, activities that involve experiencing do. ${ }^{14,15}$ This is likely because experiences are opportunities for socializing, but also for creating a meaningful life narrative and life history. As well, unlike material possessions, experiences become more meaningful and valuable over time as they are recollected and reinterpreted; in comparison, people report less pleasure from material goods over time, and material goods are more prone to disadvantageous comparisons with those of other people. ${ }^{15}$ Experiences associated with meaning, purpose and fulfillment (e.g., attending a music festival) appear more highly predictive of happiness that those associated with pleasure only (e.g., eating a good meal). ${ }^{3}$

\section{The Happiness Setpoint: Genes}

Up to $50 \%$ of the variability in happiness is inherited, which has led to the idea that each person has a happiness "setpoint". ${ }^{16,9}$ Personality traits comprising high extraversion (social and physical activity), low neuroticism (emotional stability) and high conscientiousness appear to be particularly predictive of happiness. ${ }^{17}$ Thus, genetics may predict the rate at which happiness levels return to their setpoint after an adverse event. For example, losing a spouse may decrease wellbeing by for a given period of time, after which individual tends to drift back to a level close to baseline ${ }^{13}$, but this will take longer in individuals with lower levels of happiness at baseline.

\section{Factors Related to Happiness: How do People with Epilepsy Fare?}

We have now reviewed some of the factors identified as predicting wellbeing and life satisfaction in the general population. Now let us look at the research for each of these factors in people with epilepsy.

\section{Money, Work, Income and Epilepsy}

People with epilepsy have lower rates of employment, lower socioeconomic status, and lower income than their peers without epilepsy, particularly if seizures are not controlled. ${ }^{18-22}$ If employed, people with epilepsy are often underemployed (i.e., working below the level expected based on prior training or education). Contributing factors to unemployment and underemployment in epilepsy include seizure severity, comorbidities, and low self-efficacy, but many studies indicate that seizurerelated factors cannot fully explain employment rates in epilepsy. ${ }^{23,19}$ Although successful treatment such as epilepsy surgery may increase employment, ${ }^{23,24}$ marginal gains in employment have been reported in some series. ${ }^{25}$ Conversely, being employed is related to higher self-efficacy in people with epilepsy. ${ }^{26}$ Childhood-onset epilepsy is associated with worse socioeconomic outcome than onset in adulthood. ${ }^{27,19}$ Thus, most people with epilepsy struggle with challenges involving employment, income and socioeconomic status, all of which are factors known to reduce wellbeing and life satisfaction in the general population.

\section{Marriage, Family and Epilepsy}

People with epilepsy have lower marriage and cohabitation rates, tend to live with parents or alone more often, and fewer have children than in the general population. ${ }^{27,19,22}$ This situation is not necessarily normalized by surgery or by attaining a seizure-free status. ${ }^{23}$ Those with the lowest rates of marriage/ cohabitation are people with childhood-onset epilepsy. ${ }^{19}$ Marriage is particularly unlikely in men with intractable epilepsy with onset in childhood. ${ }^{28}$ Thus, epilepsy is related to a higher risk of not finding a marriage or life partner, and of not establishing a family; as we have reviewed above, these are both risk factors for lower wellbeing as evidenced in happiness research.

\section{Experiential Activities and Epilepsy}

Living with a diagnosis of epilepsy has traditionally meant living with activity restrictions. Restrictions in specific everyday activities are often the first recommendation from the time of diagnosis (limits on swimming, driving, bathing/showering unsupervised, etc.). Prior to this, the long history of institutionalization of people with epilepsy can be seen as an extreme instance of restrictions on normal everyday activities, with a legacy that likely still affects perceptions regarding capacity for independence and ability to take part in everyday activities. For example, restrictions on sports activities have strong historical antecedents that include a 1968 position statement from the American Medical Association recommending restrictions on the activity of people with epilepsy due to concerns about injury or seizure induction. ${ }^{29}$ Partially due to these historical factors, people with epilepsy have a lower participation in sports and reduced fitness level ${ }^{29,30}$, and take part in fewer leisure activities than people without epilepsy. ${ }^{31}$ Overprotection also manifests itself at the individual level, within families. Families where there is a child with an epilepsy diagnosis typically take part in fewer leisure activities. ${ }^{32}$ Because experiential activities such as sports, leisure and recreational pursuits increase wellbeing, overprotection and protectiveness (even when well-intentioned) causing restrictions in everyday activities may have deleterious effects on wellbeing in persons with epilepsy. Further, because families as a unit tends to engage in fewer leisure activities, there may also be broader effects on the wellbeing of the rest of the family members through restricted exposure to experiential activities. For adolescents, the single restriction of not being able to drive can be a catalyst in reducing socializing, community access, employment and romantic relationships. ${ }^{33}$

\section{Socializing and Epilepsy}

People with epilepsy experience a higher degree of social isolation, and some of this relates to or is exacerbated by restrictions in activities (leisure, sports, family activities), and for adults, restrictions related to employment where many social networks are formed. As noted above, more people with epilepsy live alone than in the general population, and for families with children who have epilepsy, support networks may shrink with seizure severity ${ }^{34}$, along with leisure activities ${ }^{32}$ that would connect the family with other people. As we will see below, stigma may be a potent factor in intentionally restricting social 
contacts and limiting activities with other people to avoid potential embarrassment, disclosure, or actual discrimination.

\section{The Missing Factors: Stigma and Comorbidity} Stigma: Definitions and Mechanisms

Stigma can be defined as a loss of social value ${ }^{35,36}$ that manifests itself through several mechanisms, including labeling, stereotyping, discrimination, separation from the majority group, and which is allowed to occur within the majority group. While this definition makes sense, it is difficult initially to understand how stigma can be debilitating, and how stigma can become a self-fulfilling prophecy. Can stigma in epilepsy really be so bad that it has the potential to lead to disability? A major similarity among conditions associated with stigma is that stigma is enacted publicly through legislation, media, health services, educational materials and popular attitudes, but is also felt internally through internalized stigma, actual experiences of discrimination, and perceptions of the environment and community as stigmatizing (i.e., felt or perceived stigma). ${ }^{37}$ Thus, stigma is a process that the stigmatized individual reacts to and defends against through specific strategies. ${ }^{35-38}$ These defensive and compensatory strategies include social withdrawal, limiting activities involving other people, engaging in active concealment, and nondisclosure. When these compensatory mechanisms are taken to an extreme in order to guard against discrimination and stigma, the result can be actual disability because activity restrictions and social withdrawal have effectively removed the individual from engagement in everyday life.

\section{Epilepsy and the Legacy of Stigma}

To fully understand stigma in epilepsy, one must reluctantly turn to history, where the record shows a legacy of negative attitudes towards people with epilepsy, including a long history of viewing epilepsy as evidence of criminality, violent tendencies, sexual deviance, sin and demonic possession. While the intent of this review is not to delve in detail on the history of attitudes towards people with epilepsy, it is important to be reminded how recently negative attitudes towards people with epilepsy were part of the fabric of daily life, through legislated discrimination against people with epilepsy. For instance, as late as 1928, the Legislative Assembly of Alberta enacted the Sexual Sterilization Act. The Act, drafted to protect the gene pool, allowed for sterilization of mentally disabled persons in order to prevent the transmission of undesirable traits to offspring, including persons with epilepsy. This was only repealed in 1972; a similar act was in existence in British Columbia, and in several American states. Also impossible to ignore is the medicalization of negative stereotypes, evident in the writings of very prominent figures of the 20th century, including Kraeplin's "epileptic insanity" and "epileptic personality", which he reported on in the 1920 s, and which were associated with a number of negative characteristics. ${ }^{39}$ Against this bleak picture, there have been major positive strides: attitudes towards people with epilepsy have improved significantly with each decade, according to attitude surveys. For example, in terms of the statement, "I would object to my child playing with a child with epilepsy", $24 \%$ endorsed this statement in 1949 , compared to only $6 \%$ in 1979. ${ }^{40}$
However, we cannot yet even begin to be complacent about attitudes towards epilepsy. While we like to think of epilepsy as a purely "medical" condition such as diabetes (and many of us use a diabetes analogy with patients in terms of thinking of epilepsy and taking a matter-of-fact attitude towards it), epilepsy is actually rated as being much closer to AIDS in terms of prejudice and negative stereotypes than to diabetes, which is a relatively low-stigma condition. ${ }^{41}$

A discussion of attitudes towards people with epilepsy would not be complete without mentioning the study by Jacoby et $\mathrm{al}^{42}$ in United Kingdom (UK) adults, where 19\% felt that epilepsy was a mental health problem, $51 \%$ felt that people with epilepsy are treated differently, and $90 \%$ felt that it was frightening to see a seizure. Because fear is often the root cause of prejudice along with ignorance, these findings indicate that negative stereotypes of people with epilepsy are still very much present in peoples' attitudes. Also of import is a study by MacLeod and Austin ${ }^{43}$ of over 19,000 American adolescents. Again, keeping in mind that ignorance and fear are often precursors for prejudice, $52 \%$ had little knowledge about epilepsy, $40 \%$ were not sure if people with epilepsy were dangerous or not, only $31 \%$ would date someone with epilepsy and, most tellingly, less than $50 \%$ would tell their friends if they had epilepsy. Thus, the need for secrecy about this condition was felt even in these adolescents without epilepsy, demonstrating that stigma is not an attitude that grows from having negative experiences as a result of having epilepsy, but is instead part of generally held attitudes in the general public, molded prior to adulthood.

Turning now towards people with epilepsy, how severe is felt stigma, and how does it affect daily life? Baker et $\mathrm{al}^{44}$ surveyed people in 15 European countries and found that $51 \%$ of people with epilepsy felt stigmatized. Westbrook's studies on adolescents with epilepsy are also important in understanding the roots of felt stigma in people with epilepsy. ${ }^{45,46}$ While the majority of adolescents with epilepsy reported that they did not feel stigmatized, their actions contradicted this: most kept their epilepsy status hidden (59\%), and most rarely talked about their epilepsy (70\%). Importantly, few had disclosed their conditions even to friends $(15 \%)$, compared to a much higher proportion in other chronic conditions (59\%). Thus, felt stigma is common in people with epilepsy, it is international, and as the MacLeod and Austin ${ }^{43}$ study shows, negative attitudes towards epilepsy are present early in life in people without epilepsy. Further, people with epilepsy engage in defensive actions (avoiding disclosure, maintaining secrecy) to avoid stigma, even when felt stigma is denied.

\section{Happiness Factors and Stigma}

Is stigma a marker for role restrictions, fewer social relationships, and other factors that predict lower wellbeing? There is evidence that this may be the case. In an interesting study contrasting a number of stigmatizing conditions such as leprosy, AIDS, epilepsy, and tuberculosis, Van Brakel ${ }^{37}$ studied a number of social indicators of success, including marriage, interpersonal relationships, mobility (a key problem for epilepsy due to driving restrictions), employment, access to treatment, education, leisure activities, and attendance at social functions. All of these were lower in people with stigmatizing conditions, including epilepsy. This effect also appears to go beyond the 
individual with the stigmatizing condition: in parents of children with epilepsy, higher stigma perceptions are related to lower rate of family leisure activities. ${ }^{47}$

\section{Stigma and Public Health}

There is ample evidence that stigma adversely affects the individual, as reviewed above. But does this have relevance on a broader scale? There is compelling and accumulating evidence that conditions associated with stigma have a major effect on public health, because individuals with these conditions are likely to have delays in seeking a diagnosis and in seeking treatment, and have lesser treatment adherence and poorer medication management. ${ }^{5,37}$ This means that stigmatizing conditions cost more to assess, treat and manage than nonstigmatizing conditions of equal medical severity. Incidentally, on a broader scale, stigma in epilepsy is thought to contribute to both a lower rate of grant funding for epilepsy research ${ }^{21}$ and to negative or inaccurate information in mass media, including major US newspapers. ${ }^{48}$

\section{Comorbidity and Wellbeing}

The term comorbidity refers to the presence of two or more diseases with distinct etiologies, pathogenesis, and pathophysiology occurring in the same individual for a defined time period. ${ }^{49,50}$ Other conceptualizations of comorbidity in epilepsy refer to a broader definition of comorbidity to include conditions that may be a secondary effect of epilepsy itself (e.g., secondary depression). While reviews of comorbidity in epilepsy can be found elsewhere ${ }^{51-56}$, it is important to highlight some of the main comorbidities in epilepsy, and explore how these comorbidities may impact wellbeing.

Of psychiatric comorbidities, mood and behavioural disorders (depression, anxiety, and in children, ADHD) are the most common comorbidities, and all tend to lower quality of life. Thus, comorbidities themselves carry their own burden with regard to role restrictions and poor coping, which, when combined with neurological variables inherent to epilepsy, likely potentiate adverse effects on wellbeing. Thus, an adult with epilepsy who also struggles with depression is even less likely to take part in experiential activities that could alleviate low mood, and a family struggling with a child who has ADHD in addition to seizures may further restrict their leisure activities to avoid having to deal with challenging behaviors in public, in addition to worrying about a seizure in public. Research indicates that comorbidities contribute significantly to role limitations in people with epilepsy. ${ }^{57}$ Exacerbating this situation is the fact that the stigma associated with health conditions such as epilepsy and AIDS can worsen psychiatric morbidity. ${ }^{37}$

\section{Addressing the Problem: Intervention Programs for Wellbeing and Quality of Life}

From our discussion thus far, it is amply evident that people with epilepsy face significant challenges in terms of maintaining an adequate level of wellbeing because epilepsy adversely affects so many of the basic components that are known to contribute to life satisfaction, including work, marriage, socializing, and experiential activities. Epilepsy is unique among most neurological conditions in affecting almost all the domains necessary for a sense of life satisfaction, but it is not unique among stigmatizing conditions, which are also affected broadly in those domains underlying wellbeing. This broad, negative effect on happiness factors is likely the reason that most studies of neurological and epilepsy-related variables such as seizure frequency and medications fall short in explaining the pervasive problem with quality of life that permeates most research on epilepsy. Simply put, epilepsy is a condition that can make it difficult to put together all the ingredients necessary for creating a full, satisfying and meaningful life. Searching for those missing ingredients through new drugs or devices aimed at reducing seizure frequency is not likely to be fruitful, without also addressing the other missing components of wellbeing such as work, socializing, family, and experiential activities.

As practitioners, we are often struck by the unique inner strength and success of some patients who are able to achieve personal success and life satisfaction where others fail despite repeated attempts at support and intervention. Understanding the factors that help build internal and external resources for dealing with adversity in epilepsy is critically important so that we can become better able to promote and support resilience, resourcefulness and courage in people living with epilepsy.

To date, there exist only a relatively small number of intervention programs geared to improve wellbeing in persons with epilepsy. These include education and support for adults with epilepsy ${ }^{58}$, education and support for families of children with epilepsy ${ }^{59}$, programs aimed specifically at increasing selfefficacy in medication management ${ }^{60,26}$, cognitive-behavioral therapy for addressing depression and coping ${ }^{61,62}$, and importantly, a preventative program aimed at reducing stigma and negative attitudes about epilepsy in schoolchildren. ${ }^{63,64}$ Despite the existence of these pioneering programs, most epilepsy programs in North American medical centres do not provide comprehensive intervention programs that address the psychosocial, educational, vocational and family support needs of patients and their families. No directly programs addressing the wellbeing of caregivers (primarily mothers and spouses) of people with epilepsy could be found in the epilepsy literature, despite the high rate of maternal depression, parental stress and effects on family members. ${ }^{65-68}$ Clearly, development of specialized programs aimed exclusively at promoting wellbeing for people with epilepsy are needed..$^{69,70}$

\section{Comprehensive Treatment Plans and Practical Prescriptions for Increasing Wellbeing}

Based on the existing research, a comprehensive treatment plan for people with epilepsy would include the components listed in Table 1. While programs of this kind are clearly needed, there may also be ways for the individual practitioner to assist people with epilepsy in maximizing quality of life. There are specific interventions that have been used to boost wellbeing in the general population ${ }^{1}$, but none of these has been used to improve wellbeing in people with epilepsy. These might involve increasing social contacts and networks, increasing experiential activities (leisure, sports, travel), and using other simple interventions developed by Positive Psychology such as identifying three positive events each day, and the expression of gratitude (see Seligman ${ }^{1}$ for examples).

At this point in the discussion, the definition of health provided by the World Health Organization (WHO) bears repeating: 
Table 1: Increasing wellbeing in Epilepsy: Treatment components for Epilepsy programs

- Work skills training aimed at promoting employment and reducing unemployment/underemployment

- Counseling and therapy focusing specifically on independence, active coping and self-efficacy

- Counseling, coaching and assisting people in establishing and maintaining romantic and social relationships

- Screening and treatment for comorbidities (e.g., depression, anxiety, ADHD)

- Parenting skills training aimed at promoting independence in children and adolescents with epilepsy

- Transition programs for youth directly training autonomy and independence in managing medical care

- Stigma prevention (e.g., community educational programs)

- Support for families for preventing activity restrictions and burn-out (e.g., peer support networks, educational programs, counseling, family mentoring)

Table 2: Increasing wellbeing in Epilepsy: Prescriptions for practitioners

- Look beyond seizure control and medication; how is your patient doing in life, generally? Higher wellbeing might translate into better adherence to medical treatment and health behaviors.

- Educate patients about the components of wellbeing (e.g., the beneficial effect of work, social contact, romantic relationships, leisure and other experiential activities)

- Ask about your patient's social life, work situation, recreation/hobbies, and make it clear to your patient that working on each of these areas should be a focus of treatment, in addition to medications and other medical interventions, and set specific goals.

- Tell your patients to get out and get involved; inform them that social isolation should be actively avoided as part of their management plan to increase quality of life; check in with your patients as to their social life, and encourage dating and socializing as specific components of their treatment

- Suggest simple approaches and treatments aimed specifically at wellbeing, such as exercise programs, travel, sports, family time, prosocial acts like volunteering, etc.

- Refer patients who are struggling with work, marriage, and family life to appropriate services (individual therapy/counseling, marital counseling, vocational counseling, etc)

- Tell caregivers about the importance of building independence in their children and adolescents (remind them to guard against overprotection, a factor associated with low adult independence)
Health is a state of complete physical, mental and social wellbeing and not merely the absence of disease or infirmity**

Central in this definition is the word "wellbeing", which takes us back to our discussion of factors known to increase wellbeing in healthy people as per the research in Positive Psychology, and to our discussion of the factors underlying many of the challenges to wellbeing in people with epilepsy. How do we translate this knowledge into practical guidelines for people with epilepsy? Tables 2 and 3 show suggestions for use by health practitioners and people with epilepsy. Suggestions for practitioners are not restricted to any particular health profession,

Table 3: Increasing wellbeing in Epilepsy: Simple prescriptions for people living with Epilepsy

- Take part fully in life; don't let epilepsy define who you are.

- Learn about epilepsy, so that you can be confident about managing your seizures.

- Make sure you socialize regularly. Don't let epilepsy keep you away from spending time with other people; socializing is an important component of your wellbeing.

- Find something you enjoy and do it regularly. Don't let epilepsy keep you in the house, or keep you from activities you enjoy. This is true for children as well.

- Don't let epilepsy restrict family life. Make sure you are building in pleasurable activities for you and your family.

- If you are alone and socially isolated, make an extra effort to be around people, even for short periods every day. This is important for your overall health.

- Take stock: make sure you are not restricting yourself from activities that you enjoy, and make sure that you don't hold negative attitudes or stereotypes about epilepsy. If you do, get help by asking your health care provider for educational materials, and/or to refer you to a counselor to work on your feelings about having epilepsy.

- Exercise regularly, and eat well. This helps your body, but it also is very important for building your mental stamina, which will help you cope better when something unexpected happens in your life.

- If you are a caregiver, make sure to take care of yourself first, so that you can be a good caregiver to others.

- Make sure you understand your epilepsy. Ask your health practitioners questions, and keep asking until you feel comfortable in making decisions about your epilepsy. Many people don't fully understand their own health care issues; being an informed consumer helps you stay in charge of your medical care, and will make you feel more comfortable with dealing with medical issues.
**Preamble to the Constitution of the World Health Organization as adopted by the International Health Conference, New York, 19-22 June, 1946; signed on 22 July 1946 by the representatives of 61 States (Official Records of the World Health Organization, no. 2, p. 100) and entered into force on 7 April 1948. 
but are general enough that they can apply to any practitioner, including physicians, nurses, psychologists, and social workers. Readers are encouraged to contact the author to provide further suggestions and feedback for refining and expanding these lists.

\section{REFERENCES}

1. Seligman MEP. Authentic happiness: Using the new Positive Psychology to realize your potential for lasting fulfillment. 2002; New York: Free Press.

2. Seligman MEP, Csikszentmihalyi M. Positive psychology: An introduction. Am Psychol. 2000;55(1):5-14.

3. Kesebir P, Diener E. In pursuit of happiness: Empirical answers to philosophical questions. Perspect Psychol Sci. 2008;3(2): $117-25$.

4. Danner D, Snowdon D, Friesen W. Positive emotions in early life and longevity: Findings from the nun study. J Pers Soc Psychol. 2001;80:804-13.

5. Jacoby A, Snape D, Baker GA. Epilepsy and social identity: The stigma of a chronic neurological disorder. Lancet Neurol. 2005; 4:171-8.

6. Diener E, Horowitz J, Emmons RA. Happiness in the very wealthy. Social Indicators Research. 1985;16:263-74.

7. Hagerty MR. Social comparisons of income in one's community: Evidence from national surveys of income and happiness. J Pers Soc Psychol. 2000;78(4):764-71

8. Dunn EW, Aknin LB, Norton MI. Spending money on others promotes happiness. Science. 2008;319:1687-8.

9. Lucas RE, Clark AE, Yannis G, Diener E. Unemployment alters the set point for life satisfaction. Psychol Sci. 2004;15:8-13.

10. Bockerman P, Ilmakunnas P. Elusive effects of unemployment on happiness. Social Indicators Research. 2006;79:159-69.

11. Diener E, Seligman MEP. Beyond money: Towards an economy of well-being. Psychological Science in the Public Interest. 2004; $5: 1-31$.

12. Helliwell JF, Putnam Rd. The social context of wellbeing. Philos Trans R Soc Lond B Biol Sci. 2004 Sep 29;359(1449):1435-46.

13. Bennett KM. Psychological wellbeing in later life: The longitudinal effects of marriage, widowhood and marital status change. Int $\mathbf{J}$ Geriatr Psychiatry. 2005;20:280-4.

14. Diener E, Biswas-Diener R. Will money increase subjective wellbeing? Social Indicators Research. 2002;57:1119-69.

15. Van Boven L. Experientialism, materialism and the pursuit of happiness. Review of General Psychology. 2005;9(2):132-42.

16. Lykken D, Tellegen A. Happiness is a stochastic phenomenon. Psychol Sci. 1996;7:186-9.

17. Weiss A, Bates TC, Luciano M. Happiness is a personal(ity) thing: The genetics of personality and well-being in a representative sample. Psychol Sci. 2008;19(3):205-10.

18. Lindsten H, Stenlund H, Edlund C, Forsgren L. Socioeconomic prognosis after a newly-diagnosed unprovoked epileptic seizure in adults: A population-based case-control study. Epilepsia. 2002;43(10):1239-50

19. Sillanpää M, Haataja L, Shinnar S. Perceived impact of childhoodonset epilepsy on quality of life as an adult. Epilepsia. 2004; 45(8):971-7.

20. Smeets MJ, van Lierop BAG, Vanhoutvin JPG, Aldenkamp AP, Nijhuis FJN. Epilepsy and employment: Literature review. Epilepsy \& Behav. 2007;10:354-62.

21. Theodore WH, Spencer SS, Wiebe S, Langfitt JT, Ali A, Shafer PO, et al. Epilepsy in North America: A report prepared under the auspices of the Global Campaign Against Epilepsy, the International Bureau for Epilepsy, the International League Against Epilepsy, and the World Health Organization. Epilepsia. 2006:47(10): 1700-22

22. Wakamato J, Nagao H, Hayashi M, Morimoto T. Long-term medical, educational and social prognoses of childhood-onset epilepsy: A population-based study in a rural district in Japan. Brain Dev. 2000;22:246-55.
23. Dupont S, Tanguy M-E, Clemenceau S, Adam C, Hazemann P, Baulac M. Long-term prognosis and psychosocial outcomes after surgery for MTLE. Epilepsia. 2006;47(12):2115-24

24. Jones JE, Berven NL, Ramirez L, Woodard A, Hermann BP. Longterm psychosocial outcomes after anterior temporal lobectomy. Epilepsia. 2002;43(8):896-903

25. Chin PS, Berg AT, Spencer SS, Lee ML, Shinnar S, Sperling M, et al. Patient-perceived impact of resective epilepsy surgery. Neurology. 2006;66:1882-7.

26. DiIorio C, Shafer PO, Letz R, Henry TR, Schomer DL, Yeager K, et al. Behavioral, social, and affective factors associated with self-efficacy for self-management among people with epilepsy. Epilepsy Behav. 2006;9:158-63.

27. Shackleton DP, Kasteleijn-Nost Trenité DGA, de Craen AJM, Vandenbroucke JP, Westendorp RGJ. Living with epilepsy: Long-term prognosis and psychosocial outcomes. Neurology. 2003;61:64-70

28. Szabó CA, Rothner AD, Kotagal P, Erenberg G, Dinner DS, Wylie E. Symptomatic or cryptogenic partial epilepsy of childhood onset: Fourteen-year follow-up. Pediatr Neurol. 2001;24:264-9.

29. Howard GM, Radloff M, Sevier TL. Epilepsy and sports participation. Curr Sports Med Rep. 2004;3:15-19.

30. Steinhoff BJ, Neususs KO, Thegeder H, Reimers CD. Leisure time activity and physical fitness in adults with epilepsy. Epilepsia. 1996;37:1221-7.

31. RESt-1 Group. Social aspects of epilepsy in the adult in seven European countries. Epilepsia. 2000;41(8):998-1004.

32. Shore CP, Austin JK, Huster GA, Dunn DW. Identifying risk factors for maternal depression in families of adolescents with epilepsy. J Spec Pediatr Nurs. 2002;7(2):71-80.

33. Sample PL, Ferguson PL, Wagner JL, Pickelsimer EE, Selassie AW. Experiences of persons with epilepsy and their families as they look for medical and community care: A focus group study from South Carolina. Epilepsy Behav. 2006;9:649-62.

34. Nolan KJ, Camfield CS, Camfield PR. Coping with Dravet syndrome: Parental experiences with a catastrophic epilepsy. Dev Med Child Neurol. 2006;48:761-5.

35. Jacoby A. Stigma, epilepsy, and quality of life. Epilepsy Behav. 2002;3:S10-20.

36. Link BG, Phelan JC. Conceptualizing stigma. Annu Rev Sociol. 2001;27:363-85

37. Van Brakel WH. Measuring health-related stigma: A literature review. Psychol Health Med. 2006;11(3):307-34

38. Heijnders M, Van Der Meij, S. The fight against stigma: An overview of stigma-reduction strategies and interventions. Psychol Health Med. 2006;11(3):353-63.

39. Blumer D. Psychiatric aspects of epilepsy. Washington, DC: American Psychiatric Press. 1984

40. Caveness WF, Gallup GH. A Survey of public attitudes toward epilepsy in 1979 with an indication of trends over the past thirty years. Epilepsia. 1980;21(5):509-18.

41. Fernandes PT, Salgado PCB, Noronha ALA, Barbosa FD, Souza EAP, Sander JW, et al. Prejudice towards chronic diseases: Comparison among epilepsy, AIDS and diabetes. Seizure. 2007; $16: 320-23$

42. Jacoby A, Gorry J, Gamble C, Baker G. Public knowledge, private grief: A study of public attitudes to epilepsy in the United Kingdom and implications for stigma. Epilepsia. 2004;45(1): 1405-15.

43. MacLeod JS, Austin JK. Stigma in the lives of adolescents with epilepsy: A review of the literature. Epilepsy Behav. 2003;4: 112-17.

44. Baker G, Brooks J, Buck D, Jacoby A. The stigma of epilepsy: A European perspective. Epilepsia. 1999;41(1):98-104.

45. Westbrook LE, Bauman LJ, Shinnar S. Applying stigma theory to epilepsy: A test of a conceptual model. J Pediatr Psychol. 1992;17:633-49.

46. Westbrook LE, Silver EJ, Coupey SM, Shinnar S. Social characteristics of adolescents with idiopathic epilepsy: A comparison to chronically ill and nonchronically ill peers. J Epilepsy. 1991;4:87-94. 
47. Austin JK, MacLeod J, Dunn DW, Shen J, Perkins SM. Measuring stigma in children with epilepsy and their parents: Instrument development and testing. Epilepsy Behav. 2004;5:472-82.

48. Caspermeyer JJ, Sylvester EJ, Drazkowski JF, Watson GL, Sirven JI. Evaluation of stigmatizing language and medical errors in neurology coverage by US newspapers. Mayo Clin Proc. 2006; 81(3):300-6.

49. Wittchen, HU. Critical issues in the evaluation of comorbidity of psychiatric disorders. Br J Psychiatry Suppl. 1996;168 Suppl 30: 9-16.

50. Vella G, Aragona M, Alliani D. The complexity of psychiatric comorbidity: A conceptual and methodological discussion. Psychopathology. 2000;33(1):25-30.

51. Devinsky O. Psychiatric comorbidity in patients with epilepsy: Implications for diagnosis and treatment. Epilepsy Behav. 2003; 4:S2-10.

52. Gilliam F, Hecimovic H, Sheline Y. Psychiatric comorbidity, health, and function in epilepsy. Epilepsy Behav. 2003;4:S26-30.

53. Kanner AM. Depression in epilepsy: A frequently neglected multifaceted disorder. Epilepsy Behav. 2003;4:S11-9.

54. Téllez-Zenteno JF, Matijevic S, Wiebe S. Somatic comorbidity of epilepsy in the general population in Canada. Epilepsia. 2005; 46(12):1955-62

55. Téllez-Zenteno JF, Patten SB, Jetté N, Williams J, Wiebe S. Psychiatric comorbidity in epilepsy: A population-based analysis. Epilepsia. 2007;48(12):2336-44.

56. Vazquez B, Devinsky O. Epilepsy and anxiety. Epilepsy Behav. 2003;4:S20-5.

57. Zeber JE, Copeland LA, Amuan M, Cramer JA, Pugh MJV. The role of comorbid psychiatric conditions on health status in epilepsy. Epilepsy Behav. 2007;10:539-46.

58. May TW, Pfafflin M. The efficacy of an educational treatment program for patients with epilepsy (MOSES): Results of a controlled, randomized study. Epilepsia. 2002;43(5):539-49.

59. Snead K, Ackerson J, Bailey K, Schmitt MM, Madan-Swain A, Martin RC. Taking charge of epilepsy: The development of a structured psychoeducational group intervention for adolescents with epilepsy and their parents. Epilepsy Behav. 2004;5: $547-56$.
60. Dilorio C, Shafer PO, Letz R, Henry TR, Schomer DL, Yeager K, et al. Project EASE: A study to test a psychosocial model of epilepsy medication management. Epilepsy Behav. 2004;5: 92636.

61. Au A, Chan F, Li K, Leung P, Li P, Chan J. Cognitive-behavioral group treatment program for adults with epilepsy in Hong Kong. Epilepsy Behav. 2003;4:441-6.

62. Goldstein LH, McAlpine M, Deale A, Toone BK, Mellers JDC. Cognitive behaviour therapy with adults with intractable epilepsy and psychiatric co-morbidity: Preliminary observations on changes in psychological state and seizure frequency. Behav Res Ther. 2003;41:447-60.

63. Martiniuk ALC, Speechley KN, Secco M, Campbell MK. Development and psychometric properties of the Thinking about Epilepsy questionnaire assessing children's knowledge and attitudes about epilepsy. Epilepsy Behav. 2007a;10:595-603.

64. Martiniuk ALC, Speechley KN, Secco M, Campbell MK, Donner A. Evaluation of an epilepsy education program for Grade 5 students: A cluster randomized trial. Epilepsy Behav. 2007b; 10(4):604-10.

65. Chapieski L, Brewer V, Evankovich K, Culhane-Shelburne K, Zelman K, Alexander A. Adaptive functioning in children with seizures: Impact of maternal anxiety about epilepsy. Epilepsy Behav. 2005;7:246-52.

66. Cottrell L, Khan A. Impact of childhood epilepsy on maternal sleep and socioemotional functioning. Clin Pediatr. 2005;44:613-16.

67. Iseri PK, Ozten E, Aker AT. Posttraumatic stress disorder and major depressive disorder is common in parents of children with epilepsy. Epilepsy Behav. 2006;8:250-5.

68. Wirrell EC, Wood L, Hamiwka LD, Sherman EMS. Parenting stress in mothers of children with intractable epilepsy. Epilepsy Behav. 2008;13(1):169-73

69. Ramaratnam S, Baker GA, Goldstein LH. Psychological treatments for epilepsy. Cochrane Database of Syst Rev. 2005, Issue 4.

70. Wagner JL, Smith G. Psychosocial intervention in pediatric epilepsy: A critique of the literature. Epilepsy Behav. 2006;8: $39-49$. 


\title{
Is Functional Hemispheric Lateralization Guided by Structural Cerebral Asymmetry?
}

\author{
Juhn A Wada
}

\begin{abstract}
Lateralized hemispheric function is guided by structural cerebral asymmetry" remains an attractive hypothesis. It is plausible that genetically determined events lead to structural asymmetry that in turn guide lateralized functional development. However, hemispheric specializations are neither inevitable consequences of early local cytoarchitectural differences nor immutably fixed in structure. The human brain possesses dynamic plasticity as its primary mission and can override and transcend hemispheric differences for preservation of higher cognitive functions such as speech and language.
\end{abstract}

RÉSUMÉ: La latéralisation hémisphérique fonctionnelle est-elle guidée par l'asymétrie des structures cérébrales? «La fonction hémisphérique latéralisée est guidée par l'asymétrie cérébrale structurale » demeure une hypothèse alléchante. Il est plausible que des événements déterminés génétiquement entraînent une asymétrie structurale qui guide le développement fonctionnel latéralisé. Cependant, les spécialisations hémisphériques ne sont pas des conséquences inévitables de différences cytoarchitecturales locales précoces ou fixées immuablement dans la structure. La mission première du cerveau humain est la plasticité dynamique et elle peut outrepasser et transcender les différences hémisphériques pour la préservation des fonctions cognitives supérieures comme la parole et le langage.

Can. J. Neurol. Sci. 2009; 36: Suppl. 2 - S25-S31

Cerebral organization of speech and language function has been an integral part of epileptological concern in general $^{1}$, and epilepsy surgery in particular ${ }^{2}$. The basis for its lateralization comes from a long history of scientific enquiry involving clinical, genetic, evolutionary, hormonal, and anatomical speculations in addition to an influential but controversial concept of initial equipotentiality introduced by Lennenberg ${ }^{3}$.

A baby acquires native language within a few years without specific analytical effort and prior to any formal grammatical training that comes much later during schooling. Initial comprehension and then emission of native language sounds (and sign language) are most likely intrinsic and neurobiologically based, while subsequent acquisition of reading and writing - abilities that require much conscious effort-are more likely extrinsic and culturally based, although existence of developmental dyslexia suggests that reading ability may require certain neural mechanisms ${ }^{4}$.

Reports of infants' preference for the mother's voice over another female ${ }^{5}$ as well as babies' preference for stories read by the mother during the last ten weeks of pregnancy ${ }^{6}$ suggest that the learning and laying down of memory trace of speech pattern may evolve prenatally in utero. A recent study ${ }^{7}$ addressing the question of lateralization of language function to the left hemisphere concluded that language laterality is linked to the processes of learning and memory trace formation rather than the physical or phonological properties of speech sound. It implies that left hemisphere language may be linked to its putative advantage of building up memory traces for any language elements, irrespective of their acoustic make-up. What this advantage may be is not known, however. Regardless of interpretation, the left hemisphere of the majority of the righthanded population must undergo change not only for language

From Neuroscience and Neurology, UBC Hospital, The University of British Columbia, Vancouver, British Columbia, Canada.

Received July 25, 2008. Final Revisions Submitted August 21, 2008. Correspondence to: Juhn A. Wada, Neuroscience and Neurology, UBC Hospital, The University of British Columbia, 2255 Wesbrook Crescent, Vancouver, British Columbia, V6T 2B5, Canada. 
acquisition but also for gaining adequate knowledge and competency of language.

Historically, it was John Hughlings Jackson who stated "difference of structure of necessity implies difference in function" in his 1874 paper "On the nature of the duality of the brain." Indeed, unique form may subserve a specific function, but function could also shape the structure in terms of evolution. During the past few decades, in-vivo brain imaging has not only validated previous post-mortem observations of morphological brain asymmetry but also initiated renewed discussion on their functional, structural, and genetic implications.

As a response to the kind invitation of our Chair, Dr. Mary Connolly, on the occasion of the 30th Anniversary Meeting of the Canadian League Against Epilepsy, I am pleased to present a selective review of the hemispheric function/structure relationship on the issue, "Is functional hemispheric lateralization guided by structural cerebral asymmetry?"

\section{Developmental hemispheric asymmetry}

\section{Right hemisphere}

Morphological $^{8,9}$, and biochemical ${ }^{10}$ evidence has suggested earlier right hemisphere maturation, for which indirect support has been provided by EEG findings ${ }^{11}$ and observation of temporal lobe epilepsy ${ }^{12}$, suggesting delayed process of left hemisphere maturation to account for its vulnerability in early childhood $^{13}$.

Behaviourally, two-months-old infants with no memorybased speech discrimination ability in either hemisphere, have better right hemisphere efficiency of memory-based musical timbre discrimination ${ }^{14}$. Also, infants aged four to nine months have left visual field superiority for face recognition despite limited visual sensitivity at this age ${ }^{15,16}$. Likewise, the newborn baby displays right-lateralized cortical response to luminous stimuli ${ }^{17}$. Furthermore, infants aged one to three years have SPECT evidence of right hemisphere dominant cerebral blood flow in the posterior association area. Laterality of this asymmetry shifts to the left after three years, when babies begin to formulate sentences ${ }^{18}$.

\section{Left hemisphere}

The chronology of language output reflecting left hemisphere development is as follows: babbling at about 6-8 months, oneword emission at 10-12 months, two-word emission around two years. Sentence formation begins around three years, for which sentence comprehension must obviously be required. Spontaneous acquisition of sign system in both deaf and hearing infants ${ }^{19}$ starting with manual silent babbling ${ }^{20}$ have a comparable developmental course. Faster orientation to native language as short a duration as 1.2 seconds duration in infants age two months is reported, though this effect was neutralized when prosodic organization was scrambled ${ }^{21}$. In addition, within the first months after birth, infants are capable of not only speech perception but developing grammatical knowledge $\mathrm{e}^{22,23}$.

Electrophysiological evidence of left hemisphere dominance in infants has been accumulating over the past three decades ${ }^{24-28}$. With new brain imaging development, left temporal activation reflecting speech perception following exposure to native language as short as 1.2 seconds duration was demonstrated at two to three years of age ${ }^{29}$. Similar left-sided activation in infants was observed by optical topography ${ }^{30}$.

\section{Gross anatomical asymmetry}

With language function lateralized to the left hemisphere in the majority of the right-handed population, perisylvian structural features epitomized by left $>$ right planum temporale (PT) asymmetry were identified as putative morphological correlate. The latter is visible at gestational age 29 weeks ${ }^{31}$. The left-larger-than-right PT was originally disclosed nearly 80 years ago $^{32}$ and has been repeatedly confirmed. More recently, measure-ments of skull and CT brain scan revealed other asymmetries such as the right frontal and the left occipital petalias. An MRI morphometry and then a voxel-based statistical analysis of the amounts of gray and white matter in the normal population confirmed presence of asymmetry in not only the PT, frontal and occipital poles but also minor but persistent right $>$ left limbic system asymmetry in addition to asymmetry of the planum parietale that is independent of adjacent PT asymmetry ${ }^{33}$ and inferior frontal lobe asymmetry ${ }^{34}$. However, PT asymmetry remains the most prominent among them.

\section{Planum Temporale (PT)}

Planum Temporale asymmetry had traditionally been viewed in the context of language dominance because of its anatomical location $^{35}$. Indeed, distribution of PT asymmetry, i.e., $82 \% \mathrm{~L}>\mathrm{R}$, $13 \% \mathrm{~L}=\mathrm{R}$ and $5 \% \mathrm{~L}<\mathrm{R}$ found in our planimetric measurement of surface area in 100 adult and 100 infant brains ${ }^{31}$ is intriguingly similar to that of the pattern of cerebral speech representation of patients with known epileptogenic laterality verified by the carotid amytal test (19 studies published 1995-2006: Wada, in preparation). Discovery of PT asymmetry comparable to that of human in higher primates such as chimpanzees also suggests its evolutionary significance ${ }^{36}$. A tantalizing coincidence with invivo correlation between direction of PT asymmetry and the direction of cerebral speech lateralization, verified by the carotid amytal test, was found in a small number of patients ${ }^{37}$. However, the finding was not replicated with a larger patient population ${ }^{38}$. Intriguingly, three patients in the latter study with right cerebral dominance were noted to have particularly large right PT. On the other hand, combined neurophysiological, neurosychological (dichotic listening) and neuroimaging studies strongly suggest that PT is involved in the processing of rapidly changing temporal information and complex spectro-temporal pattern but is not a dedicated language processor ${ }^{39}$. Consistent with the latter is the observation that increasing leftward PT asymmetry is correlated with outstanding musical ability and absolute pitch, suggesting that PT asymmetry might be closely related to musical functions ${ }^{40}$. Thus, a straight forward relationship does not appear to exist between PT asymmetry per se and language lateralization, though the size of the left PT might partially explain the variability of left hemisphere specialization for language comprehension.

\section{White matter and Broca-Wernicke connectivity}

In spite of the early pioneers' prediction on the importance of connectivity for cognitive function ${ }^{41,42}$, neurobiological study focused on the white matter has began only recently. Reported 
are thicker axon myelin sheath but not neuron, glia or cell size on the left $\mathrm{PT}^{43}$ and right>left asymmetry of uncinate fasciculus with the right side being $27 \%$ larger and containing $33 \%$ more fibers - possibly reflecting integrative /global processing of the right hemisphere ${ }^{44}$.

With diffusion tensor imaging tractography that provides virtual in-vivo dissection ${ }^{45,46}$, remarkably concordant results were found between human and monkey brains that were studied by a fundamentally different technique, i.e., isotope tract tracing ${ }^{47}$. Although current technical limitations leave questions of precise origin, course, and termination of pathways unanswered, convincing evidence of $\mathrm{L}>\mathrm{R}$ asymmetry of association pathways in the normal population ${ }^{48-51}$, and more specifically $\mathrm{L}>\mathrm{R}$ asymmetry representing Wernicke-Broca connectivity involving the arcuate fasciculus, the key structure in classical aphasiology, have been described ${ }^{52-55}$, but see also $^{56}$. Thus, significant asymmetry of white matter tracts favouring the left over right hemisphere appears to be the normal structural feature of the brain of adults and children studied.

\section{Micro-anatomy}

In spite of the well-characterized gross asymmetrical feature discussed above, relatively little is known about its fine anatomical basis. Differences between two hemispheres in the size of cytoarchitechtonically defined parieto-temporal and inferior frontal regions have been described ${ }^{57}$. However, the functional significance of these size differences remains unclear although more relevant structural specialization may be reflected in other levels of morphological organization.

\section{Broca area}

One micro-anatomical feature of the left Broca area (Brodmann 45) is the presence of a distinct population of magnopyramidal neurons in deep layer III that typically furnish associational and callosal projections, and are likely involved in the speech/language circuitry of the left hemisphere. A series of studies by Hayes and Lewis ${ }^{58-60}$, found that a subpopulation of these magno-cellular neurons in the left Broca area had significantly larger soma than their right counterpart in seven brains (age 21-81) studied. This cell-size asymmetry was documented only in area 45 but not in adjacent areas 46 or 4 . Scheibel ${ }^{61}$ studied the dendritic branching patterns of layer III pyramidal neurons in the left frontal gyrus and found that they were more intricate than the right counterpart suggesting that this might be associated with a greater complexity of information processing. Subsequent study ${ }^{62}$ addressed putative maturational dendritic branching pattern in 17 brains of children aged 3 to 72 months and found initially prominent right $>$ left asymmetry in total basilar dendritic length and the length of proximal order dendritic segments with subsequent progressive shift to left primacy during ages three to six years. Another study ${ }^{63}$ found evidence of right $>$ left structural maturity in layer III quantitative neuron/glia distribution density in the left Broca area of neonates, which then progressively reversed its trend to left $>$ right by the age of two years. Amunt's study ${ }^{64}$ examined the developmental cytoarchitectonic pattern of the Broca area in 34 brains (ages 3.5 months to 85 years). Asymmetry was found at age one year which increased with age in area 45; an adult-like, left $>$ right asymmetry in the volume fraction of cell bodies was reached by 5 years in area 45 and 11 years in area 44 . This time course was significantly delayed in comparison with the primary motor cortex. Furthermore, this cytoarchitectonic asymmetry of areas 44 and 45 continued to change throughout life, reflecting micro-structural plasticity presumably due to language practice.

\section{Wernicke area}

Seldon $^{65-67}$, was the first to address the question of cortical micro-anatomical asymmetry of posterior language region. His quantitative study of the Wernicke regions of both hemispheres in 74- to 89-year-old brains demonstrated that the width of individual columns and distance between those columns were greater in the left than the right. This asymmetry was not found in the primary auditory cortex. Examination of the basal dendrites of pyramidal cells disclosed that their length compensated for the hemispheric differences in columnar spacing except within posterior language regions. Thus the basal dendrites of individual pyramidal neurons are capable of contacting a similar number of adjacent cortical columns, regardless of inter-columnar spacing, except within the left Wernicke area where pyramidal neurons have longer absolute dendritic length and a greater number of neuropils, enabling more intense interaction with input. Another study ${ }^{68}$ on the basilar dendrites of supragranular pyramidal cells of the Wernicke area in 20 brains of right-handed individuals (age 1879 years) found greater total length of basilar dendrites on the left than the right but this inter-hemispheric difference was not significant in the brain of $>50$ years of age, indicating ageassociated structural changes throughout adulthood and old age. A comparable study of ten brains (age 21-71 years), however, showed the opposite trend with right $>$ left total dendritic length in $7 / 9$ brains that showed significant difference ${ }^{69}$. Whether such discrepancy reflects variation in tissue sampling from the "language cortex" based on gross anatomical landmarks remains unknown.

Comparison of peripheral neuronal space, the spacing density of neurons within columns, and the gray level index per microcolumn in the PT between human (seven brains, age 9-86 years) and subhuman primate (eight chimpanzees and seven rhesus monkeys) brains found that only the human brain possessed robust left $>$ right asymmetry in two aspects of micro-column morphology: wider columns and more neuropil space asymmetry $^{70}$. This left PT contains a greater amount of white matter where axons are more thickly myelinated than on the right $\mathrm{PT}^{43}$. With MRI, left $>$ right asymmetry of white, but not gray, matter volume was also identified in 20 right-handed healthy adults, suggesting a preferential role for left primary auditory cortex in processing temporal aspects of auditory stimuli ${ }^{48}$. These findings are consistent with the existence of wider columns on the left, as mentioned above, since additional width would be required to accommodate increased axonal volume (among other factors). Increased axon thickness implies faster conduction rates and hence these micro-anatomical asymmetry links to functional asymmetry.

More recently, Galuske et $\mathrm{al}^{71}$ studied interconnectivity within the Wernicke area (Brodmann 22) in seven adult brains, using lipophilic tract tracers and demonstrated clearly defined patchy patterns of interconnectivity. There was no hemispheric asymmetry in the size of these patches. However, left 
hemisphere inter-patch spacing was $20 \%$ greater than the right hemispheric counterpart, suggesting more functionally distinct columnar systems are included per surface unit in the left hemisphere.

As was done for the Broca area, morphology of layer III pyramidal cell structure of the Wernicke area has also been examined in six adult brains (age 47-92 years) using markers for acetylcholinesterase histochemistry ${ }^{72}$. A number of labeled cells in each hemisphere were symmetrical, but a marked left $>$ right cell size asymmetry was noted in language-related areas. Further study involving seven adult brains (age 50-97 years) indicated that the cell size asymmetry was not limited to acetylcholinesterase containing pyramidal cells but was the property of large layer III pyramidal cells throughout the auditory processing stream, including primary auditory cortex. Outside of the auditory processing system, for example, angular gyrus, did not show such asymmetry ${ }^{73}$. Obviously, left $>$ right cell size difference implies differential structural, connectional, and activational consequences between two hemispheres.

Although Wernicke area lacks information on maturational chronology, the accumulated evidence of left $>$ right asymmetry is consistent with left language dominance in the majority of the human population, suggesting potential genetic influence on asymmetric hemispheric development.

\section{Heritability of cortical gray matter}

The issue of nature vs. nurture regarding evolution of functional and structural brain lateralization is enigmatic. Physical development of the brain is shaped by both genetic and environmental factors, commencing during the prenatal period and extending into the whole lifespan; recent studies suggest strong genetic influence on cognitive skills such as verbal and spatial ${ }^{74}$, reading skills and linguistic tasks ${ }^{75}$. Therefore, it would be important to learn how structural features of the human brain may be linked to known cognitive functions such as language. Advances in brain mapping technology allow the detailed mapping of structural features of the cerebral cortex, including gray matter distribution, gyral pattern, and brain asymmetry. Composite maps of these features, generated for large populations have the potential to disclose patterns that are not readily observable in an individual. The heritability of brain size does not appear to vary by hemispheres ${ }^{76}$, but a monozygotic twin study of cortical surface areas suggested possible differential left/right genetic influences ${ }^{77}$. In large-scale monozygotic and dizygotic twin studies, both Wernicke and Broca areas were found to display a significant heritability on the left $(\mathrm{p}<0.0001)$ but not on the right $(\mathrm{p}>0.05)$, thus indicating that the language-related cortices were under significant genetic $\operatorname{control}^{78}$. It remains to be seen whether the asymmetry is reversed in naturally right language dominant brain and how the extent or strength of heritability plays a role in evolution of intraas against inter-hemispheric reorganization of language function that is known to occur in the partial epilepsy population.

\section{Comments}

At the morphological level, the human brain appears to be asymmetrically organized in language-related areas, where the left side is distinct from those of right homologous regions and that these differences are likely important in the functional specialization of respective hemispheres. Gross asymmetry can be visualized by 29 gestational weeks, and the pattern of asymmetries appears to be under significant genetic control. Obviously, different developmental programs are at work and organize the two hemispheres during the neonatal to childhood period and beyond, manifesting differential rates of maturation, dendritic arborization, connectivity, and functional activation.

\section{Anatomical asymmetry}

Studies reviewed contained some inconsistencies. In Hutsler's study ${ }^{73}$, for example, two out of seven brains did not show significant left>right asymmetry. The first brain, of a 67year-old, showed a non-significant leftward asymmetry while the second brain of a 97-year-old showed a significant rightward asymmetry. Thus, post-mortem micro-anatomical studies of brain asymmetry have inherent uncertainty on the question of not only language lateralization but also precise localization of the "language area" from which tissues were sampled. However, the overall pattern of microstructural asymmetry is not inconsistent with the known functional layout of the human brain, which is organized asymmetrically with hemispheric specialization for key aspects of language to the left in the majority of the population.

Similarly, one can reasonably conclude that neuronal and dendritic, columnar, and connectivity structure of Broca and Wernicke areas of the left hemisphere are distinct from those of the right homologous regions, and that these differences are likely important in the functional specialization of respective hemispheres. While the posterior temporal region has been studied only in the adult brain, at least two studies on the inferior frontal region ${ }^{62,63}$ have addressed the issue of maturational pattern and found suggestive evidence of initial right $>$ left asymmetry at the neonatal period before reversing to the adult pattern of left>right asymmetry. This is consistent with the initial right>left dominance of cerebral blood flow that shifts to left $>$ right after three years ${ }^{18}$. Therefore, shifting asymmetry in the intrinsic layout of cellular organization and connections could be at least in part due to use-dependent modification of microcircuitry during the maturational process. Laborious future research will be required to gain specific information as to the precise postnatal maturational sequence in the posterior temporal regions.

\section{Functional asymmetry}

Experience with hemispherectomy taught us that severe left hemisphere damage can cause contralateral transfer of left hemisphere function while retaining good language capability though with subtle deficit ${ }^{79}$ in addition to a crowding effect on native right hemisphere functions. Decades of carotid amytal tests and cortical stimulating studies have also provided us with convincing evidence of intra- and inter-hemispheric language reorganization as a consequence of partial epileptogenesis often remote from the eloquent cortical areas of the left hemisphere. Among them, mesial temporal lobe structure-particularly the hippocampus - appears to be potent in generating "reorganizational force" (Wada and Kosaka, in press). Such functional remodeling engages plastic capability of the brain that involves complex processes of synaptic strengthening, synaptic weakening/elimination, synaptogenesis, synapse remodeling and 
neurogenesis. At present, similarity/dissimilarity of consequently remodeled right hemisphere function as against "natural" right hemisphere language organization remains unknown. Likewise, structural mechanisms underlying intra- and inter-hemispheric language reorganization is unknown.

The right hemisphere is known to participate in the normal language network in a context of higher level language tasks such as comprehending metaphors, "getting" jokes, deriving themes, drawing inferences, and establishing global coherence. Our knowledge on the localization of such functions within the right hemisphere is scarce, although it is generally assumed to take place in the homologous areas of the left hemisphere language networks. With spectacular advances in brain imaging, evidence of right hemisphere participation in language tasks in left hemisphere-damaged population is accumulating. A recent fMRI study found that the right inferior frontal regions activated by a verbal fluency task in left temporal lobe epilepsy or following left hemispherectomy are not homologous to those of the healthy population or pre-hemispherectomy-activated region $^{80}$.

As discussed, functional hemispheric specialization appears associated with the development of micro-structural differences between hemispheres with differential columnar and connectivity patterns favouring the left hemisphere in the language- related frontal and temporal regions at a very early stage of development. Are these structural hemispheric differences fixed in the human brain? Language reorganization seen in the epilepsy patient population suggests that nature and nurture are interdependent. A number of questions arise: If lateralized language function is supported by uniquely lateralized structural specialization, what may be the structural mechanism of its reorganization? Similarly, if L $>$ R white matter asymmetry identified by DTI tractography involving the arcuate fasciculus is an aspect of quintessential structural underpinnings of the language representation, what structural features underlie trans-hemispheric transfer or dissociated bilateral language reorganization? Does natural right language dominant brain posses a mirror image pattern of the left dominant brain? Should those morphological patterns become identified, could they be potential clinical markers of the pattern of language representation?

\section{EPILOGUe}

The molecular mechanisms involved in the evolution of cerebral hemispheric asymmetry are largely unknown, and future studies will have to be guided by a new knowledge about how the brain evolves from symmetry to asymmetry. The fact that the language faculty is an exclusive human attribute with no subhuman models is a daunting challenge. However, the limits of the investigator's imagination are the only constraints on the acquisition of new knowledge. While emerging new observations require cautious interpretation, technology such as brain imaging is evolving very rapidly and has already been proven to enhance our understanding of the human brain structure and function. With advancing technologies and creative in-vivo exploration of the human brain, one can hope that one day a reliable demonstration of the underpinning of the neurobiological mechanism and its variations for speech and language functions in health and disease will become a reality.

\section{ACKNOWLEDGEMENTS}

This study was aided by the Epilepsy Research Fund, Faculty of Medicine, The University of British Columbia. Special thanks are given to Matthew George Wada Willett, my grandson the digital native, who helped me navigate the process of electronic submission.

\section{REFERENCES}

1. Penfield W, Roberts L. Speech and Brain Mechanism. Princeton; Princeton University Press, 1959.

2. Wada JA. A fateful encounter: Sixty years later - A reflection on the Wada Test. Epilepsia. 2008; 49:726-7.

3. Strauss E, Wada JA, Kosaka B. The neurobiological basis of lateralized cerebral function: Review. In: Kimura D, editor. Human Neurobiology on Language. Berlin: Springer-Verlag; $1983 ; 2: 115-27$.

4. Beaton AA. Dyslexia, reading, and the Brain: A Sourcebook of Psychological and Biological research. Hove, UK; Psychology Press. 2004.

5. DeCasper AJ, Fifer WP. On human bonding: Newborn prefer their mother's voices. Science. 1980; 208:1174-6.

6. De Casper AJ, Spence MJ. Prenatal maternal speech influences newborn's perception of speech sounds. Infant Behav Dev. 1986; 9:133-50

7. Shtyrov Y, Pihko E, Pulvermueller P. Determinants of dominance: Is language laterality explained by physical or linguistic features of speech? Neuroimage. 2005; 27:37-47.

8. Chi JG, Dooling EC, Gilles FH. Left right asymmetries of the temporal speech areas of the human fetus. Arch Neurol. 1977; 34:346-8

9. Simonds RJ, Scheibel, AB. The postnatal development of the motor speech area: a preliminary study. Brain Lang. 1989; 37:42-58.

10. Bracco L, Tiezzi, A, Giananneschi A, Campanella C, Amaducci L. Lateralization of choline acetyltransferase (Cnat) activity in foetus and adult brain. Neurosc Lett. 1984; 50:301-5.

11. Rey JH, Pond DA, Evance CC. Clinical and Electroencephalographic studies of temporal lobe function. Proc Royal Soc Med. 1949; 42:891-904.

12. Taylor DC. Differential rates of cerebral maturation between sexes and hemispheres. Lancet. 1969; 2:140-2.

13. Vicari S, Albertoni A, Chilosi AM, Cipriani P, Cioni G, Bates E, Plasticity and reorganization during language development in children with early brain injury. Cortex. 2000; 36:31-48.

14. Best CT, Hoffman H, Glanville BB. Development of infant ear asymmetries for speech and music. Percept Psychophys. 1982; 31:75-85

15. De Schonen S. Mathievet E. First come, First served: A scenario about development of hemispheric specialization in face recognition during infancy. Eur Bull Con Psychol. 1989; 9 (1):344.

16. De Schonen S, Deruelle C. Visual field asymmetries are present in infancy; A comment on Hata's study on children's performances. Neuropsychologia. 1990; 28:1053-62.

17. Crowell DH, Jones RH, Kapuniani LE, Nakagawa JK. Unilateral cortical activity in newborn humans: An early index of cerebral dominance? Science. 1973; 180:205-8.

18. Chiron C, Jambaque I, Nabbout R, Lounes R, Syrota A, Dulac O. The right brain hemisphere is dominant in human infants. Brain. 1977; 130:1057-65.

19. Morgan G, Woll B, editors. Direction in sign language acquisition. Amsterdam; Benjamins. 2002.

20. Petitto LA, Holowka S, Sergio LE, Ostry D. Language rhythms in baby hand movements. Nature. 2001; 413 (6951):35-6.

21. Dehaene-Lambertz G, Houston D. Faster latency orientation toward native language in two-month old infants. Lang Speech. 199; 41:7-43.

22. Kuhl PK. A new view of language acquisition. Proc Natal Acad Sci. 2000 Oct 24;97(22):11850-7. 
23. Hirsh-Pasek, K, Colinkoff, RM. The origins of grammar: evidence from early language comprehension. Cambridge: MIT Press; 1996.

24. Eimas PD, Sequeland ER, Jasczyk P, Vigorit J. Speech perception in infants. Science. 1971; 171:504-6.

25. Moffitt AR. Consonant cue perception by twenty to twenty four week old infants. Child Development. 1971; 42:717-31.

26. Molfese DI, Freeman Jr RB, Palermo DS. The ontogeny of brain lateralization for speech and nonspeech stimuli. Brain Lang. $1975 ; 2: 356-68$.

27. Wada JA. Pre-language and fundamental asymmetry of the infant brain. Ann NY Acad Sci. 1977; 299:370-7.

28. Treub SE, Ravinovitch MS. Auditory linguistic sensitivity in early infancy. Developmental Psychology. 1972; 6:74-7.

29. Dehaena-Lambertz G, Dehaena S, Hertz-Pannier L. Functional neuroimaging of speech perception in infants. Science. 2002; 298:201-3

30. Pena M, Maki A, Kovacik D, Dehaene-Lambertz G, Koizume H, Bouquet F. Sounds and silence: an optical topography study of language recognition at birth. Proc Nat Acad Sci. 2003; 100:20 11702-5.

31. Wada JA, Clarke R, Hamm A. Cerebral hemispheric asymmetry in humans: cortical speech zones in 100 adult and 100 infant brains. Arch Neurol. 1975; 32:239-46.

32. Pfeiffer RA. Pathologie des Hoerstrahlung duner der Corticalen Hoersphare In: Bumke O, Foerster O, editors. Handbuch der Neurologie. Berlin, Springer: 1836; 6. p. 533-626.

33. Jaenke L, Schlaug G, Huang Y. Asymmetry of the planum paerietale. Neuroreport. 1994; 5:1161.

34. Falzi G, Perrone P, Vignolo 1. Right-Left asymmetry in anterior speech region. Arch Neurol. 1982: 39, 239-40.

35. Geshwind N, Levitzkey W. Left/right asymmetries in temporal speech region. Science. 1968; 161:186-7.

36. Gannon PG, Holloway RL, Broadfield DC, Braun AR. Asymmetry of chimpanzee planum temporale: Humanlike pattern of Wernicke's brain language area homolog. Science. 1978; 279: 220-2.

37. Foundas AL, Leonard CM, Heilman KM. Morphologic cerebral asymmetries and handedness; the pars triangularis and planum temporale. Arch Neurol. 1995; 52:501-8.

38. Dorsaint-Pierre R, Penhue VB, Watkins KE. et al. Asymmetries of the planum temporale and Heschl's gyrus: relationship to language lateralization. Brain. 2006; 129:1164-76.

39. Griffith TD, Warren JD. The planum temporale as a computational hub. Trends Neurosci. 2002; 25:349-53.

40. Schlaug G, Jaenke L, Huang Y, Steinmetz H. In vivo evidence of structural brain asymmetry in musicians. Science. 1995; 267 (5198):699-701.

41. Wernicke C. Some new studies on aphasia. Fortschr Med, 1885:824-30. Translated in Eling P, editor: Reader in the history of aphasia. Vol. 4 Amsterdam: John Benjamins; 1994. p. 90-8.

42. Dejerine J. Anatomie des centres nerveux. Vol 1. Paris; Rueff et Cie 1895.

43. Anderson B, Southern B, Powers R. Anatomic asymmetries of the posterior superior temporal lobes: A postmortem study. Neuropsych Neuropsychol Behav Neurol. 1999; 12: 247-54.

44. Highley JR, Walker MA, Earl MM, Crow TJ, Harrison PJ. Asymmetry of the uncinate fasciculus: A postmortem study of normal subjects and schizophrenic patients. Cereb Cortex. 200; $12: 1218-24$.

45. Mesulam M. Imaging connectivity in the human cerebral cortex: the next frontier. Ann Neurol. 2005; 57:5-7.

46. Catani M. From hodology to function. Brain. 2007; 139:602-5.

47. Schmahmann JD, Pandya DN, Wang R, Dai G, D'Arceuil HE, de Crespingny AJ et al. Association fiber pathways of the brain: parallel observations from diffusion spectrum imaging and autoradiography. Brain. 2007; 130:630-53.

48. Penhune VR, Zatore RJ, MacDonald JD. Interhemispheric anatomical differences in human primary auditory cortex: probabilistic mapping and volume measurement from magnetic resonance scans. Cerebral Cortex. 1996; 6:661-70.
49. Good CD, Johnsrude I, Ashburner J, Henson RNA, Friston KJ, Frankowiak RS. Cerebral asymmetry and the effects of sex and handedness on brain volume: a voxel-based morphometric analysis of 465 normal adult human brains. Neuroimage. 2001; 14:685-700.

50. Pujol J, Lopez-Sara A, Deus J, Cardoner N, Sebastian-Galles N, Geraldo C, et al. Lateral asymmetry of the human brain studied by volumetric magnetic resonance imaging. Neuroimage. 2002; 17:670-9.

51. Schmithorst VJ, Wilke M, Dardzinski B, Holland SK. Correlation of white matter diffusivity and anisotropy with age during childhood and adolescence: a cross-sectional diffusion-tensor MR imaging study. Radiology. 2002; 222:212-8.

52. Buechel T, Raedler T, Sommer M, Sach M, Weiller C, Koch MA. White matter asymmetry in the human brain: a diffusion tensor imaging study. Cerebral cortex. 2004; 14:945-51.

53. Catani M, Jones DK, Ffytche DH. Perisylvian language networks of the human brain. Ann Neurol. 2005; 57: 8-16.

54. Parker G JM, Luzzi S, Alexander DC, Wheeler-Klingshott CAM, Ciccarelli O, Ralph MAL. Lateralization of ventral and dorsal auditory-language pathways in the human brain. Neuroimage. 2005; 24:656-66

55. Powell HWR, Parker GJM, Alexander DC, Symms MR, Boulby P, Wheeler-Kingshott CAM, et al. Hemispheric asymmetries in language-related pathways: A combined functional MRI and trasctography study. Neuroimage. 2006; 32:388-99.

56. Rodrigo S, Oppenheim G, Chassoux F, Golestani N, Cointepas Y, Poupon $\mathrm{C}$, et al. Uncinate fasciculus fiber tracking in mesial temporal lobe epilepsy. Initial findings. Eur Radiol. 2007; 17: 1663-8.

57. Galaburda AM, Sanides F, Geschwind N. Human brain: cytoarchitectonic left-right asymmetries in the temporal speech region. Arch Neurol. 1978; 35:812-7.

58. Hayes T, Lewis D. Hemispheric differences in layer III pyramidal neurons of the anterior language area. Arch Neural. 1993; 50: 501-5.

59. Hayes T, Lewis D. Anatomical specialization of anterior motor speech area: hemispheric differences in magnopyramidal neurons. Brain Lang. 2005; 49:289-308.

60. Hayes, T. Lewis D. Magnopyramidal neurons in the anterior motor speech region. Arch Neurol. 1996; 53:1277-83.

61. Scheibel A, Paul L, Fried I, Foethythe A, Tomiyasu U, Wechsler A, et al. Dendritic organization of the anterior speech area. Exp Neurol. $1985 ; 87: 109-17$.

62. Simmons RJ, Scheibel A. The postnatal development of the motor speech area; a preliminary study. Brain Lang. 1989; 37:42-58.

63. Bogolepova LN, Malofeeva LI. Characteristics of the development of speech motor areas 44 and 45 in the left and right hemispheres of the human brain in early postnatal ontogenesis. Neurosci Behav Physiol. 2000; 31:349-54.

64. Amunts K, Schleicher A, Ditterich A, Zilles K. Broca's region: cytoarchitectonic asymmetry and developmental changes. J Comp Neural. 2003; 465:72-89.

65. Seldon HL. Structure of human auditory cortex I: Cytoarchitectonics and dendrite distribution. Brain Res. 1981a; 229: 277-94.

66. Seldon HL. Structure of human auditory cortex II: Axon distribution and morphological correlates of speech perception. Brain Res. 1981b; 229:295-310.

67. Seldon HL. Structure of human auditory cortex III: statistical analysis of dendritic trees. Brain Res. 1982; 249:211-21.

68. Jacobs B, Scheibel A. A quantitative dendritic analysis of Wenicke's area in humans. I. Life span changes. J Comp Neurol. 1993; 327: 83-96.

69. Anderson B, Rutledge V. Age and hemisphere effects on dendritic structure. Brain. 1996; 119:1983-90.

70. Buxhoeveden DP, Switala AE, Litaker M, Roy E, Cassanova MF. Lateralization of micro columns in human planum temporale is absent in nonhuman primates. Brain Behav Evol. 2001; 57: $349-58$. 
71. Glauske RAW, Sclote W, Bratzke H, Singer W. Interhemispheric asymmetries of the modular structure in human temporal cortex. Science. 2000; 289:1946-9.

72. Hutsler JJ, Gazzaniga MDS. Acetylcholinesterase staining in human auditory and language cortices. Regional variation of structural features. Cerebral Cortex. 1996; 6:260-70.

73. Hutsler JJ. The specialized structure of human language cortex: pyramidal cell size asymmetries within auditory and language associated regions of the temporal lobes. Brain Lang. 2003; $86: 226-41$.

74. Alarcon M, Flomin R, Fulker DW, Corley R, Defries JC. Multivariate path analysis of cognitive abilities data at 12 years of age in the Colorado adoption project. Genet. 1998; 28:255-64.

75. Gayan J. Olson RK. Reading disability. Evidence for genetic etiology. Eur Child Adolesc Psychiatry. 1999; 8:52-5.
76. Pennington BF. A twin MRI study of size variation in human brain. J Cog Neurosci. 2000; 12:223-32.

77. Tramo MJ, Loftus WC, Thomas CE, Green RL, Mott LA, Gazzaniga MS. Surface area of human cerebral cortex and its gross morphological subdivisions. J Cog Neurosci. 1995; 7 : 292-301.

78. Thompson P, Cannon TD, Narr KL, van Erp T, Poutanen VK, Huttunen M, et al. Genetic influences on brain structure. Nature Neuroscience. 2001; 4:1253-7.

79. Pulsifer MB, Brandt J, Salorio CF, Vining EP, Carson BS, Freeman JM. The cognitive outcome of hemispherectomy in 71 children. Epilepsia. 2004; 45:243-54.

80. Voet NL, Adcock E, Flitney DE, Behrens TEJ, Hart Y, Stacey R, et al. Distinct Right frontal lobe activation in language processing following left hemisphere injury. Brain. 2006; 129:754-66. 


\section{Kindling Session}

\section{Introductory Remarks}

Can. J. Neurol. Sci. 2009; 36: Suppl. 2 - S32

Kindling was discovered by Graham Goddard in the late 1960s, and was immediately recognized as a power example of both neuroplasticity and complex partial epilepsy with secondary generalization. In the act of remodeling the brain to elicit triggered kindled convulsive seizures, many other functions associated with those kindled networks are reorganized, and become behaviorally aberrant when activated. As a result, several comorbid features develop with epileptogenesis and the establishment of the kindled state, all of which exhibit strong parallels to the human condition. The five papers presented in this session on kindling speak to some of these issues. McIntyre and Gilby describe kindling as a model of epilepsy, its utility and validity, while Burnham furthers this exposé by showing how amygdala kindled seizures manifest motorically in clonus and tonus when the animal is suspended. Leung describes the neuroplasticity that is evident in the hippocampus during partial kindling, and the relationship between long-term potentiation, kindling-induced potentiation and their relationships to learning and its disruption. Teskey additionally defines how cortical kindling alters plasticity in the motor cortex and presents several procedures that can ameliorate its impact. Finally, Gilby addresses the genetic and environmental influences that can make rats naturally seizureprone or seizure-resistant and the fact that a predisposition to seizure is associated with behavioral comorbidities in rodents that are similar to those observed in humans afflicted with ADHD and autism spectrum disorder.

Dan McIntyre Ottawa, Ontario 


\title{
Kindling as a Model of Human Epilepsy
}

\author{
Dan C. McIntyre, Krista L. Gilby
}

\begin{abstract}
The evidence supporting the suggestion that kindling is a good model of human temporal lobe epilepsy is briefly reviewed. Parallels between the human condition, involving both partial and secondarily generalized seizures, and kindling in rats and other animals are drawn and contrasted.
\end{abstract}

RÉSUMÉ: L'embrasement comme modèle de l'épilepsie chez l'humain. Nous revoyons les données en faveur de l'hypothèse selon laquelle l'embrasement serait un bon modèle de l'épilepsie chez l'humain. Nous mettons en évidence les similitudes et les différences entre cette pathologie chez l'humain, tant en ce qui concerne les crises partielles que celles qui sont secondairement généralisées, et l'embasement chez le rat et chez d'autres animaux.

Can. J. Neurol. Sci. 2009; 36: Suppl. 2 - S33-S35

Kindling has been used productively as a model of epileptogenesis and human complex partial seizures with secondary generalization for nearly 40 years. The evidence supporting its validity has been revisited many times over that period, including excellent discussions by $\mathrm{Wada}^{1}, \mathrm{McNamara}$ et $\mathrm{al}^{2}$, Sato et $\mathrm{al}^{3}$, Coulter et $\mathrm{al}^{4}$ and Bertram ${ }^{5}$ to name a few.

We originally defined kindling as the process whereby daily electrical activation of a neuronal site in the forebrain, which triggered a focal after-discharge (AD), resulted over days in progressive increases in that discharge and its associated behavioral responses ${ }^{6}$. Those increasing responses eventually culminated in secondarily generalized convulsive seizures and, ultimately, spontaneous seizures (e.g.,.$^{7}$ ) that no longer needed to be triggered by the investigator.

This progressive process clearly resulted in relatively permanent changes in the nervous system, changes that could easily be reactivated many weeks or months later with little loss in efficacy. Seemingly activation of a discrete focal area progressively and permanently first enhances local excitability and reduces inhibition, and then, second, through its projections (and arguably by other means, including ephaptic transmission and/or gap junctions), recruits a broader neural network. In doing so, focally kindled discharges ultimately usurp many levels of structure/function throughout the entire nervous system.

There are several features of kindling that support its validity as a model of human epilepsy. One, the behavioral patterns observed during partial seizures triggered from the amygdala or hippocampus (Stage 1 and 2; Racine, ${ }^{8}$ ) bear a striking resemblance to those of human complex partial seizures with origins believed to be in the temporal lobe. This includes arrest of movement, oral automatisms, and reduced responsiveness to external stimulation. Also similar between limbic kindled rats and human temporal lobe epilepsy (TLE) are the clonic motor patterns during secondary generalization. Two, the EEG activity from the amygdala or hippocampus associated with the kindled seizures are similar to human complex partial seizures with rhythmic polyspikes changing into spike and wave patterns. Three, the anticonvulsants effective against kindled seizures are remarkably similar to the human condition, where phenobarbital, carbamazepine, valproate and diazepam can suppress generalized amygdala kindled seizures (e.g., $\left.{ }^{9}\right)$. Four, in both humans and kindled rats, inter-ictal spikes develop, which vary considerably between individuals, and, in kindling, dissipate with disuse or non-activation. In both humans and kindling, persistent seizure activity increases the frequency of the inter-ictal events, as does slow-wave sleep. Five, the presence of seizures can be spontaneous. Of course, 'spontaneous' seizures define the human condition. With kindling, however, much variation in spontaneity occurs that depends upon many factors, including the species. For example, rats often exhibit spontaneous seizures after several hundred kindling provocations, while cats require only a few dozen stimulations ${ }^{7,10}$. Finally, does the primate brain (including man) kindle? The rhesus monkey readily kindles partial seizures, but secondarily generalizes very poorly from those partial seizures, whereas the photosensitive baboon, Papio papio, readily kindles and emits spontaneous seizures. In this regard, it is clear that there are significant variations between both species and strains of the same species in their seizure vulnerability. Indeed, this was the impetus that led us to develop through selective breeding a strain of rat that is seizure-prone versus a strain that is seizureresistant ${ }^{11,12}$.

\footnotetext{
From the Department of Psychology, Institute of Neuroscience, Carleton University, Ottawa, Ontario, Canada.

Received December 9, 2008. Final Revisions Submitted January 8, 2009. Correspondence to: Dan C. McIntyre, Department of Psychology, Institute of Neuroscience, Carleton University, 1125 Colonel By Drive, Ottawa, Ontario, K1S 5B6, Canada.
} 
Every species examined so far, including all mammals and even amphibians, has shown kindling in various forms and degrees; thus it would seem unlikely that the human animal would be exempt from this effect. Indeed there are reports of patients receiving multiple ECT treatments who began showing spontaneous seizures ${ }^{13}$, or a patient in whom generalized seizures were triggered as a complication after repeated brain stimulations for intractable pain ${ }^{14}$. In addition, there have been six different neurologists during the past 30 years who have reported to one of us (DCM) that they have observed kindling in several of their epileptic patients who were undergoing repeated electrical brain stimulation as part of exploratory studies into focal activation of seizures and their associated responses. In these cases, the daily focal limbic stimulations produced progressive increases in the duration and complexity of the triggered ADs, which were paralleled by increases in the associated behavioral responses - events that characterize our original definition of kindling.

In the study of epilepsy, there are other virtues of kindling as well. First, kindling allows you to study the involvement of any brain structure (limbic, neocortical, thalamic, etc.) in the development of epileptogenesis and spontaneous seizures. Here we can assess fundamental differences between structures in a) local excitability, b) progressive changes associated with repeated focal provocation, c) speed and extent of recruitment, and d) ultimate form(s) of the EEG and behavioral expression. Further, against the backdrop of kindling, we can study many other variables. For example, how does the genetic background of the animal impact the electrophysiological and behavioural events recruited during epileptogenesis (e.g., ${ }^{11,12,15}$ ). Second, because spontaneous seizures do not quickly appear with kindling, there is lots of time to thoroughly study the electrophysiological/molecular events underlying that development. This unique position is quite unlike that of models of epileptogenesis that employ protracted status epilepticus (SE) for their induction. Those models usually and unfortunately manifest considerable brain damage and spontaneous seizures can begin shortly after the SE event leaving little time to study or manipulate their development. Further to this point, because kindling ultimately can produce spontaneous seizures but does not produce obvious frank brain damage, we know that brain damage associated with protracted SE is not necessary for the development of spontaneous seizures. Thus, rather than creating damage, kindling clearly promotes changes in excitability, morphology and connectivity in neuroplastic networks. Perhaps this neuroplasticity is what epilepsy is all about, and that the 'minimal' brain damage seen in some of human epilepsy cases (e.g., TLE) is a consequence of the seizures and not their cause, as was suggest many years ago by Gastaut ${ }^{16}$.

Kindling in rats provides us with many other fascinating data that should be corroborated or compared to human epilepsy. First, there are different focal AD thresholds in different structures before and after kindling. For example, the amygdala and hippocampus have the lowest AD thresholds in the rat brain. This fact nicely predicts the unique vulnerability of these two sites in the onset of human TLE. Interesting, and perhaps critically important, the adjacent cortical structures in the rat brain (e.g., entorhinal, perirhinal and piriform) have relatively high $\mathrm{AD}$ thresholds before kindling, but drop precipitously shortly before secondary generalization. These cortical structures are essential for the generalization process in the rat ${ }^{17}$ and the clinical manifestation of TLE (see below). In perhaps a related fashion, the seizure-prone Fast rats natively have much lower $\mathrm{AD}$ thresholds in these parahippocampal structures than the resistant Slow rats ${ }^{12}$, which we believe is why they secondarily generalize so rapidly during epileptogenesis using any technique.

Are the genetic differences in seizure vulnerability and differential cortical excitability in parahippocampal networks that we see in our Fast and Slow rat models related to similar differences between humans? This outcome is suggested by the work of several investigators. For example, Wennberg et al ${ }^{18}$ reported that focal recordings in the temporal lobe of human patients with TLE showed that seizures beginning in the amygdala or parahippocampal gyrus were more likely to propagate and give rise to clinical symptoms than focal onset seizures of hippocampal origin. They proposed that inhibitory circuits within the hippocampus per se might function to prevent or limit seizure spread (perhaps like the 'paradoxical' rise AD thresholds in the dentate gyrus during hippocampal kindling). These results are consistent with the observation of many other neurologists who have indicated that focal seizures of hippocampal origin have clinical expression only if they recruit parahippocampal gyrus (i.e., parahippocampal cortical networks). Indeed, Wieser's group has suggested that the parahippocampal gyrus in humans is the amplifier of all temporal lobe seizures.

These results recorded in human TLE have interesting corollaries in the rat kindling literature. For example, once a focal $\mathrm{AD}$ threshold has been reached in a structure, parahippocampal structures are the fastest kindling structures in the forebrain (speed in the order of insular/perirhinal, piriform and entorhinal cortices). This speed in epileptogenesis to convulsive seizure expression is manifested first by kindling rate (number of daily stimulations necessary to recruit the first fully generalized seizure); the kindling rates of the three cortical structures are typically $\sim 1-3,4-8,5-18$ stimulations, respectively, which can be compared to the amygdala and dorsal hippocampus of $\sim 12$ and 40, respectively. Second, once convulsive seizures are kindled, differential recruitment speed from the three cortical structures is also seen in the latencies to elicit the convulsive event from the onset of the electrical stimulus, where latencies from the three structures of $1-2 s, 3-5 s, 3-8 s$ are recorded, respectively (e.g., $\left.{ }^{17}\right)$. Third, convulsive expression of human temporal lobe seizures is clearly unilateral, but can spread to become bilateral much like in the kindled rat. In the kindled rat, both amygdala and hippocampal seizures spread ipsilaterally to the frontal cortical motor areas, where they initially become bilateral through the corpus callosum and recruitment of the contralateral cortex $\left(\right.$ e.g.,$\left.{ }^{17}\right)$. Finally, progressive seizure recruitment of the various structures is predetermined in the rats, and is associated with predetermined behavioral expressions, i.e., specific motor patterns and stages. The progressive motor stages seen in kindled seizures are also seen in the various forms of increasing intensities of $\mathrm{SE}^{19}$.

The brain structures involved in seizures can be measured by various activation markers like c-Fos and ${ }^{14} \mathrm{C}$-2-deoxyglucose autoradiography. Such activity markers indicate the same discrete, progressive pattern of structures are involved with the 
same associated behavioral expressions regardless of the means or origins of the induced seizure, e.g., partial seizures initiated from the prefrontal cortex involve exactly the same structures as partial seizures initiated from the amygdala ${ }^{20}$, which are also similarly to those observed during partial seizures initiated via systemic injection of a drug ${ }^{17}$ ! Whether similarities exit between behavioral seizure forms and central nervous system structure activation in human epilepsies needs to be addressed.

In summary, because of the many similarities between kindling and human epilepsy, especially TLE, we feel that kindling is an excellent model of epileptogenesis, but, as indicated recently by Bertram ${ }^{5}$, its utility is dependent upon the questions being asked of it.

\section{REFERENCES}

1. Wada JA. Kindling as a model of epilepsy. Electroencephalogr Clin Neurophysiol Suppl. 1978; 34:309-16.

2. McNamara JO, Byrne MC, Dasheiff RM, Fitz JG. The kindling model of epilepsy: a review. Prog Neurobiol. 1980;15:139-59.

3. Sato M, Racine RJ, McIntyre DC. Kindling: basic mechanisms and clinical validity. Electroencephalogr Clin Neurophysiol. 1990; 76:459-72.

4. Coulter DA, McIntyre DC, Löscher W. Animal models of limbic epilepsies: what can they tell us? Brain Pathol. 2002; 12(2): 240-56.

5. Bertram E. The relevance of kindling for human epilepsy. Epilepsia. 2007; 48 Suppl 2:65-74.

6. Goddard GV, McIntyre DC, Leech CK. A permanent change in brain function resulting from daily electrical stimulation. Exp Neurol. 1969; 25:295-330.

7. Pinel JPJ, Rovner LI. Experimental epileptogenesis: kindling induced epilepsy in rats. Exp Neurol. 1978; 58:190-202.

8. Racine RJ. Modification of seizure activity by electrical stimulation. II. Motor seizure. Electroencephalogr Clin Neurophysiol. 1972; 32(3):281-94.
9. Albright PS, Burnham WM. Development of a new pharmacological seizure model: effects of anticonvulsants on cortical- and amygdala-kindled seizures in the rat. Epilepsia. 1980; 21(6):681-9.

10. Wada JA, Osawa T. Spontaneous recurrent seizure state induced by daily electric amygdaloid stimulation in Senegalese baboons (Papio papio). Neurol. 1976; 26(3):273-86.

11. Racine RJ, Steingart M, McIntyre DC. Development of kindlingprone and kindling-resistant rats: selective breeding and electrophysiological studies. Epilepsy Res. 1999; 35(3):183-95.

12. McIntyre DC, Kelly ME, Dufresne C. FAST and SLOW amygdala kindling rat strains: comparison of amygdala, hippocampal, piriform and perirhinal cortex kindling. Epilepsy Res. 1999; 35 (3): 197-209.

13. Naoi T. Electroencephalographic study of the electroconvulsive treatment. Psychiat Neurol Jpn. 1959; 61:871-94.

14. Sramka M, Sedlak P, Nadvornik P. In: WH Sweet, editor. Neurological treatment in psychiatry, pain and epilepsy. Baltimore, MD: University Park Press; 1977.p. 651.

15. Gilby KL. Altering innate seizure-disposition during neurodevelopment: an investigation into contributing epigenetic factors. Can J Neurol Sci. [In press 2008].

16. Gastaut H. International league against epilepsy report of the quadrennial meeting, so-called "psychomotor" and "temporal" epilepsy: a critical study. Epilepsia. 1953; 2:56-100.

17. McIntyre DC, Gilby KL. Mapping seizure pathways in the temporal lobe. Epilepsia. 2008;49 Suppl 3:23-30.

18. Wennberg R, Arruda F, Quesney LF, Olivier A. Preeminence of extrahippocampal structures in the generation of mesial temporal seizures: evidence from human depth electrode recordings. Epilepsia. 2002; 43:716-26.

19. McIntyre DC, Kelly ME, Staines WA. The pathophysiology of seizure circuitry in status epilepticus. In: Waterlain CG, Treiman DM, editors. Status epilepticus: mechanisms and management. Cambridge MA: MIT Press; 2006. p. 229-39.

20. Handforth A, Ackermann RF. Mapping of limbic seizure progressions utilizing the electrogenic status epilepticus model and the ${ }^{14} \mathrm{C}$-2-deoxyglucose method. Brain Res Brain Res Rev. $1995 ; 20: 1-23$. 


\title{
Kindling, Long-Term Potentiation and Spatial Memory Performance
}

\section{Stan Leung}

\begin{abstract}
Kindling and long-term potentiation (LTP) are two common paradigms of synaptic plasticity. Initially proposed as a model of learning of memory, kindling is considered as a model of epilepsy, with LTP filling in its role as a model of learning and memory. This review suggests that LTP is not critical for kindling-induced epileptiform activity such as spontaneous interictal spikes. Repeated theta-frequency primed burst stimulations (PBs) and repeated ADs (kindling) of the hippocampal commissures were compared in their ability to induce potentiation and to disrupt spatial behavior. Repeated PBs and kindling both induced large potentiation of the CA1 basal dendritic synapse, but only hippocampal kindling disrupted the retention of spatial task on the radial arm maze. While there was evidence that transynaptic potentiation was more persistent after hippocampal kindling than repeated PBs, disruption of inhibition rather than enhancement of excitation may more readily explain the disruption of spatial behavior by kindling. In conclusion, there is little evidence that LTP is essential for the epileptiform activity or the disruption of spatial behavior after hippocampal kindling.
\end{abstract}

RÉSUMÉ: Embrasement, potentialisation à long terme et fonctionnement de la mémoire spatiale. L'embrasement et la potentialisation à long terme (PLT) sont deux paradigmes fréquents de la plasticité synaptique. L'embrasement a été proposé initialement comme modèle de la mémoire impliquée dans l'apprentissage, mais on le considère maintenant comme un modèle de l'épilepsie et la PLT sert de modèle de l'apprentissage et de la mémoire. Cette revue suggère que la PLT ne joue pas un rôle critique dans l'activité épileptiforme induite par l'embrasement telles les pointes interictales spontanées. Nous avons comparé la capacité de stimulations de bouffées répétées induites par fréquence thêta et de post-décharges répétées (embrasement) des commissures de l'hippocampe à induire une potentialisation et à perturber le comportement spatial. Des SB répétées et un embrasement ont tous deux induit une potentialisation importante des synapses dendritiques basales CA1, mais seulement l'embrasement hippocampique a perturbé la rétention des tâches spatiales effectuées dans le labyrinthe radial à plusieurs bras. Bien que certaines données étaient en faveur d'une potentialisation transsynaptique plus persistante après un embrasement hippocampique qu'après une SB répétée, la perturbation de l'inhibition plutôt qu'un rehaussement de l'excitation pourrait mieux expliquer la perturbation du comportement spatial par l'embrasement. Nous concluons qu'il existe peu d'indications que la PLT soit essentielle l'activité épileptiforme ou la perturbation du comportement spatial après l'embrasement de l'hippocampe.

Can. J. Neurol. Sci. 2009; 36: Suppl. 2 - S36-S38

\section{Kindling or LTP as a model of learning and memory}

The kindling paradigm is an important animal model of epilepsy. Kindling is the process that repeated and spaced stimulations of the brain evoke afterdischarges (ADs) of increasing duration, accompanied by behavioral convulsions of increasing severity ${ }^{1,2}$. Earlier, kindling was also suggested as a model of learning and memory ${ }^{1,3,4}$. Today, long-term potentiation (LTP) is considered the best cellular mechanism of learning and memory. Long-term potentiation is a long-lasting increase in synaptic transmission, typically measured by an increase in excitatory postsynaptic potentials (EPSPs) ${ }^{5}$.

Whether LTP participates in the kindling-induced plasticity is the main theme of this review. Mention has been made that some structures designed for flexible associative memory, such as the hippocampus, may show sensitivity to both LTP and epileptic seizure. Indeed, we confirmed that the LTP threshold and the AD threshold were similar in behaving rats when particular hippocampal afferents were stimulated ${ }^{6}$. However, the

From the Department of Physiology \& Pharmacology and Program in Neuroscience, University of Western Ontario, London, Ontario, Canada.

Received December 9, 2008. Final Revisions Submitted December 11, 2008. Correspondence to: L. Stan Leung, Department of Physiology and Pharmacology, Medical Sciences Bldg, University of Western Ontario, London, Ontario, Canada. 
hippocampus is not particularly susceptible to kindling, if kindling susceptibility is measured by the number of ADs needed to achieve generalized stage $\mathrm{V}$ seizures (known as full kindling). For the rat, full kindling of the dorsal hippocampus required about $45 \mathrm{ADs}$ compared to $<5$ times for the piriform cortex or perirhinal cortex ${ }^{7}$.

Association between learning and seizure sensitivity, for one or more structures, does not show that seizure and learning shares the same mechanism. A similar argument may be raised against conclusions based on a third factor that affects both learning and seizure. For example, a protein synthesis inhibitor (or aging) was reported to impair both learning and kindling ${ }^{4}$. While suppression of kindling by inhibition of protein synthesis (or aging) is interesting, it does not suggest that kindling and learning requires the same mechanism.

I will address the question whether LTP participates in two types of kindling-induced plasticity - 1) epileptiform activity and 2) spatial maze performance.

\section{LTP participation in induction of epileptiform activity}

Cain $^{8}$ provided a definitive review that LTP does not contribute critically to kindling or epilepsy. Potentiation of EPSPs by kindled seizures, which will be referred to as kindlinginduced potentiation (KIP), was only associated with the early stages of kindling. The LTP-inducing stimuli did not change AD threshold or advance the severity and the stage of AD induced ${ }^{8}$. Complementing these results, we showed that LTP did not induce spontaneous interictal spikes (SISs).

Spontaneous interictal spikes are epileptiform transients that appear between seizures. We found that a hippocampal AD induced an increase in SISs in a partially kindled animal ${ }^{9}$. We stimulated the basal dendritic afferents to CA1, by either high frequency trains $(1-\mathrm{s}, 100-\mathrm{Hz})$ that evoked an $\mathrm{AD}$ or by theta frequency primed bursts (PBs) that induced LTP without evoking an AD. One PB consisted of a priming pulse followed $190 \mathrm{~ms}$ (theta wavelength) later by a burst of ten $100-\mathrm{Hz}$ pulses. Repeated PBs and ADs were delivered at hourly intervals, five to six times a day for two days ${ }^{10}$.

Repeated PBs or repeated ADs (kindling) both induced potentiation of the basal dendritic CA1 synapse (Figure). However, only kindling were able to induce SISs after a few $\mathrm{ADs}$, but repeated $\mathrm{PBs}$ was ineffective ${ }^{10}$. Infusion of an $\mathrm{N}$ methyl-D-aspartate receptor blocker APV in the lateral ventricles blocked LTP of the basal dendritic CA1 synapse but did not suppress SIS induction by a hippocampal $\mathrm{AD}^{10}$. Thus, although most SISs resemble large basal dendritic EPSPs ${ }^{9}$, LTP alone did not generate SISs. Other studies suggested that a loss of GABAA inhibition in CA3 induced SISs ${ }^{11,12}$.

\section{LTP participation in behavioral disruption}

We also found that hippocampal kindling, but not repeated PBs, resulted in a retention deficit on a radial arm maze $(\mathrm{RAM})^{13}$. Rats were first trained to retrieve food from four of eight arms of a RAM. Then, ADs or PBs were delivered hourly, five to six times a day over two days. Both PB-stimulated and kindled rats showed potentiation of the basal dendritic synapse in CA1 (Figure). Trans-synaptic potentiation by PBs or kindling was indicated by enhancement of the medial perforant path (MPP) to dentate gyrus (DG) response ${ }^{13}$, and by the appearance

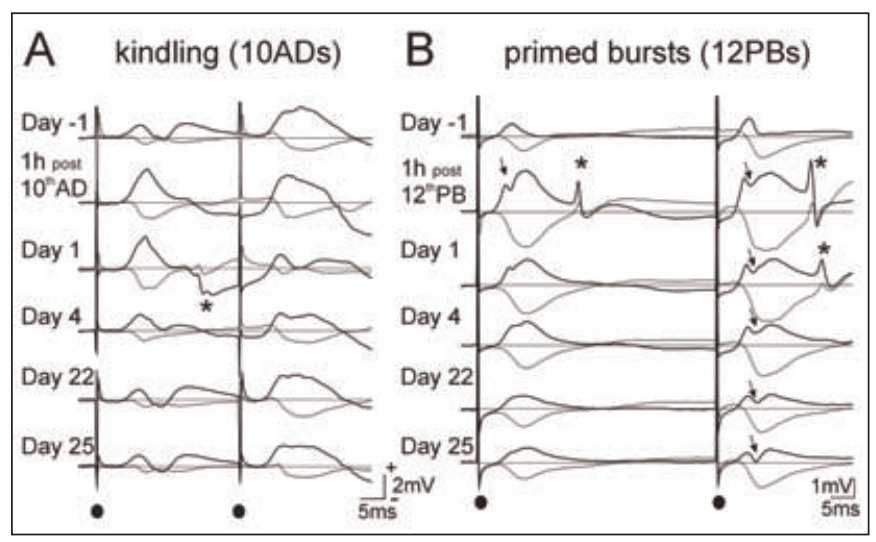

Figure: Both partial kindling (A) or repeated primed burst (PB) stimulation (B) of hippocampal CAl induced long-lasting potentiation of the population postsynaptic excitatory potentials; 10 afterdischarges $(A D s)$ and 12 PBs were delivered over two days. Average evoked potentials were recorded 1 day (day-1) before ADs and PBs and up to 25 days after (day 25). Positive (up) and negative (down) responses were recorded respectively from electrodes in the apical and basal dendritic layers of CA1, following commissural basal dendritic afferent stimulation. Paired pulses were delivered, with $30 \mathrm{~ms}$ and $50 \mathrm{~ms}$ interpulse intervals in $A$ and $B$, respectively. Enhancement was largest 1 $h$ after the last $A D$ or $P B$, but persisted for days after. Filled circles, stimulus artifacts; $\downarrow$ population spike; * late recurrent response from the entorhinal cortex-hippocampus circuit. Modified from Leung and Shen (2006).

of a hippocampus-entorhinal-hippocampus recurrent response (indicated by $*$ in the Figure). The MPP to DG transynaptic potentiation was stronger and more long-lasting following kindling than repeated $\mathrm{PBs}^{13}$.

Despite the lack of disruption of spatial behavior by several LTP paradigms [reviewed in ${ }^{5}$, Moser et $\mathrm{al}^{14}$ was able to disrupt water maze spatial learning if LTP of the MPP to DG on one side of the rat was extensively "saturated" after the contralateral hippocampus was lesioned. Input-output relation of the MPP to DG transmission in our kindled rats did not show a rapidly rising input-output curve characteristic of LTP saturation (unpublished data, Leung and Shen). Only transynaptic but not monosynaptic CA1 potentiation differed between kindling and repeated PBs (Figure). Perhaps potentiation of EPSPs alone is insufficient to explain the disruption of spatial behavior. Instead, other changes in inhibition or synaptic modulation in the hippocampus unique for kindling (and not LTP) may be involved. The latter changes include an increase in inhibition in the $\mathrm{DG}^{15,16}$, a decrease in sensitivity of the GABAB presynaptic autoreceptors ${ }^{17}$ or heteroreceptors $^{18}$, and a general decrease in GABAA receptor mediated inhibition in CA $1^{19,20}$. Changes of inhibition may, in turn, affect the degree of $\mathrm{LTP}^{5}$ and contribute to trans-synaptic potentiation in kindled animals.

Amygdala kindling was reported to disrupt the conditioned emotional response $\mathrm{e}^{21}$ and amygdala and hippocampal kindling induced emotional and psychotic behaviors ${ }^{22,23,24}$. Preliminary observations indicated that repeated hippocampal LTP was unable to induce the latter behaviors, although careful studies remain to be done. 


\section{ACKNOWLEDGEMENT}

Research was supported by NSERC and CIHR grants.

\section{REFERENCES}

1. Goddard GV, McIntyre DC, Leech CK. A permanent change in brain function resulting from daily electrical stimulation. Exp Neurol. 1969; 25:295-330.

2. Racine RJ. Modification of seizure activity by electrical stimulation. II. Motor seizure. Electroencephalogr Clin Neurophysiol. 1972; 32:281-94.

3. Goddard GV, Douglas RM. Does the engram of kindling models the engram of normal long term memory? Can J Neurol Sci. 1975; 2:385-94.

4. Morrell F, Toledo-Morrell L. Kindling as a model of neuronal plasticity. In: Kindling 3. Wada JA, editor. New York: Raven Press; 1986. p. 17-33.

5. Bliss TVP, Collingridge G, Morris R. Synaptic plasticity in the hippocampus. In: LTP the hippocampus book. Andersen P, Morris R, Amaral D, Bliss T, O'Keefe J, editors. Oxford: Oxford University Press; 2006. p.343:474.

6. Leung LS, Shen B. Long-term potentiation of the apical and basal dendritic synapses following local stimulation in CA1 of freely moving rats. J Neurophysiol. 1995; 73:1938-46.

7. McIntyre DC, Poulter MO, Gilby K. Kindling: some old and some new. Epilepsy Res. 2002; 50:79-92.

8. Cain DP. Long-term potentiation and kindling: how similar are the mechanisms? Trends Neurosci. 1989; 12:6-10.

9. Leung LS. Spontaneous hippocampal interictal spikes following local kindling: time-course of change and relation to behavioral seizures. Brain Res. 1990; 513:308-14.

10. Leung LS. Evaluation of the hypothesis that interictal spikes are caused by long-term potentiation. Epilepsia. 1994; 35:785-794.

11. Wong RK, Traub RD. Synchronized burst discharge in disinhibited hippocampal slice. I. Initiation in $\mathrm{CA} 2-\mathrm{CA} 3$ region. $\mathrm{J}$. Neurophysiol. 1983; 49(2):442-58.

12. Leung LS, Shen B. Hippocampal partial kindling decreased hippocampal GABA-B receptor efficacy and wet dog shakes in behaving rats. Behav Brain Res. 2006; 173(2):274-81.
13. Leung LS, Shen B. Hippocampal CA1 kindling but not long-term potentiation disrupts spatial performance. Learn Mem. 2006;13: $18-26$.

14. Moser EI, Krobert KA, Moser MB, Morris RG. Impaired spatial learning after saturation of long-term potentiation. Science. 1998; 281:2038-42.

15. de Jonge M, Racine RJ. The development and decay of kindlinginduced increases in paired-pulse depression in the dentate gyrus. Brain Res. 1987; 412:318-28.

16. Mody I. Synaptic plasticity in kindling. Adv Neurol. 1999; 79:63143.

17. Wu C, Leung LS. Partial hippocampal kindling decreases efficacy of presynaptic GABAB autoreceptors in CA1. J Neurosci. 1997; 17:9261-9.

18. Poon N, Kloosterman F, Wu C, Leung LS. Presynaptic GABAB receptors on glutamatergic terminals of CA1 pyramidal cells decrease in efficacy after partial hippocampal kindling. Synapse. 2006; 59(3):125-34.

19. Leung LS, Zhao DC, Shen B. Long-lasting effects of partial hippocampal kindling on hippocampal physiology and function. Hippocampus. 1994; 4:696-704.

20. Lopes da Silva FH, Kamphuis W, Titulaer M, Vreugdenhil M, Wadman WJ. An experimental model of progressive epilepsy: the development of kindling of the hippocampus of the rat. Ital $\mathbf{J}$ Neurol Sci. 1995; 6:45-57.

21. McIntyre DC, Molino A. Amygdala lesions and CER learning: long term effect of kindling. Physiol Behav. 1972; 7:1055-8.

22. Adamec RE. Partial kindling of the ventral hippocampus: identification of changes in limbic physiology which accompany changes in feline aggression and defence. Physiol Behav. 1991; 49:443-53.

23. Kalynchuk LE, Pinel JP, Treit D, McEachern JC, Kippin TE. Persistence of the interictal emotionality produced by long-term amygdala kindling in rats. Neurosci. 1998; 85:1311-9.

24. Ma J, Leung LS. Schizophrenia-like behavioral changes after partial hippocampal kindling. Brain Res. 2004; 997:111-8. 


\title{
Mechanisms Underlying Behavioural Co- Morbidities Associated with Kindling
}

\author{
G. Campbell Teskey
}

\begin{abstract}
There is a substantial incidence of interictal behavioural comorbidities with epilepsy. These comorbidities can often be more difficult to treat than the seizures themselves and are a significant burden to the afflicted individuals and health care system. This article provides a brief overview of the behavioural comorbidities associated with epilepsy in humans and how the kindling of animals models these behavioural anomalies. Specific attention is paid to kindling in frontal cortex, its effects on skilled reaching behaviour and underlying mechanisms.
\end{abstract}

\begin{abstract}
RÉSUMÉ: Mécanismes sous-jacents dans les comorbidités comportementales associées à l'embrasement. Il existe une incidence importante de comorbidités comportementales interictales dans l'épilepsie. Ces comorbidités sont souvent plus difficiles à traiter que les crises elles-mêmes et constituent un lourd fardeau pour les individus atteints et pour le système de soins de santé. Cet article offre un bref survol des comorbidités comportementales associées à l'épilepsie chez l'humain et indique comment l'embrasement chez des modèles animaux illustre ces anomalies comportementales. Nous portons une attention particulière à l'embrasement du cortex frontal, ses effets sur ses effets sur le mouvement orienté et les mécanismes sous-jacents des mécanismes sous-jacents.
\end{abstract}

Can. J. Neurol. Sci. 2009; 36: Suppl. 2 - S39-S40

Interictal behavioural comorbidities associated with epilepsy represent a significant health burden ${ }^{1}$ and are often more difficult to treat than the seizures themselves ${ }^{2}$. People with epilepsy have been reported to have a higher incidence and severity of anxiety and depression ${ }^{3}$, poorer verbal and spatial memory ${ }^{4}$, more frequent gender specific sexual dysfunctions ${ }^{5,6}$ and deficits in skilled motor performance ${ }^{7}$ that are related to the site of origin of the seizures. For instance, skilled motor deficits can occur in people with epileptic foci in their frontal cortex. However, it has proven difficult to determine whether these behavioural anomalies are due to the seizures themselves or the effects of anticonvulsive medications, social stigma, and/or pre-existing individual differences in people that develop epilepsy ${ }^{8}$. Furthermore, the neurobiological substrates underlying these behavioural anomalies remain poorly understood.

Animal models provide an opportunity to examine the effects of repeated seizures without the confounding influences of social stigma or drugs ${ }^{9}$. Interictal behavioural changes have been effectively modeled using the electrical kindling technique. Kindled animals show altered anxiety-like and aggressionrelated behaviours ${ }^{10-11}$, altered spatial memory abilities ${ }^{12}$ and alterations in sex hormones and sexual function ${ }^{13}$ depending on the kindling location and number of seizures.

Can kindling in the rat frontal cortex model the skilled motor deficits described in people with frontal cortex epileptic foci? The rat sensorimotor neocortex is a ripe target for examining this question. Within the sensorimotor neocortex there are movement representations, better known as motor maps, that when stimulated result in the elicitation of movements via the activation of discrete muscle groups. When these areas are ablated, rats show a reduction in their ability to perform with the affected body musculature ${ }^{14}$. For instance, when a region of sensorimotor neocortex known as the caudal forelimb area is removed, rats show both an altered expression of skilled forelimb behaviours as well as a lower success rate on tasks utilizing these skilled behaviours. Thus, performing a skilled task using the forelimb is dependent on the integrity of the neocortical caudal forelimb area.

Henry et $\mathrm{al}^{15}$ kindled rats using stimulation to the midline corpus callosum at the level of the caudal forelimb area and then examined skilled reaching using the single pellet task. This task requires rats to repeatedly reach through an open vertical slit in a Plexiglas chamber for a single food pellet. Non-kindled rats performed the task as expected. Kindled rats made just as many attempts, but their success at retrieving the food pellets attained asymptotic levels significantly below the success rate achieved
From the Behavioural Neuroscience Research Group, Department of Psychology, University of Calgary, Calgary, Alberta, Canada.

Received December 9, 2008. Final Revisions Submitted December 11, 2008. Correspondence to: G. Campbell Teskey, Behavioural Neuroscience Research Group, Department of Psychology, University of Calgary, Calgary, Alberta, Canada. 
by non-kindled rats. A detailed kinematic analysis of the reaching behaviour made from the videotaped record showed that kindled rats employ an altered strategy for reaching. Normally rats bring their elbow to midline before extending the forelimb through the vertical slit. However, the kindled rats do not perform this subcomponent of the behaviour, and the elbow remains well to the side of the open vertical slit. As a result, the kindled rats "swipe" towards the side of the pellet, rather than trapping the pellet from above as do non-kindled rats. As a frequent consequence of the swiping motion, the rats miss the pellet altogether and thus attain lower success at retrieving the pellet. The kindled rats that do successfully grasp the pellet often drop it as they bring it to their mouths. Instead of facing the palm of their hand towards their mouth, kindled rats only partially turn their wrist so that the palm is facing upward at approximately a $135^{\circ}$ angle as opposed to the $180^{\circ}$ angle seen in the non-kindled rats. The food pellet will then slip out of the hand as the rat raises it to its mouth. In order to determine if the altered motor performance and reduced reaching success in kindled rats generalized to other tasks, rats were also required to walk across a horizontal ladder that was missing some randomly removed rungs. Kindled rats make more forelimb faults than control rats on this task as well.

A plausible mechanism for the altered motor behaviours is expansion of motor maps that we observe following neocortical kindling ${ }^{16}$ and hippocampal kindling when there is propagation of epileptiform activity into the neocortex ${ }^{17,18}$. The expanded motor maps are in turn likely due to synaptic potentiation in neocortical layer V. Teskey et $\mathrm{al}^{16}$ and Monfils et $\mathrm{al}^{19}$ have reported that expansion of movement representations following seizures are highly correlated to the magnitude of potentiation of the polysynaptic component of the callosal-neocortical evoked response, which has a sink in upper layer $\mathrm{V}$ and a source in deep layer $\mathrm{V}$. The technique used to derive the motor maps appears to elicit movement by stimulating horizontal connections between groups of synaptically connected neocortical neurons rather than via direct excitation of corticospinal neurons. Moreover, motor maps can be reduced in size by applying low-frequency stimulation that results in a long-term depression of synaptic efficacy $^{20}$ and we have recently shown that low-frequency stimulation can also reverse the kindling-induced map expansion $^{18}$. Taken together these observations suggest that synaptic efficacy between layer $\mathrm{V}$ neurons may a necessary contributor to overall motor map size.

\section{SUMMARY}

Electrical kindling of specific brain regions results in interictal behavioural disturbances that are related to the functions that are normally supported by those brain areas. When the seizure focus is found in homologous areas in people with epilepsy, many of them experience comparable interictal behavioural disturbances. In the case of frontal cortex kindling we have found reduced levels of performance and altered forelimb kinematics on a skilled reaching task that model motor disturbances in people with frontal cortex foci. The neurobiological substrates for these alterations in interictal behaviour may be accounted for by reorganization of motor maps that in turn is based upon enhanced synaptic efficacy of layer $\mathrm{V}$ horizontal fibers.

\section{REFERENCES}

1. Engel J Jr, Pedley TA. Epilepsy: a comprehensive textbook. Philadelphia: Lippincott-Raven; 1998.

2. Tellez-Zenteno JF, Matijevic S, Wiebe S. Somatic comorbidity of epilepsy in the general population in Canada. Epilepsia. 2005;46: 1955-62.

3. Nubukpo P, Preux PM, Houinato D, Radji A, Grunitzky EK, Avode $\mathrm{G}$, et al. Psychosocial issues in people with epilepsy in Togo and Benin (West Africa) I. Anxiety and depression measured using Goldberg's scale. Epilepsy Behav. 2004;5:722-7.

4. Alessio A, Damasceno BP, Camargo CH, Kobayashi E, Guerreiro CA, Cendes F. Differences in memory performance and other clinical characteristics in patients with mesial temporal lobe epilepsy with and without hippocampal atrophy. Epilepsy Behav. 2004;5:22-7.

5. Isojarvi JI. Reproductive dysfunction in women with epilepsy. Neurology. 2003;61:S27-34.

6. Isojarvi JI, Lofgren E, Juntunen KS, Pakarinen AJ, Paivansalo M, Rautakorpi I, et al. Effect of epilepsy and antiepileptic drugs on male reproductive health. Neurology. 2004;62:247-53.

7. Hernandez MT, Sauerwein HC, Jambaque I, De Guise E, Lussier F, Lortie A, Dulac O, et al. Deficits in executive functions and motor coordination in children with frontal lobe epilepsy. Neuropsychologia. 2002;40:384-400.

8. Wiebe S, Matijevic S, Eliasziw M, Derry PA. Clinically important change in quality of life in epilepsy. J Neurol Neurosurg Psychiatry. 2002;73:116-20.

9. Pitkanen A, Schwartzkroin PA, Moshe SL. Models of Seizures and Epilepsy. Burlington, MA: Elsevier Academic Press; 2006.

10. Adamec R, Young B. Neuroplasticity in specific limbic system circuits may mediate specific kindling induced changes in animal affect-implications for understanding anxiety associated with epilepsy. Neurosci Biobehav Rev. 2000;24:705-23.

11. Kalynchuk L. Long-term amygdala kindling in rats as a model for the study of interictal emotionality in temporal lobe epilepsy. Neurosci Biobehav Rev. 2000;24:691-704.

12. Hannesson DK, Corcoran ME. The mnemonic effects of kindling. Neurosci Biobehav Rev. 2000;24:725-51.

13. Edwards HE, MacLusky NJ, Burnham WM. The effect of seizures and kindling on reproductive hormones in the rat. Neurosci Biobehav Rev. 2000;24:753-62.

14. Whishaw IQ. Loss of the innate cortical engram for action patterns used in skilled reaching and the development of behavioral compensation following motor cortex lesions in the rat. Neuropharmacology. 2000;39:788-805.

15. Henry LC, Chang C, Teskey GC. Kindling alters rat skilled motor behaviour. Soc Neurosci Abstr. 2004;29:451.14.

16. Teskey GC, Monfils MH, VandenBerg PM, Kleim JA. Motor map expansion following repeated cortical and limbic seizures is related to synaptic potentiation. Cereb Cortex. 2002;12:98-105.

17. van Rooyen F, Young NA, Larson SEM, Teskey GC. Hippocampal kindling leads to motor map expansion. Epilepsia. 2006;47: 1383-91.

18. Ozen LJ, Young NA, Koshimori Y, Teskey GC. Low-frequency stimulation reverses kindled-induced neocortical motor map expansion. Neuroscience. 2008 Apr 22;153(1):300-7.

19. Monfils MH, VandenBerg PM, Kleim JA, Teskey GC. Long-term potentiation induces expanded movement representations and dendritic hypertrophy in layer $\mathrm{V}$ of rat sensorimotor neocortex. Cereb Cortex. 2004;14:586-93.

20. Teskey GC, Young NA, van Rooyen F, Larson SEM, Flynn C, Monfils MH, et al, Goertzen CD. Induction of neocortical longterm depression results in smaller movement representations, fewer excitatory perforated synapses and more inhibitory synapses. Cereb Cortex. 2007;17:434-42. 


\section{Epilepsy and Memory Dysfunction}

Can. J. Neurol. Sci. 2009; 36: Suppl. 2 - S41

Dr. Juhn Wada who described the carotid artery injection of sodium amytal in the Journal of Neurosurgery in 1960, provided historical background which set the stage for the plenary session addressing the topic of epilepsy and memory. The intracarotid sodium amytal or Wada procedure has been an integral part of the pre-surgical evaluation of patients since the 1960s. The lack of availability of sodium amytal in 2003 resulted in a search for alternative medications and Dr. Marilyn Jones-Gotman and colleagues described their experience of etomidate at the Montreal Neurological Institute ${ }^{1}$. Etomidate, an imidazole has a rapid onset and short duration of action and minimal hemodynamic or adverse effects. The ability to maintain an infusion following the initial bolus injection until all memory items are presented is an advantage over sodium amytal. In addition, changes to the procedure has enhanced both speech and memory testing, and this is referred to as etomidate speech and memory testing or eSAM. Of 57 proceedures, obtundation was rarely observed and occurred in patients with extensive damage in the contralateral cerebral hemisphere. EEG slowing occurs on average 40 seconds following initiation of the injection, speech arrest soon thereafter and contralateral arm weakness approximately 50 seconds following initiation of injection. EEG slowing was observed in $75 \%$ in the contralateral frontal lobe.

Adverse effects of etomidate were minimal, a shiver like movement in the contralateral arm and occasionally bilaterally. Determination of hemisphere dominance for speech was successful. The authors observed advantages in memory testing using eSAM versus their prior experience with intracarotid sodium amytal. The main advantage of using etomidate appears to be the fact that an infusion can be maintained until all the memory items are presented.

The potential for decline in memory function following temporal lobe surgery is a major area of concern for physician and patient. The natural history of uncontrolled temporal lobe epilepsy and the deterioration in memory that often occurs with uncontrolled epilepsy further complicate the issue. Dr. Mc Glone and colleagues describe their experience of patient and observer perception of memory change after temporal lobe resection, using the Memory Observation Questionnaire ${ }^{2}$. Only $10 \%$ of patients or informants reported deterioration in memory while the remainder experienced improvement or no change. A metaanalvsis of six publications on subiective memorv testing in patients over the age of 16 years who had temporal lobe resections for temporal lobe epilepsy, with pre and postoperative memory perception testing, provided similar results. This is an important area for further research.

The relative deficiency of published data on memory testing in children with intractable epilepsy in contrast to adults is highlighted in the review by Dr. Mary Lou Smith ${ }^{3}$. The impact of seizures on the developing brain, particularly on attention and memory networks contrasts with the effects in the mature brain. Memory difficulties are very commonly reported by children with intractable epilepsy and their families. In their experience of refractory epilepsy at the Hospital for Sick Children, the study population was heterogenous and not limited to those with temporal lobe epilepsy. On objective memory testing, up to $60 \%$ of children had impairments on one or more memory tasks and $70 \%$ reported a perception of memory and cognitive difficulties which had a significant impact on quality of life.

Further research is critical in the pediatric population with refractory epilepsy and correlation with factors such as age at seizure onset, seizure frequency, medication effect, localization, pathological basis and effects of surgery. The higher prevalence of dyspastic brain lesions or dual pathology in children with temporal lobe epilepsy contrasts with the adult population where mesial temporal lobe sclerosis is the most commonly reported pathology, likely has a very significant impact on memory function in children.

\section{Mary B. Connolly Vancouver, British Columbia}

\section{REFERENCES}

1. Jones-Gotman M, Sziklas V, Djordevic J. Two intracarotid anesthetic procedures: The intracarotid amobarbital procedure and the Etodimate speech and memory test. Can J Neurol Sci. 2009 (in press)

2. Williams J, Martin M, Mc Glone J. Perception of memory changes after temporal lobe resections for complex partial seizures. Can J Neurol Sci. 2009 (in press)

3. Smith ML. "I can't remember": Memory deficits in children with epilepsy. Can J Neurol Sci. 2009; 36 Suppl 2:S42-5. 


\title{
“I Can't Remember": Memory Deficits in Children with Epilepsy
}

\author{
Mary Lou Smith
}

\begin{abstract}
Compared with the literature on epilepsy in adults, there is relatively little written about memory in children. This paucity of findings exists despite the fact that childhood is a critical time for laying down memories that contribute to adult attainments. This paper reviews the evidence for memory deficits in children with intractable epilepsy. The nature of these deficits and their impact on the child's daily function are described. The evidence of neural, seizure-related and treatment factors that contribute to these impairments is presented.
\end{abstract}

RÉSUMÉ: «Je ne me souviens pas » : déficit de mémoire chez les enfants épileptiques. Résumé : Il existe peu d'écrits sur la mémoire chez les enfants épileptiques alors que ce sujet a reçu plus d'attention chez les adultes et ceci malgré le fait que l'enfance est un moment critique pour l'établissement des souvenirs qui contribuent aux réalisations à l'âge adulte. Cet article revoit les données sur les déficits de mémoire chez les enfants présentant une épilepsie réfractaire. Nous décrivons la nature de ces déficits et leur impact sur la fonction quotidienne de l'enfant et nous présentons les données sur les facteurs neuraux, reliés aux crises et au traitement qui contribuent à ces déficits.

Can. J. Neurol. Sci. 2009; 36: Suppl. 2 - S42-S45

The inspiration for the title for this article was drawn from a conversation with a 15-year-old girl with intractable epilepsy who described her struggles in school. ${ }^{1}$ In our clinical and research work with children and adolescents with medically refractory epilepsy at the Hospital for Sick Children, we have found that her experience is a common one, as many of these youth struggle with learning and memory problems. This article reviews the evidence for memory deficits in children with epilepsy.

Childhood is a time when there is a rapid acquisition of new skills and new knowledge that forms the foundation for further cognitive development. Children appear like sponges who soak up information and incorporate easily into their behavioural and cognitive repertoires. After the age of four to five years, the main "job" of a child for the next decade and a half or longer is to be a student. Our education system rests on the principle that children will learn and retain knowledge, and that each subsequent year in school can build on information taught and presumably retained from the previous years. Assessment of the child's progress is heavily dependent on tests that require memory. Thus, the child who has a poor memory will be significantly disadvantaged and will struggle on a daily basis with the consequences of that weakness.

\section{Patient and family concerns about memory}

It has long been recognized that memory deficits are among the most common complaints of adults with epilepsy. This point was well illustrated in a survey by Thompson and Corcoran ${ }^{2}$ in which almost 800 people with epilepsy were asked about the frequency of everyday memory failures, such as forgetting where things have been put, of losing things, going back to check if one had done something that one had intended to do, and being unable to say a word, although that word was known and "on the tip of one's tongue". People with epilepsy reported a much higher frequency of such compared with a control population. Those with epilepsy also rated the annoyance arising from such memory failures as higher. Relatives rated the frequency of forgetting among their family members with epilepsy as even higher than did the persons themselves, which suggests that another effect of the epilepsy may be to induce forgetting of how often they do forget.

Although such large scale surveys have not been conducted with children, deficits in cognition, including memory, are

From the Department of Psychology, University of Toronto Mississauga and The Hospital for Sick Children, Toronto, Ontario, Canada.

Received July 17, 2008. Final Revisions Submitted July 29, 2008. Correspondence to: Mary Lou Smith, 3359 Mississauga Road North, Mississauga, Ontario, L5L 1C6, Canada. 
identified by children with epilepsy and their parents as a significant concern. Arunkumar et $\mathrm{al}^{3}$ asked parents of 80 children and adolescents with epilepsy to list in order of importance their concerns about living with or caring for their children with epilepsy; children who were old enough to be interviewed were asked to express (independently of their parents) their own concerns about having epilepsy. For both parents and children, the second most common item identified was that of the cognitive effects of epilepsy. They worried about learning disabilities, academic difficulties, poor attention and concentration, and impoverished memory.

\section{Memory deficits in children with intractable epilepsy}

My colleagues and I have been following children with medically refractory epilepsy and have documented a high incidence of memory deficits among this group. ${ }^{4-7}$ We have administered standardized objective tests of memory that examine learning, recall and recognition of a variety of stimuli, including verbal materials such as lists of words and the details of stories, and visual materials such as designs, faces and spatial patterns. In addition we have developed questionnaires that report on everyday memory functioning from the perspective of both the child and the parent. ${ }^{8}$ We have also learned a considerable amount about these deficits by asking the children to tell us what they experience and their ideas on the factors that contribute to these problems..$^{1,7}$

On objective tests of memory, we have found that up to $60 \%$ of children had impairments on one or more of these tasks. The Figure illustrates this finding for one particular verbal memory test. In this task, the examiner read brief (one paragraph) stories to the child who was then asked to tell back the story immediately after hearing it and again after a 30-minute delay. This task is similar to the type of memory demand that a child commonly experiences in the classroom. We found that as a group, these children perform at a level that is about a standard deviation below the population mean. When we examined performance at an individual level, we found that approximately half of this sample had deficits in recall.

\section{Impact of memory impairments on everyday function}

The incidence of memory impairment becomes even more astounding when the children's own perspectives are taken into consideration. In interviews about the impact of their seizures on their quality of life, $70 \%$ of the sample reported problem with aspects of learning and memory. ${ }^{1,7}$ Memory deficits were identified as a significant impediment to progress in school, and also as having an impact on the youth's sense of self worth, as some labeled themselves as "stupid" because of their struggles with learning and retaining their schoolwork. These young people identified a number of key factors that characterized their learning difficulties and that contribute to their deficits. They struggled with retention of new information or instructions, retrieval of words, and retrieval of previously learned material. They noted the need for frequent repetition due to the difficulty with registering new information as it is taught and because of rapid forgetting and trouble remembering even over the span of one day to the next.

These youth were also able to identify the impact of seizures and postictal periods as having an intermittent or transitory impact on their memory, whereby they would not be able to register or retain information for minutes up to a day. These children recognized that seizures and postictal confusion created difficulties in their attention and ability to focus in class, which they related to later problems in learning. Antiepileptic medications and fatigue were cited by these children as additional influences on their attention that contributed to their decreased ability to remember.
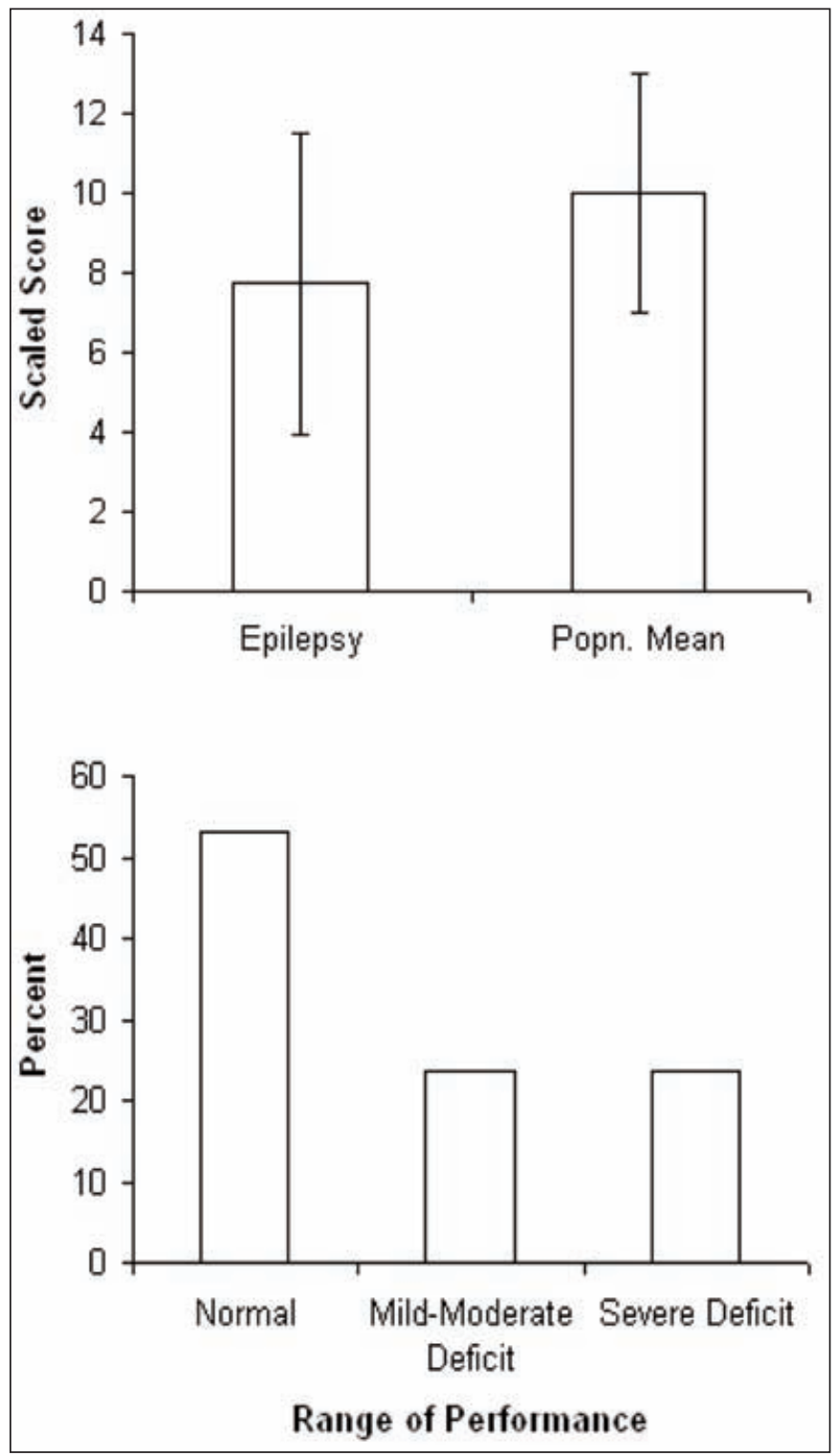

Figure: Graph above illustrates recall of the details of a story by children with intractable epilepsy compared with the mean in the normal population. Error bars represent 1 standard deviation. Graph below shows the percentage of children in the epilepsy group falling within the normal range, having a mild to moderate impairment (1 to 2 standard deviation below the mean), or a severe (> 2 standard deviations) deficit on the story recall task. Popn.=population 
It is not surprising that problems in the realm of attention can affect memory; accurate and efficient encoding of material is essential for storage and later retrieval. We have previously demonstrated the importance of attention for good memory in this population with our questionnaire of everyday memory. ${ }^{8}$ This questionnaire addresses the ways in which children use their memories on a day-to-day basis, such as recognizing neighbours' faces, learning the words to new songs, remembering to take their lunch to school, and recalling multiple-step instructions. These aspects of memory function as rated by the children or by their parents were significantly predicted by symptoms associated with inattention.

One fascinating finding emerging from our interviews was that children complained that personal events from the recent and remote past were often forgotten, with some children complaining that they had little sense of their earlier childhood. ${ }^{7}$ Although there is research on autobiographical memory systems in adults with epilepsy, ${ }^{9,10}$ no systematic investigation has been done with children, perhaps due to the greater complexity in accessing these memory systems due to developmental factors. However, in a case study of a boy with left temporal-lobe epilepsy with onset at seven years it was reported that his mother had noted that he had difficulty recalling personal events and remembering what he had seen or read at school. ${ }^{11}$ These difficulties predated the onset of seizures by about one year. Compared with his twin brother, he recalled significantly fewer remote personal events that involved him and his family.

\section{Components of memory are compromised in childhood epilepsy}

To date, little work has been done on identifying whether certain aspects of memory are more problematic than others in children with epilepsy (for example whether learning, storage or retrieval might be more affected). As mentioned earlier, attention may play an important role in everyday memory in this population. Performance on memory tasks in pediatric epilepsy has been found to be influenced by attention, suggesting that there may be difficulties with the initial encoding of information. ${ }^{12}$ Working memory is also important for the recognition and recall of information. ${ }^{13}$ Children with left temporal lobe epilepsy have been described as having most difficulty with delayed recall of verbal information, ${ }^{14}$ implying either difficulty with retrieval or that their memories are susceptible to rapid forgetting.

\section{Factors contributing to the memory deficits}

Cognitive deficits are present early in the course of epilepsy and perhaps before the onset of seizures. Children with idiopathic localization-related or primary generalized epilepsy studied approximately ten months after seizure onset had mild generalized cognitive difficulties. ${ }^{15}$ It is thought that these deficits were related to structural brain anomalies. Even in children evaluated soon after their first seizure, those with an abnormality detected on MRI performed more poorly on cognitive tasks than children without a significant brain abnormality. ${ }^{16}$ These differences were widespread, and were found in the areas of intelligence, memory, language, processing speed, verbal learning and memory, and executive functions, with all these domains affected relatively equally.
In adults with epilepsy, memory impairments are described most often in association with temporal-lobe seizures. In children, these deficits may be more ubiquitous. For example, memory deficits have been found among children with intractable temporal lobe epilepsy, frontal epilepsy and absence epilepsy. ${ }^{14}$ The severity of the deficits varied by syndrome; those with absence epilepsy were found to have mild problems, and those with temporal-lobe epilepsy had the most severe difficulties.

Several investigators have reported memory deficits in children with epilepsy of temporal-lobe onset, but the patterns of findings they observed differed across studies. Findings similar to those seen in adults have been documented in some studies, in that left temporal-lobe seizure foci were associated with verbal memory deficits and right temporal-lobe foci were associated with visuo-spatial deficits. ${ }^{17-20}$ Others have found no differences between the effects of seizures arising from the left or right temporal lobes on memory performance across a variety of verbal and spatial tasks. ${ }^{12,21-24}$ Children with hippocampal abnormality at the onset of their seizure disorder showed considerable variability in their neuropsychological profiles ${ }^{16}$ as opposed to the more specific deficits in language and memory that have been documented in adults. ${ }^{25}$

There is little research on the effects of antiepileptic medications on memory in children, although such effects have been demonstrated in adults. In children, topiramate can result in forgetfulness and impaired memory, and also in reduced attention and concentration, which can secondarily affect memory. ${ }^{26}$ Some studies have found that performance on memory tasks does not vary with the number of antiepileptic medications the child is taking. ${ }^{4,5}$

Age at seizure onset and the duration (total years or proportion of life) of the seizure disorder have commonly been targeted as suspects in the deficits associated with epilepsy. With children, such studies have largely addressed intelligence. In the realm of memory, the few existing findings are mixed, in that relations with these variables have been found in some studies ${ }^{4,15}$ but not in others. 5,20

\section{Conclusions}

Memory impairments are common in children with intractable epilepsy, but less is known about the incidence of such deficits in children with well controlled seizures. These impairments have serious effects on the child's quality of life and self esteem. There are obvious implications for the child's progress at school, and over time, these deficits may have a cumulative effect that can impact on the ability to function effectively in higher education, training and vocational situations. There are few data on the components of the memory system that may be vulnerable to disruption in childhood epilepsy. Further research is also needed to understand the neurological, seizure-related and treatment factors that influence memory in children.

\section{REFERENCES}

1. Elliott IM, Lach LM, Smith ML. "I just want to be normal". A qualitative study exploring how children and adolescents perceive the impact of intractable epilepsy on their quality of life. Epilepsy Behav. 2005;7:664-78. 
2. Thompson PJ, Corcoran R. Everyday memory failures in people with epilepsy. Epilepsia. 1992; 33 Suppl 6:S18-20.

3. Arunkumar G, Wyllie E, Kotagal P, Ong HT, Gilliam F. Parent- and patient-validated content for pediatric epilepsy quality-of-life assessment. Epilepsia. 2000;41:1474-84.

4. Mabbott DM, Smith ML. Material-specific memory in children with temporal and extra-temporal lobectomies. Neuropsychologia. 41;2003:995-1007.

5. Smith ML, Elliott IM, Lach LM. Cognitive skills in children with intractable epilepsy: Comparison of surgical and non-surgical candidates. Epilepsia. 2002;43:631-37.

6. Smith ML, Elliott IM, Lach L. Cognitive, psychological and family function after pediatric epilepsy surgery. Epilepsia. 2004;45: $650-60$.

7. Smith ML, Elliott IM, Lach LM. Memory outcome after pediatric epilepsy surgery: Objective and subjective perspectives. Child Neuropsychol. 2006;12;151-60.

8. Kadis DS, Stollstorff M, Elliott I, Lach L, Smith ML. Cognitive and psychological predictors of everyday memory in children with intractable epilepsy. Epilepsy Behav. 2004;5:37-43.

9. Lah S, Lee T, Grayson S, Miller L. Effects of temporal lobe epilepsy on retrograde memory. Epilepsia. 2006;47:615-25.

10. Viscontas IV, McAndrews MP, Moscovitch M. Remote episodic memory defitics in patients with unilateral temporal lobe epilepsy and excisions. J. Neurosci. 2000; 20:5853-7.

11. Cronel-Ohayon S, Zesiger P, Davidoff V, Boni A, Roulet E, Deonna $\mathrm{T}$. Deficit in memory consolidation (abnormal forgetting rate) in childhood temporal lobe epilepsy. Pre and postoperative longterm observation. Neuropediatrics. 2006;37:317-24.

12. Williams J, Griebel ML, Dykman RA. Neuropsychological patterns in pediatric epilepsy. Seizure. 1998;7:223-8.

13. Smith ML, Stollstorff M, Hoosen-Shakeel S, Elliott IM, Lach L. The relationship of attention to memory in children with intractable epilepsy. Epilepsia. 2001;42 Suppl 7:103.

14. Nolan MA, Redoblado MA, Lah S, Sabaz M, Lawson JA, Cunningham AM, et al. Memory function in childhood epilepsy syndromes. J Paediatr Child Health. 2004;40:20-7.

15. Hermann B, Jones J, Sheth R, Dow C, Koehn M, Seidenberg M. Children with new-onset epilepsy: neuropsychological status and brain structure. Brain. 2006;29(Pt. 10):2609-19.
16. Byars AW, deGrauw TJ, Johnson CS, Fastenau PS, Perkins SM, Egelhoff JC, et al. The association of MRI findings and neuropsychological functioning after the first recognized seizure. Epilepsia. 2007;48:1067-74.

17. Beardsworth ED, Zaidel DW. Memory for faces in epileptic children before and after brain surgery. J Clin Exp Neuropsych. 1994;16:589-96.

18. Cohen M. Auditory/verbal and visual/spatial memory in children with complex partial epilepsy of temporal lobe origin. Brain Cogn. 1992;20:315-26.

19. Jambaqué I, Dellatolas G, Dulac O, Ponsot G, Signoret JL. Verbal and visual memory impairment in children with epilepsy. Neuropsychologia. 1993;31:1321-37.

20. Jambaqué I, Dellatolas G, Fohlen M, Bulteau C, Watier L, Dorfmuller G, et al. Memory functions following surgery for temporal lobe epilepsy in children. Neuropsychologia. 2007; 45: 2850-62.

21. Williams J, Phillips T, Griebel ML, Sharp GB, Lange B, Edgar T, et al. Patterns of memory performance in children with controlled epilepsy on the CVLT-C. Child Neuropsychol. 2001;7:15-20.

22. Lendt M, Helmstaedter C, Elger CE. Pre- and postoperative neuropsychological profiles in children and adolescents with temporal lobe epilepsy. Epilepsia. 1999;40:1543-50.

23. Hershey T, Craft S, Glauser TA, Hale S. Short-term and long-term memory in early temporal lobe dysfunction. Neuropsychology. 1998;12:52-64

24. Jocic-Jakubi B, Jovic NJ. Verbal memory impairment in children with focal epilepsy. Epilepsy Behav. 2006;9:432-9.

25. Baxendale SA, van Paesschen W, Thompson PJ, Connelly A, Duncan JS, Harkness WF, et al. The relationship between quantitative MRI and neuropsychological functioning in temporal lobe epilepsy. Epilepsia. 1998;39:158-66.

26. Elterman RD, Glauser TA, Wyllie E, Reife R, Wu SC, Pledger G. A double-blind, randomized trial of topiramate as adjunctive therapy for partial-onset seizures in children. Topiramate YP Study Group. Neurology. 1999;52:1338-44. 


\title{
The Patient's Experience of Memory Change after Elective Temporal Lobe Resection
}

\author{
Jaime Williams, Mora Martin, Jeannette McGlone
}

\begin{abstract}
Subjective memory has emerged as a relevant indicator of outcome following temporal lobe resection (TLR) for the treatment of intractable temporal lobe epilepsy. Study 1 asks whether patients undergoing TLR experience subjectively-perceived memory changes one year following surgery. The Memory Observation Questionnaire provided data for both individual and group level analyses. Reliable change index results indicated that most patients and informants (i.e., a family or close friend) reported no change or improvement after the surgery, and 7.8\% reported deterioration. Aggregate scores showed that mean ratings of subjective memory ratings significantly improved or did not change following surgery. Study 2 is a meta-analysis of six different publications on subjective memory comprising 465 TLR patients and 171 informants (i.e., 25 effect sizes). The weighted mean effect size of 0.27 was small, yet significantly larger than zero in the direction of perceived improvement. These findings suggest that most TLR surgical epilepsy patients do not notice post-operative changes in their memory function. Accordingly, we propose that a comprehensive discussion of surgical risks and benefits incorporates both patient impressions, along with objective memory outcomes.
\end{abstract}

RÉSUMÉ: L'expérience du patient concernant les changements mnésiques après la résection élective du lobe temporal. On sait maintenant que la mémoire subjective est un indicateur pertinent de résultat après une résection du lobe temporal (RLT) pour le traitement de l'épilepsie temporale pharmaco-résistante. Dans la première étude, on a demandé à des patients qui avaient subi une RLT si eux-mêmes percevaient des changements mnésiques un an après la chirurgie. Les données ont été recueillies au moyen du Memory Observation Questionnaire et nous avons effectué des analyses individuelles et de groupe. Les résultats d'indices de changement fiables indiquent que la plupart des patients et des informateurs (ex. un membre de la famille ou un ami proche) n'ont rapporté aucune modification ou amélioration après la chirurgie et 7,8\% ont rapporté une détérioration. Les scores totaux ont montré que les taux moyens d'évaluation de la mémoire subjective se sont améliorés de façon importante ou n'ont pas changé après la chirurgie. La deuxième étude est une méta-analyse de six publications sur la mémoire subjective chez 465 patients qui avaient subi une RLT et 171 informateurs (c.-à-d. 25 tailles d'effet). La taille d'effet moyenne pondérée était petite, soit 0,27, mais significativement plus grande que zéro en faveur d'une amélioration perçue. Selon ces observations, les patients épileptiques qui ont subi une RLT chirurgicale ne remarquent pas de changement de leur fonction mnésique après la chirurgie. Nous proposons donc qu'une discussion complète des risques et des bénéfices de la chirurgie doive inclure tant les impressions des patients que les résultats objectifs concernant la mémoire.

Can. J. Neurol. Sci. 2009; 36: Suppl. 2 - S46-S50

Temporal lobe resection (TLR) is a highly established treatment option for medically intractable complex partial seizures $(\mathrm{CPS})^{1,2}$. Increasingly, neuropsychological information such as that used to predict or prevent memory loss is important in specialists' and patients' decision about whether to recommend or undergo surgery ${ }^{3,4}$. Objective, neuropsychological test data have provided the basis for memory assessment $^{5}$, but more recently patient self-appraisal of functioning has come to the forefront of medical and epilepsy outcome research ${ }^{6,7}$. This paper strengthens and consolidates the subjective memory literature by describing a previously unpublished study on memory complaints following TLR and presenting a meta-analysis synthesizing the outcome literature of TLR and self-reported memory change.

\section{Study 1}

\section{METHODS}

Adult participants underwent unilateral resections for medically intractable temporal lobe epilepsy between 1990 and
2006 in Halifax, NS (i.e., 48 anterior temporal lobe resections, 16 selective amygdalohippocampectomies). Neuropsychological evaluations were conducted $8.8(\mathrm{SD}=10.0)$ months before and approximately one year following surgery (mean months $=12.7$, $\mathrm{SD}=2.5$ ). The $\%$ delayed retention on Logical Stories from the Wechsler Memory Scale ${ }^{8,9}$ provided an objective verbal memory score. The Memory Observation Questionnaire -Total Scores (MOQ) assessed subjective complaints ${ }^{10,11}$. Two forms reflect the patient's opinion $(\mathrm{A}=$ current state, $\mathrm{B}=$ change since surgery) and two parallel A and B forms reflect the informant's opinion about the patient.

From the Departments of Psychology, Queen Elizabeth II Health Sciences Centre (JW, JMG); Dalhousie University (MM), Halifax, NS; University of Saskatchewan (JW), Saskatoon, SK, Canada.

Received July 21, 2008. Final Revisions Submitted July 29, 2008 Correspondence to: Jeannette McGlone, Department of Psychology, Dalhousie University, Halifax, Nova Scotia, B3H 4J1, Canada. 


\section{RESULTS}

Group Analyses. Table 1 shows the means and standard deviations of the MOQ, and \% WMS Logical Stories Delayed Recall by Time and Side of Surgery, where higher scores reflect better outcomes. Two-by-two analysis of variances (i.e., Time, a repeated measure, and Side) indicated main effects of Time for the MOQ-SB (F1, $62=5.8, \mathrm{p}<0.05)$, MOQ-RA $(\mathrm{F} 1,51=5.3$, $\mathrm{p}<0.05)$ and MOQ-RB $(\mathrm{F} 1,52=10.2, \mathrm{p}<0.01)$. Patients and informants reported significantly improved memory functioning after than before surgery. MOQ-SA results indicated a significant main effect for Side, $(\mathrm{F} 1,62=5.2, \mathrm{p}<0.05)$; patients with left lesions reported significantly lower memory ratings than those with right lesions. No other comparison reached the .05 significance level. The \% Logical Stories Delayed Recall results showed a trend towards an interaction of Time by Side, i.e., worse verbal memory after left than right TLR (F1, 62,=2.2, ns).

Reliable Change Index. Reliable Change Index methodology identifies percentages of patients who report improvement, deterioration, or no reliable change. Data obtained from 11 nonsurgical individuals with medically controlled epilepsy were used to calculate the reliable change intervals for the $\mathrm{MOQ}^{12,13}$. Figure 1 displays these percentages. Four separate chi-square analyses indicated that each form of the MOQ produced a significantly uneven distribution (i.e., MOQ-SA, $x 2(2)=79.7, p$ $<.001$; MOQ-SB, x2(2) = 66.1, p < .001; MOQ-RA, x2(2) = $29.8, \mathrm{p}<.001 ; \mathrm{MOQ}-\mathrm{RB}, \mathrm{x} 2(1)=30.6, \mathrm{p}<.001)$.

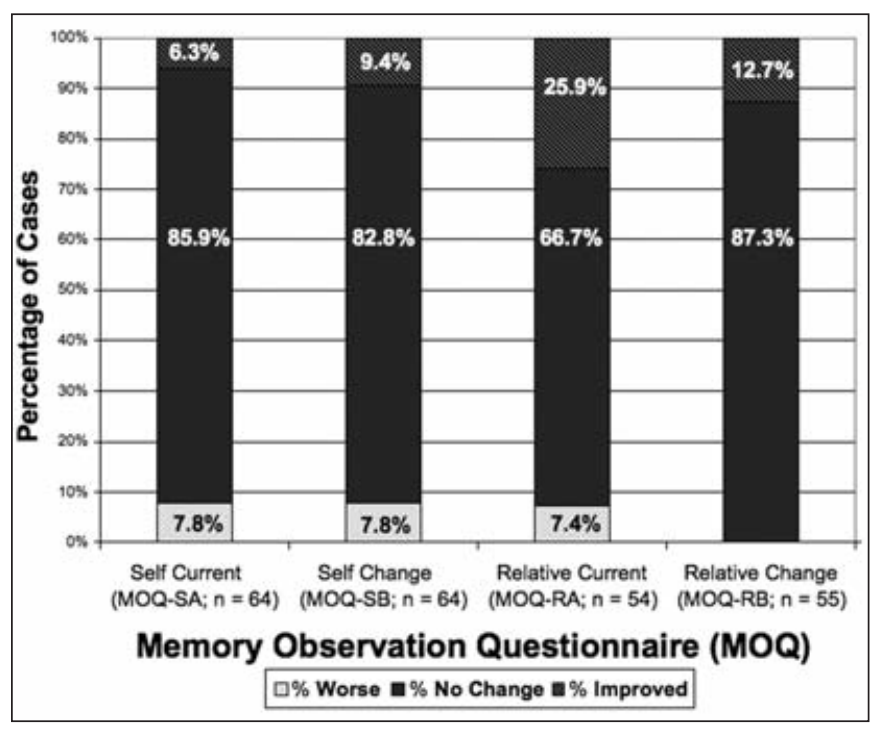

Figure 1: Percentage of patients and their relatives who rated the patients' memory worse versus no change versus improved pre-to one year post-operatively on the Memory Observation Questionnaire determined through a reliable change index. Note. Reliable change interval was calculated from 11 patients with medically controlled epilepsy tested one year apart (McGlone et al., X 1999).

Table 1: Subjective memory, depression, and psychosocial adjustment results for patients with temporal lobe resections and their relatives

\begin{tabular}{c|l|l|l|l}
\hline Test & & \multicolumn{1}{|c|}{ Pre-Operative } & & \multicolumn{1}{c}{ Post-Operative } \\
\hline MOQ-SA & $\mathrm{N}$ & Mean $(S D)$ & $\mathrm{N}$ & Mean $(S D)$ \\
Left & & & & \\
Right & 34 & $38.2(11.0)$ & 34 & $37.3(14.1)$ \\
Combined & 30 & $42.4(12.5)$ & 30 & $45.1(10.6)$ \\
MOQ-SB & 64 & $40.1(11.8)$ & 64 & $41.0(13.0)$ \\
Left & & & & \\
Right & 34 & $39.4(17.1)$ & 34 & $46.1(26.6)$ \\
Combined & 30 & $42.8(11.2)$ & 30 & $48.0(16.9)$ \\
Left & 64 & $41.0(14.6)$ & 64 & $47.0 *(22.4)$ \\
Right & & & & \\
Combined & 29 & $34.2(14.7)$ & 29 & $40.4(13.5)$ \\
MOQ-RA & 25 & $40.7(15.6)$ & 25 & $43.2(12.9)$ \\
Left & 54 & $37.2(15.3)$ & 54 & $41.7 *(13.2)$ \\
Right & & & \\
Combined & 29 & $41.2(22.8)$ & 29 & $54.9(49.3)$ \\
MOQ-RB & 26 & $38.5(23.2)$ & 26 & $57.2(30.9)$ \\
Right & 55 & $40.0(22.8)$ & 55 & $56.0 *(41.3)$ \\
Combined & & & & \\
\hline WMS Logical Stories Delayed Recall (percentage) & 34 & $27.5(19.6)$ & 34 & $23.1(13.4)$ \\
\hline & 30 & $29.7(18.4)$ & 64 & $26.9(14.7)$ \\
\hline
\end{tabular}

GDS = Geriatric Depression Scale; MOQ = Memory Observation Questionnaire; SA, SB, RA, RB, subject and relative forms, parts A and B; WPSI = Washington Psychosocial Seizure Inventory. Pre and post ratings significantly different using dependent t-test $* \mathrm{p}<.05 ; * * \mathrm{p}<.01$. 


\section{Study 2: Meta-Analysis}

\section{METHODS}

Studies were identified through multiple search strategies and included if they met the following criteria: 1) all patients were at least 16-years-old; 2) patients had temporal lobe epilepsy; 3) TLR was the procedure for seizures; 4) results analyzed differences between pre and post-operative time frames.

\section{ANAlyses}

Effect size statistics (ES; Hedges' g) were calculated for preto post-operative differences using the meta-analysis software package DSTAT ${ }^{14}$. Separate standardized mean difference ES were calculated for each measure of self-reported memory within each study. The ES were combined to yield a weighted mean ES, which was converted to a z-statistic to allow for an evaluation of whether the statistic was significantly different from 0 .

\section{RESULTS}

Nineteen pertinent studies were identified, but thirteen of these did not meet our criteria ${ }^{15-27}$ (see + in references). Table 2 summarizes the patient characteristics and study designs from the remaining studies ${ }^{11,28-31}$ including Study 1 described herein ( $\mathrm{n}=6$ studies). Twenty-five study-level ES were calculated totaling 465 patients and 171 informants. Figure 2 displays ES and $95 \%$ confidence intervals. Homogeneity of ES was found among the memory ratings (QT $(24)=30.63, \mathrm{p}>0.05)$. The

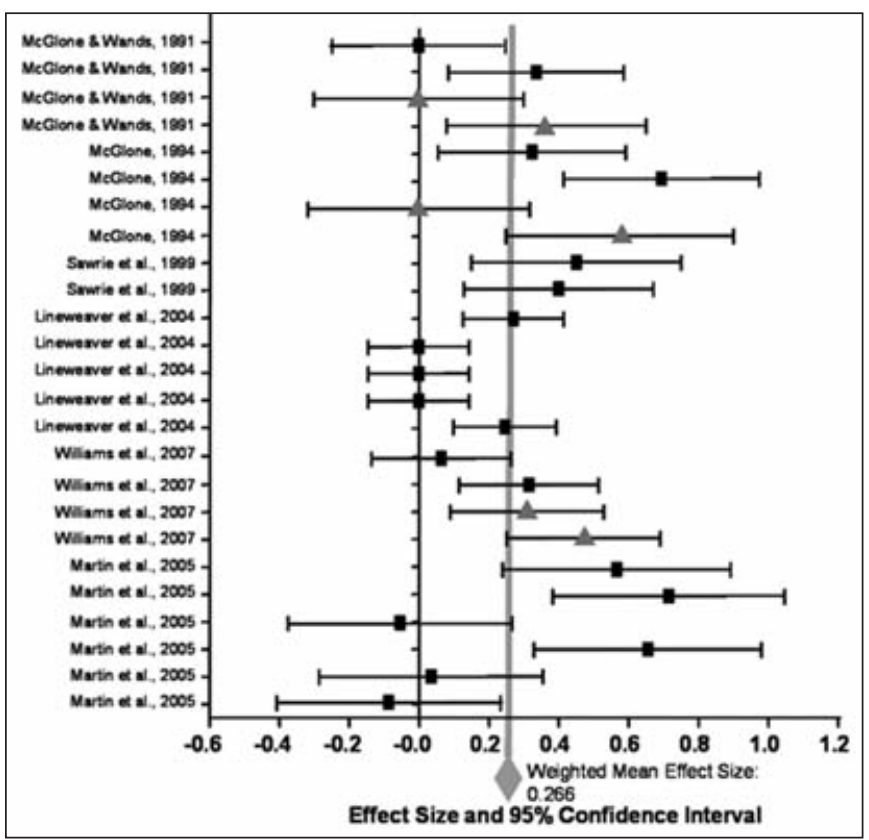

Figure 2: Effect sizes and confidence intervals calculated for all measures of self-reported memory in the studies included in the metaanalysis. Note. Grey triangles represent effect sizes calculated from relatives' ratings of their patient's memory function. Note. The citation "Williams et al., 2007" refers to the work published in Study 1 of this document.

Table 2: Study characteristics of investigations included in the meta-analysis

\begin{tabular}{|c|c|c|c|c|c|c|c|}
\hline Study & Study design & $\begin{array}{l}\text { Number of } \\
\text { patients }\end{array}$ & Patient sex & Handedness & $\begin{array}{l}\text { Mean age } \\
\text { years (SD) }\end{array}$ & $\begin{array}{l}\text { Measure of } \\
\text { self-reported } \\
\text { memory }\end{array}$ & $\begin{array}{l}\text { No of } \\
\text { effect sizes } \\
\text { calculated }\end{array}$ \\
\hline $\begin{array}{l}\text { McGlone \& } \\
\text { Wands (1991) }\end{array}$ & $\begin{array}{l}\text { Between } \\
\text { subjects }\end{array}$ & $\begin{array}{l}\text { pre: } 31 \text { patients } \\
21 \text { relatives } \\
\text { post: } 72 \text { patients } \\
65 \text { relatives }\end{array}$ & $\begin{array}{l}\text { pre: } 14 \text { male } \\
17 \text { females } \\
\text { post: } 34 \text { males } \\
38 \text { females }\end{array}$ & Not reported & $\begin{array}{l}>16 \text {, pre-op } \\
\text { N/A, post-op }\end{array}$ & MOQ & 4 \\
\hline $\begin{array}{l}\text { McGlone } \\
(1994)\end{array}$ & $\begin{array}{l}\text { Repeated } \\
\text { measures }\end{array}$ & $\begin{array}{l}47 \text { patients } \\
30 \text { relatives }\end{array}$ & $\begin{array}{l}23 \text { males } \\
24 \text { females }\end{array}$ & $\begin{array}{l}47 \text { right } \\
0 \text { left }\end{array}$ & $31.3(11.0)$ & MOQ & 4 \\
\hline $\begin{array}{l}\text { Sawrie et al. } \\
\text { (1999) }\end{array}$ & $\begin{array}{l}\text { Repeated } \\
\text { measures }\end{array}$ & 65 patients & $\begin{array}{l}27 \text { males } \\
38 \text { females }\end{array}$ & Not reported & $34.6(11.2)$ & $\begin{array}{l}\text { QOLIE } \\
\text { (Memory } \\
\text { subscale) }\end{array}$ & $2 *$ \\
\hline $\begin{array}{l}\text { Lineweaver } \\
\text { et al. }(2004)\end{array}$ & $\begin{array}{l}\text { Repeated } \\
\text { measures }\end{array}$ & 136 patients & $\begin{array}{l}65 \text { males } \\
71 \text { females }\end{array}$ & $\begin{array}{l}116 \text { right } \\
20 \text { left }\end{array}$ & $33.9(8.5)$ & MAC-S & 5 \\
\hline $\begin{array}{l}\text { Martin et al. } \\
(2006)\end{array}$ & $\begin{array}{l}\text { Repeated } \\
\text { measures }\end{array}$ & 50 patients & Not reported & Not reported & $\begin{array}{l}37.6(10.4) \text { - right TLR } \\
35.7(9.7)-\text { left TLR }\end{array}$ & MASQ & $6 *$ \\
\hline $\begin{array}{l}\text { Williams et al. } \\
\text { (2007) }\end{array}$ & $\begin{array}{l}\text { Repeated } \\
\text { measures }\end{array}$ & $\begin{array}{l}64 \text { patients } \\
55 \text { relatives }\end{array}$ & $\begin{array}{l}27 \text { males } \\
37 \text { females }\end{array}$ & $\begin{array}{l}50 \text { right } \\
14 \text { left or } \\
\text { ambidextrous }\end{array}$ & $35.0(11.4)$ & MOQ & 4 \\
\hline
\end{tabular}

MOQ = Memory Observation Questionnaire; QOLEI = Quality of Life in Epilepsy Inventory - 89; MAC-S = Memory Assessment Clinics SelfRating Scale - subscales used: Ability, Frequency, General Memory, Decline, Distress; MASQ = Multiple Abilities Self-Report Questionnaire subscales used: Verbal Memory, Attention/Concentration, Visual Spatial Memory; Note. The citation "Williams et al., 2007" refers to the work published in Study 1 of this document; *Left and right TLR patients' data analyzed separately. 
weighted mean ES was $\mathrm{Md}=+0.266$, a value that was significantly higher than zero $(\mathrm{z}=5.31, \mathrm{p}<.001,95 \%$ confidence interval $=+0.12$ to +0.28$)$, and would be considered to be small.

\section{General Discussion}

Results from Study 1 indicated that mean ratings of subjective memory did not deteriorate following surgery except in about $7.8 \%$ of the sample according to reliable change index. Our meta-analysis suggests that this outcome is consistent within the literature, robust across measurement instruments, informants (i.e., patient versus relative), study design, patient age, and length of follow-up, however, the results cannot be generalized to non-literate or extratemporal lobe resection samples. Nevertheless, these findings are important because beliefs about the self predict behaviour in real-world situations ${ }^{32}$ and beliefs affect one's ability to accomplish tasks via motivational and persistence pathways ${ }^{33}$. It is possible that, along with improved seizure control, quality of life, depressed mood, and psychosocial adjustment, stable memory self-efficacy may predict the presence of positive, health-enhancing behaviours after surgery, rendering subjective memory highly relevant to persons with epilepsy considering TLR and to physicians deciding whether to recommend surgery to a given patient. When analyzing the risks versus the benefits of TLR, subjective memory findings provide another piece of valuable information to consider in addition to physical benefits and risks, including the likelihood of changes in scores on objective memory tests ${ }^{5,34}$. Future research needs to identify the determinants of increased memory complaints after surgery.

\section{ACKNOWLEDGEMENTS}

This work was supported in part by a grant from the Epilepsy Association of Nova Scotia Research Fund. We acknowledge the Queen Elizabeth - II Clinical Psychology Pre-doctoral Internship Program (Halifax, Nova Scotia) for support. The authors thank neurosurgeons Drs. Robert Brownstone, David Clarke, and William Howes, neurologist Dr. Mark Sadler, and neuropsychologist Dr. Sherri Carter for their clinical contributions and Dr. Bradley Frankland for statistical advice. We acknowledge Dr. Ivan Valdivia and Shirley Munk for data collection and Marsha Penner for support. We thank Drs. Christie Clason, Gregory Lee and David Loring for providing us with useful information and summaries of their work on subjective memory. We confirm that we have read the Journal's position on issues involved in ethical publication and affirm that this report is consistent with those guidelines.

\section{REFERENCES}

Note: *indicates that these studies were included in the metaanalysis; +indicates that these studies were identified as being relevant, but did not meet the inclusion criteria for the metaanalysis

1. Engel J, Wiebe S, French J, Sperling M, Williamson D, Spencer R, et al. Practice parameter: temporal lobe and localized neocortical resections for epilepsy: report of the quality standards subcommittee of the American Academy of Neurology, in association with the American Epilepsy Society and the American Association of Neurological Surgeons. Neurology. 2003; 60: 538-47.
2. Wiebe S, Gafni A, Blume WT, Girvin JP. An economic evaluation of surgery for temporal lobe epilepsy. J Epilepsy. 1995; 8: 227-35.

3. Wiebe S. Effectiveness and safety of epilepsy surgery: What is the evidence? CNS Spectr. 2004; 9: 120-22, 126-32.

4. Téllez-Zenteno JF, Dhar R, Hernandez-Ronquillo L, Wiebe S. Long-term outcomes in epilepsy surgery: antiepileptic drugs, mortality, cognitive and psychosocial aspects. Brain. 2007; 130 (Pt 2): 334-45.

5. Lee TM, Yip JT, Jones-Gotman M. Memory deficits after resection from left or right anterior temporal lobe in humans: a metaanalytic review. Epilepsia. 2002; 43: 3, 283-91.

6. Devinsky O. Quality of life in epilepsy. Time to practice what we preach. Epilepsy Behav. 2000; 1: 89-90.

7. Langfitt JT, Westerveld M, Hamberger JM, Walczak TS, Cicchetti DV, Berg AT, et al. Worsening of quality of life after epilepsy surgery. Neurology. 2007; 68: 1988-94.

8. Wechsler D. Wechsler Adult Intelligence Scale-Revised: manual. New York: The Psychological Corporation; 1981.

9. Wechsler D. Wechsler Memory Scale: 3rd edition. San Antonia, Texas: The Psychological Corporation; 1997.

10. Humphrey D, McGlone J, Leffley A, Gupta S, Evans D. Manual for the Memory Observation Questionnaire and Memory Observation Questionnaire-2. Unpublished manuscript; 1995.

11. *McGlone J. Memory complaints before and after temporal lobectomy: Do they predict memory performance or lesion laterality? Epilepsia. 1994; 35: 529-39.

12. McGlone J, Clarke D, Sadler R, Valdivia I, Penner M. Vagal nerve stimulation did not enhance memory after twelve months of treatment. J Int Neuropsychol 2003; Soc. 9: 189.

13. McGlone J, Valdivia I, Penner M, Williams J, Sadler RM, Clarke DB. Quality of life and memory after vagus nerve stimulator implantation for epilepsy. Can J Neurol Sci. 2008; 35: 287-96.

14. Johnson BT. DSTAT 1.10: Software for the meta-analytic review of research literatures. Hillside, NJ: Erlbaum; 1993.

15. +Baños JH, LaGory J, Sawrie S, Faught E, Knowlton R, Prasad A, et al. Self-report of cognitive abilities in temporal lobe epilepsy: Cognitive, psychosocial, and emotional factors. Epilepsy Behav. 2004; 5 : 37-43.

16. +Bennett-Levy J, Polkey CE, Powell GE. Self-report of memory skills after temporal lobectomy: The effect of clinical variables. Cortex. 1980; 16: 543-57.

17. +Clason CL, Lee GP, Loring DW. Do subjective material-specific memory complaints predict objective material-specific memory performance in epilepsy surgery patients? J Int Neuropsychol Soc. 2006; 12 (S1): 15.

18. +Elizhauster A, Leidy NK, Meador K, Means E, Willian MK. The relationship between memory performance, perceived cognitive function, and mood in patients with epilepsy. Epilepsy Res. 1999; 37: 13-24.

19. +Gleissner U, Helmstaedter C, Quiske A, Elger CE. The performance-complaint relationship in patients with epilepsy: a matter of daily demands? Epilepsy Res. 1998; 32: 401-9.

20. +Goldstein LH, Polkey CE. Behavioural memory after temporal lobectomy or amygdalo-hippocampectomy. Br J Clin Psychol. 1992a; 31: 75-81.

21. +Goldstein LH, Polkey CE. Everyday memory after unilateral temporal lobectomy or amygdalo-hippocampectomy. Cortex. 1992b; 28: 189-201.

22. +Hermann BP, Seidenberg M, Dohan FC Jr., Wyler AR, Haltiner A, Bobholz J, et al. Reports by patients and their families of memory change after left anterior temporal lobectomy: relationship to degree of hippocampal sclerosis. Neurosurgery. 1995; 36: 39-45.

23. +Kadis DS, Stollstorff M, Elliott I, Lack L, Smith ML. Cognitive and psychological predictors of everyday memory in children with intractable epilepsy. Epilepsy Behav. 2004; 5: 37-43.

24. +O'Shea MF, Saling MM, Bladin PF, Berkovic SF. Does naming contribute to memory self-report in temporal lobe epilepsy? J Clin Exp Neuropsychol. 1996; 18: 98-109.

25. +Piazzini A, Canevini MP, Maggiori G, Canger R. The perception of memory failures in patients with epilepsy. Eur J Neurol. 2001; 8: 613-20. 
26. +Prevey ML, Delaney RC, Mattson RH. Metamemory in temporal lobe epilepsy: self-monitoring of memory functions. Brain Cogn. 1988; 7: 298-311.

27. +Smith M, Elliott IM, Lach L. Memory outcome after pediatric epilepsy surgery: objective and subjective perspectives. Child Neuropsychol. 2006; 12: 151-64.

28. *Lineweaver TT, Naugle RI, Cafaro AM, Bingaman W, Lüders HO. Patients' perceptions of memory functioning before and after surgical intervention to treat medically refractory epilepsy. Epilepsia. 2004; 45: 1604-12.

29. *Martin R, Griffith HR, Sawrie S, Knowlton R, Faught E. Determining empirically based self-reported cognitive change: development of reliable change indices and standardized regression-based change norms for the multiple abilities selfreport questionnaire in an epilepsy sample. Epilepsy Behav. 2006; 8: 239-45
30. *McGlone J, Wands K. Self-report of memory function in patients with temporal lobe epilepsy and temporal lobectomy. Cortex. 1991; 27: 19-28.

31. *Sawrie SM, Martin RC, Kuzniecky R, Faught E, Morawetz R, Jamil F, et al. Subjective versus objective memory change after temporal lobe epilepsy surgery. Neurology. 1999; 53: 1511-17.

32. Kihlstrom JK, Klein SB. The self as a knowledge structure. In: Wyer RS, Srull TK, editors. Handbook of social cognition, vol 1. Eribaum, Hillsdale, New Jersey; 1994. p. 153-208.

33. Bandura A. Social foundations of thought and action: a social cognitive. Englewood Cliffs, New Jersey: Prentice Hall; 1986.

34. Vaz, SA. Nonverbal memory functioning following right anterior temporal lobectomy: a meta-analytic review. Seizure. (2004); 13 (7): 446-452. 


\title{
Intracarotid Amobarbital Procedure and Etomidate Speech and Memory Test
}

\author{
M. Jones-Gotman, V. Sziklas, J. Djordjevic
}

\begin{abstract}
The intracarotid amobarbital procedure (IAP) has for over 50 years been an important component of the presurgical investigation of patients with epilepsy who are candidates for surgical intervention as treatment for their seizures. Owing to increasing frequency and duration of amobarbital shortages, alternatives for this drug have been sought and implemented, but until now only the drug was changed, while the basic procedure remained essentially the same as that used with amobarbital. This paper describes the Montreal Neurological Institute experience using etomidate in place of amobarbital and introducing a significant change in the procedure: after an initial bolus injection, an infusion is used to maintain the level of hemianesthesia during critical test times. Results of 28 patients tested with this procedure are compared to results from 40 patients tested in the standard IAP.
\end{abstract}

\begin{abstract}
RÉSUMÉ: Test d'amobarbital intracarotidien et test de langage et de mémoire à l'étomidate. Le test d'amobarbital intracarotidien est depuis plus de 50 ans un élément important de l'évaluation des patients atteints d'épilepsie qui sont candidats à la chirurgie comme traitement de leurs crises. À cause d'une pénurie de plus en plus fréquente et prolongée d'amobarbital, on a cherché des alternatives à l'utilisation de ce produit, mais à ce jour seulement le produit a changé alors que la technique de base est demeurée essentiellement la même. Cet article décrit l'utilisation de l'étomidate au lieu de l'amobarbital ainsi qu'un changement important dans la technique d'administration à l'Institut neurologique de Montréal. Après l'injection d'un bolus initial, une infusion est utilisée pour maintenir le niveau d'hémianesthésie pendant les moments critiques du test. Nous comparons les résultats obtenus chez 28 patients évalués au moyen de cette technique aux résultats chez 40 patients évalués au moyen du test d'amobarbital standard.
\end{abstract}

Can. J. Neurol. Sci. 2009; 36: Suppl. 2 - S51-S54

In the 1950's Dr. Juhn Wada introduced North America to the concept of anesthetizing one hemisphere, allowing the remaining, awake, hemisphere to be tested separately for speech functions ${ }^{1-3}$. His procedure, which for years used the barbiturate amobarbital as the anesthetizing agent, will be referred to here as an intracarotid anesthetic procedure (IAP). The IAP has for approximately half a century been an important tool in epilepsy surgery, used to determine cerebral dominance for language and to predict postsurgical memory function in patients who are candidates for surgical treatment of intractable epilepsy $y^{4,5}$.

IAP basics. Nearly all epilepsy programs using the IAP follow a same basic procedure. The drug is injected into one hemisphere through the internal carotid artery (an exception is the injection route used for superselective procedures, which will not be discussed here). The injection produces anesthesia of the injected hemisphere, lasting about four to eight minutes. Speech and memory functions of the awake hemisphere are tested during inactivation of the injected one. Simple tasks are used for this because of the short time frame in which testing can be done and because the tasks must be performed by just one hemisphere. Using simple tasks also allows the same test to be given to almost all patients without respect to intellectual level, allowing comparison of any patient's results to those of a large body of data on other patients. Also, simple tasks are sufficient to yield the information sought in this procedure.

A baseline is established on speech tasks before injection, and preinjection memory items are shown so that retrograde memory can be assessed in a recognition test at the end of the procedure. New memory items are shown shortly after injection, while the effect of the drug should still be at its maximum; this allows anterograde memory to be assessed in the final recognition test,

\footnotetext{
From the Montreal Neurological Institute, McGill University, Montreal, QC, Canada. Received July 23, 2008. Final Revisions Submitted July 29, 2008. Correspondence to: M. Jones-Gotman, Montreal Neuroligical Institute, 3801 University Street, Montreal, Quebec, H3A 2B4, Canada.
} 
which is given after the drug effect is clearly finished according to EEG and measures of contralateral arm and finger strength. The step that causes most problems in the IAP is the presentation of new memory items after injection. It is important that the memory items be seen while the injected hemisphere is fully under the effect of the drug so that one can be confident that the memory test is addressing only the awake hemisphere. The problem is that the effect of the drug begins to dissipate essentially immediately after injection, with the result that memory test results may be uncertain owing to partial return of function in the injected hemisphere.

Introducing an alternative anesthetic agent. In the past several years there have been recurring shortages of amobarbital, and in some countries it has been completely inaccessible. Therefore, a few other anesthetic agents have been used for the IAP. The one used most frequently is methohexital (Brevital) ${ }^{6-8}$, an extremely short-acting barbiturate that must be re-injected in the course of a procedure in order to maintain an appropriate level of hemianesthesia while speech and postinjection memory testing is performed. When that or other anesthetic agents have been used, the choice of drug has been the only alteration in the test, and the general procedure has remained as outlined above.

In June 2003 amobarbital became completely unavailable for a prolonged period of time, prompting the epilepsy team of the Montreal Neurological Hospital to look for a permanent replacement. We chose to use etomidate (R-(+)-ethyl-1-(1phenylethyl)-1H-imidazole-5-carboxylate), which is an imidazole derivative and a potent nonbarbiturate hypnotic agent ${ }^{9}$. Etomidate has a rapid onset, short duration of action and minimal hemodynamic effects. It is in common intravenous use in operating rooms, intensive care units and emergency departments, where it is considered safe and effective. In those settings, myoclonus, tremor and dystonic posturing have been reported in $86.6 \%$ of patients, most often at the beginning of deep anesthesia ${ }^{10}$. According to a few reports, etomidate may also increase spike activity in patients with epilepsy ${ }^{11,12}$. In keeping with that, we have seen activation of interictal epileptic discharge in $33 \%$ of our procedures. This was always ipsilateral to injection; it began when slow waves began and ended before the slow waves ended. There were no behavioral changes associated with that discharge and injection has never provoked a seizure during our procedures ${ }^{9}$.

Etomidate has the advantages of amobarbital, making it a good choice as a replacement anesthetizing agent. However, in addition to initiating its use as a new IAP drug, we introduced an important change in the procedure, which we call the etomidate speech-and-memory test, or eSAM. After making the initial bolus injection, we maintain the level of hemianesthesia with an infusion until all of the new (critical) memory items have been presented. The initial bolus is $2 \mathrm{mg}(0.03-0.04 \mathrm{mg} / \mathrm{kg})$, which is injected into the internal carotid by an anesthetist using an infusion pump. That is followed by the infusion $(0.003-0.004$ $\mathrm{mg} / \mathrm{kg} / \mathrm{min}$ ) at a rate of $6 \mathrm{cc}$ per hour. On average it takes about $60 \mathrm{sec}$ to complete injection of the bolus, and the infusion is maintained for about $51 / 2 \mathrm{~min}$, calculated from the beginning of the bolus injection. The time at which the infusion should be discontinued is determined by the neuropsychologist, who signals the anesthetist after all language tasks have been sampled satisfactorily and all memory items have been presented.
Experience with first 57 eSAM tests. As the injection begins, patients raise their arms, wiggle all fingers and begin counting. The first effect to appear upon injection is slow waves in the EEG, which occur on average $40 \mathrm{sec}$ after initiation of the injection. The second effect is that finger wiggling slows, and then stops, on the hand contralateral to injection (at about 41.5 $\mathrm{sec}$ ). At about $43 \mathrm{sec}$ the patient slurs words while counting, and if the injected hemisphere is speech dominant, stops counting. Finally, on average $50 \mathrm{sec}$ after initiation of injection the contralateral arm falls slowly to the bed. Thus, in contrast to the essentially immediate effect of injection in a standard IAP, the effect occurs gradually, taking almost a minute, in eSAM.

During the infusion we observe continuous slow waves in the EEG ipsilateral to injection, and in $75 \%$ of injections there are lesser slow waves also in the frontal region contralateral to injection. This is not different from the EEG pattern in IAP, where there is contralateral frontal slowing in $78 \%$ of injections. A complete hemiplegia and, in the case of dominant-hemisphere injections, aphasia remain evident throughout the infusion. Upon terminating the infusion the drug effects wane gradually over a period of about 4 minutes. During this period of recovery language errors (if the speech dominant hemisphere was injected) occur in the same way as in a standard IAP, the difference being that they occur later in the test in eSAM.

Our experience as of the first 57 tests has been that good contact with the patient is maintained during the infusion, so that lengthening the time of complete hemianesthesia has allowed a longer period in which testing can occur while the drug remains fully effective. Only rarely have there been occasions of obtundation; these were in conjunction with extensive damage contralateral to injection. In those cases, infusion was stopped and the test was continued in the same way that a normal IAP is performed, carrying it out while recovery is taking place.

We have observed only one side effect using etomidate; that is a shiver-like tremor that has occurred during the infusion in $46 \%$ of injections ${ }^{9}$. When this occurred it was typically on the contralateral hand and arm, but occasionally it occurred also on the ipsilateral hand. It never occurred on the ipsilateral side alone. This effect was mild, and in $58 \%$ of cases it was so mild as to be almost imperceptible. It was never accompanied by epileptiform abnormalities on the EEG.

Speech and memory testing using eSAM. The procedure that we use for the behavioral tests in eSAM is the same as we have used in our IAP for the past ten years or so $^{13}$, when we revamped the procedure that had previously been used for many years. At that time we initiated inclusion of a practice on the day before the real test; the practice is identical to the real test except that there is no injection. In the practice and the real tests we first establish a baseline in which we select, from a pool of 12 items, six each to be used in postinjection speech tests (reading, spelling, word repetition, sentence repetition). The selection ensures that all items tested under the influence of the drug were passed easily as a baseline. Comprehension (using a simplified Token Test), naming common objects, counting forward and backward, and reciting the days of the week forward and backward are also included in speech testing. Eight real objects are shown as preinjection memory items, to be recognized at the end of the procedure. 
After injection we cycle through the different speech tasks, presenting just two items per task so that all are sampled early in the test (this was important for the IAP when there was a rush to perform the tests before the drug would begin to wear off). Items on which there are errors or failures to respond are presented again, and the cycling continues until correct responses have been given to all speech items.

Eight new memory objects are shown after all speech tasks have been sampled once (one cycle; approximately $3 \frac{1}{1 / 4}$ minutes after initiation of the injection). This is a departure from our IAP procedure in which, because of the time pressure, presentation of memory items began at one minute after injection. In eSAM, presentation of the memory objects lasts two minutes on average, after which speech testing is resumed. When all speech tasks have been completed correctly and the power measures and EEG have returned to baseline (mean of 13 minutes after injection), recognition is tested using the eight preinjection objects, eight postinjection objects, and eight new objects as recognition foils. They are shown one at a time in a yes-no recognition paradigm. A score of $65 \%$ correct or better is considered a "pass", and comparison of the performance of the two hemispheres is also taken into account.

Determination of hemispheric dominance for speech was not a problem with the IAP, especially after the change in protocol (limiting each task to two items and cycling through the tasks) to ensure that all speech tasks would be sampled during the drug effect. Thus the advantage of the eSAM is found in memory testing. We compared memory results of our first 28 patients tested with eSAM to the last 40 tested with IAP, looking first at the time of presentation of each of the eight postinjection memory items with respect to return of the EEG to baseline ${ }^{14}$. In IAP, the number of items presented during EEG slow waves varied according to hemispheric dominance and whether injection was ipsilateral or contralateral to seizure focus. The worst situation was during injections ipsilateral to a dominant temporal-lobe focus, in which on average only two of the eight items were shown before EEG had returned to baseline, and it was only when injection was ipsilateral to a nondominant temporal-lobe focus that all eight items were shown during the full drug effect. Injections contralateral to the seizure focus fared better, but neither for dominant nor for nondominant hemisphere injections did all eight objects get shown during the full drug effect. In contrast, in eSAM all objects were shown during the full drug effect in all of these conditions (see Figure).

Memory test results must be interpreted cautiously when final recognition is good but memory items had been presented while slow waves were diminishing in the EEG (and contralateral hand and arm strength were recovering). This is the problem faced in IAP and that is no longer an issue in eSAM.

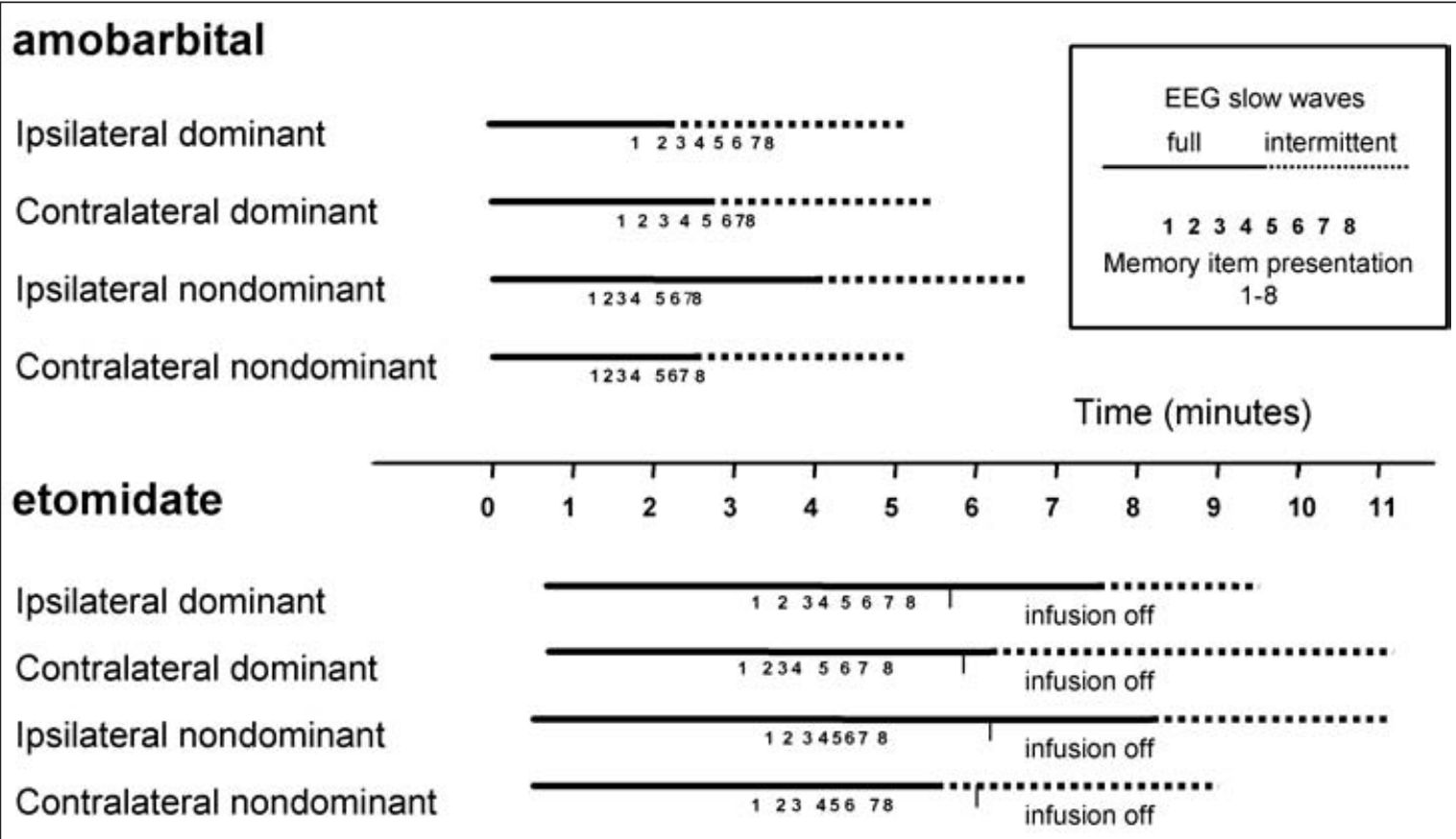

Figure: Time after injection at which each memory item was presented during amobarbital IAP and during eSAM. Condition of injection is categorized according to ipsilateral or contralateral to seizure focus, and whether injection is into the hemisphere dominant or nondominant for speech. The numbers 1-8 on the time lines indicate the mean time at which the memory item was presented. Solid lines indicate continuous, and dotted lines intermittent, slow waves on EEG. All patients had two injections, one ipsilateral and one contralateral to the seizure focus. 


\section{Conclusion}

More than half a century has passed since Juhn Wada introduced the notion of putting half the brain to sleep while the other half is tested. Despite the use of newer technologies notably functional magnetic resonance imaging - to explore language and memory, the methodology of the IAP continues to be a critical part of preoperative evaluation of patients who are candidates for surgical treatment of epilepsy. The difficulties encountered in the past several years for obtaining amobarbital are no longer an obstacle preventing the procedure from being offered, given that a viable alternative (etomidate) is available. The additional advantage of prolonging the drug effect by maintaining infusion until the critical information is obtained has improved the efficacy of the procedure.

\section{ACKNOWLEDGMENT}

This work was supported in part by operating grant MOP 53274 awarded to M. Jones-Gotman and V. Sziklas by the Canadian Institutes of Health Research. The change from amobarbital to etomidate and incorporation of an infusion into the procedure was a joint project of Francois Dubeau, Jean Gotman, Mark Angle, Donatella Tampieri, Andre Olivier, Frederick Andermann and the authors of this paper.

\section{REFERENCES}

1. Wada J, Rasmussen T. Intracarotid injection of sodium Amytal for the lateralization of cerebral speech dominance: experimental and clinical observations. J Neurosurgery. 1960;17:226-82.

2. Wada JA. Youthful season revisited. Brain Cogn. 1997 Feb;33(1): 7-10.

3. Wada JA. Clinical experimental observations of carotid artery injections of sodium amytal. Brain Cogn. 1997 Feb;33(1):11-3.

4. Jones-Gotman M, Smith ML, Wieser HG. Intraarterial amobarbital procedures. In: Engel J, Pedley, T, editors. Epilepsy: A Comprehensive Textbook: 2nd edition. New York: Lippincott Williams \& Wilkins; 2008. p. 1833-41.

5. Milner B, Branch C, Rasmussen T. Study of short term memory after intracarotid injection of sodium Amytal. Trans Am Neurol Assoc. 1962;87:224-6.

6. Bacia T, Bendarzewska-Nawrocka B, Szymanska O, Dowzenko A, Sadowski Z. A comparison of Wada test for cerebral speech dominance by use of amytal or brietal. Neurol Neurochir Pol. 1998;32 Suppl 2:247-61.

7. Buchtel HA, Passaro EA, Selwa LM, Deveikis J, Gomez-Hassan D. Sodium methohexital (brevital) as an anesthetic in the Wada test. Epilepsia. 2002 Sep;43(9):1056-61.

8. Isnard J, Garde P, Fischer C, Duquesnel J, Mauguiere F. [Clinical and electroencephalographic manifestations during the Wada test using intracarotid injection of methohexital (Brietal)]. Rev Neurol. 1994;150(4):266-7.

9. Jones-Gotman M, Sziklas V, Djordjevic J, et al. Etomidate speech and memory test (eSAM): A new drug and improved intracarotid procedure. Neurology. 2005;65(11):1723-9.

10. Reddy RV, Moorthy SS, Dierdorf SF, Deitch RD, Jr, Link L. Excitatory effects and electroencephalographic correlation of etomidate, thiopental, methohexital, and propofol. Anesth Analg. 1993 Nov; 77(5):1008-11.

11. Ebrahim ZY, DeBoer GE, Luders H, Hahn JF, Lesser RP. Effect of etomidate on the electroencephalogram of patients with epilepsy. Anesth Analg. 1986 Oct;65(10):1004-6.

12. Krieger W, Copperman J, Laxer KD. Seizures with etomidate anesthesia. Anesth Analg. 1985 Dec;64(12):1226-7.

13. Jones-Gotman M, Sziklas V. Intracarotid amobarbital procedure: A redesign. Epilepsia. 1999;40.

14. Jones-Gotman M, Sziklas V, Djordjevic J, Dubeau F, Gotman J. Intracarotid anesthetic procedures: eSAM compared to IAP. Epilepsia. 2005;46(8):84. 


\title{
Clinical Intracranial Overview of Seizure Synchrony and Spread
}

\author{
Warren T. Blume
}

\begin{abstract}
Ictal semiology most effectively localizes epileptogenesis, but the clinician must be aware of seizure propagation as an influence upon seizure manifestations. This article first reviews basic mechanisms of seizure spread, including alteration of usual routes in some patients whose seizures begin in childhood. In addition to intra-cortical spread, propagation pathways include the commissures, thalamus and brain stem. The second section reviews common clinical phenomena consequent to a few frequently encountered propagation patterns.
\end{abstract}

\begin{abstract}
RÉSUMÉ: Survol clinique de la synchronie et de la propagation des crises. C'est la séméiologie ictale qui localise le plus efficacement l'épileptogenèse et le clinicien doit savoir que la propagation des crises influence les manifestations des crises. Cet article revoit d'abord les mécanismes de base de la propagation des crises, dont les modification des voies habituelles chez certains patients dont les crises commencent dans l'enfance. En plus de la propagation intra-corticale, les voies de propagation incluent les commissures, le thalamus et le tronc cérébral. La deuxième partie revoit des phénomènes cliniques courants résultant de quelques modes de propagation fréquents.
\end{abstract}

Can. J. Neurol. Sci. 2009; 36: Suppl. 2 - S55-S57

Although the landmark work of Penfield and Jasper ${ }^{1}$ accurately charted the relationships between seizure semiology and site(s) of epileptic discharge, such semiology in some patients may signify the site of seizure propagation rather than origin $^{2}$. From experimental work, Jasper ${ }^{3}$ concluded that " in many instances the area of secondary projection receives sufficient excitatory drive or inhibitory effects are suppressed so that it becomes capable of sustained epileptic discharge". Therefore the clinician should be aware of potential pathways of ictal spread to refine an interpretation of clinical phenomena. Both normal cerebral connectivity and neuronal pathways developed in the process of epileptogenesis likely participate in seizure spread. This article describes some of these possible routes as disclosed by basic and clinical research, i.e. intracortical, thalamic and commissural.

\section{Intracortical}

A human scalp and subdural EEG study of frontal lobe seizures found that seizures initially propagated to contiguous structures more commonly than to the contralateral hemisphere ${ }^{4}$. This reflects either intra-cortical or thalamic spread. This and the subsequent section discuss data concerning each route.

In addition to horizontal inhibitory fibres within each of several cortical layers 5 , excitatory collaterals of pyramidal cells and spiny stellate cells also interconnect cortical columns ${ }^{6}$.

Epileptiform discharges can propagate in a variety of horizontal pathways if cortical inhibition is strongly impaired ${ }^{7}$. Even when cortex is only slightly inhibited, neuronal activity changes from a contained local process to one that propagates over long distances ${ }^{8}$. However, only moderate inhibition revealed that participation of axonal pathways in layer 5 and 6 were critical for seizure spread ${ }^{7,9}$ involving both AMPA and NMDA receptors. AMPA-mediated discharges propagate five times faster than do those involving NMDA receptors ${ }^{8}$, but overall propagation velocity may not be uniform - depending upon the threshold of synchronous activation of neuronal aggregates within each region ${ }^{10}$. Such essential involvement of deep layers indicates that of intrinsically bursting neurons which have the widest horizontal arbors of cortical cells ${ }^{11}$.

Although intra-cortical propagation appears to initiate in deep layers, such is followed by higher-amplitude activity in upper cortical layers ${ }^{9}$. Yang and Benardo ${ }^{12}$, using 4-aminopyridine (4-AP) to study cortical laminar synchronous activity, found resulting discharges to be driven by glutamergic transmission in middle and deep layers, but by GABAergic transmission in superficial layers. Do these studies combine to suggest that intra-cortical seizure propagation involves first excitatory then inhibitory horizontal transmission in a complex, multilayered interaction? 
Studies employing gap junction (GJ) blockers and openers indicate that CJs are involved in propagation of cortical and hippocampal seizure activity ${ }^{13-15}$.

Although seizure propagation often follows normal cortical pathways, aberrant routes remain available if the disorder begins while the nervous system is immature as remodeling during ontogenesis is use-dependent. Thus, seizure activity may allow persistence of connections that would normally have undergone "pruning", producing the "hyperconnected cortex"16.

\section{Thalamic}

Several studies of propagation from chronic experimental cortical epileptic foci found substantial spread to the thalamus and other subcortical regions. Spread to a homotopic cortical region never occurred without thalamic involvement ${ }^{17}$. Morillo et $\mathrm{al}^{18}$ also demonstrated prominent thalamic epileptiform activity from a sensorimotor chronic focus that preceded and enhanced that of the homotopic cortex. Substantial propagation of epileptic discharge to thalamus may underlie thalamic neuron loss in temporal lobe epilepsy (TLE) patients as disclosed by magnetic resonance spectroscopy ${ }^{19}$. Moreover, a matrix of calbindin-immunoreactive neurons extends throughout the thalamus and projects widely over the superficial areas of the cortex ${ }^{20}$. Corticothalamic afferents to this matrix would thus be projected back to adjacent cortical areas effecting cortical-tocortical spread.

Maturation influences direction of principal spread: Caveness et $\mathrm{al}^{21}$ demonstrated a shift from thalamic (newborn) to contiguous cortical (adolescent) as the Macaca mulatta matures. Lack of pruning of this immature epileptic pathway (above) would increase ictal spread options among those with early-onset epilepsy.

\section{Commissural Pathways}

As the corpus callosum (CC) interconnects most cortical areas except the occipital striate area and primary sensory and motor areas of distal extremities, it plays a prominent role in seizure propagation ${ }^{22}$. In humans an average inter-hemispheric propagation time of 10 milliseconds (ms) for spike-waves suggests a CC route ${ }^{23}$. However, the CC also mediates substantial inhibition ${ }^{24,25}$ and homotopic excitatory- inhibitory postsynaptic potential (EPSP-IPSP) sequences to stimuli have been described ${ }^{26}$.

\section{Brain Stem}

Video analyses of human secondarily generalized seizures suggest propagation to the brain stem to mediate the evolving extensor tonic and symmetrical semiology as a seizure progresses (Baz and Blume, unpublished). These features may reflect augmenting reticulospinal tract engagement as Burnham ${ }^{27}$ found with reticular formation stimulation with increasing amperage. Brain stem spread may occur via corticoreticular fibres originating from motor and possibly occipital cortices ${ }^{28}$.

\section{SOME CLINICAL PHENOMENA REFLECTING SEIZURE PROPAGATION}

\section{Temporal: Intra- and Inter-}

Most temporal lobe seizures (TLS) begin in the hippocampus
(HPC $)^{29,30}$, but clinical manifestations require propagation to other structures. As the subiculum receives the inital and principal HPC output and coveys impulses to the amygdala (AM) directly or via the entorhinal cortex , its involvement may be requisite for propagation of most HPC seizures ${ }^{31,32}$. However, this pathway does not always operate: only a minority of HPCoriginating seizures propagate, less often than do AM or parahippocampal gyrus (PHG) ones ${ }^{30}$. AM electrical stimulation may elicit various symptoms of TLS, but HPC stimulation does not $^{33,34}$. Abundant AM efferents to hypothalamus, thalamus and brainstem may effect such symptoms.

While human HPC electrical stimulation ${ }^{35}$ indicate potential inter-HPC propagation times of 90-180 ms, inter-HPC ictal propagation times have been reported to vary from 0.5 to $>100$ $\sec ^{36-38}$ suggesting several alternate propagation routes and delays. Most seizures spreading beyond the mesial temporal region go initially to the ipsilateral temporal neocortex, but some propagate first to the contralateral HPC (38), possibly via the dorsal HPC commissure ${ }^{39}$. Seizures could spread to the contralateral TL from the temporal neocortex via the anterior commissure, dorsal hippocampal commissure or the splenium depending upon neocortical ictal distribution ${ }^{39}$. However studies with bilateral frontal and temporal implanted electrodes found that ipsilateral then (via corpus callosum) contralateral frontal spread usually precedes contralateral temporal ictal involvement ${ }^{40,41}$. Ictal amnesia and automatisms are among semiologies that usually reflect bilateral spread ${ }^{34}$.

\section{Occipital-temporal}

Occipital seizures may propagate to the mesial temporal region via the "ventral stream", a multisynaptic pathway that terminates primarily in the amygdala but also in the parahippocampal area ${ }^{42-44}$. Perhaps greater "synaptic efficency", afforded by the high frequency action potentials of epileptic bursts $^{45}$ allows passage through the many synapses. Seizures may also spread to the premotor cortex via the "dorsal stream", i.e. from the occipital cortex to the parietal-occipital area, thence to the medial dorsal parietal area that projects directly to the premotor area ${ }^{46}$. These ventral and dorsal projection streams underlie the limbic dyscognitive and asymmetrical motor seizures encountered in studies of occipital seizure patients ${ }^{47,48}$.

\section{Orbital frontal}

Munari and Bancaud ${ }^{49}$ described ictal fear, epigastric and olfactory sensations, and oro-alimentary automatisms consequent to seizure spread from the orbital frontal cortex to the amygdala and insula. Suspect this situation in any patient with: 1) intractable limbic-like seizures and no anterior-mesial temporal EEG spikes, 2) no temporal MRI pathology, and 3) frontal lobe semiology in some seizures.

\section{REFERENCES}

1. Penfield W, Jasper H. Epilepsy and the functional anatomy of the human brain. Boston: Little Brown; 1954.

2. So EL. Value and limitations of seizure semiology in localizing seizure onset. J Clin Neurophysiol. 2006; 23(4):353-7.

3. Jasper HH. Mechanisms of propagation:extracellular studies. In: Jasper HH, Ward AA, Pope A, editors. Basic mechanismsms of the epilepsies. Boston: Little Brown; 1969. p.421-8.

4. Blume WT, Ociepa D, Kander V. Frontal lobe seizure propagation: scalp and subdural EEG studies. Epilepsia. 2001;42(4):491-503. 
5. Szentagothai J. Architecture of the cerebral cortex. In: Jasper HH, Ward AA, Pope A, editors. Basic mechanisms of the epilepsies. Boston: Little Brown; 1969. p.13-28.

6. Brodal P. The cerebral cortex. In: Brodal P. The central nervous system. 3rd edition. Oxford: Oxford; 2004. p.435-64.

7. Telfeian AE, Connors BW. Layer-specific pathways for the horizontal propagation of epileptiform discharges in neocortex. Epilepsia. 1998; 39:700-8.

8. Connors BW, Telfeian AE. Dynamic properties of cells, synapses, circuits, and seizures in neocortex. In: Williamson PD, Siegel DW, Thadani VM, Gazzaniga MS, editors. Philadelphia: Lippincott Williams and Wilkins; 2000. p.141-52.

9. Telfeian AE, Connors BW. Epileptiform propagation patterns mediated by NMDA and nonNMDA receptors in neocortex. Epilepsia. 1999; 40:1580-6.

10. Wadman WJ, Gutnick MJ. Non-uniform propagation of epileptiform discharge in brain slices of rat neocortex. Neuroscience. 1993; 52:255-62.

11. Chagnac-Amitai Y, Luhmann HJ, Prince DA. Burst-generating and regular spiking layer 5 pyramidal neurons of rat neocortex have different morphological features. J Comp Neurol. 1990; 296(4): 598-613.

12. Yang L, Benardo LS. Laminar properties of 4-aminopyridineinduced synchronous network activities in rat neocortex. Neuroscience. 2002; 111(2):303-13

13. Gajda Z, Gyengesi E, Hermesz E, Ali KS, Szente M. Involvement of gap junctions in the manifestation and control of the duration of seizures in rats in vivo. Epilepsia. 2003;44(12):1596-1600.

14. Nilsen KE, Kelso AR, Cock HR. Antiepileptic effect of gapjunction blockers in a rat model of refractory focal cortical epilepsy. Epilepsia. 2006; 47(7):1169-75.

15. Medina-Ceja L, Cordero-Romero A, Morales-Villagran A. Antiepileptic effect of carbenoxolone on seizures induced by 4aminopyridine: A study in the rat hippocampus and entorhinal cortex. Brain Res. 2008; 1187:74-81.

16. Innocenti GM, Berbel P. Analysis of an experimental cortical network: 1) architectonics of visual areas 17 and 18 after neonatal injections of ibotenic acid: similarities with human microgyria. J Neural Transplant Plast. 1991; 2:1-28.

17. Wilder BJ, Schmidt RP. Propagation of epileptic discharge from chronic neocortical foci in monkey. Epilepsia. 1965; 6:297-309.

18. Morillo LE, Ebner TJ, Bloedel JR. The early involvement of subcortical structures during development of a cortical seizure focus. Epilepsia. 1982; 23:571-85.

19. Hetherington HP, Kuzniecky RI, Vives K, Devinsky O, Pacia S, Luciano D, et al. A subcortical network of dysfunction in TLE measured by magnetic resonance spectroscopy. Neurology. 2007; 69(24):2256-65

20. Jones EG. The thalamic matrix and thalamocortical synchrony. Trends Neurosci. 2001; 24(10):595-601.

21. Caveness WF, Echlin FA, Kemper TL, Kato M. The propagation of focal paroxysmal activity in the Macaca mulatta at birth and at 24 months. Brain. 1973; 96:757- 64

22. Ottino CA, Meglio M, Rossi GF, Tercero E. An experimential study of the structure mediating bilateral synchrony of epileptic discharges of cortical origin. Epilepsia.1971;12:299-311.

23. Lemieux JF, Blume WT. Topographical evolution of spike-wave complexes. Brain Res. 1986; 373(1-2): 275-87.

24. Crowell RM, Ajmone Marsan C. Topographical distribution and patterns of unit activity during electrically induced afterdischarge. Electroenceph Clin Neurophysiol. 1972; Suppl 31: 59-73.

25. Blume WT. Corpus callosum section for seizure contral: rationale and review of experimental and clinical data. Cleve Clin Q. 1984; 51:319-32.

26 Schwartzkroin PA, Futamachi KJ, Noebels JL, Prince DA. Transcallosal effects of a cortical epileptiform focus. Brain Res. 1975; 99:59-68.

27. Burnham WM. Electrical stimulation studies: generalized convulsions triggered from the brain-stem. In: Fromm GH, Faingold CL, Browning RA, Burnham WM, editors. Epilepsy and the reticular formation. New York: Alan R. Liss; 1987: p. 25-38.

28. Brodal P ibidem. Reticular formation. 2004. p. 333-45.
29. So NK. Depth electrode studies in mesial temporal epilepsy. In: Luders HO, editor. Epilepsy surgery. New York: Raven; 1992.p. 371-84.

30. Wennberg R, Arruda F, Quesney LF, Olivier A. Prominence of extrahippocampal structures in the generation of mesial temporal seizures: evidence from human depth electrode recordings. Epilepsia. 2002; 43(7): 716-26.

31. Stafstrom CE. The role of the subiculum in epilepsy and epileptogenesis. Epilepsy Curr. 2005; 5(4): 121-9.

32. Gloor P. Subcortical contacts of the hippocampal system. In: Gloor P. The temporal lobe and limbic system. New York: Oxford; 1997. p. 475

33. Feindel W, Penfield W. Localization of discharge in temporal lobe automatism. Arch Neurol Psychiat. 1954; 72: 605-30.

34. Gloor P. Role of amygdala in temporal lobe epilepsy. In: Gloor P. The temporal lobe and limbic system. New York: Oxford; 1997. p. 691-707.

35. Adam C, Hasboun D, Clemenceau S, Dupont S, Baulac M, Hazemann P. Fast contralateral propagation of afterdischarges induced by stimulation of medial temporal lobe. J Clin Neurophysiol. 2004; 21(6):399-403

36. Lieb JP, Engel J Jr, Babb TL. Interhemispheric propagation time of human hippocampal seizures I. Relationship to surgical outcome. Epilepsia. 1986; 27(3):286-93

37. Quesney LF. Clinical and EEG features of complex partial seizures of temporal lobe origin. Epilepsia 1986; 27 Suppl 2:S27-45.

38. Spencer SS, Williamson PD, Spencer DD, Mattson RH. Human hippocampal seizure spread studied by depth and subdural recording: the hippocampal commissure. Epilepsia. 1987; 28(5):479-89.

39. Gloor P The temporal isocortex. In: Gloor P. The temporal lobe and limbic system. NewYork: Oxford; 1997. p. 234.

40. Lieb JP, Dasheiff RM, Engel J Jr. Role of the frontal lobes in the propagation of mesial temporal lobe seizures. Epilepsia. 1991;32(6): 822-37.

41. Adam C, Saint-Hilaire J-M, Richer F. Temporal and spatial characteristics of intracerebral seizure propagation: predictive value in surgery for temporal lobe epilepsy. Epilepsia. 1994; 35(5):1065-72.

42. Jones EG, Powell TP. An anatomical study of converging sensory pathways within the cerebral cortex of the monkey. Brain 1970; 93:793-820.

43. Turner BH, Mishkin M, Knapp M. Organization of the amygdalopetal projections from modality-specific cortical association areas in the monkey. J Comp Neurol. 1980; 191: $515-43$

44. Gloor P. The hippocampal system. In: Gloor P, editor. The temporal lobe and limbic system. New York: Oxford; 1997. p. 356.

45. Lisman JE. Bursts as a unit of neural information: making unreliable synapses reliable. Trends Neurosci. 1997;20(1):38-43.

46. Wise SP, Boussaoud D, Johnson PB, Caminiti R. Premotor and parietal cortex: corticocortical connectivity and combinatorial computations. In: Cowan WM, Shooter EM, Stevens CF, Thompson RF, editors. Ann Rev Neurosci. 1997; 20:25-42.

47. Williamson PD, Thadani VM, Darcy TM, Spencer DD, Spencer SS, Mattson RH. Occipital lobe epilepsy: clinical characteristics, seizure spread patterns, and results of surgery. Ann Neurol. 1992; 31:3-13

48. Blume WT, Wiebe S, Tapsell LM. Occipital epilepsy: lateral versus mesial. Brain. 2005;128:1209-25.

49. Munari C, Bancaud J. Electroclinical symptomatology of partial seizures of orbital frontal origin. In: Chauvel P, Delgado-Escueta $\mathrm{AV}$, Halgren E, Bancaud J, editors. Advances in neurology: frontal lobe seizures and epilepsies. 1992; 57:257-65. 


\title{
Insular Cortex Epilepsy: An Overview
}

\author{
Dang Khoa Nguyen, Dong Bach Nguyen, Ramez Malak, Alain Bouthillier
}

\begin{abstract}
In this review the authors discuss insular cortex epilepsy, an under-recognized localization-related syndrome that may explain some temporal (but also frontal and parietal lobe) epilepsy surgery failures. The insula may generate a variety of symptoms (including visceral, motor and somatosensory) that mimic temporal, frontal or parietal lobe onset seizures. Intracerebral electrodes directly implanted in the insula are currently the only way to confirm insular seizures. Consideration should be given to exploration of the insular cortex in MRI negative patients with seizure semiology consistent with insular onset seizures. Electroencephalographers should have a low threshold to sample this region, especially in the absence of a structural lesion. Microneurosurgical technical advances allow resective surgery of the insula with relatively low morbidity.
\end{abstract}

\begin{abstract}
RÉSUMÉ: Épilepsie insulaire : exposé sommaire. Dans cette revue, les auteurs discutent de l'épilepsie insulaire, un syndrome relié à sa localisation au cortex insulaire, qui est sous-identifié et qui peut expliquer certains échecs de la chirurgie pour épilepsie du lobe temporal (mais également du lobe frontal ou du lobe pariétal). L'insula peut générer une variété de symptômes (dont des symptômes viscéraux, moteurs et somesthésiques) qui imitent des crises prenant naissance dans le lobe temporal, le lobe frontal ou le lobe pariétal. Des électrodes implantées directement dans l'insula sont actuellement la seule façon de confirmer les crises insulaires. On doit envisager l'exploration du cortex insulaire chez les patients dont les crises sont compatibles avec une origine insulaire et dont l'IRM est négative. Les électroencéphalographistes devraient penser à examiner cette région, surtout en l'absence de lésions structurales. Les progrès techniques en microchirurgie neurologique permettent une résection chirurgicale de l'insula avec une morbidité relativement faible.
\end{abstract}

Can. J. Neurol. Sci. 2009; 36: Suppl. 2 - S58-S62

The Island of Reil, or the insular cortex, is named after the German physician and anatomist Dr. Johann Christian Reil who authored an early description of the insular lobe $e^{1,2}$. The insula is a highly developed structure, totally encased within the brain at the depths of the Sylvian fissure and covered by the frontal, parietal and temporal opercula. The insula has wide connections with the neocortex, basal ganglia, thalamus, limbic structures and olfactory cortex. These numerous connections subserve the complex functional spectrum of the insular lobe that include: (a) somatosensory functions; (b) auditory functions; (c) language functions; (d) a primary visceral/autonomic sensory and motor area, (e) and a supplementary motor area ${ }^{3,4}$.

\section{The insula as a cause of epilepsy surgery failure?}

Guillaume and Mazars ${ }^{5-7}$ and subsequently Penfield and Jasper $^{8,9}$ recognized that seizures emanating from the insula may have semiology similar to temporal lobe seizures. These investigators speculated that persistent seizures following a temporal lobe resection might be explained by the failure to remove a focus within the insula. These observations prompted resections of the temporal lobe and portions of the insula in patients with robust interictal insular spikes ${ }^{10}$ noted during intraoperative electrocorticography. However, this surgical strategy declined following the report by Silfvenius et $\mathrm{al}^{10}$ that showed that insular resection, when added to temporal lobectomy, failed to increase epileptic control and significantly increased surgical morbidity.

Recent studies have reignited interest in insular lobe epilepsy ${ }^{11-17}$. Isnard et $\mathrm{al}^{11}$ used chronic depth stereotactic EEG electrodes to examine the role of the insular cortex in patients with possible temporal lobe epilepsy (TLE). Among 21 patients with drug-refractory "TLE", two patients were discovered to have seizures originating in the insula. Neither of these patients achieved seizure control following a temporal resection that spared the insular cortex (in contrast to excellent seizure outcomes in 15 of 17 who did not have insular onset seizures). Aghakhani et $\mathrm{al}^{14}$ reported six patients with electroclinical findings suggestive of TLE but associated with somatosensory auras suggestive of extratemporal ictal onset. None of these patients was improved by temporal lobe surgery despite intracranial EEG evidence that the temporal lobe (TL) participated in generating seizures. The inferior parietal region

From the Service de Neurologie (DKN, DBN), Service de Neurochirurgie (RM, AB), Hôpital Notre-Dame du CHUM, Université de Montréal, Montréal, QC, Canada. Received July 29, 2008. Final Revisions Submitted August 5, 2008. Correspondence to: Dang K. Nguyen, Service de Neurologie, Hôpital Notre-Dame du CHUM, 1560 rue Sherbrooke Est, Montréal, Québec, H2L 4M1, Canada. 
was also often involved at ictal onset but its removal did not result in better seizure control. The authors acknowledged that the insula might have been involved but could not confirm it due to the lack of intracerebral electrodes placed directly within the insula. Ryvlin et $\mathrm{al}^{15}$ reported three patients with drug-resistant non-lesional nocturnal frontal lobe (FL) epilepsy whose intracerebral EEG ictal onset primarily involved the insula rather than the mesial or orbitofrontal cortex. Authors speculated about the role of the insula in other patients with non-lesional drugresistant nocturnal hypermotor seizures at their institutions who failed to respond to frontal lobe surgery and in whom intracerebral EEG investigation did not explore the insular cortex. These case series support the original concept that lack of recognition of insular epilepsy could explain some temporal, but also parietal or frontal epilepsy surgery failures ${ }^{14-17}$.

\section{Insular cortex epilepsy: Not so rare?}

The Lyon group found five cases of insular cortex epilepsy among 50 consecutive patients investigated by SEEG recordings between January 1996 and December 200111,12. The study population consisted of patients with "atypical" TLE as suggested by the presence of ictal symptoms (and/or scalp EEG) compatible with early spread of seizures to the suprasylvian opercular cortex (lip and face paresthesias, laryngeal constriction, tonic or clonic movements of the face, dysarthria or motor aphasia, gustatory illusions, hypersalivation, postictal facial paresis) or to the infrasylvian opercular cortex (such as auditory hallucinations or early sensory aphasia).
Increasingly aware of the various faces of insular cortex epilepsy, our group, since 2004, has broadened our indications for insular cortex sampling with intracerebral electrodes. In general, the decision to sample the insula with intracerebral electrodes is made in the context of (a) non-lesional parietal lobe (PL) like epilepsy; (b) non-lesional frontal lobe-like epilepsy; (c) non-lesional temporal lobe-like epilepsy; (d) and atypical temporal lobe like epilepsy as defined by the Lyon group. Coincident with a lower threshold to sample the insula, we found amongst a series of 18 consecutive patients with intracranial electrodes, four patients with insular seizures (See Table 1$)^{18}$. Thus, insular cortex epilepsy may not be so rare in refractory epilepsy surgical candidates.

\section{Cortical stimulation}

Cortical stimulation may be used to better define the characteristics of insular cortex seizures. From 1945 to 1953, Penfield stimulated 82 separate exposed insular points from 36 awake patients following temporal lobectomies: $40 \%$ of the stimulations produced visceral responses while another $40 \%$ resulted in various sensory responses (notably in the mouth and the upper extremities ${ }^{8}$. However, as stimulation was performed intraoperatively, there was no monitoring of possible afterdischarges that would enter doubt into the presumption that the evoked response is the effect from localized stimulation rather than stimulus propagation to a distant structure. The most comprehensive data on insular stimulation comes from the Lyon group $^{12,19,20}$ who have reported the clinical responses obtained by

Table: Demographics, presurgical findings, intracranial EEG results, and surgical outcome of four patients with insular seizures

\begin{tabular}{|c|c|c|c|c|c|c|c|c|c|c|c|c|}
\hline Age & Sex & Aetiology & Semiology & MRI & FDG PET & ictal SPECT & $\begin{array}{l}\text { Intracerebral } \\
\text { electrodes }\end{array}$ & $\begin{array}{l}\text { Seizure } \\
\text { focus }\end{array}$ & Cortectomy & $\begin{array}{l}\text { Outcome } \\
\text { (Engel) }\end{array}$ & $\mathrm{F}-\mathrm{U}(\mathrm{mo})$ & Pathology \\
\hline 23 & $F$ & Meningitis & $\begin{array}{l}\text { left hand and } \\
\text { throat } \\
\text { paresthesias, } \\
\text { epigastric } \\
\text { sensation, feeling } \\
\text { of strangulation, } \\
\text { confusion }\end{array}$ & $\begin{array}{l}\text { R } \\
\text { hemispheric } \\
\text { atrophy, R } \\
\text { hippocampal } \\
\text { sclerosis } \\
\end{array}$ & Not done & $\begin{array}{l}\text { R temporal, } \\
\text { right insula, } \\
\text { left frontal }\end{array}$ & $\begin{array}{l}1 \text { grid, } 2 \text { strips, } \\
3 \text { depths }\end{array}$ & $\begin{array}{l}\text { R temporo- } \\
\text { insular }\end{array}$ & $\begin{array}{l}\mathrm{R} \text { temporo- } \\
\text { insular }\end{array}$ & la & 38 & gliosis (HS) \\
\hline 36 & $M$ & Unknown & $\begin{array}{l}\text { right hand and } \\
\text { limb paresthesias } \\
\text { followed by arm } \\
\text { elevation }\end{array}$ & Normal & Normal & $\begin{array}{l}\text { L frontal, } \\
\text { parietal and } \\
\text { cingulate } \\
\text { gyrus }\end{array}$ & $\begin{array}{l}1 \text { grid, } 1 \text { depth, } \\
5 \text { strips }\end{array}$ & $\mathrm{L}$ insular & $\begin{array}{l}\text { L posterior } \\
\text { insular }\end{array}$ & $\begin{array}{l}\text { III (la post- } \\
\text { gamma } \\
\text { knife) }\end{array}$ & 35 & n.a. \\
\hline 37 & $F$ & Unknown & $\begin{array}{l}\text { sudden arousal, } \\
\text { asymetric tonic } \\
\text { posturing, } \\
\text { complex motor } \\
\text { automatisms; } \\
\text { diurnal lip and } \\
\text { right hand } \\
\text { paresthesias }\end{array}$ & $\begin{array}{l}\text { Non-specific } \\
\text { L posterior } \\
\text { insular } \\
\text { millimetric T2 } \\
\text { signal }\end{array}$ & $\begin{array}{l}\text { Discrete L insular } \\
\text { hypometabolism }\end{array}$ & $\begin{array}{l}\text { Multiple non- } \\
\text { localizing }\end{array}$ & $\begin{array}{l}1 \text { depth, } 11 \\
\text { strips }\end{array}$ & L insular & Pending & n.a. & n.a. & n.a. \\
\hline 26 & & Unknown & $\begin{array}{l}\text { Sensation that the } \\
\text { thorax, lower jaw } \\
\text { and throat were } \\
\text { swollen, fear, } \\
\text { anxiety, déjà vu, } \\
\text { confusion, } \\
\text { automatisms }\end{array}$ & Normal & $\begin{array}{l}\text { R temporal } \\
\text { hypometabolism }\end{array}$ & $\begin{array}{l}\mathrm{R} \text { temporal, } \\
\text { parietal }\end{array}$ & $\begin{array}{l}5 \text { depths, } 4 \\
\text { strips }\end{array}$ & $\begin{array}{l}\text { R temporo- } \\
\text { insular }\end{array}$ & $\begin{array}{l}\text { Right } \\
\text { temporo- } \\
\text { insular }\end{array}$ & la & 17 & $\begin{array}{l}\text { gliosis (CA4); } \\
\text { ectopic giant } \\
\text { neurons }\end{array}$ \\
\hline
\end{tabular}

: $\mathrm{L}=$ left; $\mathrm{R}=$ right; F-U = follow-up; n.a = non-available or non-applicable. 
stimulating up to 144 insular sites in 50 patients with atypical temporal-lobe epilepsy studied by stereotactic EEG (SEEG). Only responses that were evoked in the absence of any afterdischarge were included in their studies. These authors found (in decreasing order of frequency) somatosensory, viscerosensitive and auditory responses as well as dysarthria and miscellaneous responses. Additional findings included the existence of a topographic specificity inside the insular cortex as somatosensory responses were mainly evoked in the posterior three fourths of the explored insula while viscerosensitive (and visceromotor) responses were mainly evoked from the anterior three fourths.

At our institution, nine epileptic patients underwent cortical stimulation of the insula during their intracranial study ${ }^{21}$. The most frequently evoked responses in our series were congruent with data found in the literature on insular stimulation in that all previously reported responses were reproduced: somatosensory $(62 \%)$, visceral $(12 \%)$, motor $(12 \%)$, auditory (9\%), vestibular (3\%) and language (3\%) disturbances. Although our findings are limited by the low number of insular sites stimulated and because some responses were associated with focal afterdischarges (albeit brief and localized to the stimulated contact), the fact that most of our findings are congruent with those reported by the Lyon group is mutually strengthening. These human cortical studies clearly demonstrate the potential of the insula to generate a variety of symptoms usually suggestive of temporal, parietal or frontal-lobe like epilepsies.

\section{How can we identify insular cortex epilepsy?}

The evidence described above suggests that insular cortex epilepsy is a great mimic, disguised at times as TL, PL or FL epilepsy. In our series of four patients with insular seizures, two had TL-like epilepsy, one had FL-like epilepsy, and one had PLlike epilepsy (Table $)^{18}$. However, analysis of our data and the literature indicate that it is possible to suspect insular cortex epilepsy cases by careful symptom exploration. Insular seizures should be suspected in the presence of the combination of ictal symptoms early in the attack of visceral (nausea, vomiting, changes in gastric motility, salivation, gustatory illusions), motor (tonic posturing, early tonic-clonic movements, complex hypermotor behaviour) and especially somatosensory (warmth, numbness, tightness, vibration, pain, laryngeal constriction) symptoms. Language, vestibular and auditory symptoms may also be present concomitantly although less frequently. In our series $^{18}$, one patient with frequent FL epilepsy-like nocturnal hypermotor seizures had the insula sampled simply because she reported contralateral or bilateral hand paresthesias during her rare diurnal seizures. Two individuals were thought to have TL epilepsy but had the insula sampled due to early throat paresthesia in one patient (who had coexisting hippocampal sclerosis), and a sensation of jaw/thoracic swelling in the second patient (without hippocampal atrophy). The fourth patient was initially thought to have non-lesional PL epilepsy due to somatosensory auras but implantation confirmed the insular origin.

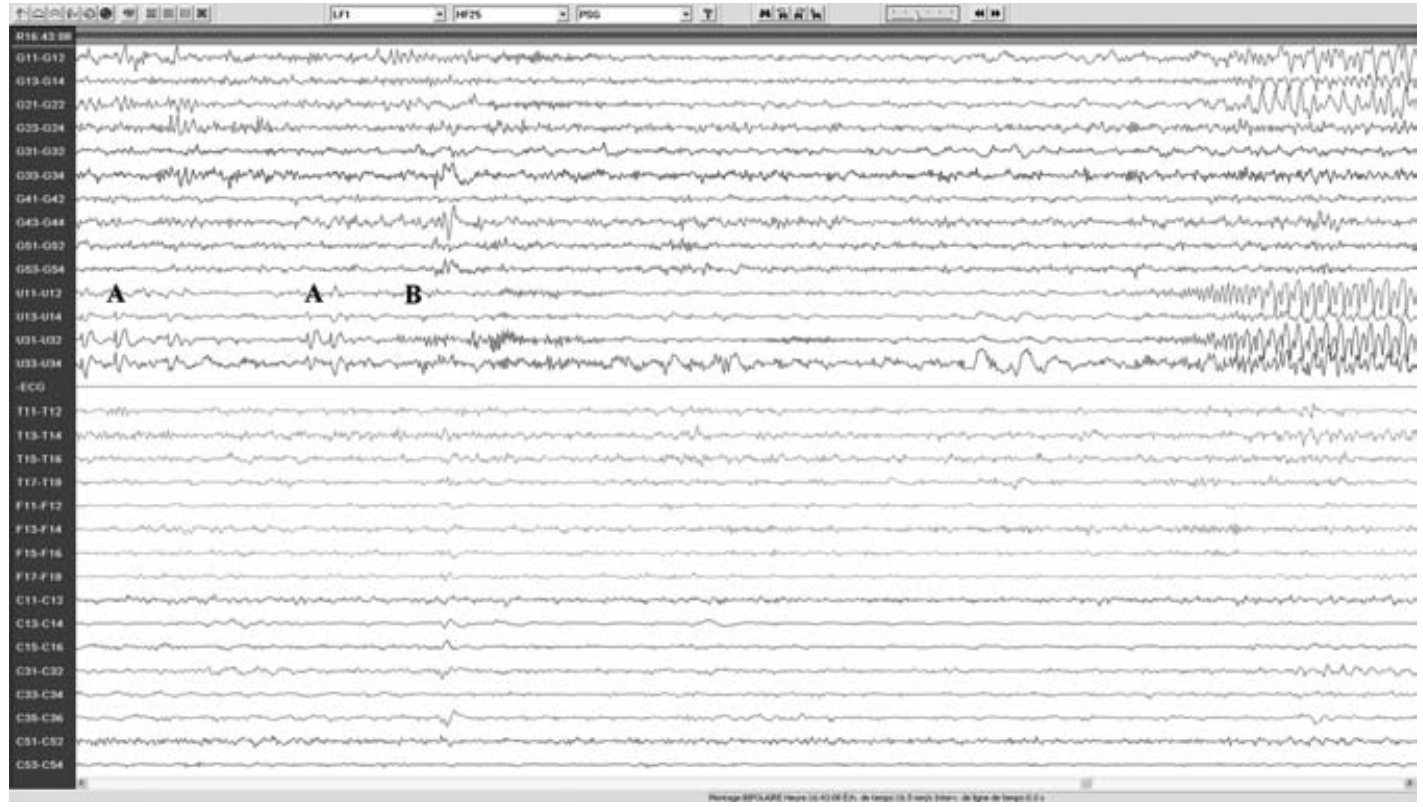

Figure 1: Intracerebral recording of interictal insular spikes $(A)$ and an insular seizure $(B)$ in case 3. A low-voltage fast-activity is noted at seizure onset eventually evolving into rhythmic spiking activity. Abbreviations: $F=$ electrode contacts from subdural strips covering the orbito-frontal, fronto-polar, dorso-lateral frontal regions; $I=$ electrode contacts from subdural strips covering the interhemispheric region ending in the anterior, middle and posterior cingulate gyrus; $U=$ electrode contacts from the insular depth electrodes; $T=$ electrode contacts from the subdural strips covering the temporal lobe; $P=$ electrode contacts from subdural strips covering the parietal region. 


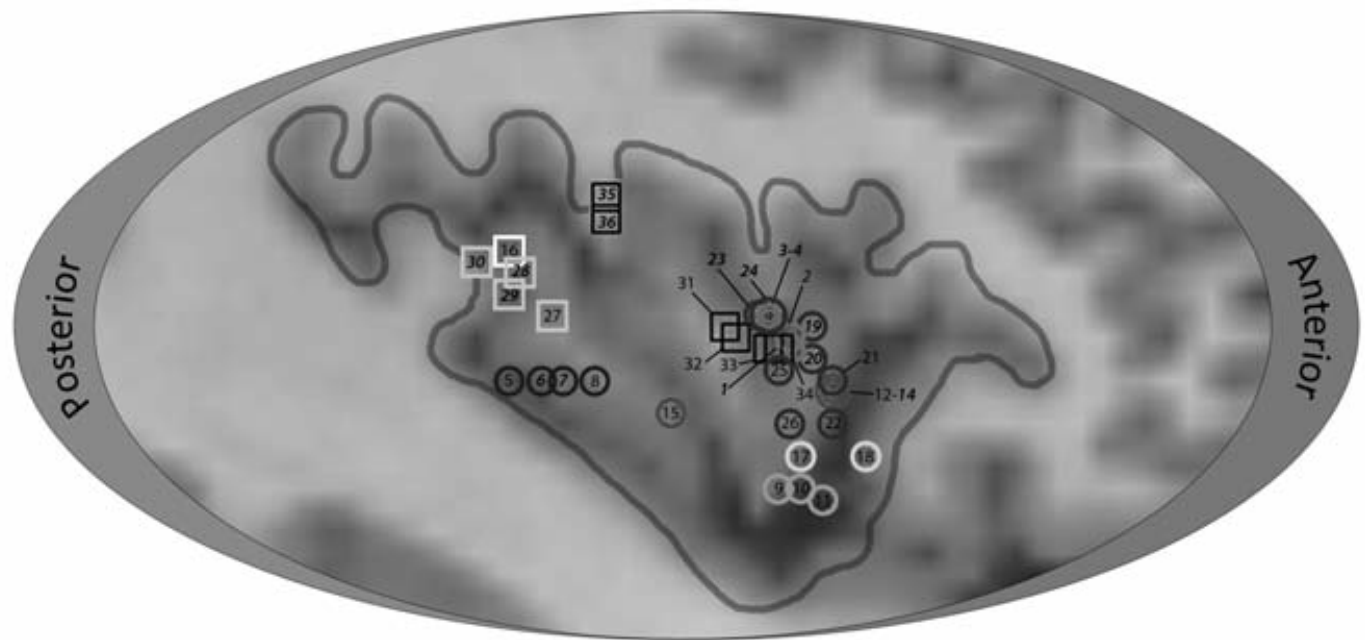

Figure 2: Analysis of individual cortical stimulation data is poorly informative because only three to eight insular sites were stimulated per patient. For our topographic analysis, all evoked responses were pooled on a single sagittal insular image. Each shade of gray represents an individual patient. Right insular contacts are represented by circles, left insular contacts, by squares. Numbers in semi-bold italic indicate evoked responses which were followed by a brief localized afterdischarge. This plotting shows that most of the insular surface was explored. Although viscerosensory evoked sensations were all located in the anterior portion of the insula, somatosensory evoked responses were widely distributed without clear topography.

Non-invasive investigations are less helpful. Video-scalp EEG can lateralize or regionalize the epileptogenic zone but cannot differentiate temporal lobe seizures from insular seizures ${ }^{11,12,18}$. Magnetic resonance imaging should be carefully analyzed for any subtle abnormalities within the island of Reil ${ }^{18,22}$. Ictal single photon emitted computed tomography (SPECT) will frequently show insular activation but its significance will be diluted by other sites of activation due to rapid spread ${ }^{18}$.

Confirmation of insular seizures requires an invasive study in absence of a clear epileptogenic lesion ${ }^{11,12,18}$. The choice of depth stereotactic recordings versus open craniotomy with implantation of intracerebral electrodes will depend on the individual case and the expertise/preference of each centre. For example, the Lyon group employs Talairach's stereotactic grid to implant transopercular electrodes perpendicular to the midsagittal plane ${ }^{11,12}$. Our centre prefers investigations with both depth and subdural electrodes to take advantage of the precision of depth recordings with the spatial coverage afforded by subdural strips and grids $^{18}$. For example, patients with early somatosensory or viscerosensory or hypermotor symptoms, require extensive coverage of the parietal lobe, temporal lobe and several frontal regions. We ensure direct placement of the electrode on the insular surface (to reduce the risk of damaging major insular arteries) by opening the Sylvian fissure. In our series of ten patients, two suffered complications directly related to the implantation of electrodes in the insula: one had contusion of Wernicke's area during dissection with transient dysphasia, one had mild transient distal limb weakness from an insular depth electrode inserted too deeply reaching the internal capsule.

\section{Is insular cortex Epilepsy operable?}

Access to the insula requires the surgeon to dissect the Sylvian fissure, retract highly functional opercular zones, pass through a wall of dense Sylvian vessels, and avoid deeper structures (internal capsule, basal ganglia, lenticulostriate arteries) $)^{5,6,10}$. More than twenty years following the landmark study by Silfvenius ${ }^{10}$, enthusiasm for insular surgery has returned as a consequence of advances in micro-neurosurgical techniques.

We recently conducted a literature review to evaluate the risks and benefits of insular surgery ${ }^{21}$. We found eleven surgical series $^{23-38}(\mathrm{~N}=299$ patients $)$ published since 1988 involving insular resections (with or without operculectomies or frontal/temporal corticectomies) ${ }^{21}$. Most surgeries were primarily performed for tumor or vascular malformation resection but $78 \%$ of patients had concomitant seizures. An Engel Class I outcome was obtained in $81 \%$ of patients. A transient hemiparesis occurred in $17 \%$ and a permanent deficit in $3 \%$. Transient dysphasia was reported in $16 \%$ of the 148 patients who had operations in the dominant hemisphere. Only 2 cases of permanent dysphasia occurred $(1.4 \%)^{21}$. All cases of permanent deficit (paresis or dysphasia) were related to an ischemic infarction in the lenticulostriate artery territory $26,35,37$.

We retrospectively reviewed all patients operated for insular pathologies at our institution over the last ten years ${ }^{21}$. Ten patients were found with seven insular resections performed for refractory epilepsy surgery and three for tumor removal. Four of the resections were performed in the left hemisphere. After a mean follow-up of 54 months (range 14 to 122 months), Engel Ia outcome was achieved in all of the patients, except one. This 
patient had an Engel III outcome after the initial partial insular resection but became seizure-free (Engel Ia) following insular gamma-knife surgery. No permanent paresis occurred but $30 \%$ (3/10) experienced new-onset transient hemiparesis postoperatively. In two additional patients a pre-operative hemiparesis transiently worsened. Among resections in the language dominant hemisphere, one of two tumour patients sustained a transient deterioration of preoperative dysphasia while none of two in the epilepsy group experienced a post operative language deficit. All deficits cleared by a three month follow-up visit.

\section{CONCLUSION}

Our observations from the evaluation of four patients with insular cortex epilepsy and extraoperative cortical stimulation in nine subjects implanted with insular intracerebral electrodes add to the growing evidence that a proportion of surgical candidates with drug-resistant epilepsy have an epileptogenic zone that involves the insula. Under-appreciation of this localizationrelated syndrome may be responsible for some epilepsy surgery failures. Enhanced knowledge of the function and surgical anatomy of the insula allow resection of this area with reasonable expectations for seizure control and acceptable morbidity.

\section{ACKNOWLEDGEMENTS}

This work was supported by a Clinical Scientist Research Bursary from the Centre de Recherche du CHUM awarded to Dr. Nguyen.

\section{REFERENCES}

1. Reil JC. Die sylvische Grube. Arch Physiol. (Halle). 1809;9: 195-208.

2. Reil JC. Untersuchungen uber den Bau des grossen Gehirns im Mensche. Vierte Fortsetzung VIII. Arch Physiol. (Halle). 1809;9: $136-46$

3. Augustine J. Circuitry and functional aspects of the insular lobe in primates including humans. Brain Res Rev. 1996; 22:229-44.

4. Shelley BP, Trimble MR. The insular lobe of Reil -its anatamicofunctional behavioural and neuropsychiatric attributes in humans -a review. World J Biol Psychiatry. 2004; 5:176-200.

5. Guillaume MMJ, Mazars G. Cinq cas de foyers épileptogènes insulaires opérés. Soc Française de Neurol. 1949; 766-9.

6. Guillaume MMJ, Mazars G. Technique de résection de l'insula dans les épilepsies insulaires. Rev Neurol. 1949; 81:900-3.

7. Guillaume MMJ, Mazars G, Mazars Y. Indications chirurgicales dans les épilepsies dites 'temporalis'. Rev Neurol. 1953; 88: 461-501.

8. Penfield W, Faulk ME. The insula: further observations on its function. Brain. 1955; 78:445-70.

9. Penfield W, Jasper HH. Epilepsy and the functional anatomy of the human brain. Boston; Little, Brown. 1954.

10. Silfvenius H, Gloor P, Rasmussen T. Evaluation of insular ablation in surgical treatment of temporal lobe epilepsy. Epilepsia. 1964; 5:307-20.

11. Isnard J, Guenot M, Ostrowsky K, Sindou M, Mauguière F. The role of the insular cortex in temporal lobe epilepsy. Ann Neurol. $2000 ; 48: 614-23$

12. Isnard J, Guenot M, Sindou M, Mauguière F. Clinical manifestations of insular lobe seizures: a stereo-electroencephalographic study. Epilepsia. 2004; 45(9):1079-90.

13. Cascino GD, Karnes WE. Gustatory and second sensory seizures associated with lesions in the insular cortex seen on magnetic resonance imaging. J Epilepsy. 1990; 3:185-7.

14. Aghakhani Y, Rosati A, Dubeau F, Oliver A, Andermann F. Patients with temporoparietal ictal symptoms and inferomesial EEG do not benefit from anterior temporal resection. Epilepsia. 2004; 45(3):230-6.
15. Ryvlin P, Mnotu L, Demarquay G, Hirsch E, Arzimanoglou A, Hoffman D, et al. Nocturnal hypermotor seizures, suggesting frontal lobe epilepsy, can originate in the insula. Epilepsia. 2006; 47(4):755-65

16. Ryvlin P. Avoid falling into the depths of the insular trap. Epileptic Disord. 2006; 8(2) Suppl. 2:37-56.

17. Ryvlin P, Kahane P. The hidden causes of surgery-resistant temporal lobe epilepsy: extratemporal or temporal plus? (editorial review). Curr Opin Neurol. 2005; 18:125-7.

18. Nguyen DK, Nguyen DB, Malak R, Leroux JM, Carmant L, SaintHilaire JM, et al. Revisiting the role of the insula in refractory partial epilepsy. Epilepsia. 2009 Mar;50(3):510-20.

19. Ostrowsky K, Isnard J, Ryvlin P, Guénot M, Fischer C, Mauguière F. Functional mapping of the insular cortex: clinical implication in temporal lobe epilepsy. Epilepsia. 2000; 41(6):681-6.

20. Ostrowsky K, Magnin M, Ryvlin P, Isnard J, Guénot M, Mauguière F. Representation of pain and somatic sensation in the human insula: a study of responses to direct electrical cortical stimulation. Cerebral Cortex. 2002; 12:376-85.

21. Nguyen DK, Malak R, Bouthillier A, Carmant L, Cossette P, Giard $\mathrm{N}$, et al. Microsurgery of epileptic foci for the insular region (submitted to J Neurosurg)

22. Kaido T, Otsuki T, Nakama H, Kaneko Y, Kubota Y. Complex behavioral automatism arising from insular cortex. Epilepsy Behav. 2006; 8:315-9.

23. Yasargil MG. Microneurosurgery. Vol. IIIB. New York: Thieme Medical Publishers. 1988.

24. Yasargil MG, von Ammon K, Cavazos E, Doczi T, Reeves IJD , Roth P. Tumors of the limbic and paralimbic systems. Acta Neurochir. 1992; 118:40-52.

25. Yasargil MG. Microneurosurgery. Vol. IVB. New York: Thieme Medical Publishers. 1996.

26. Bertalanffy H, Gilsbach JM, Eggert HR, Seeger W. Microsurgery of deep-seated cavernous angiomas: Report of 26 cases. Acta Neurochir (Wien). 1991; 108:91-9.

27. Zentner J, Meyer B, Stangl A, Schramm J. Intrinsic tumors of the insula: a prospective surgical study of 30 patients. J Neurosurg. 1996; 85(2):263-71.

28. Vanaclocha V, Saiz-Sapena N, Garcia-Casasola C: Surgical treatment of insular gliomas. Acta Neurochir (Wien). 1997; 139: 1126-35.

29. Heffez DS: Stereotactic transsylvian, transinsular approach for deep-seated lesions. Surg Neurol. 1997; 48:113-24.

30. Meyer FB, Bates LM, Goerss SJ, Friedman JA, Windschitl WL, Duffy JR, et al. Awake craniotomy for aggressive resection of primary gliomas located in eloquent brain. Mayo Clin Proc. 2001; 76(7):677-87.

31. Duffau H, Bauchet L, Lehericy S, Capelle L. Functional compensation of the left dominant insula for language. Neuroreport. 2001; 12(10):2159-63.

32. Duffau H, Capelle L, Lopes M, Bitar A, Sichez JP, van Effenterre R. Medically intractable epilepsy from insular low-grade gliomas: improvement after an extended lesionectomy. Acta Neurochir. 2002; 144(6):563-72.

33. Duffau H, Capelle L. Incontinence after brain glioma surgery: new insights into the cortical control of micturition and continence. $\mathrm{J}$ Neurosurg. 2005; 102(1):148-51.

34. Duffau H, Fontaine D. Successful resection of a left insular cavernous angioma using neuronavigation and intraoperative language mapping. Acta Neurochir. 2005; 147(2):205-8.35 Duffau H, Taillandier L, Gatignol P, Capelle L. The insular lobe and brain plasticity: lessons from tumor surgery. Clin Neurol Neurosurg. 2006; 108:543-8.

36. Tirakotai W, Sure U, Benes L, Krischek B, Bien S, Bertalanffy H. Image-guided transsylvian, transinsular approach for insular cavernous angiomas. Neurosurgery. 2003; 53(6):1299-304.

37. Lang FF, Olansen NE, DeMonte F, Gokaslan ZL, Holland EC, Kalhorn C, et al. Surgical resection of intrinsic insular tumors: complication avoidance. J Neurosurg. 2001; 95(4): 638-50.

38. Lei W, Mao-zhi Z, Ji-zong Z, Guo-lu M, Xiao-di H. Clinical features and minimally invasive surgery of insular lesions: 42 cases. Chin Med J. 2004; 117(7):1104-8. 


\section{The Catastrophic Epilepsies}

Can. J. Neurol. Sci. 2009; 36: Suppl. 2 - S63

The catastrophic epilepsies in children are usually associated with intractable epilepsy and developmental delay or change in cognitive state. They include many disorders and syndromes such as malformations of cortical development, Rasmussen's encephalitis, infections, trauma, metabolic conditions and the epileptic encephalopathies. This term describes a condition in which the epileptiform abnormalities themselves contribute to a progressive disturbance in cerebral function.

In his reflection of the epileptic encephalopathies, Farrell ${ }^{1}$ notes that there has been limited progress in the successful treatment of these disorders and discusses various reasons for this. In reviewing the factors, it is clear that an underlying lack of the pathophysiology in many cases makes it difficult to classify, treat and prognosticate.

Our reliance on clinical outcome measures that may not be the most relevant for the crucial age range for cognitive development also makes these disorders frustrating,

Stockler-Ipsiroglu ${ }^{2}$ on the other hand, emphasizes an important area in which epilepsy is a major feature - the metabolic epilepsies. Her review focuses on the ability to make a definitive diagnosis in order to treat, provide genetic counseling and a prognosis. The epilepsies are discussed based on various criteria such as treatability, age of onset, seizure type and pathogenetic background.
A diagnostic workup is included. By understanding the pathophysiology, specific treatment modalities such as the ketogenic diet for cerebral glucose transporter (GLUT1) deficiency and specific dietary regimen for Guanidinoacetate methyltransferase (GAMT) deficiency are recommended.

Plecko and Stockler ${ }^{3}$ continue further work on a specific group of metabolic epilepsies, the vitamin B6 dependent seizures. Information on this topic has grown exponentially over time and we have four genetically determined vitamin B6 dependent epilepsies.

The seizure semiology, EEG findings and most importantly the specific diagnostic tests and treatment strategies of these neonatal epileptic encephalopathies are well described.

Catastrophic epilepsies are varied in etiology and presentation and this review highlights a few of the areas of progress as well as reminds us that much work is needed.

Sharon Whiting

Ottawa, Ontario

\section{REFERENCES}

1. Farrell K. Reflections on the metabolic encephalopathies. Can J Neurol Sci. 2009;36 Suppl. 2:S64-S66.

2. Stockler-Ipsiroglu S, Plecko B. Metabolic Encephalopathies: a diagnostic challenge. Can J Neurol Sci. 2009;36 Suppl. 2:S67-S72.

3. Plecko B, Stockler S. Vitamin B6 dependent seizures. Can J Neurol Sci. 2009;36 Suppl. 2:S73-S77. 


\title{
Reflections on the Epileptic Encephalopathies
}

\author{
Kevin Farrell
}

\begin{abstract}
Although the epileptic encephalopathies have a profound impact on neurological development, there has been limited progress made in the successful treatment of these disorders. This article suggests that the limited understanding of the pathophysiology of the encephalopathies, the lack of a good animal model of these disorders, the failure to understand the impact of etiology on response to treatment, and the absence of a reliable method for measurement of cognitive change in response to treatment are factors that contribute to the limited progress.
\end{abstract}

RÉSUMÉ: Considérations sur les encéphalopathies épileptiques. Bien que les encéphalopathies épileptiques aient un impact important sur le développement neurologique, il y a peu de progrès dans le traitement efficace de ces pathologies. Cet article suggère que la compréhension limitée de la physiopathologie de ces encéphalopathies, le manque de modèles animaux adéquats, l'insuffisance de la compréhension de l'impact de l'étiologie sur la réponse au traitement et l'absence d'une méthode fiable de mesure des changements cognitifs dans la réponse au traitement sont des facteurs qui contribuent au peu de progrès.

Can. J. Neurol. Sci. 2009; 36: Suppl. 2 - S64-S66

The term "epileptic encephalopathy" describes a condition in which the epileptiform abnormalities themselves contribute to a progressive disturbance in cerebral function ${ }^{1}$. The epileptic encephalopathies include syndromes such as early myoclonic encephalopathy, Ohtahara syndrome, West syndrome, Dravet syndrome, myoclonic astatic epilepsy and Lennox-Gastaut syndrome, which are characterized by particular seizure types, EEG abnormalities and other clinical features. They also include conditions, such as Landau-Kleffner syndrome (LKS) and epilepsy with continuous spike waves during slow wave sleep (CSWS) in which epileptic seizures may or may not occur. The critical feature is that the epilepsy per se is believed to contribute to the progressive disturbance in cerebral function.

These conditions have a profound impact on neurological development, particularly in the areas of cognition and behaviour. The lack of response to treatment that occurs in the majority of affected children results in a delay in neurological development and often the emergence of abnormalities of attention. These have a major impact on the child and family and ultimately compromise the ability of the child to achieve competitive employment and live independently as an adult. The epileptic encephalopathies are not uncommon and in a 20 year cohort of children attending an urban teaching hospital epilepsy, West syndrome occurred in 9\%, Lennox-Gastaut syndrome in $1.5 \%$, and LKS, Ohtahara syndrome, myoclonic astatic epilepsy, and CSWS in $0.2 \% \mathrm{each}^{2}$. Thus, the epileptic encephalopathies not only have a major impact on the child and family but also a considerable social and financial impact on society.
Despite the burden of illness imposed by the epileptic encephalopathies, there has been very limited progress made in the successful treatment of these disorders. The purpose of this article is to discuss some of the factors that may contribute to the lack of success in the management of these disorders.

\section{Lack of Good Animal Models}

Our understanding of the pathophysiology of the epileptic encephalopathies is limited. It has been suggested that a variety of neuronal insults occurring during a critical stage in brain development may result in the development of an epileptic encephalopathy ${ }^{3}$. However, the dearth of good animal models of these disorders has compromised our ability to understand the mechanisms underlying the epileptic encephalopathies.

It has been suggested that excessive corticotrophin-releasing hormone $(\mathrm{CRH})$ expression and activity may play a role in the pathogenesis of infantile spasms and possibly other encephalopathic epilepsies ${ }^{4,5}$. Corticotrophin-releasing hormone

From the Division of Neurology, British Columbia's Childrens Hospital, Vancouver and Department of Pediatrics, University of British Columbia, Vancouver, British Columbia, Canada.

Received September 4, 2008. Final Revisions Submitted September 10, 2008. Correspondence to: Kevin Farrell, Division of Neurology, British Columbia's Childrens Hospital, 4480 Oak Street, Vancouver, British Columbia, V6H 3V4, Canada. 
receptor expression is very active in rodents at a time approximating early infancy in humans ${ }^{3}$ and $\mathrm{CRH}$ has been shown to cause severe seizures and neuronal death in immature animal brains ${ }^{6}$. In addition, cerebrospinal fluid (CSF) corticotrophin (ACTH) levels have been demonstrated to be reduced in infants with infantile spasms ${ }^{3}$ and chronic activation of CRH receptors would be expected to decrease ACTH levels. ACTH has a wide range of actions in the brain and several observations suggest that ACTH acts directly on melanocortin to suppress excessive $\mathrm{CRH}$ production, which in turn reduces epileptogenicity and neuronal damage ${ }^{3}$.

The pathophysiology may also involve abnormal neuronal excitotoxicity and overexpression or excessive activation of glutamate receptors ${ }^{3}$. Several lines of evidence suggest that AMPA receptors may be involved and also that excessive NMDA receptor expressivity may also play a role ${ }^{3}$. Compounds that block NMDA receptors are effective in some developmental animal models of epilepsy ${ }^{7}$ and felbamate, a drug that has efficacy in Lennox-Gastaut syndrome, has some selectivity for NMDA receptors ${ }^{8}$.

Most of the epileptic encephalopathies are intractable to the conventional antiepileptic drugs and treatments such as the ketogenic diet and ACTH have been discovered serendipitously to be effective. This suggests that the current models used for the development of antiepileptic drugs are unlikely to lead to effective treatment for epileptic encephalopathies and highlights the need for the development of animal models of epileptic encephalopathies.

\section{Etiology of The Encephalopathy Influences Response To Treatment}

The selection of antiepileptic treatment is usually based on seizure type and/or epilepsy syndrome. However, just as the natural history and response to treatment of most medical disorders is influenced by the underlying disease, the underlying cause of symptomatic infantile spasms may influence response to treatment. Chiron demonstrated that spasms associated with tuberous sclerosis responded much better to vigabatrin than to corticosteroid $^{9}$. Similarly, Carmant demonstrated in a prospective study that infantile spasms due to neonatal strokes and hypoxic ischemic encephalopathy responded less favourably to vigabatrin than those due to tuberous sclerosis and cortical dysplasia $^{10}$. Similarly, Vigevano observed that vigabatrin was more effective than ACTH in spasms due to cerebral malformations and tuberous sclerosis whereas ACTH proved more effective in perinatal hypoxic-ischemic injury ${ }^{11}$. Vigevano has also demonstrated that children with infantile spasms who had a family history of epilepsy and/or febrile seizures all responded to treatment with either ACTH, nitrazepam or phenobarbital and had a good outcome ${ }^{12}$. These observations demonstrate that the response to treatment can be influenced by the underlying disease, which should be considered in selection of therapy and in the design of clinical trials ${ }^{13}$.

The concept that certain epileptic encephalopathies may be due solely to genetic factors is exemplified by myoclonic astatic epilepsy in which the characteristic features include normal development prior to the onset of epilepsy, absence of a history of neurological insult and a high incidence of a positive family history of epilepsy. Similarly, SCN1A mutations have been demonstrated in $79 \%$ of children with Dravet syndrome, which is also characterized by normal development prior to the onset of epilepsy, absence of a history of neurological insult and a high incidence of a positive family history of epilepsy and of febrile seizures ${ }^{14}$. Both of these syndromes demonstrate that epileptic encephalopathy may be the characteristic manifestation of certain epilepsies in which genetic factors are believed to be the sole cause. The role of genetic factors in the other epileptic encephalopathies is less well appreciated. However, Vigevano described 17 children with spasms who had a family history of epilepsy or febrile seizures, or who subsequently developed at follow-up an EEG trait characteristic of idiopathic epilepsy, e.g., rolandic spikes or photoconvulsive response ${ }^{12}$. These children all had normal neuropsychological development following control of the spasms and an idiopathic etiology was posited. These suggest that some epileptic encephalopathies are manifestations of idiopathic epilepsy and raises the possibility that certain genes may predispose to the development of an epileptic encephalopathy.

\section{Delay In Recognition Of The Encephalopathy}

Recognition that the child has an epileptic encephalopathy is very often delayed for a variety of reasons. Slowing in the rate of development is frequently gradual and the parents, who are often in a stage of denial in the early months, commonly attribute any behavioural or developmental changes to the side-effects of medication. In addition, the slowing is usually overshadowed initially by the seizures which can be emotionally very traumatic for the parents. Thus, the parents may not accept the reality of the slowing in neurological development for many months, particularly in encephalopathies that start after infancy.

Physicians may also fail to appreciate the cognitive impact because of the ingravescent nature of the developmental slowing and because any changes are usually attributed to the frequent changes in medication that occur as a consequence of the difficulty in controlling the seizures. Most of the epileptic encephalopathies are characterized by frequent interictal discharges of high amplitude, and such abnormalities should heighten the index of suspicion of an epileptic encephalopathy, particularly if they are more prominent during sleep. These EEG features are usually prominent at the onset of infantile spasms and early in the course of Lennox-Gastaut syndrome ${ }^{15}$ and the other encephalopathies.

\section{What Outcome Measures Are Clinically Significant?}

Although the major long term morbidities associated with the epileptic encephalopathies are cognitive and behavioural, seizure frequency is the most common outcome measure used to evaluate interventions. One reason for the lack of measurement of cognitive and/or behavioural outcomes is the absence of a valid and reliable method for the measurement of cognitive and behavioural change that would be suitable for clinical trials. Such an instrument would have to be sensitive to change over a relatively short period of time - weeks or months. In addition, it would have to be valid over the age range that epileptic encephalopathies normally present, which usually span from one to seven years of age.

The primary outcome measure in most studies of antiepileptic drugs in epileptic encephalopathies is change in seizure 
frequency rather than number of patients that achieve complete control. Thus, placebo-controlled studies of felbamate ${ }^{16}$, lamotrigine $^{17}$, topiramate ${ }^{18}$, and rufinamide ${ }^{19}$ have all demonstrated a significant improvement in seizure control in children with Lennox-Gastaut syndrome. However, although these studies demonstrate a reduction in seizure frequency that reaches significance, only the study involving felbamate demonstrated patients who became completely seizure free. This contrasts markedly with a randomized controlled trial of the ketogenic diet in which 22 of 40 children on a $4: 1$ ratio and 11 of 36 on a 3:1 ratio became seizure free ${ }^{20}$. In this study, 32 of the 40 children receiving the $4: 1$ ratio and 19 of the 36 on the $3: 1$ ration had either infantile spasms or Lennox-Gastaut syndrome. These data indicate that complete seizure control is a viable outcome measure in children with epileptic encephalopathies and suggest that a trial of the ketogenic diet should be considered much earlier in the course of treatment of the epileptic encephalopathies.

Clinical experience suggests that children with epileptic encephalopathies who do not achieve complete seizure control continue to have a disturbance in neurological development. Thus, if seizure frequency is used as a surrogate measure, the outcome should be considered as a dichotomous variable, seizure freedom or lack of seizure freedom. In addition, the EEG should also be considered in measurement of the response to an intervention. Interictal epileptiform activity has been demonstrated to influence cognitive function in certain populations $^{21}$. Many of the epileptic encephalopathies are characterized by frequent high voltage epileptiform discharges. Furthermore, children with certain epileptic encephalopathies, e.g. CSWS, may have no epileptic seizures and be characterized only by interictal discharges. This suggests that both the clinical seizure response and the interictal EEG should be considered when the outcome is measured. Such an approach has been proposed by a consensus of experts as the primary outcome measure for treatment of epileptic spasms, i.e., complete seizure control and resolution of hypsarrythma ${ }^{22}$. A similar approach should be considered also for the other epileptic encephalopathies.

In conclusion, success in the management of the epileptic encephalopathies will require a better understanding of the pathophysiology of these disorders and a re-evaluation of many of the clinical assumptions that are currently held.

\section{REFERENCES}

1. Engel J Jr, International League Against Epilepsy (ILAE). A proposed diagnostic scheme for people with epileptic seizures and with epilepsy: Report of the ILAE task force on classification and terminology. Epilepsia. 2001 Jun;42(6): 796-803.

2. Kramer U, Nevo Y, Neufeld MY, Fatal A, Leitner Y, Harel S. Epidemiology of epilepsy in childhood. a cohort of 440 consecutive cases. Pediatr Neurol. 1998;18:46-50.

3. Rho JM. Basic science behind the catastrophic epilepsies. Epilepsia. 2004;45 Suppl 5:5-11.

4. Baram TZ. Pathophysiology of massive infantile spasms: Perspective on the putative role of the brain adrenal axis. Ann Neurol. 1993 Mar;33(3):231-6.

5. Brunson KL, Khan N, Eghbal-Ahmadi M, Baram TZ. Corticotropin (ACTH) acts directly on amygdala neurons to down-regulate corticotropin-releasing hormone gene expression. Ann Neurol. 2001 Mar;49(3):304-12.
6. Brunson KL, Eghbal-Ahmadi M, Bender R, Chen Y, Baram TZ. Long-term, progressive hippocampal cell loss and dysfunction induced by early-life administration of corticotropin-releasing hormone reproduce the effects of early-life stress. Proc Natl Acad Sci USA. 2001 Jul 17;98(15):8856-61.

7. Kohl BK, Dannhardt G. The NMDA receptor complex: A promising target for novel antiepileptic strategies. Curr Med Chem. 2001 Sep;8(11):1275-89.

8. Rho JM, Donevan SD, Rogawski MA. Mechanism of action of the anticonvulsant felbamate: Opposing effects on N-methyl-Daspartate and gamma-aminobutyric acidA receptors. Ann Neurol. $1994 \mathrm{Feb} ; 35(2): 229-34$.

9. Chiron C, Dumas C, Jambaque I, Mumford J, Dulac O. Randomized trial comparing vigabatrin and hydrocortisone in infantile spasms due to tuberous sclerosis. Epilepsy Res. 1997 Jan;26(2):389-95.

10. Carmant L, Weiss SK, Whiting S, Wirrell E, Donner E, Dooley JM, et al. Etiology baed treatment of infantile spasms. Epilepsia. 2007;48(Suppl 8).

11. Vigevano F, Cilio MR. Vigabatrin versus ACTH as first-line treatment for infantile spasms: A randomized, prospective study. Epilepsia. 1997 Dec;38(12):1270-4.

12. Vigevano F, Fusco L, Cusmai R, Claps D, Ricci S, Milani L. The idiopathic form of West syndrome. Epilepsia. 1993;34:743-6.

13. Lux AL, Osborne JP. The influence of etiology upon ictal semiology, treatment decisions and long-term outcomes in infantile spasms and West syndrome. Epilepsy Res. 2006 Aug;70 Suppl 1:S77-86.

14. Harkin LA, McMahon JM, Iona X, Dibbens L, Pelekanos JT, Zuberi SM, et al. The spectrum of SCN1A-related infantile epileptic encephalopathies. Brain. 2007 Mar;130(Pt 3):843-52.

15. Blume WT. The EEG features of the lennox-gastaut syndrome. In: Niedermeyer E, Degen R, editors. The Lennox-Gastaut Syndrome. New York: Allan Liss; 1988. p. 159-76.

16. Lennox-Gastaut FSGi. Efficacy of felbamate in childhood epileptic encephalopathy (lennox-gastaut syndrome). N Engl J Med. 1993;328:29-33.

17. Motte J, Trevathan E, Arvidsson JF, Barrera MN, Mullens EL, Manasco P, et al. Lamotrigine for generalized seizures associated with lennox-gastaut syndrome. N Engl J Med. 1997;337: 1807-12.

18. Sachdeo RC, Glauser TA, Ritter F, Reife R, Lim P, Pledger G. A double-blind, randomized trial of topiramate in lennox-gastaut syndrome. Neurology. 1999;52:1882-7.

19. Glauser T, Kluger G, Sachdeo R, Krauss G, Perdomo C, Arroyo S. Rufinamide for generalized seizures associated with lennoxgastaut syndrome. Neurology. ePub ahead of print Apr 92008 as 10.1212/01.wnl.0000303813.9580.0d

20. Seo JH, Lee YM, Lee JS, Kang HC, Kim HD. Efficacy and tolerability of the ketogenic diet according to lipid: nonlipid ratios--comparison of 3:1 with 4:1 diet. Epilepsia. $2007 \mathrm{Apr}$; 48(4):801-5.

21. Binnie $\mathrm{CD}$. Cognitive impairment during epileptiform discharges: is it ever justifiable to treat the EEG? Lancet Neurol. 2003 Dec; 2(12):725-30.

22. Lux AL, Osborne JP. A proposal for case definitions and outcome measures in studies of infantile spasms and West syndrome: consensus statement of the West Delphi Group. Epilepsia. 2004 Nov;45(11):1416-28. 


\title{
Metabolic Epilepsies: Approaches to a Diagnostic Challenge
}

\author{
Sylvia Stöckler-Ipsiroglu, Barbara Plecko
}

\begin{abstract}
Although inborn errors of metabolism (IEM) are a relatively rare cause of epilepsy in children, their diagnosis is important with respect to treatment, prognosis and genetic counselling. In addition to seizures and epilepsy, IEM may produce a complex clinical picture in which epilepsy is only one of the various neurologic manifestations including developmental delay / regression, mental retardation, movement disorders, micro- / macrocephaly, as well as cerebral grey and white matter changes. Dysmorphic features and cerebral dysgenesis may also be part of a metabolic epilepsy syndrome (e.g. disorders of peroxisomal biogenesis, glutaric aciduria type 2, pyruvate dehydrogenease complex deficiency). Metabolic epilepsies may dominate the clinical presentation (e.g. pyridoxine dependent epilepsy) or may precede further neurologic deterioration (e.g. neuronal ceroid lipofuscinosis) and additional organ involvement (e.g. liver failure in Alpers (POLG1) disease). Metabolic epilepsies often present with myoclonic seizures (e.g. Gaucher Disease type 3, mitochondrial syndromes) and, as a rule, patients presenting with predominantly myoclonic seizures should be carefully investigated for these types of metabolic epilepsies. Patients with very early onset of epilepsy are considered at high risk for an underlying IEM as well. In this review we present an overview of metabolic epilepsies based on various criteria such as treatability, age of onset, seizure type, and pathogenetic background. Exemplary disorders will be described in more detail including cerebral glucose transporter (GLUT1) deficiency, pyridoxine dependent epilepsy, neuronal ceroid lipofuscinosis, cathepsin D deficiency, Alpers syndrome (POLG deficiency), and guanidinoacetate methyltransferase (GAMT) deficiency.
\end{abstract}

RÉSUMÉ: Épilepsies métaboliques : la démarche diagnostique, un défi pour le clinicien. Bien que les erreurs innées du métabolisme (EIM) soient une cause relativement rare d'épilepsie chez les enfants, leur diagnostic est important pour le traitement, le pronostic et le conseil génétique. En plus de l'épilepsie, les EIM peuvent donner lieu à un tableau clinique complexe au sein duquel l'épilepsie est seulement une des différentes manifestations neurologiques qui incluent également un retard/une régression du développement, un retard mental, des troubles du mouvement, une micro/macrocéphalie, ainsi que des changements au niveau de la substance grise et de la substance blanche du cerveau. Des traits dysmorphiques et une dysgénésie cérébrale peuvent également faire partie du syndrome de l'épilepsie métabolique (ex. les maladies liées à la biogenèse des peroxisomes,

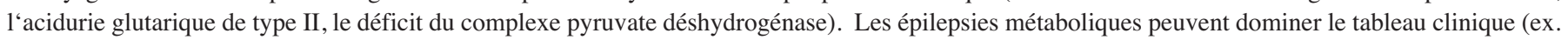
l'épilepsie dépendante de la pyridoxine) ou peuvent précéder une détérioration neurologique ultérieure (ex. les céroïde-lipofuscinoses neuronales) et l'atteinte d'autres organes (ex. l'insuffisance hépatique dans la maladie d'Alpers (POLG1)). Les symptômes initiaux des épilepsies métaboliques sont souvent des crises myocloniques (ex. la maladie de Gaucher de type 3, les syndromes mitochondriaux) et, en règle générale, chez les patients qui ont des crises myocloniques prédominantes on devrait rechercher attentivement ces épilepsies métaboliques. On considère que les patients chez qui l'épilepsie survient tôt sont à haut risque d'être porteurs d'une EIM sous-jacente. Dans cette revue, nous présentons une synthèse des épilepsies métaboliques fondée sur différents critères tels une maladie traitable, l’âge de début, le type de crises et le contexte pathogénétique. Certaines maladies sont décrites en détail à titre d'exemples, dont le déficit en transporteur cérébral du glucose (GLUT1), l'épilepsie pyridoxine-dépendante, les céroïdelipofuscinoses neuronales, le déficit en cathepsine D, le syndrome d'Alpers (déficit en POLG) et le déficit en guanidinoacétate méthyltransférase (GAMT).

Can. J. Neurol. Sci. 2009; 36: Suppl. 2 - S67-S72

Inborn errors of metabolism (IEM) constitute one segment of the various causes of seizures and epilepsy in children. Given the fact that causal treatment is available for some of these disorders, this group of patients deserves particular attention.

There are more than 200 IEM which are associated with epilepsy but single IEM are rare (most of them with an incidence of rarer than 1:100,000 newborns) and their diagnostic evaluation tends to be a major clinical and logistical challenge. Diagnostic work up often requires invasive procedures (e.g. skin and muscle biopsies) and the analytical work up is mostly restricted to a few laboratories scattered worldwide. Moreover, financial costs associated with many of the tests exceed $\mathrm{S} 1,000$ dollars per single test. For all these reasons, neonatologists, pediatric neurologists and biochemical geneticists strive to have diagnostic clues and decision criteria for an effective and

From the Department of Pediatrics (SSI, BP), University of British Columbia, Vancouver, British Columbia, Canada; Department of Pediatrics (BP), Medical University Graz, Austria.

Received August 19, 2008. Final Revisions Submitted August 25, 2008. Correspondence to: Sylvia Stöckler-Ipsiroglu, Department of Pediatrics, University of British Columbia, British Columbia Children's Hospital, K3-204-4480 Oak Street Vancouver, British Columbia,V6H 3V4, Canada. 
efficient metabolic work up of their patients. Several very useful review articles focus on particular aspects of IEM and metabolic epilepsies. ${ }^{1-5}$ In this review we present an overview of metabolic epilepsies based on various criteria such as treatability, age of onset, seizure type, pathogenetic background and association with cerebral dysgenesis. From each group we will highlight several examples and describe them in more detail. This review makes no claim to be complete but rather reflects our own experience with the challenges in the metabolic work up of patients presenting with etiologically unresolved seizures and epilepsies.

\section{General approach for the diagnostic work up of metabolic epilepsies}

As a first orientation for when and how to start a metabolic work up, the division of metabolic epilepsies into the following groups can be useful:

Treatable metabolic epilepsies

Metabolic epilepsies with a characteristic age of onset

Metabolic epilepsies with a characteristic seizure type / course of epilepsy

Metabolic epilepsies classified according to their pathogenetic background

\section{Treatable METABOLIC EPILEPSIES}

It is evident that epilepsies where causal treatment is expected to improve the outcome significantly should be ruled out first. Table 1 shows the most important treatable metabolic epilepsies as opposed to disorders where no causal treatment available. Table 2 is a practical guide for the diagnosis of the most important treatable metabolic epilepsies.

\section{Example of a treatable metabolic epilepsy:}

\section{Cerebral glucose transporter (GLUT1) deficiency}

GLUT1 deficiency is one of the most important differential diagnoses of metabolic epilepsies which should be ruled out in every patient with unexplained seizures.

GLUT1 deficiency causes an impaired transport of glucose into the brain and results in decreased brain glucose supply and neuroglycopenia. The main manifestation of GLUT1 deficiency is cerebral seizures. The age of onset of clinically overt seizures is within the first few months of life. Neonatal seizure onset is not typical but apneic spells and opsoclonus like eye movments have retrospectively been found in the history of patients with GLUT1 deficiency and can be interpreted as possible seizure manifestations. The clinical manifestations of GLUT1 deficiency are not confined to epileptic sezures: patients can also exhibit paroxysmal events such as alternating hemiplegia, intermittent ataxia, intermittent headache and confusional states. The longterm outcome may be a complicated by mental retardation and ataxic and spastic movement disorders.

Characteristics of seizures include the following. Seizures typically occur in early infancy between one and four months of age and start as fragmentary focal seizures involving eyes, facial muscles or limbs, staring spells and behavioural arrest. As the brain matures, seizures become more generalized including convulsive and non-convulsive manifestations such as generalized tonic clonic and myoclonic and atonic seizures as well as atypical absences. In summary, the clinical manifestion of epileptic activity is variable and many unclassified seizures may be observed in patients with GLUT1 deficiency.

The frequency of seizures varies between daily occurrence of multiple seizures and seizure activities separated by days, weeks or months. Seizures often, but not exlusively, occur in the morning or in the fasting state when, in the presence of low normal blood glucose levels, the apriori defective cerebral glucose transport is even more impaired. Seizures show a limited to absent response to anticonvulsant medication. Phenobarbital, as a known inhibitor of GLUT1, may lead to deterioration of seizure activity.

Early in infancy the EEG may be normal, while focal slowing and spikes appear later in infancy. Generalized 2.5-4 Hz spikewave (SW) discharges appear in childhood and later in life. Significant improvement of preprandial EEG has been reported in the postprandial state. ${ }^{6}$

The diagnostic hallmark of GLUT1 deficiency is hypoglycorrhachia with CSF glucose levels beteween 0.9 and $2.7 \mathrm{mmol} / \mathrm{L}$ (mean $1.7 \pm 1.3$ ). A CSF to blood glucose ratio lower than 0.4 is a more specific diagnostic marker with a characteristic range between 0.19 and 0.46 (mean $0.33 \pm 0.14$ ). CSF lactate is low normal $(0.3-1.15 \mathrm{mmol} / \mathrm{L})$. As the CSF / blood glucose ratio is influenced by fluctuations in blood glucose levels, it is important to measure the blood to CSF glucose ratio in the fasting state. In order to avoid elevations of blood glucose due to stress caused by the lumbar puncture (LP) procedure,

Table 1: Metabolic epilepsies causally treatable vs untreatable

\begin{tabular}{l|l}
\multicolumn{1}{c|}{$\begin{array}{c}\text { Causal treatment with significant } \\
\text { response }\end{array}$} & \multicolumn{1}{c}{ No causal treatment } \\
\hline Biotinidase def & CDG syndromes \\
\hline Creatine synthesis def (AGAT, GAMT) & Creatine transporter defect \\
\hline $\begin{array}{c}\text { GLUT 1 def } \\
\text { response }\end{array}$ & D-2 OH Glutaric aciduria \\
\hline $\begin{array}{c}\text { Pyridoxine dependent / folinic acid } \\
\text { Causponsive epilepsy }\end{array}$ & GABA Transaminase deficiency \\
\hline $\begin{array}{c}\text { Cobalamin C/D defects } \\
\text { Pyridoxalphosphate dependent seizures }\end{array}$ & Molybdenium cofactor def / Sulfite oxidase def \\
& \\
\hline Serine biosynthesis def & Mertochondriopathies (e.g. Alpers Syndrome, \\
\hline Gaucher disease type 3 & Non-ketotic hyperglycinemia \\
\hline
\end{tabular}

$\mathrm{CDG}=$ Congenital disorders of glycosylation; $\mathrm{AGAT}=$ Arginine: glycine amidinotransferase; GAMT=Guanidinoacetate methyltransferase; GLUT1=Cerebral glucose transporter; MERRF=Myoclonic Epilepsy associated with Ragged Red Fibers. 
Table 2: Treatable primary metabolic epilepsies and practical guide to diagnosis

\begin{tabular}{l|l|l|l}
\hline Disease & $\begin{array}{l}\text { Clinical response to } \\
\text { treatment }\end{array}$ & $\begin{array}{l}\text { Biochemical } \\
\text { Diagnosis }\end{array}$ & $\begin{array}{l}\text { Diagnostic } \\
\text { Material }\end{array}$ \\
\hline $\begin{array}{l}\text { Pyridoxine dependent } \\
\text { seizures }\end{array}$ & $\begin{array}{l}\text { Resolution of } \\
\text { seizures after } \\
50-100 \mathrm{mg} \\
\text { pyridoxine i.v. }\end{array}$ & $\begin{array}{l}\text { High alpha-aminoadipic } \\
\text { semialdehyde } \\
\text { High pipecolic acid }\end{array}$ & U, P, CSF \\
\hline $\begin{array}{l}\text { Pyridoxal-phosphate } \\
\text { responsive seizures }\end{array}$ & $\begin{array}{l}\text { Improvement of } \\
\text { seizures upon oral } \\
\text { pyridoxalphosphate }\end{array}$ & $\begin{array}{l}\text { Low HVA \& 5-HIAA } \\
\text { High glycine \& threonine }\end{array}$ & CSF \\
\hline $\begin{array}{l}\text { Serine biosynthesis defects } \\
\begin{array}{l}\text { Cerebral creatine deficiency } \\
\text { in GAMT deficiency } \\
\text { Cerebral creatine deficiency in }\end{array}\end{array}$ & & Low serine & P, CSF \\
AGAT deficiency & High GAA, low creatine & U, P, CSF \\
\hline $\begin{array}{l}\text { GLUT 1 deficiency } \\
\text { Low GAA }\end{array}$ & U,P, CSF \\
\hline
\end{tabular}

GAMT=Guanidinoacetate methyltransferase deficiency; AGAT= Arginine glycine amidinotransferase deficiency; CRTR=Creatine transporter deficiency; GLUT 1=Cerebral glucose transporter deficiency; HVA=Homovanillic acid; 5-HIAA=5-hydroxyindoleacetic acid; GAA= Guanidinoacetate; U=Urine; $\mathrm{P}=\mathrm{Plasma}$; $\mathrm{CSF}=$ Cerebrospinal fluid.

blood glucose is measured 30 minutes before the LP. Diagnosis is confirmed by genetic analysis of the GLUT1 transporter gene (SLC2A1). Glucose uptake studies in red blood cells and Western blot analysis of the GLUT1 protein may be necessary to confirm the pathogenic nature of newly identified mutations in the SLC2A1 gene. SLC2A1 deficiency is inherited autosomal dominantly.

The ketogenic diet (KD) is the treatment of choice in GLUT1 deficiency. Administration of a diet where most of the carbohydrate intake is substituted by fat, results in permanent ketosis and makes ketone bodies (which are transported across the blood brain barrier via an independent transporter) an alternative energy substrate for the brain. ${ }^{7,8}$ Some patients do not become seizure-free upon KD and need additional anticonvulsive treatment. In most patients mental retardation and a movement disorder persist despite treatment.

\section{Metabolic epilepsies with characteristic age of onset}

The age of onset is an important differential diagnostic criterion for metabolic epilepsies. Table 3 shows the most important metabolic epilepsies classified according to their age of onset.

\section{Pyridoxine dependent epilepsy (PDE): a metabolic epilepsy with neonatal onset}

Pyridoxine dependent epilepsy is a treatable metabolic epilepsy with characteristic onset in the neonatal period. Intrauterine seizure onset at the end of the third trimester has been reported in several cases. There are also a number of patients known with seizure onset beyond the neonatal period. The diagnosis of pyridoxine dependent epilepsy has been based on the demonstration of a response to a standardised treatment trial with pyridoxine. With the recent discovery of the underlying gene defect (antiquitin gene deficiency coding for $\alpha-$ aminoadipic semialdehyde dehydrogenase $)^{9,10}$ a diagnostic marker (increased urinary excretion of $\alpha$-aminoadipic semialdehyde) has become available. The availability of this biomarker will give new insights in the phenotypic spectrum of PDE and will open new treatment options. ${ }^{11}$

\section{Neuronal ceroid lipofuscinosis (NCL): a metabolic epilepsy with characteristic age of onset}

Neuronal ceroid lipofuscinosis is a group of progressively degenerative neurometabolic disorders characterised by the triad epilepsy, dementia and amaurosis. NCLs are caused by a variety of autosomal recessive gene defects with intracellular (neuronal) storage material called ceroid lipofuscin as a common surrogate. At least ten different gene defects causing an NCL phenotype are known so far. The various NCLs differ in their characteristic age of onset. Table 4 shows the characteristic onset of the various NCLs. As a rule of thumb, epilepsy associated with developmental arrest and regression is the first presenting symptom in NCLs with early (infantile) onset, whereas retinopathy and amaurosis appear later in the course of the disease. In NCLs with later onset (late infantile and juvenile NCL), retinopathy and amaurosis are the first presenting symptoms whereas epilepsy and mental regression appear later in the course of the disease.

With the molecular characterization of the NCLs, the diagnostic strategies have changed. Tissue (skin, rectal) biopsies and electron microscopic demonstration of characteristic neuronal lipofuscin inclusions are no longer required as a primary screening for all NCLs.

Table 3: Metabolic epilepsies: Age at manifestation

\begin{tabular}{|c|c|}
\hline Neonatal / untreatable & $\begin{array}{l}\text { Pyridoxine dependent epilepsy, } \\
\text { Pyridxoalphosphate dependent epilepsy, } \\
\text { Serine biosynthesis defects } \\
\text { Molybdenium cofactor def / sulfite oxidase } \\
\text { def, Non-ketotic hyperglycinemia, Zellweger } \\
\text { Syndrome, Congenital NCL }\end{array}$ \\
\hline $\begin{array}{l}1-6 \mathrm{mo} / \text { treatable } \\
1-6 \mathrm{mo} / \text { untreatable }\end{array}$ & $\begin{array}{l}\text { GLUT1 def, Biotinidase def, } \\
\text { Menkes disease }\end{array}$ \\
\hline $6-12 \mathrm{mo} /$ untreatable & Infantile NCL, Alpers Syndrome \\
\hline $1-\geq 6$ y / treatable & Creatine synthesis def (AGAT, GAMT) \\
\hline $1-\geq 6$ y / untreatable & $\begin{array}{l}\text { Late infantile NCL, mitochondrial (MERRF), } \\
\text { Creatine transporter defect, Sialidosis, } \\
\text { Gangliosidosis }\end{array}$ \\
\hline
\end{tabular}

NCL=Neuronal ceroidlipofuscinosis; GLUT1=Cerebral glucose transporter; AGAT=Arginine:glycine amidinotransferase;

GAMT=Guanidinoacetate methyltransferase; MERRF=Myoclonic Epilepsy associated with Ragged Red Fibers. 
Table 4: Neuronal ceroidlipofusinoses

\begin{tabular}{|c|c|c|c|}
\hline Age & Gene & Enzyme & Clinical \\
\hline $\begin{array}{c}\text { Infancy }(80 \%) \\
\text { later }\end{array}$ & $\begin{array}{c}\text { CLN1 } \\
\text { CLN2 } \\
\text { CLN } 5,6,7,8\end{array}$ & $\begin{array}{c}\text { PTT } \\
\text { (Palmitoyl-protein-thioesterase) } \\
\text { TPP } \\
\text { (Tripeptidyl-thioesterase) } \\
\text { Membrane bound proteins }\end{array}$ & $\begin{array}{l}\text { Seizures, } \\
\text { visual loss }\end{array}$ \\
\hline Schoolage & CLN3 & Membrane bound proteins & $\begin{array}{c}\text { Visual loss } \\
\text { dementia, seizures }\end{array}$ \\
\hline Adulthood & CLN4 & Membrane bound proteins & $\begin{array}{c}\text { Visual loss, } \\
\text { dementia, seizures }\end{array}$ \\
\hline \multicolumn{4}{|c|}{$\begin{array}{l}\text { Rule of thumb } \\
\text { Young: Epilepsy } \\
\text { choolage: Blindness }\end{array}$} \\
\hline
\end{tabular}

Currently the following strategy is recommended for the diagnostic work up of NCLs ${ }^{12}$ :

- In young children with epilepsy and mental regression:

Determination of PTT (Palmitoyl-Proteine-Thioesterase) and of TPP (Tripeptidyl Thioesterase) (both tests can be done in blood spots) for CLN1 and CLN2 defects respectively. Only if both tests are negative, a tissue (skin or rectal) biopsy and electron microscopic demonstration of lipofuscin inclusion bodies is required. In case of a positive electron microscopic finding, CLN 6, 7, and 8 genes are investigated for final molecular genetic confirmation.

- In older children with retinopathy and mental regression: Demonstration of vaculolated lymphocytes and subsequent mutation analysis of the CLN3 gene. In patients with absent vacuolated lymphocytes and / or CLN3 gene sequence, mild variants of CLN1 and CLN2 should be considered and respective testing initiated. For algorithm see http:// www.orpha.net/data/patho/GB/CLN-figure.pdf

\section{Cathepsin D deficiency}

Cathepsin D is a lysosomal protease and its deficiency is an additional NCL which has been described recently. Both childhood onset with retinopathy and mental regression ${ }^{13}$ and a congenital form with epilepsy as predominant presentation ${ }^{14}$ have been described thus far. The congenital form of cathepsin D deficiency has been described in two unrelated famililes of Pakistani and British origin. The patients had intrauterine deceleration of head growth, jerky fetal movements, microcephaly and severve brain atrophy at birth with neonatal intractable seizures and apnea. They later developed severe spasticity. Brain autopsy showed subtotal loss of neurons, lack of myelination and autofluorescent granular osmiophilic deposits. Although only two families have been described so far with congenital NCL, cathepsin D deficiency should be considered as a differential diagnosis in newborns with microcephaly and intractable neonatal seizures. Diagnosis is made by determination of cathepsin D activity and mutation analysis. Determination of cathepsin D activity in blood spots is possible.

\section{Metabolic epilepsies with a characteristic seizure type / course of epilepsy}

Clinical and EEG expression of epilepsy is mainly determined by the type of lesions and the level of maturation of the brain when the lesions occur. Some areas within the brain may be more susceptible to damage by specific metabolic compounds (e.g. organic acids / basal ganglia) or may have regional differences in substrate turnover (e.g. creatine in grey matter). Secondary impairment of the metabolism and transport of other cerebral compounds may play another important role for neuronal damage. As most of the metabolic epilepsies have a very low incidence and the complexity of epileptologic symptmatology is not considered in the descriptions of the clinical phenotype, knowlege about specific seizure semiology in the various metabolic epilepsies is poor. Nevertheless, for a few metabolic epilepsies a common seizure phenotype can be delineated. For example, non-ketotic hyperglycinemia presents with neonatal myoclonic seizures, apnea and burst suppression pattern in the EEG. PDE mostly presents in the neonatal period with a variable spectrum of seizure types and burst suppression patterns as well as continuous high voltage rhythmic delta activity and absence of sleep patterns have been observed in pretreatment EEG's. Patients with cerebral creatine deficiency caused by guanidinoacetate methyltransferase (GAMT) deficiency may have characteristic head drop seizures and their EEG can show high voltage theta-delta activity with multifocal spikes. Infantile spasms and West syndrome have been described in the few patients known so far with serine synthesis defects. For more examples see Table 5 of epilepsy.

Alpers Syndrome (Polymerase gamma 1 [POLG1] deficiency): a metabolic epilepsy with a characteristic course

Alpers Syndrome (progressive neuronal degeneration of childhood with liver disease) is characterised by the triad refractory seizures, psychomotor regression and liver failure. The characteristic age of onset is between one and three years but several patients with later onset have been described. The typical course includes an nonspecific developmental delay in early infancy prior to an explosive onset of intractable seizures and subsequent severe cortical atrophy with loss of psychomotor skills and progressive spasticity. Seizure onset is often with a focal status epilepticus and epilepsia partialis continua can be a special feature. This neurologic break down is followed by progressive liver failure (steatosis, fibrosis, cirrhosis). Acute liver failure has been reported in association with pharmacological anticonvulsive treatment (valproic acid) ${ }^{15}$

Alpers Syndrome is an autosomal recessively inherited disorder caused by mutations in the gene encoding for the catalytic subunit of polymerase gamma (POLG1). Polymerase gamma is a nuclear encoded protein which exerts its action in the mitochondria as the unique mitochondrial DNA polymerase. The mitochondrial DNA polymerase (pol- $\gamma$ ) is essential for mitochondrial DNA replication and repair. Pol- $\gamma$ comprises a catalytic $\alpha$-subunit which is encoded by the nuclear POLG1 gene and an accessory (DNA binding) $\beta$ subunit (encoded by the 
Table 5: Metabolic epilepsies: Seizure type and course of epilepsy

\begin{tabular}{l|l}
\hline Myoclonic seizures, Myoclonus epilepsy & $\begin{array}{l}\text { Mitochondrial (e.g. MERRF) } \\
\text { Sialidosis, Galctosialidosis, Gaucher disease type 3, } \\
\text { NCL }\end{array}$ \\
\hline $\begin{array}{l}\text { Infantile spasms, } \\
\text { West syndrome }\end{array}$ & Serine synthesis defects \\
\hline $\begin{array}{l}\text { Refractory mixed, focal component, status } \\
\text { epilepticus, epilepsia partialis continua }\end{array}$ & Alpers (POLG1) \\
\hline Focal and later on generalized seizures & GLUT1 def \\
\hline Epileptic-encephalopathic & \\
\hline $\begin{array}{l}\text { Epileptic-encephalopathic with neonatal } \\
\text { central apnea and burst suppression pattern }\end{array}$ & Non ketotic hyperglycinemia \\
\hline Head drop seizures & GAMT deficiency \\
\hline
\end{tabular}

MERRF=Myoclonic Epilepsy associated with Ragged Red Fibers; $\mathrm{NCL}=$ Neuronal ceroidlipofuscinosis; $\mathrm{POLG}=$ Polymerase gamma; GLUT1 $=$ Cerebral glucose transporter; GAMT $=$ Guanidinoacetate methyltransferase.

nuclear POLG2 gene). ${ }^{16}$ Although deficient pol- $\gamma$ results in progressive mitochondrial DNA depletion and subsequently impaired electrone transport chain function, patients with Alpers syndrome do not necessarily have high plasma lactate levels while normal respiratory chain complex activities in a muscle biopsy do not necessarily rule out this disease. Therefore, patients with clinical symptoms suggestive of Alpers syndrome (progressive hepatocerebral involvement) should immediately be investigated for POLG1 mutations even in the absence of lactic acidosis. The number of reported Alpers-associated POLG mutations is more than 35 . The most frequent POLG1 mutations are A467T and W748S and screening for these two mutations constitutes a rapid and sensitive test for confirming the clinical diagnosis of Alpers Syndrome. ${ }^{17}$

\section{Metabolic epilepsies classified according to their pathogenetic background}

Table 6 shows various pathogenetic mechanisms which may cause seizures and epilepsy in metabolic epilepsies. The understanding of the pathogenesis provides the primary clue for causal treatment of various metabolic epilepsies: for example the therapeutic effect of the ketogenic diet is based on the shift of neuronal energy supply from glucose to ketone bodies. It leads to significant improvement of seizures not only in GLUT 1 deficiency but also other disorders of defective energy supply such as pyruvate dehydrogenase deficiency. It is possibly beneficial in other defects of glycolysis associated with neurologic manifestations (e.g. phosphoglycerate kinase deficiency). Another example is the beneficial effect of oral serine supplementation in serine biosynthesis defects which go along with congenital microcephaly, severe intractable seizures, spastic tetraplegia, and severe psychomotor retardation as well as
Table 6: Metabolic epilepsies: Pathogenesis

\begin{tabular}{|c|c|}
\hline Energy supply & Mitochondrial (MERRF, Alpers) \\
\hline Substrate deficiency & $\begin{array}{l}\text { Creatine deficiency syndromes (AGAT, GAMT, CRTR) } \\
\text { Serine def }\end{array}$ \\
\hline Cofactor & $\begin{array}{l}\text { PDE (antiquitin deficiency), Pyridoxal-phosphate responsive } \\
\text { seizures, }\end{array}$ \\
\hline Neurotransmitter & $\mathrm{NKH}, \mathrm{GABA}$ transaminase, GABA transporter \\
\hline Neurotoxic & $\begin{array}{l}\text { GAMT, neurogenic organoacidurias (e.g. L-2OH glutaric } \\
\text { aciduria), Adenylosuccinate lyase def }\end{array}$ \\
\hline Storage disorder & NCL, NPC, Sialidosis, Gangliosidosis \\
\hline $\begin{array}{l}\text { Structural (cerebral } \\
\text { malformations / } \\
\text { dysgenesis) }\end{array}$ & $\begin{array}{l}\text { Peroxisomal biogenesis (Zellweger Syndrome, neonatal ALD, } \\
\text { infantile Refsum), Glutaric aciduria type 2, } \\
\text { Molybdenium cofactor def, CDG syndromes, } \\
\text { Pyruvate dehydrogenase def }\end{array}$ \\
\hline
\end{tabular}

MERRF=Myoclonic Epilepsy associated with Ragged Red Fibers; AGAT=Arginine: glycine amidinotransferase; GAMT=

Guanidinoacetate methyltransferase; CRTR=Cerebral creatine transporter; NCL=Neuronal ceroidlipofuscinosis; $\mathrm{POLG}=$ Polymerase gamma; GLUT1=Cerebral glucose transporter; PDE=Pyridoxine dependent epilepsy; $\mathrm{NKH}=$ Non ketotic hyperglycinemia; $\mathrm{NCL}=$ Neuronal ceroidlipofuscinosis; NPC=Niemann Pick type C;

$\mathrm{ALD}=$ Adrenoleukodystrophie; GLUT1=Cerebral glucose transporter; $\mathrm{CDG}=$ Congenital disorders of glycosylation.

reduction of cerebral white matter and incomplete myelination. ${ }^{18,19}$

Guanidinoacetate methyltransferase (GAMT) deficiency: understanding the pathophysiology gives a clue to causal treatment

Guanidinoacetate methyltransferase is one of the three inborn errors of creatine metabolism characterized by cerebral creatine deficiency. ${ }^{20}$ : arginine-glycine amidinotransferase (AGAT) deficiency, guanidinoacetate methyltransferase (GAMT) deficiency, and cerebral creatine transporter (CRTR) deficiency. Mental retardation and epilepsy are consistent clinical manifestations in all three. ${ }^{21}$ However, while in AGAT and CRTR deficiency cerebral seizures occur occasionally and are easily treatable with antiepileptic drugs, in GAMT deficiency seizures may be pharmacoresistant and may result in epileptic encephalopathy. In a survey of 27 patients with GAMT deficiency, cerebral seizures were reported as a constant finding in almost all patients. Epilepsy was intractable in $78 \%$. Seizure types included myoclonic, generalized tonic clonic, sporadic partial complex seizures and head drop attacks. ${ }^{22}$

The creatine-creatine phosphate system plays an important role in the storage and transmission of phosphate bound energy. Therefore, creatine deficiency as observed in GAMT deficiency results in reduced availability of the high energy compound creatine phosphate. Pathobiochemically, GAMT deficiency is 
Table 7: Treatment recommendations for guandinoacetate methyltransferase (GAMT) deficiency

\begin{tabular}{l|c|c}
\hline \multicolumn{1}{c|}{ Medication/Diet } & $\begin{array}{c}\text { Dosage } \\
(\mathbf{m g} / \mathbf{k g} / \mathbf{d})\end{array}$ & $\begin{array}{c}\text { Dosages } \\
\text { per day }\end{array}$ \\
\hline Creatine monohydrate & 400 & $3-6$ \\
\hline L-Ornithine hydrochloride & $100^{*}$ & $3-6$ \\
Low dose* & $800^{*}$ & \\
High dose* & 100 & 3 \\
\hline Sodium benzoate & $15-25^{* *}$ & $3-6$ daily meals \\
\hline L-Arginine intake & $0.2-0.7 \mathrm{~g} / \mathrm{kg}$ & $3-6$ daily meals \\
\hline Arginine free amino acid mixture
\end{tabular}

* Aim of low dose substitution is to provide sufficient amounts of ornithine to the urea cycle (target plasma ornithine concentration 100$200 \mathrm{Whol} / \mathrm{L}$ ). Aim of high dose substitution is to potentially inhibit competitively AGAT activity by high intracellular ornithine concentrations $(\mathrm{Km}=300 \mathrm{Whol} / \mathrm{L})$. ** corresponds to $0.4-0.7 \mathrm{~g} / \mathrm{kg}$ natural protein. Arginine free essential amino acid mixture has to be substituted in order to meet age dependent physiological amino acid requirements.

characterized not only by cerebral creatine deficiency but additionally by accumulation of guanidinoacetate which is substrate to the deficient enzyme actitvity. Guanidinoacetate is a neurotoxic substance which has an epileptogenic effect in vitro, and in GAMT deficiency CSF guanidinoacetate concentrations are more than 100 fold higher than normal. ${ }^{23}$ Therefore it seems most probable that these high concentrations in the brain compartment contribute considerably to the pathophysiology of the disease, in particular of epilepsy.

Treatment of GAMT deficiency aims to restore the cerebral creatine pool and to reduce the accumulation of guanidinoacetate. ${ }^{24}$ Oral substitution of creatine-monohydrate alone is effective in almost normalization of the cerebral creatine pool and reduction of guanidinoacetate accumulation is achieved by additional arginine restriction, as this aminoacid is the rate limiting substrate for guanidinoacetate synthesis. For current treatment recommendations for GAMT deficiency see Table 7.

\section{REFERENCES}

1. Buist NRM, Dulac O, Bottigliere T, Gärtner J, Rinaldo P, Wolf NI. Metabolic evaluation of infantile epilepsy: summary recommendations of the Amalfi Group. J Child Neurology. 2002 Dec;17 Suppl 3:3S98-102.

2. Greene CL, Goodman SI. Catastrophic metabolic encephalopathies in the newborn period. Evaluation and management. Clin Perinatol. 1997 Dec; 24(4):773-86.

3. Nordli DR, De Vivo DC. Classification of infantile seizures: Implications for identification and treatment of inborn errors of metabolism. J Child Neurol. 2002 Dec;17 Suppl 3:3S3-3S8.

4. Vigevano F, Bartuli A. Infantile epileptic syndromes and metabolic etiologies. J Child Neurol. 2002 Dec; 17 Suppl 3:3S9-3S14.

5. Wolf NI, Bast T, Surtees R. Epilepsy in inborn errors of metabolism. Epileptic Disord. 2005 Jun; 7(2):67-81.
6. von Moers A, Brockmann K, Wang D, Korenke CG, Huppke P, De Vivo DC, et al. EEG features of glut-1 deficiency syndrome. Epilepsia. 2002 Aug:43(8):941-5.

7. Magrath G, Macdonald A, Whitehouse W. Dietary practices and use of the ketogenic diet in the UK. Seizure. 2000 Mar; 9(2):128-30.

8. Morris AA. Cerebral ketone body metabolism. J Inherit Metab Dis. 2005; 28 (2):109-21.

9. Mills PB, Struys E, Jakobs C, Plecko B, Baxter P, Baumgartner M, et al. Mutations in antiquitin in individuals with pyridoxinedependent seizures. Nat Med. 2006 Mar;12(3):307-9.

10. Plecko B, Paul K, Paschke E, Stoeckler-Ipsiroglu S, Struys E, Jakobs C, et al. Biochemical and molecular characterization of 18 patients with pyridoxine-dependent epilepsy and mutations of the antiquitin (ALDH7A1) gene. Hum Mutat. 2007 Jan; 28(1): 19-26.

11. Plecko B, Stöckler S. Vitamin B6 dependent seizures. Can J Neurol Sci. 2008.

12. Kohlschutter A. Neuronal ceroidlipofuscinoses. Orphanet Encyclopedia January 2004. http://www.orpha.net/data/patho/ GB/uk-CLN.pdf.

13. Steinfeld R, Reinhadt K, Schreiber K, Hillebrand M, Kraetzner R, Bruck W, et al. Cathepsin D deficiency is associated with a human neurodegenerative disorder. Am J Hum Genet. 2006 Jun; 78(6): $988-98$.

14. Siintola E, Partanen S, Stromme P, Haapanen A, Haltia M, Maehlen $\mathrm{J}$, et al. Cathepsin D deficiency underlies congenital human neuronal ceroid-lipofuscinosis. Brain. 2006 Jun; 129(Pt 6): 1438-45.

15. Gordon N. Alpers syndrome: progressive neuronal degeneration of children with liver disease. Dev Med Child Neurol. 2006 Dec; 48(12):1001-3.

16. Copeland WC. Inherited mitochondrial diseases of DNA replication. Annu Rev Med. 2008;59:131-46.

17. Nguyen KV, Sharief FS, Chan SSL, Copeland WC, Naviaux RK. Molecular diagnosis of Alpers syndrome. J Hepatol. 2006 Jul; 45(1):108-16.

18. de Koning TJ, Duran M, Dorland L, Gooskens R, Van Schaftingen E, Jaeken J, et al. Beneficial effects of L-serine and glycine in the management of seizures in 3-phosphoglycerate dehydrogenase deficiency. Ann Neurol. 1998 Aug; 44(2):261-5.

19. Jaeken J, Detheux M, Van Maldergem L, Frijns JP, Alliet P, Foulon $\mathrm{M}$, et al. 3-Phosphoglycerate dehydrogenase deficiency and 3phosphoserine phosphatase deficiency: inborn errors of serine biosynthesis. J Inherit Metab Dis. 1996;19(2):223-6.

20. Stöckler S, Holzbach U, Hanefeld F, Marquardt I, Helms G, Requart $M$, et al. Creatine deficiency in the brain: a new, treatable inborn error of metabolism. Pediatr Res. 1994 Sep; 36(3):409-13.

21. Stromberger C, Bodamer OA, Stöckler-Ipsiroglu S. Clinical characteristics and diagnostic clues in inborn errors of creatine metabolism. J Inherit Metab Dis. 2003; 26(2-3):299-308.

22. Mercimek-Mahmutoglu S, Stoeckler-Ipsiroglu S, Adami A, Appleton R, Araújo HC, Duran M, et al. GAMT deficiency: features, treatment, and outcome in an inborn error of creatine synthesis. Neurology. 2006 Aug 8; 67(3):480-4.

23. Stöckler S, Marescau B, De Deyn PP, Trijbels JM, Hanefeld F. Guanidino compounds in guanidinoacetate methyltransferase deficiency, a new inborn error of creatine synthesis. Metabolism. 1997 Oct; 46(10):1189-93.

24. Stöckler-Ipsiroglu S, Battini R, de Grauw T, Schulze A. Disorders of creatine metabolism. In Blau N, Hoffmann GF, Leonard J, Clarke JTR, editors. Physician's guide to the treatment and follow-up of metabolic diseases. Heidelberg (Germany): Springer Verlag; 2005. p. 255-65. 


\title{
Vitamin $B_{6}$ Dependent Seizures
}

\author{
Barbara Plecko, Sylvia Stöckler
}

\begin{abstract}
Vitamin $\mathrm{B}_{6}$ is an abundant cofactor in aminoacid- and neurotransmitter metabolism. Physiologic availability depends on dietary supply, intact absorption and conversion of pyridoxamine and pyridoxine into the only active cofactor, pyridoxal-5'-phosphate (PLP) in liver. By now we know of four genetic epilepsies with vitamin $\mathrm{B}_{6}$ dependent seizures. Two are caused by reduced synthesis/availability of PLP (Pyridox(am)in-phosphate oxidase (PNPO) deficiency and infantile hypophosphatasia) and two by increased utilization/inactivation (pyridoxine-dependent epilepsy and hyperprolinemia type II). Aside from hyperprolinemia type II these disorders usually present with therapyresistant (myoclonic) seizures in the neonatal period. The EEG findings may range from burst suppression pattern to unspecific slowing or may even be normal. All four disorders can be diagnosed by reliable biomarkers and be confirmed by molecular analysis of the respective genes. While PLP would benefit all four entities, PNPO patients are typically resistant to pyridoxine and need PLP substitution. Especially in neonatal, therapyresistant seizures, these disorders have to be considered early, to prevent irreversible neurologic damage.
\end{abstract}

RÉSUMÉ: Crises épileptiques dépendantes de la vitamine B6. La vitamine B6 est un cofacteur abondant du métabolisme des acides aminés et des neurotransmetteurs. Sa disponibilité physiologique dépend de l'apport alimentaire, d'une absorption efficace et de la conversion de la pyridoxamine et de la pyridoxine en pyridoxal-5'-phosphate (PLP), le seul cofacteur actif, dans le foie. Nous connaissons maintenant quatre épilepsies génétiques dépendantes de la vitamine B6. Deux sont causées par une synthèse/biodisponibilité réduite du PLP (le déficit en pyridox(am)ine-phosphate oxydase (PNPO) et l'hypophosphatasie) et deux par une utilisation/inactivation augmentée (l'épilepsie dépendante de la pyridoxine et l'hyperprolinémie de type II). Sauf dans l'hyperprolinémie de type II, les symptômes initiaux de ces maladies sont des crises myocloniques résistantes au traitement en période néonatale. Les enregistrements ÉEG peuvent varier, allant d'un tracé complètement plat (burst suppression) à un ralentissement non spécifique et ils peuvent même être normaux. Ces quatre maladies peuvent être diagnostiquées au moyen de biomarqueurs fiables et être confirmées par analyse moléculaire des gènes respectifs. Bien que la PLP puisse être bénéfique dans ces quatre maladies, la résistance à pyridoxine est typique chez les patients atteints de PNPO et ils ont besoin d'une substitution par la PLP. Chez les patients qui présentent des crises épileptiques pharmaco-résistantes, surtout en période néonatale, ces maladies doivent être envisagées promptement afin de prévenir des dommages neurologiques irréversibles.

Can. J. Neurol. Sci. 2009; 36: Suppl. 2 - S73-S77

Though pyridoxine dependent epilepsy has been known for decades our knowledge on underlying disease mechanisms and the discovery of other genetically determined forms of vitamin $\mathrm{B}_{6}$ responsive seizures has grown tremendously over the past few years.

In this overview on pyridoxine dependent seizures we will like to first give a brief introduction on pyridoxine metabolism and its various cofactor functions. We will then focus on the four genetically determined vitamin $\mathrm{B}_{6}$ dependent epilepsies known to date and discuss their seizure semiology, EEG findings, and most important- the specific diagnostic tests and treatment strategies. In addition to those genetically determined epilepsies, vitamin $\mathrm{B}_{6}$ may also have a beneficial, unspecific anticonvulsant effect. We therefore advocate, that every child with therapyresistant epilepsy should undergo a therapeutic trial with pyridoxine or pyridoxalphosphate.

\section{Pyridoxine Metabolism}

Pyridoxine is an abundant vitamin and many food sources as beef, pork and poultry, broccoli, potatoes, grain and banana have a high vitamin $\mathrm{B}_{6}$ content, while it is low in milk and milk products. The daily demand is age dependent and increases from $0.1-0.3 \mathrm{mg} /$ day in the infant to 1.2 to $1.4 \mathrm{mg} /$ day in adult females and males respectively (Table 1). Pyridoxine can be absorbed in three different forms, called vitamers (Figure 1), but only pyridoxal-phosphate (PLP) acts as the final active cofactor. For absorption, transport and cellular uptake each vitamer has to be de-phosphorylated and re-phosphorylated. Subsequently pyridoxine- and pyridoxamin-5 phosphate are converted into PLP in the liver by the pyridox(am)ine-5-phosphate oxidase (PNPO). Pyridoxal-phosphate is a cofactor of various enzymatic

From the Division of Biochemical Diseases and Cystic Fibrosis (BP, SS), Children's and Women's Health Center, University of British Columbia, Vancouver, BC, Canada. Department of Pediatrics (BP), Medical University Graz, Graz, Austria.

Received August 28, 2008. Final Revisions Submitted October 7, 2008. Correspondence to: Barbara Plecko, Department of Pediatrics, Medical University Graz, Auenbruggerplatz 30, A-8036 Graz, Austria. 
Table 1: Daily demand of Vitamin $B_{6}$

$\begin{array}{ll}\text { infants } & 0.1-0.3 \mathrm{mg} / \text { day } \\ \text { toddlers } & 0.4-0.5 \mathrm{mg} / \text { day } \\ 4-10 \mathrm{y} & 0.5-0.7 \mathrm{mg} / \text { day } \\ \text { teenagers } & 1.2-1.6 \mathrm{mg} / \text { day } \\ \text { adults } & \mathrm{m} 1.4 \mathrm{f} 1.2 \mathrm{mg} / \text { day }\end{array}$

Recommendations of DACH 2000

reactions in aminoacid- and neurotransmitter metabolism such as the conversion of glutamate into GABA, the glycine cleavage system, and the aromatic acid decarboxylase in serotonine and homovanillic acid synthesis. It is watersoluble and crosses the blood brain barrier easily. Few data exist on age dependent normal values of PLP in CSF.

Nutritional vitamin $\mathrm{B}_{6}$ deficiency in humans has been observed during periods of severe and prolonged malnutrition but also along with inactivation of pyridoxine in pasteurized infant formula during the early 1950's. The signs of nutritional pyridoxine deficiency are systemic and, in addition to recurrent seizures, lead to anemia, severe failure to thrive and chronic eczema.

\section{Pyridoxal-Phosphate dependent Epilepsy (OMIM 610090)}

In 2002, the Japanese group of Kang et al observed a patient with neonatal, therapyresistant seizures, which responded to the iv. administration of PLP, but recurred once the child was switched to oral pyridoxine ${ }^{1}$. In 2003, Clayton et al carefully investigated another PLP responsive patient and due to the neurotransmitter-profile of low HVA and HIAA but normal activity of the aromatic acid decarboxylase suggested a defect in vitamin $\mathrm{B}_{6}$ metabolism ${ }^{2}$. Secondary elevation of vanillactate in urine and of lactate, glycine and threonine in plasma and CSF may serve as additional biochemical markers (Figure 2), but are per se unspecific and were absent in some patients. The underlying enzyme defect is located at the level of pyridox(am)ine-5 phosphate oxidase (PNPO) (Figure 1), an enzyme expressed in liver but not in fibroblasts. The diagnosis is confirmed by molecular analysis of the PNPO gene ${ }^{3}$. Once detailed age dependent normal values for PLP in CSF have been established, decreased PLP concentrations in CSF may become a reliable diagnostic marker of PNPO deficiency. PLP is unstable in daylight. To avoid pre-analytical breakdown immediate protection of the tubes is mandatory. As with other treatable metabolic disorders it is crucial to save diagnostic samples and to start the cofactor trial without diagnostic delay. PLP is not available in iv. preparation outside of Japan and also its' oral form is unlicensed outside of Japan. Usually PLP is available as a purified powder from pharmaceutical companies or from naturopathic stores.

Patients with PNPO deficiency experience systemic PLP deficiency with neonatal epileptic encephalopathy as the leading clinical symptom. Patients are frequently born prematurely and

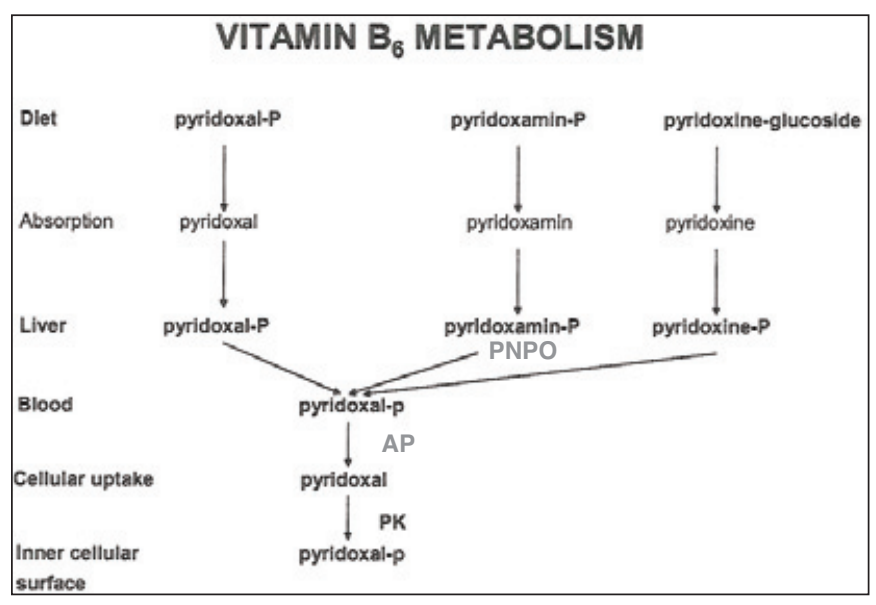

Figure 1: Pyridoxine can be absorbed as three different vitamers. For absorption, transport and cellular uptake each vitamer has to be dephosphorylated and re-phosphorylated. In the liver pyridoxine- and pyridoxamin-5 phosphate are converted into the only active cofactor pyridoxal-phosphate (PLP) by the pyridox(am)ine-5-phosphate oxidase (PNPO).

have a neonatal seizure onset within hours after birth. Seizures are mainly myoclonic and may be associated with peculiar, roving eye movements. In addition patients show prolonged crying and agitation as signs of their metabolic encephalopathy. EEG may show multifocal discharges or a burst suppression pattern, but in some cases has been normal, even during sleep ${ }^{4}$. Seizures are typically resistant to common anticonvulsants and are resistant to pyridoxine, but immediately respond to oral (or

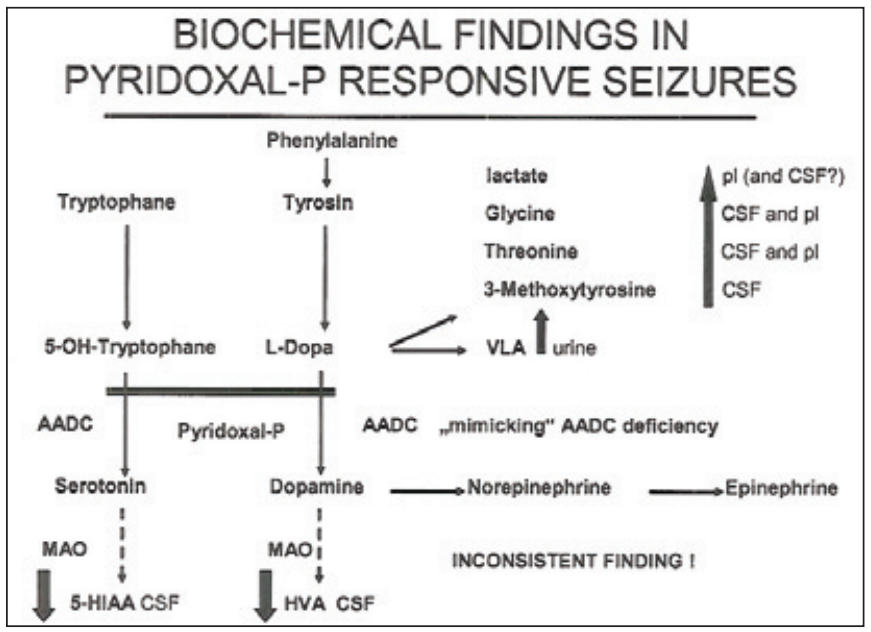

Figure 2: Pyridoxal-phosphate acts as a cofactor of aromatic acid decarboxylase $(A A D C)$ and various enzyme reactions in aminoacid metabolism. Secondary elevation of vanillactate in urine and of lactate, glycine and threonine in plasma and CSF have first been described in pyridoxal-phosphate dependent epilepsy. Nevertheless these findings are inconsistent and can be seen in other conditions with PLP depletion. 
i.v.) PLP, $30 \mathrm{mg} / \mathrm{kg}$. As in classic pyridoxine dependent epilepsy, a positive response may be associated with severe apnea, and resuscitation equipment should be at hand if a neonate is tested for this disorder. In addition to the epileptic encephalopathy many patients show signs of systemic PLP deficiency with failure to thrive, anemia and eczematous skin alterations ${ }^{4}$.

Treatment consists of life long substitution of pharmacological oral doses of PLP. Many patients need dosages of 30$50 \mathrm{mg} / \mathrm{kg} /$ day in four to six single dosages (SD) to stay seizure free. Despite seizure control, overall psychomotor development has been poor in most patients. Inheritance is autosomal recessive with a $25 \%$ recurrence risk in forthcoming pregnancies. Prenatal diagnosis can be performed by molecular analysis of the PNPO gene, if both mutations of the PNPO gene were identified in the index patient.

\section{Infantile Hypophosphatasia (OMIM 241500)}

Infantile Hypophosphatasia is dominated by severe skeletal changes and asphyxiating thoracic dystrophy usually leading to death in infancy or early childhood. It is caused by an autosomal recessive defect of the tissue non-specific alkaline phosphatase (TNSALP). In addition to its' main function as a regulator of calcium and phosphor homeostasis, alkaline phosphatase is needed for the dephosphorylation and final uptake of PLP into the cell (Figure 1). Lack of AP leads to elevated PLP plasma levels but presumably low intracellular PLP concentrations. The diagnosis is established by determination of very low AP levels and in serum and hypercalcemia on routine chemistry and can be confirmed by molecular analysis of the TNSALP gene.

In the severe infantile form neonates may manifest with therapyresistant seizures before the skeletal disease becomes more obvious or along with neonatal respiratory distress due to congenital rickets ${ }^{5}$. In the few cases reported, seizures were focal, clonic and tonic and EEG showed a burst-suppression pattern $^{6}$. Seizures are resistant to common anticonvulsants but respond to pyridoxine. The prognosis of the neonatal forms is usually fatal during the first or second year of life due to problems of ventilation and recurrent pulmonary infections.

\section{Pyridoxine Dependent Epilepsy (PDE) (OMIM 266100)}

Pyridoxine Dependent Epilepsy has first been described by Hunt et al in 1954 in two siblings with neonatal, therapyresistant seizures ${ }^{7}$. During intercurrent pneumonia one of them received a multivitamin mixture with prompt cessation of seizures. Careful follow-up and consecutive testing of the different vitamin components revealed, that the repeated withdrawal of pyridoxine led to acute seizure recurrence and sustained response when reintroduced. It was hypothesized, that PDE may be caused by deficiency of the PLP dependent glutamate decarboxylase and lack of GABA, but once the genes for the two GAD isoforms were cloned, no mutations were found in several unrelated patients $^{8}$. In 2000 Courmier-Daire et al mapped the gene locus of PDE to $5 \mathrm{q} 31^{9}$. In this same year pipecolic acid (PA) elevations in plasma and CSF were described in three unrelated patients with PDE with an intriguing inverse correlation to the intake of pyridoxine in one of them ${ }^{10}$. These findings were later proven in another six unrelated patients with $\mathrm{PDE}^{11}$. In 2006 the underlying defect of PDE was identified at the level of $\alpha$ aminoadipic semialdehyde dehydrogenase (antiquitin) in the

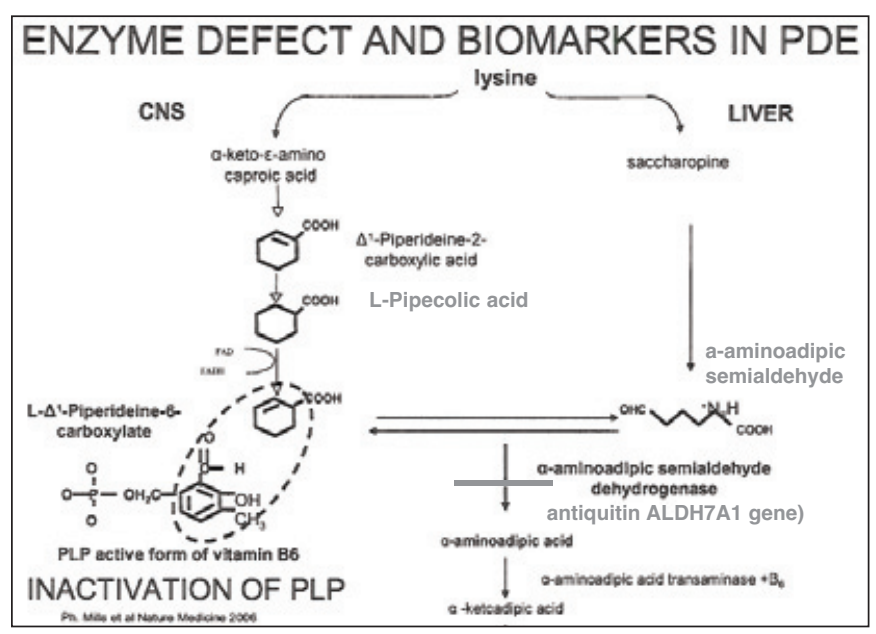

Figure 3: The underlying defect of PDE is located within the cerebral lysine degradation pathway at the level of $\alpha$-aminoadipic semialdehyde dehydrogenase (antiquitin). The accumulating $\alpha$-aminoadipic semialdehyde is in equilibrium with $\Delta 1$-piperideine-6-carboxylate (P6C). P6C interacts with PLP in a Knoevenagel condensation, thus inactivating PLP and leading to severe PLP deficiency, restricted to the brain.

lysine degradation pathway (Figure 3$)^{12}$. The accumulating $\alpha$ aminoadipic semialdehyde is in equilibrium with $\Delta 1$ piperideine-6-carboxylate (P6C). P6C interacts with PLP in a Knoevenagel condensation, thus inactivating PLP and leading to severe PLP deficiency, restricted to the brain. There are no data on CSF aminoacids or neurotransmitters in PDE patients off pyridoxine, but the profile could well be identical to PLP dependent epilepsy. PA in plasma and, more specific, $\alpha$ aminoadipic semialdehyde in urine, serve as reliable diagnostic biomarkers of antiquitin deficiency. Both compounds remain elevated during treatment with pyridoxine, making a pyridoxine withdrawal unnecessary. The diagnosis is confirmed by molecular analysis of the antiquitin ALDH7Al gene ${ }^{12-15}$, recurrence risk is $25 \%$ and prenatal diagnosis is feasible in forthcoming pregnancies.

The clinical presentation of PDE has been well characterized by several authors ${ }^{16,17}$. The classic form presents in the neonatal period with a variety of different seizures. Patients usually present with refractory seizures soon after birth. Seizures are typically refractory to common anticonvulsants, while they promptly respond to intravenous or oral administration of pyridoxine. Apnea and comatous state, following the initial administration of pyridoxine have been observed in patients with PDE, but not in non-responders. In addition to this classical presentation, patients with later onset up to three years of age, delayed response to pyridoxine and/or need for very high doses have been reported. Seizure semiology varies and multiple seizure types (focal clonic, myoclonic, or secondarily generalized) can occur within the individual patient. Status epilepticus is common. The EEG patterns may vary from high voltage delta activity to focal spike and wave discharges or even burst suppression patterns. 
The diagnosis is suspected by the prompt response to the administration of pyridoxine. Pipecolic acid and alpha aminoadipic semialdehyde in plasma, urine and CSF serve as reliable diagnostic biomarkers of PDE and analysis of the antiquitin gene, located on chromosome $5 \mathrm{q} 31$.

In therapy resistant neonatal seizures $100 \mathrm{mg}$, and if ineffective, up to $500 \mathrm{mg}$ of pyridoxine should be given iv. during EEG monitoring. Alternatively pyridoxine, 15 to 30 $\mathrm{mg} / \mathrm{kg} /$ day can be given orally. In any case pyridoxine should be given over at least three consecutive days to also catch "lateresponders". Parents have to be informed that children require a lifelong therapy with pharmacological doses of pyridoxine (usually 300 to $500 \mathrm{mg} / \mathrm{day}$ ). Due to the availability of biochemical and genetic testing, a pyridoxine withdrawal is no longer necessary to prove the diagnosis. Outcome of PDE patients depends on the age at presentation, diagnostic delay and most probably also on the underlying genotype. Even intrauterine pyridoxine substitution could not prevent mental Further studies may show, if a lysine restricted diet is of additional benefit.

\section{Hyperprolinemia Type II (OMIM 239510)}

In fact the mechanism of secondary PLP inactivation by a Knoevenagel condensation has first been described in this disease ${ }^{19}$. The accumulating compound is a P5C ( $\square^{1}$-pyrroline-5carboxylate) accumulating within the proline degradation pathway. Hyperprolinemia type II is caused by an enzyme defect at the level of pyroline 5 carboxylate dehydrogenase.

The disease seems to be rare and has been first described in Irish Nomads ${ }^{20}$. Patients present with Grand mal seizures (five out of seven children) with or without mental retardation $(2 / 5)$. Patients have been reported to also respond to common anticonvulsants, but some may need a combination therapy and may be more difficult to treat. Several individuals with hyperprolinemia type II have a normal phenotype, suggesting that hyperprolinemia may be a mild condition in some cases.

Diagnosis is established by aminoacid analysis in plasma, showing very high proline concentrations around $2000 \mu \mathrm{mol} / \mathrm{l}$, retardation in an offspring with homozygosity for a stop codon ${ }^{18}$.

normal 100-450) and the excretion of P5C in urine. In cases of therapyresistance, pyridoxine, 300 to $500 \mathrm{mg} /$ day should be added and, if effective, tapering of common anticonvulsants may be tried.

\section{Conclusion}

By now we know of 4 different genetic defects that can cause vitamin $\mathrm{B}_{6}$ dependent seizures (Table 2). Table 3 shows the respective diagnostic tests and material needed to establish the diagnosis. The incidence of each of these genetic defects is unknown by now. Two of these defects are caused by PLP inactivation (PDE/antiquitin deficiency, hyperprolinemia type II) and two are caused by defects within pyridoxine metabolism itself (PNPO deficiency, infantile hypophosphatasia/alkaline phosphatase deficiency).

PLP would have the potential to treat seizures in all four genetic defects, while pyridoxine is ineffective in PNPO deficiency.

Especially in neonatal, therapy-resistant seizures, these treatable metabolic epilepsies have to be considered early on, samples be saved and a cofactor trial of vitamin $B_{6}$ initiated without diagnostic delay.

As PLP by now is unlicensed outside of Japan, we would recommend to start with $100 \mathrm{mg}$ of pyridoxine iv., followed by $30 \mathrm{mg} / \mathrm{kg} /$ day in 2-3 SD over at least three consecutive days (max daily dose $200 \mathrm{mg}$ ). In the absence of a positive response, this should be followed by a PLP trial with 30 to $50 \mathrm{mg} / \mathrm{kg} /$ day in 4-6 SD.

Early treatment is mandatory to prevent longterm sequelea. Establishment of a molecular diagnosis enables prenatal diagnosis in forthcoming pregnancies.

\section{REFERENCES:}

1. Kuo MF, Wang HS. Pyridoxal-phosphate responsive epilepsy with resistance to pyridoxine. Pediatr Neurol. 2002;26:146-7.

2. Clayton PT, Surtees RA, DeVile C, Hyland K, Heales SJ. Neonatal epileptic encephalopathy. Lancet. 2003;361:1614.

Table 3: Selective screening for $B_{6}$ dependent seizures

Table 2: Vitamin $B_{6}$ dependent seizures and inborn errors

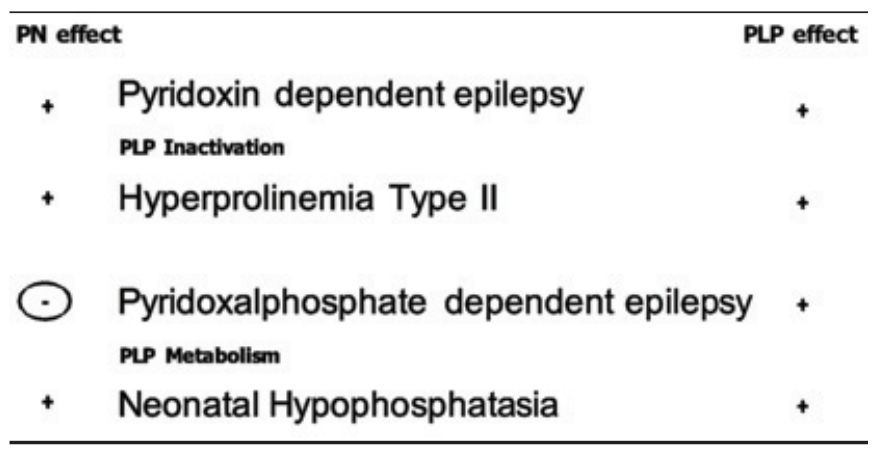

\begin{tabular}{l|lll}
\hline PLPdep.E . & URINE & PLASMA & CSF \\
Congllactate & $\begin{array}{c}\text { PLP level } \\
\text { AA, lactate }\end{array}$ & $\begin{array}{l}\text { PLP level, AA, lactate } \\
\text { neurotransmitters }\end{array}$ \\
PDE & AASA & $\begin{array}{c}\text { Ak, Phosp, Ca, Ph, } \\
\text { PLP level }\end{array}$ & \\
HP II & AASA, PA & AASA, PA \\
\hline
\end{tabular}

Pip dep. E - Pyridoxalphosphate dependent epilepsy; AA - aminoacids; HP - hypophosphatasia; PDE - pyridoxine dependent epilepsy; AASA aminoadipic semialdehyde; PA - pipecolic acid; HP II - hyperprolinemia type II; P5C $\square^{1}$ pyrolline-5-carboxylate 
3. Mills PB, Surtees RA, Champion MP, Beesley CE, Dalton N, Scambler PJ, et al. Neonatal epileptic encephalopathy caused by mutations in the PNPO gene encoding pyridox(am)ine 5'phosphate oxidase. Hum Mol Genet. 2005 Apr 15;14(8): 1077-86.

4. Hoffmann GF, Schmitt B, Windfuhr M, Wagner N, Strehl H, Bagci $\mathrm{S}$, et al. Pyridoxal 5'-phosphate may be curative in early-onset epileptic encephalopathy. J Inherit Metab Dis. 2007 Feb;30(1): 96-9.

5. Litmanovitz, Reish O, Dolfin T, Arnon S, Regev R, Grinshpan G, et al. Glu274Lys/Gly309Arg mutation of the tissue-nonspecific alkaline phosphatase gene in neonatal hypophosphatasia associated with convulsions. J Inherit Metab Dis. 2002;25(1): 35-40.

6. Baumgartner-Sigl S, Haberlandt E, Mumm S, Scholl-Bürgi S, Sergi $\mathrm{C}$, Ryan L, et al. Pyridoxine-responsive seizures as the first symptom of infantile hypophosphatasia caused by two novel missense mutations (c.677T>C, p.M226T; c.1112C>T, p.T371I) of the tissue-nonspecific alkaline phosphatase gene. Bone. 2007; 40(6): 1655-61.

7. Hunt AD, Stokes J, McCrory WW, Stroud HH. Pyridoxine dependency: report of a case of intractable convulsions in an infant controlled by pyridoxine. Pediatrics. 1954;13(2):140-5.

8. Battaglioli G, Rosen DR, Gospe SM Jr, Martin DL. Glutamate decarboxylase is not genetically linked to pyridoxine-dependent seizures. Neurology. 2000;55:309-11.

9. Cormier-Daire V, Dagoneau N, Nabbout R, Burglen L, Penet C, Soufflet $\mathrm{C}$, et al. A gene for pyridoxine-dependent epilepsy maps to Chromosome 5q31. A. J Hum Genet. 2000;67:991-3.

10. Plecko B, Stöckler-Ipsiroglu S, Paschke E, Erwa W, Struys EA, Jakobs C. Pipecolic acid elevation in plasma and cerebrospinal fluid of two patients with pyridoxine-dependent epilepsy. Ann Neurol. 2000 Jul;48(1):121-5.
11. Plecko B, Hikel C, Korenke GC, Schmitt B, Baumgartner M, Baumeister F, et al. Pipecolic acid as a diagnostic marker of pyridoxine-dependent epilepsy. Neuropediatrics. 2005 Jun;36 (3):200-5

12. Mills PB, Struys E, Jakobs C, Plecko B, Baxter P, Baumgartner M, et al. Mutations in antiquitin in individuals with pyridoxinedependent seizures. Nature Medicine. 2006; 307-9.

13. Plecko B, Paul K, Paschke E, Stoeckler-Ipsiroglu S, Struys E, Jakobs C, et al. Biochemical and molecular characterization of 18 patients with pyridoxine-dependent epilepsy and mutations of the antiquitin (ALDH7A1) gene. Hum Mutat. 2007, 28(1):19-26.

14. Salomons GS, Bok LA, Struys EA, Pope LL, Darmin PS, Mills PB, et al. An intriguing "silent" mutation and a founder effect in antiquitin (ALDH7A1). Ann Neurol. 2007 Oct;62(4):414-8.

15. Kanno J, Kure S, Narisawa A, Kamada F, Takayanagi M, Yamamoto $\mathrm{K}$, et al. Allelic and non-allelic heterogeneities in pyridoxine dependent seizures revealed by ALDH7A1 mutational analysis. Mol Genet Metab. 2007. 91(4):384-9.

16. Gospe SM Jr. Current perspectives on pyridoxine-dependent seizures. J Pediatr. 1998 Jun;132(6):919-23.

17. Baxter P. Pyridoxine-dependent seizures: a clinical and biochemical conundrum. Biochim Biophys Acta. 2003 Apr 11;1647(1-2): 36-41.

18. Rankin PM, Harrison S, Chong WK, Boyd S, Aylett SE. Pyridoxine-dependent seizures: a family phenotype that leads to severe cognitive deficits, regardless of treatment regime. Dev Med Child Neurol. 2007; 49(4):300-5.

19. Farrant RD, Walker V, Mills GA, Mellor JM, Langley GJ. Pyridoxal phosphate de-activation by pyrroline-5-carboxylic acid. Increased risk of vitamin $\mathrm{B}_{6}$ deficiency and seizures in hyperprolinemia type II. J Biol Chem. 2001;276(18):15107-16.

20. Flynn MP, Martin MC, Moore PT, Stafford JA, Fleming GA, Phang JM. Type II hyperprolinemia in a pedigree of Irish travelers. Arch Dis Child. 1989;64:1699. 


\title{
Investigating Epigenetic Influences on Seizure Disposition
}

\author{
Krista L. Gilby
}

\begin{abstract}
Rats selectively bred to be seizure-prone versus resistant naturally exhibit behaviors, neuroanatomy and physiology that are reminiscent of attention deficit hyperactivity disorder (ADHD) and autism spectrum disorders (ASD) in humans. Evidence suggests these characteristics evolve via genetic/epigenetic mechanisms acting prior to birth that most likely involve aberrant lipid handling.
\end{abstract}

RÉSUMÉ: Influences épigénétiques sur la prédisposition à l'épilepsie. Les lignées de rats, produites par sélection d'animaux prédisposés à l'épilepsie et d'animaux qui y sont résistants, présentent des comportements, des caractéristiques neuroanatomiques et physiologiques qui rappellent celles du trouble déficit de l'attention avec hyperactivité et des troubles du spectre autistique chez l'humain. Selon certaines données, il y aurait des mécanismes génétiques/épigénétiques qui agissent avant la naissance et qui impliquent probablement une utilisation anormale des lipides.

Can. J. Neurol. Sci. 2009; 36: Suppl. 2 - S78-S81

The Fast and Slow kindling rat strains were originally developed in an effort to determine whether commercially available 'normal' rat strains, namely Long Evans Hooded and Wistar rats, could be selectively bred to create relatively seizureprone (Fast) versus -resistant (Slow) populations ${ }^{1}$. Indeed, through kindling (repeated electrical stimulation of the amygdala), two distinct rat populations were created with respect to seizure vulnerability after only 11 generations of breeding. This difference in seizure sensitivity has since been documented across several seizure-induction paradigms ${ }^{2-4}$ and is not only resident to the amygdala (the structure used for derivation) but extends to numerous limbic structures ${ }^{5}$. Interestingly, while breeding for seizure disposition, distinct behavioral comorbidities began to emerge in both rat populations, with Fast rats exhibiting behaviors reminiscent of attention deficit hyperactivity disorder (ADHD) and the autism spectrum of disorders (ASD) in humans. In several paradigms, Fast rats show clear hyperactive and impulsive behaviors alongside relative learning deficits compared to the Slow strain ${ }^{6}$. These are, of course, the three hallmark characteristics of ADHD. Related symptoms in ASD include a generalized learning disability, lack of responsiveness to social cues and inattentiveness and hyperactivity during the initial stages of the disorder ${ }^{7}$.

While their behavioral patterns certainly exhibit ADHD/ ASD-like characteristics, we have recently discovered that the seizure-prone Fast rats also show signs of some of the lesser known indications of ADHD/ASD in humans including dry skin, polydipsia, free fatty acid (FFA) deficiencies and stereotypic behaviors $^{8,9}$. Moreover, reduced urinary excretion of certain organic acids has also been documented in Fast compared to Slow rats, including 3- \& 4- hydroxyphenylproprionic acid (a metabolite of phenylalanine or tyrosine) and 3-indoleacetic acid (a serotonin metabolite). Both phenylethylamine (PEA), which is biosynthesized from the amino acid phenylalanine, and phenylalanine itself, are similarly reduced in the urine of humans with $\mathrm{ADHD} / \mathrm{ASD}^{10,11}$. Phenylalanine, in fact, is the chief amino acid reduced in the plasma of humans with autism and ADHD.

Accordingly, PEA levels significantly increase after methylphenidate therapy in ADHD patients that behaviorally respond to treatment, which is highly suggestive of a functional correlation $^{11}$. The low levels of 3 -indoleacetic acid observed in the urine of Fast rats are also consistent with the compromised metabolism/excretion of 5-HT metabolites documented in $\mathrm{ASD} / \mathrm{ADHD}^{12}$. Last but not least, compared to Slow rats, the neuroanatomy of the seizure-prone Fast strain bears a striking resemblance to what has been reported in both epilepsy and in ADHD/ASD patients. The most obvious parallel being a clear ventriculomegaly and reduced white matter volumes,

\footnotetext{
From the Department of Psychology, Institute of Neuroscience, Carleton University, Ottawa, Ontario, Canada.

Received December 9, 2008. Final Revisions Submitted January 8, 2009. Correspondence to: Krista L. Gilby, Department of Psychology, Institute of Neuroscience, Carleton University, 1125 Colonel By Drive, Ottawa, Ontario, K1S 5B6, Canada.
} 
particularly with respect to the corpus callosum [Figure 1]. The observation that so many of these behavioral and physiological ADHD/ASD characteristics naturally evolved during the derivation of the seizure-prone strain is perhaps not surprising considering the frequent co-occurrence of epilepsy and ADHD/ASD in humans ${ }^{13}$. Indeed, children with ADHD have a 2.5 -fold increased risk for unprovoked seizures ${ }^{14}$, while approximately $25 \%$ of children with autism will experience clinical or subclinical seizures, and those that do not are still at higher risk for seizure ${ }^{15}$. Thus, the Fast and Slow rat strains have emerged not only as an excellent behavioral model for these aggregate disorders but also, and perhaps more importantly, as a physiological and neuroanatomical homology for the predisposition.

The fact that all three of these disorders tend to cluster in families points to common elements at the level of genetic predisposition. Indeed, a genetically controlled vulnerability to seizure, and the accompanying behavioral comorbidities, is implied by the fact that our two rat populations were created via selective breeding alone. Yet, within the last 25 years, research has shown that the post-natal environment as a whole (e.g., maternal care) or more discrete post-natal events, such as

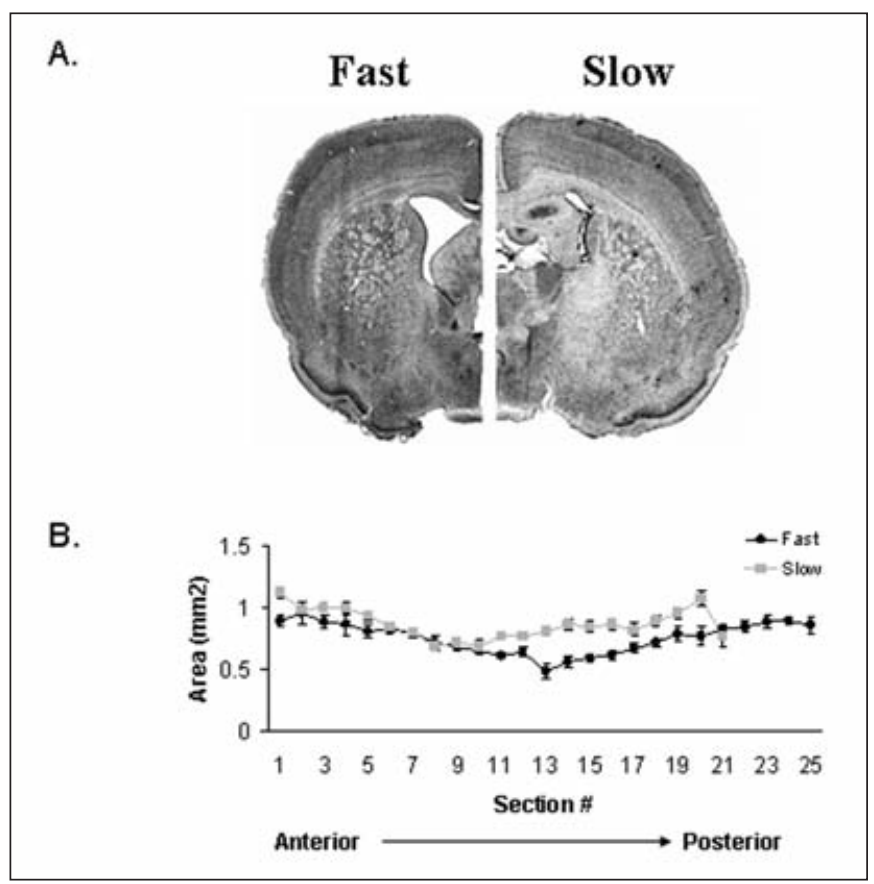

Figure 1: Adjacent coronal sections from a Fast and Slow brain (A). Fast rats show a relative ventriculomegaly, reduced dorsal hippocampal volume and thinner corpus callosum as it crosses the midline. Differences in the corpus callosum are graphically represented $(B)$ by comparing successive cross-sectional areas running anterior to posterior in Fast vs Slow rats. Fast rats exhibit a thinner, yet longer, corpus callosum than Slow rats. handling or maternal separation in rodents, can cause long term molecular fallout that is likely to impact seizure predisposition and adult behavioral phenotypes ${ }^{16,17}$. Indeed, adult behaviors in rodents, similar to those observed in Fast and Slow rats, have been correlated with differences in early mothering styles ${ }^{17}$. ADHD/ASD behaviors and seizure susceptibility in humans are also believed to have some environmental/epigenetic underpinnings, yet what they might be is a current source of controversy. In an attempt to investigate potential post-natal influences on our distinct strain phenotypes, a large crossfostering study was undertaken where Fast pups were raised by Slow mothers and vice versa. Ultimately, some maternal behavioral patterns were naturally different between the strains and then some proved malleable by fostered pup strain (i.e., pups from the opposing strain altered maternal behaviors normally exhibited by Fast or Slow mothers). Thus, very complex patterns of maternal behavior resulted across groups. However, despite the at times profound changes in maternal care, the relative seizure dispositions (unpublished data) and characteristic behaviors in Fast and Slow offspring remained unaltered ${ }^{18}$. Interestingly, however, the mere act of crossfostering alone did proportionally increase seizure sensitivity in both strains, such that even when litters were fostered within a strain (i.e., to a different mother from the same strain), seizure facilitation was evident in the offspring as adults. These data clearly demonstrate that exposure to a particular strain-specific post-natal environment is not the determining factor in the ontogeny of their distinctive phenotypes. Instead, their relative seizure sensitivity and its associated comorbidities are likely established prior to birth. However, the clear seizure facilitating effects of crossfostering the pups at all, regardless of the strain of recipient mother, speaks to a capacity to manipulate 'predisposed' animals post-natally. This finding has powerful clinical relevance as it promises a protracted period for environmental or pharmacological intervention that might prevent post-natal worsening of the predisposed genotype.

The idea that the relative Fast and Slow phenotypes are established prior to birth is highly suggestive of exclusive genetic control, yet the in utero environment can also have a profound impact on the developing fetus. Indeed, maternal diet directly influences the nutritive status of the fetus ${ }^{19}$ and, to some degree, patterns of gene expression during critical periods of development. For instance, both rat and human fetuses/newborns are natively inefficient at converting essential fatty acid (EFA) precursors to long chain polyunsaturated fatty acids (LCPUFAs), yet LCPUFA synthesis is necessary for normal placental and fetal development, such that deficiencies lead to developmental delay (a well known symptom in this aggregate of disorders ${ }^{20}$. Thus, a shortage in LCPUFAs provided from the maternal diet would profoundly affect neurodevelopment in the offspring. This is particularly relevant to our work with the Fast and Slow rats since, as seen in children afflicted with ADHD/ASD, we have documented a FFA deficiency in the plasma of our seizure-prone Fast rats, despite maintenance on the same, well balanced diet. The vast functional mandate for fatty acids during neurodevelopment suggests this deficiency in pregnant Fast females should dramatically affect neurodevelopment in the pups, including patterns of gene expression during critical periods of development. Accordingly, using differential 


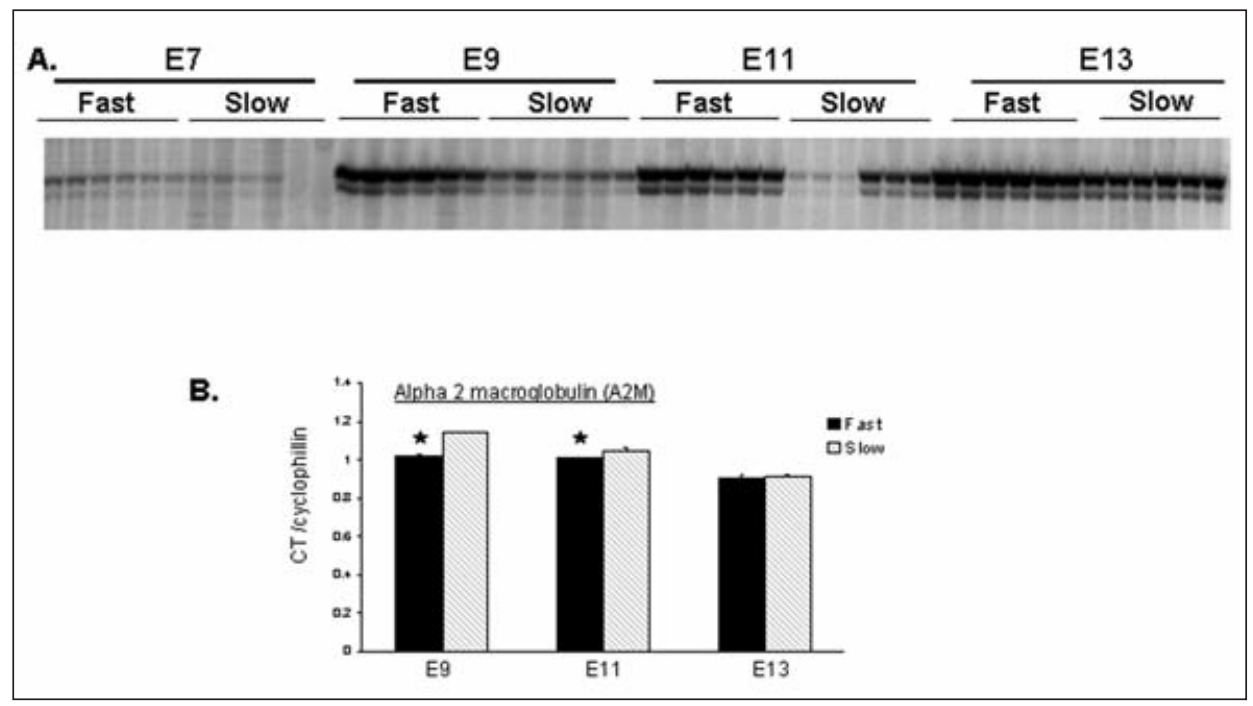

Figure 2: A section of a differential display autoradiogram showing a candidate band with higher expression in Fast versus Slow embryos at embryonic day 7 (E7), 9 and 11 (A). This band was extracted, sequenced and identified to be alpha 2 macroglobulin (A2M). QPCR analysis (B) then confirmed higher expression of A2M in Fast embryos at E11 and 13.* = significantly different at $p<.05$.

display/quantitative PCR, we have shown that gene expression patterns diverge in these strains as early as embryonic day (E) 7 such that Fast rats show premature expression of the alpha-2 macroglobulin (A2M) transcript. Slow rats do not show comparable expression until E13 [Figure 2]. A2M is a known ligand for the low density lipoprotein-related (LRP) receptor and a powerful regulator of FA metabolism and reelin (Reln)-based control mechanisms of brain formation ${ }^{21}$. Notably, Reln is already suspected as a candidate gene for ASD and some forms of epilepsy ${ }^{22}$. These findings demonstrate that Fast and Slow embryos begin to diverge as early as seven days post-conception. Aberrant lipid handling has long been suspected in ADHD/ASD and epilepsy patients and these disorders have, in many cases, been successfully treated through FA supplementation in the $\operatorname{diet}^{8}$. Yet, taken as a whole, findings in these types of studies are confusing and somewhat inconsistent. Still, it is clear that physiological/molecular mechanisms that are responsive to changes in the environment (diet, stress, etc.) provide potential epigenetic venues through which a common predisposition for these types of disorders can occur and so too the evolution of our strain phenotypes. Through these venues we should also find plausible points of non-invasive, therapeutic intervention/ prevention, which is highly desirable given the recent surge of children suffering from ADHD/ASD.

\section{REFERENCES}

1. Racine RJ, Steingart M, McIntyre DC. Development of kindlingprone and kindling-resistant rats: selective breeding and electrophysiological studies. Epilepsy Res. 1999;35:183-95.

2. Xu B, Fahnestock M, McIntyre DC, Racine RJ. Strain differences affect in induction of status epilepticus and seizure-induced morphological changes. Eur J Neurosci. 2004;20(2):403-18.
3. Gilby KL, Goncalves da Silva A, McIntyre DC. Differential GABAA subunit expression following status epilepticus in seizure-prone and seizure-resistant rats: A putative mechanism for refractory behavior. Epilepsia. 2005;46:3-9.

4. Veliskova J, Asnis J, Lado FA, McIntyre DC. Development of kindling in immature Fast and Slow kindling rats. In: Corcoran ME, Moshe SL, editors. Kindling 6. New York: Springer Science Inc; 2005. p. 19-26.

5. McIntyre DC, Kelly ME, Dufresne C. FAST and SLOW amygdala kindling rat strains: comparison of amygdala, hippocampal, piriform and perirhinal cortex kindling. Epilepsy Res. 1999;35:197-209.

6. Anisman H, McIntyre DC. Conceptual, spatial and cue learning in the Morris water-maze in Fast or Slow kindling rats: attention deficit comorbidity. J Neurosci. 2002;22(17):7809-17.

7. Jones GC. Autistic spectrum disorder: diagnostic difficulties. Prostaglandins Leukot Essent Fatty Acids. 2000;63:33-6.

8. Richardson AJ. Long-chain polyunsaturated fatty acids in childhood developmental and psychiatric disorders. Lipids. 2004:39(12):1215-22.

9. Richardson AJ. Omega-3 fatty acids in ADHD and related neurodevelopmental disorders. Int Rev Psychiatry. 2006;18(2): $155-72$.

10. Kusaga A. Decreased beta-phenylethylamine in urine of children with attention deficit hyperactivity disorder and autistic disorder. No To Hattatsu. 2002a;34(3):243-8.

11. Kusaga A, Yamashita Y, Koeda T, Hiratani M, Kaneko M, Yamada $\mathrm{S}$, et al. Increased urine phenylethylamine after methylphenidate treatment in children with ADHD. Ann Neurol. 2002b;52(3): $372-4$.

12. Richardson AJ, Ross MA. Fatty acid metabolism in neurodevelopmental disorders: a new perspective on associations between attention-deficit/hyperactivity disorder, dyslexia, dyspraxia and the autistic spectrum. Prostaglandins Leukot Essent Fatty Acids. 2000;63(1-2):1-9.

13. Kanner AM. When did neurologists and psychiatrists stop talking to each other? Epilepsy Behav. 2003;4(6):597-601. 
14. Hesdorffer DC, Ludvigsson P, Olafsson E, Gudmundsson G, Kjartnasson O, Hauser WA. ADHD as a risk factor for incident unprovoked seizures and epilepsy in children. Arch Gen Psychiatry. 2004;61(7):731-6.

15. Deonna T, Roulet E. Autistic spectrum disorder: evaluating a possible contributing or causal role of epilepsy. Epilepsia. 2006;47 Suppl 2:79-82.

16. Hsu F, Zhang G, Raol YSH, Valentino RJ, Coulter DA, BrooksKayal AR. Repeated neonatal handling with maternal separation permanently alters hippocampal GABAA receptors and behavioral stress responses. PNAS. 2003;100(21):12213-18.

17. Menard JL, Vhampagne DL, Meaney M.J. Variations of maternal care differentially influence 'fear' reactivity and regional patterns of cFos immunoreactivity in response to the shockprobe burying test. J Neurosci. 2004;129(2):297-308.

18. Gilby KL, Thorne V, Patey A, McIntyre DC. Confluence of genetic and maternal factors in determining behavioral phenotypes in rats selectively bred for Fast and Slow kindled seizures. Behav Neurosci. 2007;121(2):370-9.
19. Rooke JA, Sinclair AG, Ewen M. Changes in piglet tissue composition at birth in response to increasing maternal intake of long-chain $\mathrm{n}-3$ polyunsaturated fatty acids are non-linear. $\mathrm{Br} \mathrm{J}$ Nutr. 2001;86(4):461-70.

20. Hamosh M, Salem N Jr. Long-chain polyunsaturated fatty acids. Biol Neonate. 1998;74(2):106-20.

21. Lorent K, Overbergh L, Moechars D, De Strooper B, Van Leuven F, Van den Berghe H. Expression in mouse embryos and in adult mouse brain of three members of the amyloid precursor protein family, of the alpha-2-macroglobulin receptor/low density lipoprotein receptor-related protein and of its ligands apolipoprotein E, lipoprotein lipase, alpha-2-macroglobulin and the 40,000 molecular weight receptor-associated protein. Neuroscience. 1995;65(4):1009-25.

22. Muhle R, Trentacoste SV, Rapin I. The genetics of autism. Pediatrics. 2004;113(5):472-86. 


\title{
Extratemporal "Limbic" Seizures
}

\author{
Introductory Remarks
}

Can. J. Neurol. Sci. 2009; 36: Suppl. 2 - S82-S83

The organizing committee of the 30th Anniversary Conference of the Canadian League Against Epilepsy chose to include a plenary session on extratemporal limbic seizures. This session was chaired by myself with formal presentations from Dr. Richard McLachlan (anatomy and physiology of the limbic system), Dr. Dang Nguyen (insular seizures), and Dr. Francois Dubeau (orbital frontal and cingulate gyrus seizures).

A definition of "extratemporal limbic seizures" is lacking. An inherent problem in proposing criteria is that "the limbic system remains an enigma to many neuroscientists, primarily because nobody has succeeded in providing a generally accepted definition of it"1. Heimer and Van Hoesen indicate that the evolution of the limbic system as a concept is problematic because of neuroscientists' attempts to assign specific functions (i.e. emotions) to a series of closely related anatomical structures ${ }^{1}$. This approach contrasts with, for example, the historical approach of defining the visual system where structures were first identified and functions subsequently deduced. Heimer and Van Hoesen propose that the limbic system contains the major cortical (orbital-frontal, cingulate, and insular cortices plus the hippocampus) and cortical-like structures (laterobasal-cortical amygdala) known to be important for emotional and motivational functions ${ }^{1}$. Their review, based on modern neuroanatomical techniques, is highly recommended for the clarity of discussion and the excellent anatomic illustrations.

Accepting this definition of the limbic system we can, therefore, consider seizures arising from orbital-frontal and cingulate cortex, plus the insula, as candidates for extratemporal limbic seizures. A perusal of the epilepsy literature discloses an expanding number of case series and case reports describing patients with seizures arising from these anatomical zones. Patients usually have undergone extensive investigation (including intracranial EEG monitoring) and some have received surgical resections. These publications describe the semiology of ictal events; seizure freedom following surgery is generally accepted as proof that the resected zone was the site of seizure onset. The authors typically draw attention to the characteristics of extratemporal limbic seizures that may clinically and electroencephalographically resemble the much more common seizures of mesial temporal lobe origin.
Temporal lobectomy fails to "cure" temporal lobe epilepsy (TLE) in $20-30 \%$ of patients ${ }^{2,3}$. Failure to recognize an extratemporal origin may account for some of these TLE surgical failures. Ryvlin and Kahane recently introduced the term "temporal plus epilepsy" to describe patients with seizures characterized by prominent ictal involvement of the temporal lobe but whose seizures are initiated in, or ultimately involve, an epileptic network that may include the orbital frontal cortex, insular cortex, or other functionally connected areas ${ }^{4}$. Barba et al (in a retrospective review of their experience with stereotactic depth EEG in 58 TLE patients and 22 "TLE-plus" patients) demonstrated that ictal clinical symptoms and scalp EEG, but not MRI, were (a) useful in distinguishing these two groups and, (b) can assist in the identification of those individuals who should undergo invasive recordings prior to surgical considerations 5 .

Frontal lobe complex partial seizures (FLCPS) have been recognized for over 50 years ${ }^{6}$. The clinical similarities of FLCPS originating in the orbital-frontal cortex to seizures of temporal lobe origin were reported in the early $1970 \mathrm{~s}^{7,8}$. Although Tharp ${ }^{7}$ speculated that the impaired awareness in FLCPS of orbitalfrontal origin was secondary to ictal propagation to the temporal lobe, Ludwig et $\mathrm{al}^{8}$ considered that ictal automatisms and impaired awareness could result from ictal EEG rhythms confined to frontal structures. There are very few case reports of orbital frontal epilepsy that meet the criterion of precise ictal localization with invasive electrodes, surgical resection, and subsequent seizure freedom with long follow-up. For example, as recently as 2004 , Smith et $\mathrm{al}^{9}$ reported two cases of orbital frontal epilepsy that were seizure free five years post surgical resection and added two similar cases from the literature. Among these four cases were patients with impaired awareness associated with oroalimentary automatisms or limited loss of awareness and vigorous motor automatisms. No clinical manifestations occurred until the ictal rhythms spread to the contralateral orbital frontal cortex and both mesial temporal lobes $^{9}$. The authors recommended that invasive EEG coverage of the orbital frontal cortex be considered for epilepsy surgery candidates who have the combination of interictal frontal and/or frontal-temporal spikes on scalp EEG, nonlocalizing ictal scalp 
EEG, and a lack of a structural temporal lobe MRI abnormality. A survey of the current strategies employed by epilepsy surgical centres for patients with this clinical-EEG-neuroimaging scenario would be of interest. The dearth of information on the electro-clinical correlations of orbital-frontal seizures suggests that a collaborative effort among several large surgical centres might yield sufficient numbers of cases to further delineate this syndrome.

Cingulate gyrus seizures are well known for their protean clinical manifestations, some of which may mimic TLE. Devinsky's review ${ }^{10}$ emphasizes the brief, stereotyped, nocturnal predilection of seizures that typically lack a significant postictal phase. The clinical features may include autonomic symptoms (e.g. abdominal sensations, pallor, tachycardia, fear), altered awareness, complex automatisms (including oroalimentary, vocalization, bizarre motor), and tonic and/or clonic movements. Interictal and ictal scalp EEG may normal, falsely lateralizing or non-localizing.

Seizures arising from insular cortex, while recognized since the 1940's, have recently gained significant attention, predominantly as the result of publications from Lyon ${ }^{11,12}$. Technical advances in depth EEG, neuroimaging, and neurosurgery have contributed to enhanced recognition and therapeutic implications for this perhaps not-so-rare form of epilepsy. Isnard et $\mathrm{al}^{11}$ stress that complex partial seizures preceded by a sensation of laryngeal constriction followed by unpleasant paresthesias in large cutaneous areas and focal motor clonic jerks are highly suggestive of an insular onset. A complete discussion of this syndrome and the local experience of the Hopital Notre-Dame in Montreal is included in this supplement (see Nguyen et al).

The evolution of our understanding of the extratemporal limbic seizures (the "temporal plus epilepsies") will hopefully translate to more selective surgical treatments and improved outcomes for these intriguing syndromes.

\section{REFERENCES}

1. Heimer L, Van Hoesen GW. The limbic lobe and its output channels: implications for adaptive behavior. Neurosci Biobehav Rev. 2006;30:126-7.

2. McIntosh AM, Wilson SJ, Berkovic SF. Seizure outcome after temporal lobectomy: current research practice and findings. Epilepsia. 2001;42:1288-307.

3. Sadler RM. Failure of surgery for temporal lobe epilepsy: a review of selected topics. Adv Neurol. 2006;97:97-04.

4. Ryvlin P, Kahane P. The hidden causes of surgery-resistant temporal lobe epilepsy: extratemporal or temporal plus? Curr Opinion Neurol. 2005;18:125-7.

5. Barba C, Barbati G, Minotti L, Hoffmann D, Kahane P. Ictal and scalp-EEG findings differentiating temporal lobe epilepsies from temporal 'plus' epilepsies. Brain. 2007;130:1957-67.

6. Penfield W, Jasper H. Epilepsy and the functional anatomy of the human brain. Boston: Little Brown and Company; 1954.

7. Tharp BR. Orbital frontal seizures. An unique electroencephalographic and clinical syndrome. Epilepsia. 1972;13:627-42.

8. Ludwig B, Ajmone Marsan C, Van Buren J. Cerebral seizures of probable orbitofrontal origin. Epilepsia. 1975;16:141-58.

9. Smith JR, Sillay K, Winkler P, King DW, Loring DW. Orbitofrontal epilepsy: electroclinical analysis of surgical cases and literature review. Stereotact Funct Neurosurg. 2004;82:20-5.

10. Devinsky O, Morrell MJ, Vogt BA. Contributions of anterior cingulate cortex to behaviour. Brain. 1995;118:279-306.

11. Isnard J, Guenot M, Sindou M, Mauguiere F. Clinical manifestations of insular seizures: a stereo-electroencephalographic study. Epilepsia. 2004;45:1079-90.

12. Isnard J, Guenot M, Ostrowsky K, Sindou M, Mauguiere F. The role of the insular cortex in temporal lobe epilepsy. Ann Neurol. 2000;48:614-23.
R. Mark Sadler
Halifax, Nova Scotia 


\title{
A Brief Review of the Anatomy and Physiology of the Limbic System
}

\author{
Richard S. McLachlan
}

\begin{abstract}
The limbic system as described by Broca, Papez and MacLean is an important concept for clinicians and basic researchers but remains controversial. Part anatomy and part physiology, it is hypothesized to be the primary brain mechanism responsible for the well being of the animal. The limbic system processes sensory input from the external and internal environment to determine, through memory and motivation, the emotional, autonomic, motor and cognitive responses important for selfpreservation and survival. Disruption of limbic function by ictal activity is most commonly seen in temporal lobe epilepsy, but seizures in other parts of the limbic system can result in equally disturbing consequences.
\end{abstract}

RÉSUMÉ: Brève revue de l'anatomie et de la physiologie du système limbique. Le système limbique, tel que décrit par Broca, Papez et MacLean, est un concept important pour les cliniciens et les fondamentalistes, mais c'est un concept qui demeure controversé. Fondée en partie sur l'anatomie et en partie sur la physiologie, une hypothèse veut qu'il soit le principal mécanisme cérébral responsable du bien-être de l'animal. Le système limbique traite les afférences sensitives provenant de l'environnement externe et interne pour déterminer, par la mémoire et la motivation, les réponses émotionnelles, autonomes, motrices et cognitives qui sont importantes pour la conservation de soi et la survie. Le bouleversement de la fonction limbique par l'activité ictale est fréquent dans l'épilepsie temporale. Cependant, des crises épileptiques dans d'autres parties du système limbique peuvent donner lieu à des conséquences tout aussi perturbatrices.

Can. J. Neurol. Sci. 2009; 36: Suppl. 2 - S84-S87

Before embarking on this brief exploration of the anatomy and physiology of the limbic system, a word of caution is in order. John Hughlings Jackson put it best when he said, "The brain is not a series of centers connected by pathways but rather a hierarchically organized and highly interactive whole that cannot be understood piecemeal". Unfortunately, few clinicians or scientists are in a position to interpret brain function in the manner outlined by Hughlings Jackson. Despite this somewhat pessimistic view that the "piecemeal" approach belies understanding of brain function, it is not entirely without merit and, if nothing else, serves as a practical basis for the approach of clinicians to neurological disorders such as focal epilepsy. Thus I will proceed on that basis.

\section{History of the Limbic System}

Historically, an examination of the limbic system must begin with Ammon's Horn, a structure so described by early anatomists because of its resemblance to the horn of a ram. As the understanding of neuroanatomy matured, others perceived that this structure, lying in the floor of the lateral ventricle, looked more like a seahorse and thus the name we now use, the hippocampus, was first proposed by Julius Caesar Aranzi, an Italian anatomist, in 1564. However modern anatomists have not forsaken the ram's horn since the cornu ammonis and the dentate gyrus are now acknowledged as the two main components of the hippocampus. As it turns out, a cross section through the neural circuitry of this structure also resembles a seahorse but since the microscope was not invented until after Aranzi died, he would not have known this.

It was Paul Broca of area fame who, in 1878, coined the term "grand lobe limbique" (Figure 1) to describe the great lobe of cortex, consisting primarily of the cingulate gyrus and parahippocampal region, bordering (limbus $=$ border in Latin) each of the two cerebral hemispheres above and the brainstem below ${ }^{1}$. However, he did not apply any particular functional significance to this area other than a possible role in olfaction. It was not until the next century that scientific and clinical studies

From the Department of Clinical Neurological Sciences, University of Western Ontario, London, Ontario, Canada.

Received July 17, 2008. Final Revisions Submitted July 23, 2008 Correspondence to: Richard S. McLachlan, London Health Sciences Centre, 339 Windermere Rd, London, Ontario, N6A 5A5, Canada. 
demonstrated the importance of this and closely linked parts of the brain to an animal's well-being and survival.

In 1937, James Papez, an American neuroanatomist, proposed a theory of emotional processing in the brain that turned out to be quite controversial ${ }^{2}$. The "harmonious mechanism" that he envisaged as a neuroanatomical substrate for emotion encompassed a circuit or circle of connections from the hippocampus to the hypothalamus via the fornix, to the thalamus via the mammillothalamic tract, to the cingulate gyrus and back to the hippocampus (Figure 2). Prior to his seminal paper and that of Kluver and Bucy the same year describing the profound impact on affective behaviour of monkeys by bilateral lesions of the temporal lobes ${ }^{3}$, contemplation on the mechanism of emotion was largely the purview of psychiatrists and philosophers rather than anatomists or physiologists.

Although Papez's hypothesis served as a basis for considerable later research on the neurophysiology of emotion, it was subsequently demonstrated to be lacking in many regards. Many components of what we now know as the limbic system were not included in Papez's theory and even such an important structure as the amygdala was not mentioned. Alf Brodal, one of the pre-eminent neuroanatomists of the 20th century and not one to mince words, expressed this view in his 1981 textbook, "the theory of Papez is of historical interest only" . Pierre Gloor was only slightly more diplomatic in his 1997 book, pointing out that "this paper exerted a profound interest even though it was surprisingly short on hard data, rich on speculation and ultimately proved to be mistaken in its main thrust" 5 .

The theory of a "limbic system" (Figure 2) as a basis for emotion was proposed in 1952 by Paul MacLean based on an acknowledgement of the previous work of Broca and Papez in particular and his own experimental and clinical observations ${ }^{6}$. His description included "the cortex contained in the great limbic lobe of Broca (olfactory cortex, prepyriform area, hippocampal

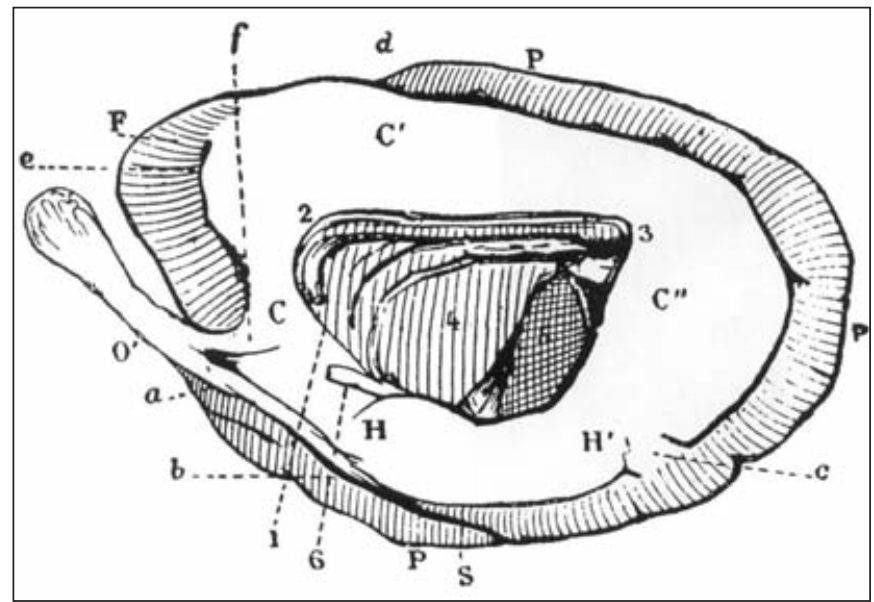

Figure 1: The great limbic lobe in an otter brain (white area) as described by Broca. $C=$ cingulate gyrus. $H=$ parahippocampal gyrus. $O=$ olfactory bulb and tract. gyrus and hippocampus; parasplenial, cingulate and subcallosal gyri) as well as "nuclear structures" (amygdala, septal nuclei, hypothalamus, epithalamus, anterior thalamic nucleus and parts of the basal ganglia)".

The concept of the limbic system to explain emotional processing has persisted and been expanded, based on both clinical and basic research, to explain a number of normal and abnormal behaviours. As a working hypothesis, it has arisen from studies of comparative anatomy, experimental physiology and clinical observation, the latter mainly from the study of epilepsy. Instrumental in formulating our current concept of the limbic system is the important Canadian contribution of Wilder Penfield, Herbert Jasper, and particularly Pierre Gloor at the Montreal Neurological Institute using intraoperative electrical stimulation of the brain ${ }^{5}$. However debate continues about the functional significance and indeed even the anatomy of the limbic system. MacLean himself was the first to recognize problems with his theory when, echoing Hughlings Jackson's statement above, he said in a response to criticism by his colleague Karl Pribram in a discussion of his 1952 paper "to be sure, the brain is such a plastic organ with so many reciprocally related structures that any attempt to draw the line in considering the localization of function must be artificial" 6 . However he goes on to imply that such thinking is more suited to the realm of philosophers than physiologists. Brodal summed up his criticism of the limbic system by quoting Goethe, "For just where fails the comprehension, a word steps promptly in as deputy"4.

\section{Function of the Limbic System}

Any stimulus, whether from the external environment or the "internal milieux", results in several adaptive reactions that fulfill the needs of the organism, all regulated through limbic pathways. These include emotional, autonomic, motor and cognitive responses linked to memory and motivation, other

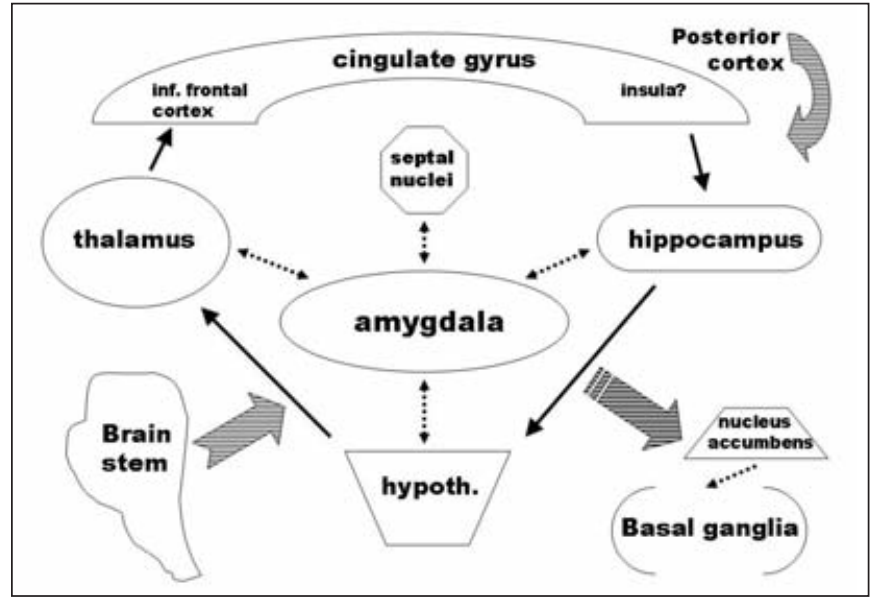

Figure 2: Representation of the main components of the limbic system. Large stripped arrows indicate primary inputs and output. Solid arrows indicate the circuit of Papez. 
major functions of the limbic system. A simplified but nonetheless accurate view is that the whole system is geared to the recognition of and reaction to novel stimuli. The amygdala appears to be the main controller of all this activity, coordinating the processing of input from the brainstem and posterior neocortex (visual, auditory and somatosensory), responding to analysis by the hippocampus as to the novelty of a stimulus in comparison to previous memories and directing the various responses noted above. Memory mechanisms and the limbic system will not be discussed here but I will comment on another fundamental component of limbic physiology, the important link between emotion, motivation and motor processing.

Goal directed behaviour such as fight or flight in response to a threatening stimulus is driven by motivation arising from activation largely of neocortical (esp. inferior frontal) components of the limbic system. A prime role of motivation is to act through the motor system to translate thoughts, sensation and emotions into movement. Gordon Mogenson, a Canadian physiological psychologist at the University of Western Ontario, hypothesized in another seminal paper in 1980 that the functional interface between limbic (motivation) and motor systems is the nucleus accumbens, a small collection of neurons in the mesial forebrain adjacent to the junction of the head of the caudate, anterior putamen and septal nuclei ${ }^{7}$. He acknowleged that this theory was based on a suggestion by the American neuroanatomist Ann Graybiel, who trained with Nauta, during a lecture given at a Toronto meeting of the Society for Neuroscience in 1976. Prominent limbic input to the nucleus accumbens is both direct from the amygdala, hippocampus and other structures and indirect via the ventral tegmentum, while the primary output is to the basal ganglia. It is at this point that activity driven primarily by cholinergic/glutaminergic transmission in the limbic system switches to dopaminergic control in the basal ganglia with GABA acting as the "break" for

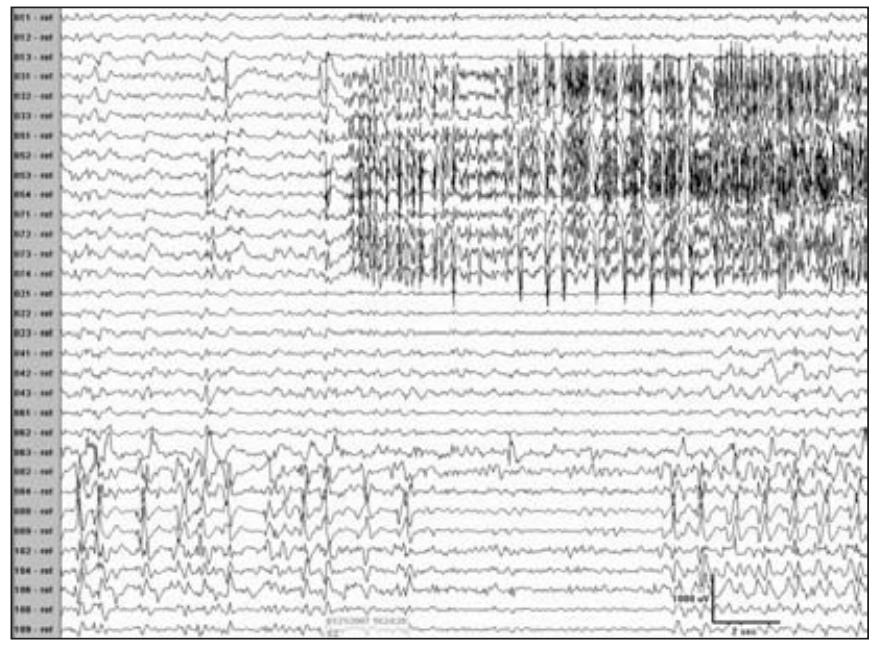

Figure 3: Depth electrode recording of left temporal lobe seizure in upper channels. Lower channels show ongoing right temporal interictal spikes. both systems. It is malfunction in the dopaminergic circuits, particularly in the nucleus accumbens, that is thought to be largely responsible for the development of various types of addiction, a disorder largely of motivation but with associated emotional, autonomic, cognitive and motor system impairments $^{8}$. It is no surprise that some consider the nucleus accumbens to be part of the limbic system while others argue that it belongs with the basal ganglia.

\section{How the System Works}

Fear along with hunger and thirst are the basic motivators for self-preservation in all animals including man. The following is a simplistic explanation of the response of the nervous system to a fearful stimulus.

You are sitting alone in a quiet room reading when there is a loud crash behind you. Over milliseconds, a signal is sent from the acoustic nerves first to the reticular activating system causing alerting and possibly a startle reaction both mediated within the brainstem. A few milliseconds later the limbic system is placed on alert through direct input via the medial forebrain bundle and indirectly through the thalamus.

The amygdala, acting as a central controller, directs the hippocampus to compare this novel auditory input to all previous experience (memory) and sets the hypothalamus on alert resulting in an increase in heart rate, blood pressure and sweating (autonomic response). When the hippocampus responds with the message that this is an unrecognized signal, the amygdala acting through the cingulate gyrus and other limbic structures generates the feeling of fear (emotional response). Now there is motivation for action and the amygdala, through the nucleus accumbens as an interface, activates the basal ganglia and the rest of the motor system causing you to jump up, turn your head and look at the source of the sound (motor response). At this point, the additional neocortical input from the visual cortex filtered

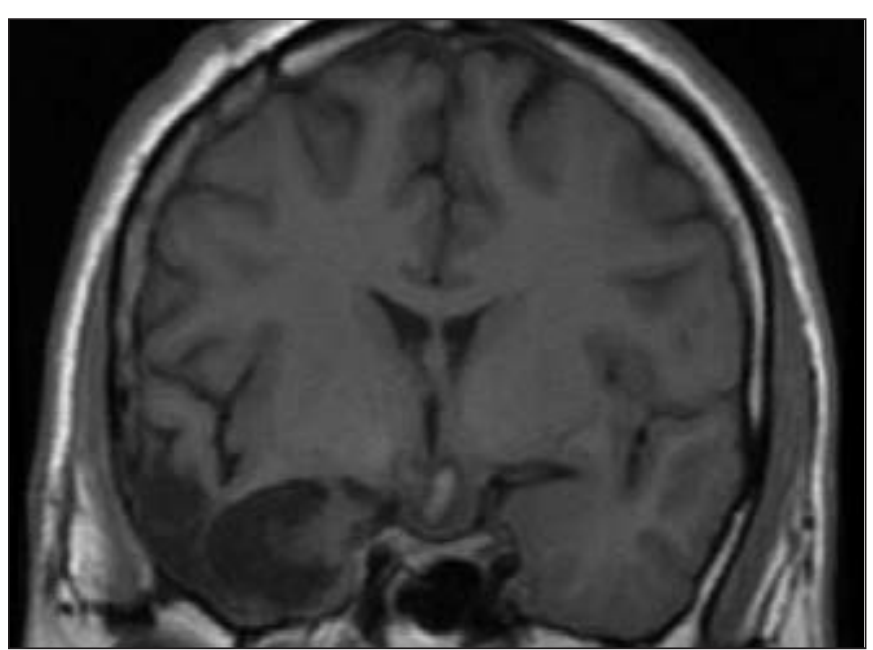

Figure 4: MRI shows previous right temporal lobectomy and stereotaxic lesioning of the hypothalamic hamartoma. 
through the hippocampus and amygdala will either enhance the limbic activity if there is a stranger standing there (requiring a cognitive response) or will shut the system down if the cat has merely knocked over a vase.

\section{Illustrative Case}

Despite ongoing controversy about the definition and even the existence of the limbic system as described by MacLean and the warning by Hughlings Jackson and others about a piecemeal approach to understanding brain function, the concept remains a useful one particularly when assessing epilepsy patients. Since this is an introduction to extra-temporal limbic epilepsy, the following case is illustrative and informative.

A 29 year old welder had seizures since age one year. Neurological examination and cognition including memory were normal. Simple partial seizures occurred daily with associated complex partial seizures once or twice per month. These consisted of an epigastric sensation (autonomic), fear (emotional) and loss of awareness with bimanual automatisms, laughing, singing, and running (motor). These of course represent activation of limbic followed by motor pathways, not through an external sensory stimulus but from an internal disturbance, namely an excessive spontaneous electrical discharge of the brain. Most commonly such discharges onset in the mesial temporal lobe and thus at age 14 years he had a right temporal lobectomy based on investigation at that time. However his seizures continued. As an adult, his EEG revealed abundant right temporal spikes from the resection line as well as some right frontal spikes. Further telemetry recording with implanted depth electrodes showed seizures arising independently in both the remaining right temporal lobe as well as the left temporal lobe (Figure 3). However an MRI demonstrated no temporal lobe pathology. What it did reveal was a large hypothalamic hamartoma. Sterotaxic lesioning of the hamartoma (Figure 4) resulted in a complete cessation of all seizure activity. In this case an extratemporal lesion in the hypothalamus caused activation of the limbic system in the same way and with the same symptoms as would occur in temporal lobe epilepsy. Such a clinical scenario is, of course, an experiment of nature that completely supports Papez's and, particularly, MacLean's view of multiple anatomical components acting together as one coordinated limbic system.

\section{REFERENCES}

1. Broca P. Anatomie comparee des circonvolutions cerebrales. Le grand lobe limbique et la scissure limbique dans la serie des mammiferes. Rev d'Anthropologie. 1878; 3: 385-498.

2. Papez JW. A proposed mechanism of emotion. Arch Neurol Psychiat. 1937; 38: 725-43.

3. Kluver H, Bucy P. "Psychic blindness" and other symptoms following bilateral temporal lobectomy in rhesus monkey. Am J Physiol. 1937; 119: 144-57.

4. Brodal A. Neurological Anatomy in Relation to Clinical Medicine. 3rd ed. New York. Oxford University Press; 1981.

5. Gloor P. The temporal lobe and limbic system. New York: Oxford University Press; 1997.

6. MacLean PD. Some psychiatric implications of physiological studies of fronto-temporal portion of limbic system (visceral brain). Electroencephalogr Clin Neurophysiol. 1952; 4: 407-18.

7. Mogenson GJ, Jones DL, Yim CY. From motivation to action: functional interface between the limbic system and the motor system. Progr Neurobiol. 1980; 14: 69-97.

8. Nestler EJ. Common molecular and cellular substrates of addiction and memory. Neurobiol Learn Mem. 2002; 78: 637-47. 


\title{
Seizures in the Intensive Care Unit Section:
}

\author{
Introductory Remarks
}

Can. J. Neurol. Sci. 2009; 36: Suppl. 2 - S88

Dr. Prasad and I were honoured to be part of the Vancouver symposium to celebrate Dr. Wada's contributions to epileptology. We feel the inclusion of "Seizures in the ICU" reflects Dr. Wada's nature, as he is one who ventures into new frontiers in epilepsy and finds answers where none existed previously.

Neurocritical care is a new branch of neurology that is concerned with life-threatening diseases of the nervous system. One of the most prominent disorders is status epilepticus (SE). SE is important in view of prevalence, the potential for increased neurological damage, increased mortality, morbidity and length of stay and the fact that it is treatable. Patients can be admitted with seizures, but more commonly they occur after admission to the ICU. Most cases if SE in ICU are nonconvulsive, even if they follow an initial convulsive phase. This poses another challenge to the intensivist and consulting neurologist: how do we detect and manage them?

In this section Dr. Prasad and I discuss these issues for children and adults. We hope the section will prove of interest and will stimulate a greater neuro-presence (including EEG) in Canada's ICUs. 


\title{
Continuous EEG Monitoring in the ICU: Challenges and Opportunities
}

\author{
G. Bryan Young
}

\begin{abstract}
Continuous EEG monitoring (CEEG) in the ICU is increasingly recognized as valuable means of monitoring cerebral function, otherwise inaccessible in the comatose patient. The principal applications are: monitoring for seizures and ischemia, guiding therapy for seizures and ischemia (especially vasospasm), adjusting levels of sedation for paralyzed or delirious patients, charting trends in brain function and prognosis. Continuous EEG monitoring is faced with numerous challenges: electrode failures (better electrodes are needed to replace standard EEG electrodes), documentation in the absence of a technologist, artifacts peculiar to ICU, prompt interpretation and review of large amounts of data, resource allocation and establishing the technology as being useful in improving outcomes and shortening ICU and hospital length of stay.
\end{abstract}

RÉSUMÉ: Monitoring ÉEG continu à l'unité de soins intensifs : défis et perspectives d'avenir. Le monitoring ÉEG continu à l'unité de soins intensifs est de plus en plus reconnu comme un moyen précieux de surveillance de la fonction cérébrale, inaccessible par d'autres moyens chez le patient comateux. Ses principales applications sont : le monitoring pour détecter des crises épileptiques et de l'ischémie, pour guider le traitement de crises d'épilepsie et d'ischémie (surtout en ce qui concerne le vasospasme), pour ajuster le niveau de sédation chez les patients paralysés ou délirants, pour documenter les tendances de la fonction cérébrale et le pronostic. Le monitoring ÉEG continu présente plusieurs défis : défauts d'électrodes (on a besoin de meilleures électrodes pour remplacer les électrodes standards d'ÉEG), la documentation en l'absence d'un technicien, les artefacts particuliers à l'unité de soins intensifs, une interprétation rapide et la revue de grandes quantités de données, l'allocation des ressources et l'établissement de la technologie comme étant utile pour améliorer l'issue et raccourcir le séjour à l'unité de soins intensifs et à l'hôpital.

Can. J. Neurol. Sci. 2009; 36: Suppl. 2 - S89-S91

In comatose patients it is not possible to monitor cerebral cortical function clinically, yet the cerebral cortex is the most vulnerable part of the brain to various insults that can continue to cause neuronal death during the ICU stay. The advent of digital EEG has provided an opportunity to assess cerebral cortical function in real time at the bedside.

\section{Potential Applications of EEG Monitoring in ICU}

Continuous EEG monitoring (CEEG) is best applied to conditions that are prevalent, carry a risk of further neurological damage and are treatable. The two most common such conditions are seizures and ischemia. All but absence seizures can contribute to brain damage. ${ }^{1}$ Seizures occur more commonly in cases of acute structural brain injury than in most metabolic encephalopathies. $^{2}$ More than $90 \%$ of seizures are nonconvulsive and cannot be diagnosed reliably without an EEG. ${ }^{3}$ The Table lists the frequency of nonconvulsive seizures (NCS) and nonconvulsive status epilepticus (NCSE) in various studies involving diverse patient populations.
Table: Series of monitored patients: Prevalence of seizures

\begin{tabular}{|c|c|c|c|c|c|c|}
\hline Series & $\begin{array}{l}\text { Young and } \\
\text { Doig }^{2}\end{array}$ & $\begin{array}{l}\text { De Lorenzo et } \\
\text { al., } 1998^{4}\end{array}$ & $\begin{array}{l}\text { Jordan, } \\
1995^{5}\end{array}$ & $\begin{array}{l}\text { Privetera et al., } \\
1994^{6}\end{array}$ & $\begin{array}{l}\text { Towne et al., } \\
2000^{7}\end{array}$ & $\begin{array}{l}\text { Vespa et al., } \\
1999^{8}\end{array}$ \\
\hline $\begin{array}{l}\text { Nature } \\
\text { of Study }\end{array}$ & $\begin{array}{l}\text { Prospective, } \\
\text { general ICU }\end{array}$ & $\begin{array}{l}\text { Prospective, } \\
\text { post-seizure } \\
\text { patients }\end{array}$ & $\begin{array}{l}\text { selected } \\
\text { neuro-ICU } \\
\text { patients }\end{array}$ & $\begin{array}{l}\text { Prospective, } \\
\text { altered } \\
\text { consciousness }\end{array}$ & $\begin{array}{l}\text { Prospective } \\
\text { coma } \\
\text { patients }\end{array}$ & $\begin{array}{l}\text { Prospective } \\
\text { head injured } \\
\text { patients }\end{array}$ \\
\hline $\begin{array}{l}\text { Sample } \\
\text { Size }\end{array}$ & $\begin{array}{l}56 \text { with } \\
\text { CEEG }\end{array}$ & $164, \mathrm{CEEG}$ & & $\begin{array}{l}\text { children, } 198 \\
\text { CEEG }\end{array}$ & $\begin{array}{l}\text { 236, EEGs } \\
\text { variable } \\
\text { duration }\end{array}$ & $94, \mathrm{CEEG}$ \\
\hline $\begin{array}{l}\text { \% with } \\
\text { seizures }\end{array}$ & $\begin{array}{l}11 \% \text { overall: } \\
32 \% \text { NCS } \\
\text { and CS of } \\
\text { ASBLs; } 4 \% \\
\text { metabolic } \\
\text { enceph. }\end{array}$ & $\begin{array}{l}48 \% \text { with } \\
\text { ongoing } \\
\text { seizures }\end{array}$ & $\begin{array}{l}34 \% \text { had } \\
\text { NCS }\end{array}$ & $\begin{array}{l}37 \% \text { had } \\
\text { NCSE }\end{array}$ & $8 \%$ in NCSE & $\begin{array}{l}22 \% \text { NCS } \\
\text { and CS }\end{array}$ \\
\hline
\end{tabular}

From the Division of Neurology, University Hospital, London, Ontario, Canada. Received July 24, 2008. Final Revisions Submitted September 10, 2008. Correspondence to: G.B. Young, Division of Neurology, Room B10-106, University Hospital, 339 Windermere Road, London, Ontario, N6A 5A5, Canada. 
Mortality increases exponentially with seizure duration. ${ }^{9}$ CEEG allows for the detection of NCS/NCSE and can monitor the effectiveness of therapy. When anesthetic agents are used ${ }^{10}$ CEEG can monitor the depth of anesthesia to avoid overshooting the target level.

Ischemia affects the EEG at values of cerebral blood flow $(\mathrm{CBF})$ - 25-30 ml/100 grams/minute -- that are well above the threshold for damage to the brain $(20 \mathrm{ml} / 100$ grams/minute or less). ${ }^{11}$ Thus EEG changes can serve as an early warning that cerebral ischemia is developing, as in vasospasm associated with subarachnoid hemorrhage. Vespa and colleagues ${ }^{12}$ used percentage alpha variability (PAV) of the EEG (a quantitative measure that can be displayed at the bedside or remotely) as a means of monitoring for vasospasm. Instituting therapy could reverse the drop in PAV and ameliorate or prevent infarction. The effects of therapy can then be monitored.

\section{Challenges}

Several challenges concern the application of CEEG in the ICU. These can be divided into technical, resources, logistics of interpretation, and evidence of effectiveness.

\section{Technical aspects}

A. Electrodes provide the crucial contact of the EEG machine and the patient. Involuntary and passive movements of ICU patients and perspiration contribute to premature electrode failure. Standard, collodion-applied disc electrodes begin to fail in six hours of CEEG recordings. ${ }^{13}$ Subdermal wire electrodes obviate much of this concern; satisfactory recordings can be obtained for days without artifact or scalp infection. ${ }^{13}$ Electrocardiographic (EKG) stick-on electrodes can provide adequate recordings with subhairline montages (see below) for 48 hours.

B. Artifacts: For long-term ICU CEEG technologists are not available to document artifacts. Although some are artifacts commonly encountered in any recording, many are peculiar to the ICU environment, e.g., those produced by water in ventilator tubing, ventilator artifact, intravenous pumps, PRISMA machine artifact and physiotherapy. ${ }^{14-16}$

C. Technology availability: Hospitals have often not provided for the increased demands for discontinuous or CEEG recordings -- both for digital EEG machines and technologist coverage. Although the patients are the most acutely ill in the hospital and the yield of positive results is high, it is difficult for hospitals and existing laboratories to adjust to the demand, especially with already strained budgets. As a temporary measure to provide EEG coverage for off-hours and weekends, we have used the subhairline montage, first described by Ebersole and colleagues. ${ }^{17}$ Many commercially available bedside ICU monitors have 4-channel EEG modules. Using stick-on EKG electrodes, we found the sensitivity for an early model with a sampling rate of $100 / \mathrm{sec}$ (EEG standards are 200/sec) captured $69 \%$ of seizures (Young et al., in press). A more recent device with a higher sampling rate, filters and improved electrodes will likely perform somewhat better, but will miss seizures that do not invade the frontal and temporal regions. This simplified EEG device is also useful in monitoring the depth of sedation and can allow titration of anesthesia, often necessary for refractory status epilepticus and for sedation of paralyzed patients (e.g., with Guillain-Barré syndrome).

\section{Interpretation}

Ideally, the EEG should be interpreted in "real time" or at least frequently, e.g., several times a day, in managing unstable, critically ill patients. This poses a huge logistical problem, as there is an enormous amount of raw data recorded at a site remote from the EEGer. Neither the technologist nor the EEGer can remain for long at the bedside. Several alternatives have been tried/suggested:

A. Teaching the nurse at the bedside to read the "raw" or unprocessed EEG. Jordan ${ }^{5}$ has found that nurses can be trained to perform this task, such that they can detect electrographic seizures after extensive training. Recognizing the occurrence of a seizure, typically with an evolutionary pattern, the development and degree of suppression/burst-suppression or gross asymmetries are the main patterns that nurses can be trained to recognize. This, however, takes great commitment from the EEGer, the nurses and technologists.

B. Networking: EEG can be transmitted to the office, reading room or home of the EEGer. Still, the enormous time commitment involved is daunting, even for one patient being monitored at a time. Imagine several!

C. Quantitative EEG allows for data reduction. Most methods rely either on amplitude-integrated or frequency domain methods to simplify and reduce the data and compress the time domain for display. These methods can be used to create trends to allow for seizure recognition, or gross changes in frequencyamplitude to allow assessment of variability over time (see excellent reviews by Agarwal et $\mathrm{al}^{18}{ }^{18}$ Rampil $^{19}$ and Scheuer and Wilson ${ }^{20}$.) Some success has been gathered with these methods with respectable sensitivity for detection of seizures, etc. (false positives are often problematic), but no controlled study has been conducted to determine the optimal method of display. Such methods should not be used in isolation, but there should always be the capability of inspecting the unprocessed EEG for quality control and for confirming epochs of interest, i.e., changes that might indicate seizures.

D. Video-EEG: Although this is not a method apart from the above recording of EEG signals, the video component is highly desirable. ${ }^{21}$ This allows for the correlation of clinical changes in the patient with the EEG recording.

\section{Evidence of Effectiveness}

Although it seems intuitively reasonable to monitor the function of the vulnerable and valued cerebral cortex in the ICU, much as continuous EKG monitoring is done, the widespread adoption of new technology in modern era demands some proof of effectiveness. Randomized controlled studies are needed to demonstrate that CEEG makes a positive difference in cost (especially ICU and outcomes (morbidity [level of function] and mortality. Since CEEG in the ICU is not yet "standard of care", such studies should be ethically feasible.

\section{Future Directions}

Along with improvements and standardization of technology, and organizational structure, cost- and outcomes-effectiveness 
studies need to be done. It seems likely that subgroups at risk for seizures and ischemia will require more sophisticated monitoring, while "sedation monitors" can be simple devices available at nearly every ICU bedside.

\section{REFERENCES}

1. Young GB, Jordan KG. Do nonconvulsive seizures damage the brain? - Yes. Arch Neurol. 1998;55:117-19.

2. Young GB, Doig GS. Continuous EEG monitoring in comatose ICU patients. Epileptiform activity in etiologically distinct groups. Neurocrit Care. 2005;2:5-10

3. Klaassen J, Meyer SA, Kowalski RG, Emerson RG, Hirsch LJ. Detection of electrographic seizures with continuous EEG monitoring in critically ill patients. Neurology. 2004;62:1743-8.

4. De Lorenzo RJ, Warterhouse EJ, Towne AR, Boggs KG, Ko D, DeLorenzo GA, et al. Persistent nonconvulsive status epilepticus after the control of convulsive status epilepticus. Epilepsia. 1998;39:833-40.

5. Jordan KG. Neurophysiologic monitoring in the neuroscience intensive care unit. J Clin Neurophysiol. 1995;13:579-26.

6. Privitera M, Hoffman M, Moore JL, Jester D. EEG detection of nontonic-clonic status epilepticus in patients with altered consciousness. Epilepsy Res. 1994;18:155-66.

7. Towne AR, Waterhouse EJ, Boggs JG, Garnett LK, Brown AJ, Smith JR Jr, et al. Prevalence of nonconvulsive status epilepticus in comatose patients. Neurology. 2000;54:340-5.

8. Vespa PM, Nenov V, Nuwer MR. Continuous EEG monitoring in the intensive care unit: early findings and clinical efficacy. J Clin Neurophysiol. 1999;16:1-13.

9. Young GB, Jordan KG, Doig GS. An assessment of nonconvulsive seizures in the intensive care unit using continuous EEG monitoring: an investigation of variables associated with mortality. Neurology. 1996;47:83-9.

10. Mirsattari SM, Sharpe M, Young GB. Treatment of refractory status epilepticus with inhalational agents: isoflurane and desflurane. Arch Neurol. 2004; 61:1254-9.
11. Astrup J, Simon L, Siesjo BK. Thresholds in cerebral ischemias the ischemic penumbra editorial. Stroke. 1981;2: 723-5.

12. Vespa PM, Nuwer MR, Juhasz C, Alexander M, Nenov V, Martin N, et al. Early detection of vasospasm after acute subarachnoid hemorrhage using continuous EEG ICU monitoring. Electroencephalogr Clin Neurophysiol. 1997;103:607-15.

13. Young GB, Ives JR, Chapman MG, Mirsattari SM. A comparison of subdermal wire electrodes with collodion-applied disk electrodes in long-term EEG recordings in ICU. Clin Neurophysiol. 2006 Jun;117(6):1376-9.

14. Young GB, Campbell VC. EEG monitoring in the intensive care unit: pitfalls and caveats. J Clin Neurophysiol. 1999;161:40-5.

15. Young B, Osvath L, Jones D, Socha E. A novel EEG artifact in the intensive care unit. J Clin Neurophysiol. 2002;19:484-6.

16. Young B, Raihan S, Ladak H, Kelly M. Rhythmic artifact of physiotherapy in intensive care unit EEG recordings. J Clin Neurophysiol. 2007 Jun;24(3):252-6.

17. Bridgers SL, Ebersole JS. EEG outside the hairline: detection of epileptiform abnormalities. Neurology. 1988;38:146-9.

18. Agarwal R, Gotman J, Flanagan D, Rosenbaltt B. Automatic EEG analysis during long-term monitoring in the ICU. Electroenceph Clin Neurophysiol. 1998;197:44-58.

19. Rampil IJ. A primer for EEG processing in anesthesia. Anesthesiol. 1998;89:980-1002.

20. Scheuer ML, Wilson SB. Data analysis for continuous EEG monitoring in the ICU: seeing the forest and the trees. J Clin Neurophysiol. 2004;21:353-78.

21. Pandian JD, Casino GD, So EL, Manno E, Fulgham JR. Digital video-electroencephalographic monitoring in the neurologicalneurosurgical intensive care unit. Arch Neurol. 2004;61:1090-4. 


\title{
Status Epilepticus in the Pediatric ICU: State of the Art
}

\author{
A.N. Prasad
}

\begin{abstract}
Status epilepticus in the pediatric intensive care setting is a neurological emergency. Its management presents profound challenges for the pediatric intensivist, and neurologist. Understanding the neurobiological factors that are operative in transition of an epileptic seizure to self-sustained status epilepticus is critical to management. Statue epilepticus in children is often heterogeneous in etiology. In this article, I examine the evidence for who is likely to be admitted to the pediatric intensive care unit for management, the risk factors, the relationship of seizure duration and evolution to status epilepticus, and the reasons for seizure refractoriness. The immediate complications and long term consequences leading to morbidity and mortality in this condition are reviewed. The problem of refractory status epilepticus is particularly more frequently encountered in the intensive care setting. Therapeutic options in the initial management and in particular addressing reasons for the development of pharmacoresistance in status epilepticus are presented. Finally, data on outcome in the pediatric ICU setting is discussed providing thus an overview of our current understanding and state of the art in the management of status epilepticus in children.
\end{abstract}

RÉSUMÉ: État de mal épileptique à l'unité de soins intensifs pédiatriques : état de la question. L'état de mal épileptique à l'unité de soins intensifs est une urgence neurologique. Son traitement présente des défis importants pour l'intensiviste pédiatrique et le neurologue et il est crucial qu'ils comprennent les facteurs neurobiologiques en cause dans la transition d'une crise épileptique vers un état de mal épileptique auto-entretenu. L'état de mal épileptique chez les enfants a souvent une étiologie hétérogène. Dans cet article, j'examine les données concernant les patients qui sont susceptibles d'être admis pour traitement à l'unité de soins intensifs pédiatriques, les facteurs de risque, la relation entre la durée des crises et l'évolution vers l'état de mal épileptique et les raisons de la pharmaco-résistance. Je revois les complications immédiates et les conséquences à long terme de cette pathologie entraînant une morbidité et une mortalité. Le problème de l'état de mal épileptique pharmaco-résistant se rencontre très fréquemment à l'unité de soins intensifs. Je discute des options thérapeutiques lors du traitement initial et j'examine les raisons du développement de la pharmaco-résistance dans l'état de mal épileptique. Finalement, je discute des données sur le résultat à l'unité de soins intensifs pédiatriques, ce qui complète un exposé général de notre compréhension actuelle et l'état de la question dans le traitement de l'état de mal épileptique chez les enfants.

Can. J. Neurol. Sci. 2009; 36: Suppl. 2 - S92-S98

In 1993, the Working Group on Status Epilepticus (SE) proposed a temporal criterion of $>30$ minutes (min) duration for an epileptic seizure to be considered as status epilepticus ${ }^{1}$. The International League Against Epilepsy (ILAE) has defined SE as 'a single epileptic seizure $>30 \mathrm{~min}$ in duration or a series of epileptic seizures during which function is not regained between ictal events in a > 30-min period'. This definition is generally accepted as the basis for epidemiological studies in the interest of uniformity and comparisons. In clinical practice, however, shorter temporal criteria have been suggested; for instance a minimum duration of five minutes of (a) continuous seizures or (b) two or more discrete seizures between which there is incomplete recovery of consciousness, as the definition of generalized convulsive SE in adults and older children $(>5$ years old $)^{2,3}$. The present recommendation is to retain the temporal criterion of 30 minutes as a cut off point beyond which the seizure can be truly termed as status epilepticus. Within the constraints of time and space, it is only possible to highlight discuss selected aspects of status epilepticus in children that are

From the Department of Pediatrics and Clinical Neurological Sciences, Children's Hospital, London Health Sciences Centre, London, Ontario, Canada.

Received April 28, 2008. Final Revisions Submitted September 10, 2008. Correspondence to: Asuri N. Prasad, Departments of Pediatrics and Clinical Neurological Sciences, Schulich School of Medicine and Dentistry, Children's Hospital, London Health Sciences Centre, 800 Commissioners Road East, London, Ontario, N6A 5W9, Canada. 
relevant to management and outcome in the setting of the intensive care unit.

\section{The Child with Status Epilepticus}

Answers to two questions are critical in understanding the nature of the pediatric patient with an epileptic seizure who is likely to be admitted to pediatric intensive care. Firstly, who is at risk of prolonged seizures? Secondly, how long do seizures last in children?

\section{Who is at risk for Status epilepticus?}

The causes of SE in any study will be influenced by geographic location (country or region specific data) and ascertainment bias. Epidemiological studies identify the incidence of SE to be the highest under age 1 year ${ }^{4,5}$. The crude incidence of SE was about 18/100,000 (Rochester, Minnesota) and 20/100,000 (Richmond, Virginia) with a U shaped curve, peaking below $1 \mathrm{yr}$ and above 65 years. Generalized convulsive seizures are more common compared to other seizure types. Febrile SE constituted 8\% of 199 first episodes of SE (19651984). A prospective population based cohort study from Finland ${ }^{6}$ suggests that more than one quarter of children with newly diagnosed epilepsy will experience SE, and nearly half of these patients with one attack will experience a subsequent attack. The risk of SE was deemed to be highest early in the course of epilepsy. Status epilepticus was the first manifestation of epilepsy in over $73 \%$ of cases, and within two years of onset in $90 \%$ of cases. A substantial proportion (16\%) of children with first ever convulsive status epilepticus will have a recurrence within a year; those with previous neurological abnormality are more likely to have a recurrence $(\mathrm{p}=0 \cdot 04)^{7}$. Risk factors that are strongly associated with recurrence of status epilepticus include: age of onset, remote symptomatic etiology, and epilepsy syndrome ${ }^{8}$. The prevalence of convulsive SE in monozygotic twins is significantly higher than in dizygotic twins ${ }^{9,10}$ suggesting a role for genetic factors in the susceptibility to status epilepticus. In summary, age, etiology, and genetic factors play critical roles in determining who gets prolonged seizures.

\section{How long do seizures last in children?}

Systematic studies on seizure duration in children have been few. A recent study designed to answer this aspect of pediatric epileptic seizures was carried out prospectively in a population of 407 children (1-19 years) with a first unprovoked afebrile seizure who had no prior exposure to antiepileptic drugs. In a prospective study of 407 children presenting with a first unprovoked afebrile seizure, Shinnar et $\mathrm{al}^{11}$ analyzed the distribution of seizure duration from ambulance and emergency room records and found that the mean seizure duration was around 12 minutes with seizures lasting $>5$ minutes in $50 \%$ of cases, $>10$ minutes in $29 \%,>20$ minutes in $16 \%$, and $>30$ minutes in $12 \%$. The authors draw attention to a significant observation; that seizures with partial onset $(62 \%>5$ minutes and $20 \%>30$ minutes) tend to be longer in duration than seizures of generalized onset $(42 \%>5$ minutes and $6 \%>30$ minutes; $\mathrm{p}<$ 0.001). Furthermore, in children with two or more seizures, the durations of the first and second seizures were highly correlated $(\mathrm{r}=0.395, \mathrm{p}<0.0001)$. While a majority of seizures $(92 \%)$ were found to remit spontaneously, around $7 \%$ of children in the study experienced seizures $>30$ minutes duration. Thus, they conclude that children with a first seizure tend to cluster around two groups with respect to seizure duration; short duration seizures in the majority and a smaller group with prolonged seizures lasting beyond 30 minutes. It is the latter group that is likely to be admitted to the intensive care unit for management.

In the same study, the authors examined the data on the conditional probability of spontaneous cessation of seizure activity, once the seizure duration had lasted beyond a specific time. Using a semilogarithmic plot and exponential derivatives to best fit the data on an intensity function curve, the authors conclude that "once a seizure has lasted for seven minutes, there is a $95 \%$ probability that it belongs to the group of seizures that last longer (> 31 minutes)". Although seizure duration estimates in this study from medical and ambulance records may not be as accurate as from video monitoring, this study draws clinically relevant conclusions about seizure duration in children. It appears that the subgroup of children who are especially vulnerable to prolonged seizures, also appear to be at risk of developing self sustained seizures, when the seizure lasts beyond a seven minute time interval from seizure onset.

Thus, to prevent progression to status epilepticus, interventions in general would need to occur within this time. Admission to the intensive care unit often becomes necessary in situations when the seizure enters the phase of self sustained status epilepticus, and treatment refractoriness appears. Aggressive management is often indicated in this phase and the attendant problems of apnea, hypotension, as well as complications relating to the underlying etiology necessitate the management of such patients in the critical care or intensive care unit. The ability to support vital functions (cardiac, respiratory) and facilities for continuous monitoring of these functions provide an ideal setting where appropriate high dose suppressant treatment (HDST) can be tried.

\section{Causes of Status Epilepticus in Childhood}

Most studies on status epilepticus point to the heterogeneous nature of causes leading to status epilepticus ${ }^{12}$. In the pediatric age group the results of a recent audit of admissions to the PICU of a tertiary care facility (Children's Hospital of Winnipeg) showed that idiopathic epilepsy and febrile status epilepticus (prolonged febrile seizures) accounted for the majority of admissions (54\%). Other etiological factors included: CNS infections, cerebral malformations/ dysgenesis, changes in the dosage of AED's, AED withdrawal, strokes, brain tumors, and inborn errors of metabolism. It was found that the etiology of SE is an important determinant of outcome, as acute as well as remote symptomatic factors, were more likely to be associated with a poor outcome ${ }^{13}$.

\section{Special Considerations}

\section{Febrile Status Epilepticus (FSE) in Childhood}

Febrile Status Epilepticus is one of the commonest causes of status epilepticus in the young under the age of two years, and consequently, a leading cause in children admitted to the PICU ${ }^{14}$. In most studies on febrile seizures only $4-5 \%$ of patients have seizures $>30$ minutes duration, consequently few studies have 
exclusively examined outcomes related to febrile status. In a prospective cohort reported by Shinnar et $\mathrm{al}^{15}$, the short term outcome was considered as good, as the mortality and morbidity was found to be low. Children with febrile status report a higher proportion of focal seizures, higher rate of pre-existing neurological abnormalities, and a higher likelihood of a family history of epilepsy. One of the more controversial aspects of febrile status epilepticus and prolonged febrile seizures has been the relationship to mesial temporal lobe epilepsy and hippocampal sclerosis ${ }^{16,17}$. Retrospective surgical series on patients undergoing temporal lobectomy have suggested that prolonged febrile seizures lasting greater than 60 minutes as a risk factor for developing mesial temporal sclerosis ${ }^{18}$. On the other hand, pathological data based on post mortem series and animal models suggest that preexisting cerebral developmental anomalies may provide a predilection for the hippocampal injury in the context of prolonged febrile seizures and febrile status ${ }^{19-22}$.

\section{Do preexisting malformations predispose to $F S E$ ?}

A recently reported developmental malformation identified on neuroimaging studies involves a hippocampal malrotation (HIMAL) with a normal corpus callosum. This involves an incomplete inversion of the hippocampus with a rounded shape and blurred internal architecture and an abnormal angle of the collateral sulcus ${ }^{23}$. In a recent report of the multicentre prospective study of febrile status epilepticus in children (FEBSTAT) ${ }^{24}$ HIMAL was present in 9 of $53(17 \%)$ cases. Hippocampal malrotation seemed to preferentially involve the left side in (9\%) of children with complex febrile seizures vs. $3 \%$ of children with simple FS. The odds ratio for having HIMAL in cases with FSE compared with simple FS was reported to be 7.0 (95\%CI 0.8-57.6). Further studies are necessary to confirm the clinical significance of this association.

\section{Infection and convulsive $S E$}

A role for specific viral triggers has gained importance following recent reports linking infection to both febrile and afebrile status epilepticus (ASE). In particular, the human herpes virus 6 infection was identified in 12 of 22 children (55\%), with first episode of status epilepticus evaluated prospectively in a Finnish study ${ }^{25}$. In this group, the infection was primary in six children. In the remainder, single cases of human herpes virus 7, parainfluenza 3, adenovirus 1 , echovirus 22, rota, influenza A and Mycoplasma pneumoniae infection were diagnosed. HHV6 infection may also be associated with prolonged FSE, as well ASE. While the immediate outcomes of SE following such primary infections appear to be good, the longer term outcomes on behavior, cognitive function and the delayed development of epilepsy remain unclear.

\section{Catastrophic Status Epilepticus in the developmentally normal school aged child}

A rare syndrome sudden onset status epilepticus in developmentally normal children with devastating consequences is recognized from personal clinical experience, as well as in the literature. These cases often are initially regarded as viral encephalitides, the clinical features of are of acute onset of an intractable convulsive status epilepticus that is refractory to all

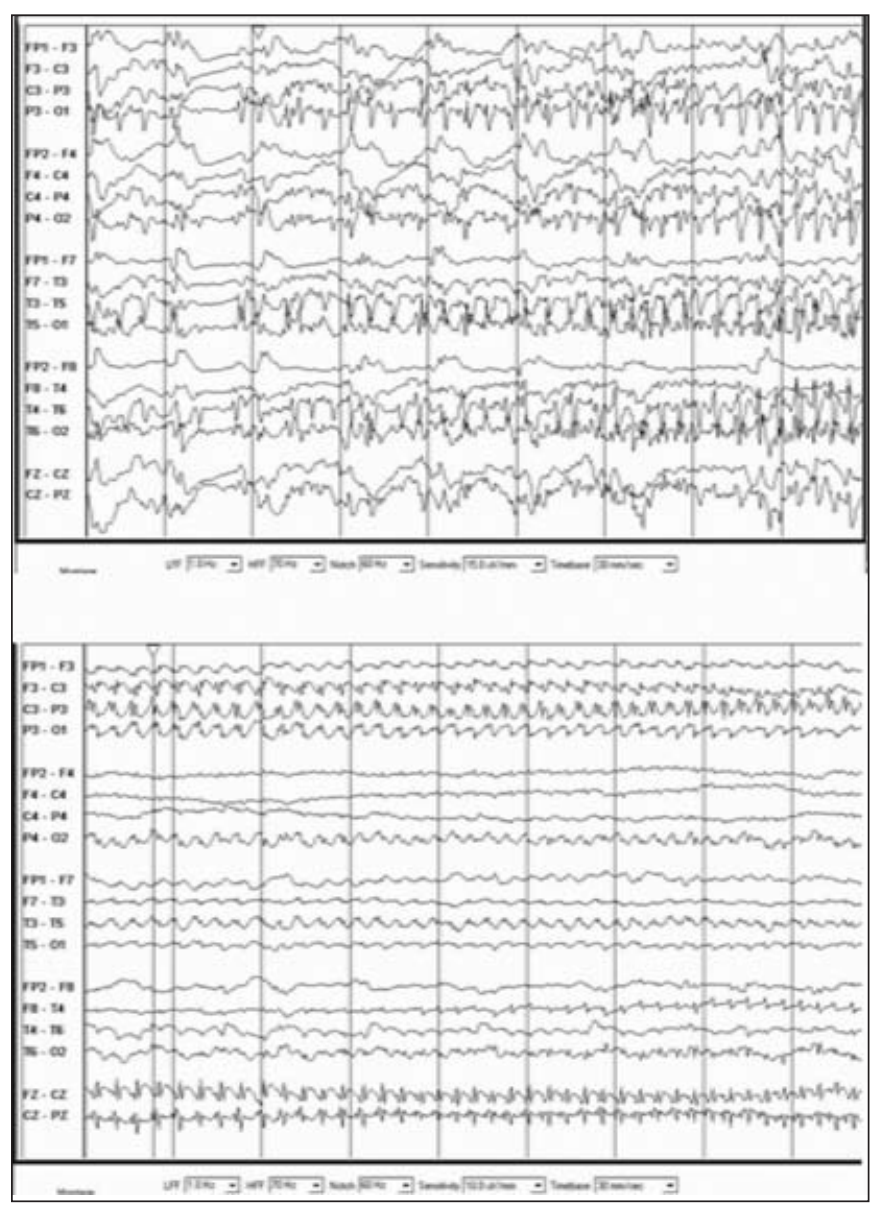

Figure 1: EEG in a patient with sudden onset intractable status epilepticus showing independent ictal rhythms with a perisylvian predominance.

treatment interventions. Often these children are treated in the intensive care setting for weeks to months with high dose suppressive therapy in a state of therapeutic coma. Mortality is high and survivors are left with severe cognitive and neurological deficits, and chronic epilepsy. No infectious agents are isolated and neuropathology shows no evidence of inflammation. Seizures are often multifocal, often perisylvian in origin (Figure 1) and progress to bihemispheric involvement ${ }^{26,27}$. Neuroimaging studies in survivors are often nonspecific and show evidence of widespread cortical and hippocampal atrophy (Figure 2). This condition may be underrecognized and underreported $^{27}$.

\section{Treatment considerations in Status epilepticus in the ICU The problem of pharmacoresistance in $S E$}

The development of refractoriness to AED therapy remains one of the enduring challenges in the management of status epilepticus in the ICU setting. All treatment protocols issued to parents, and used by transport teams, in the ER and PCIU should 


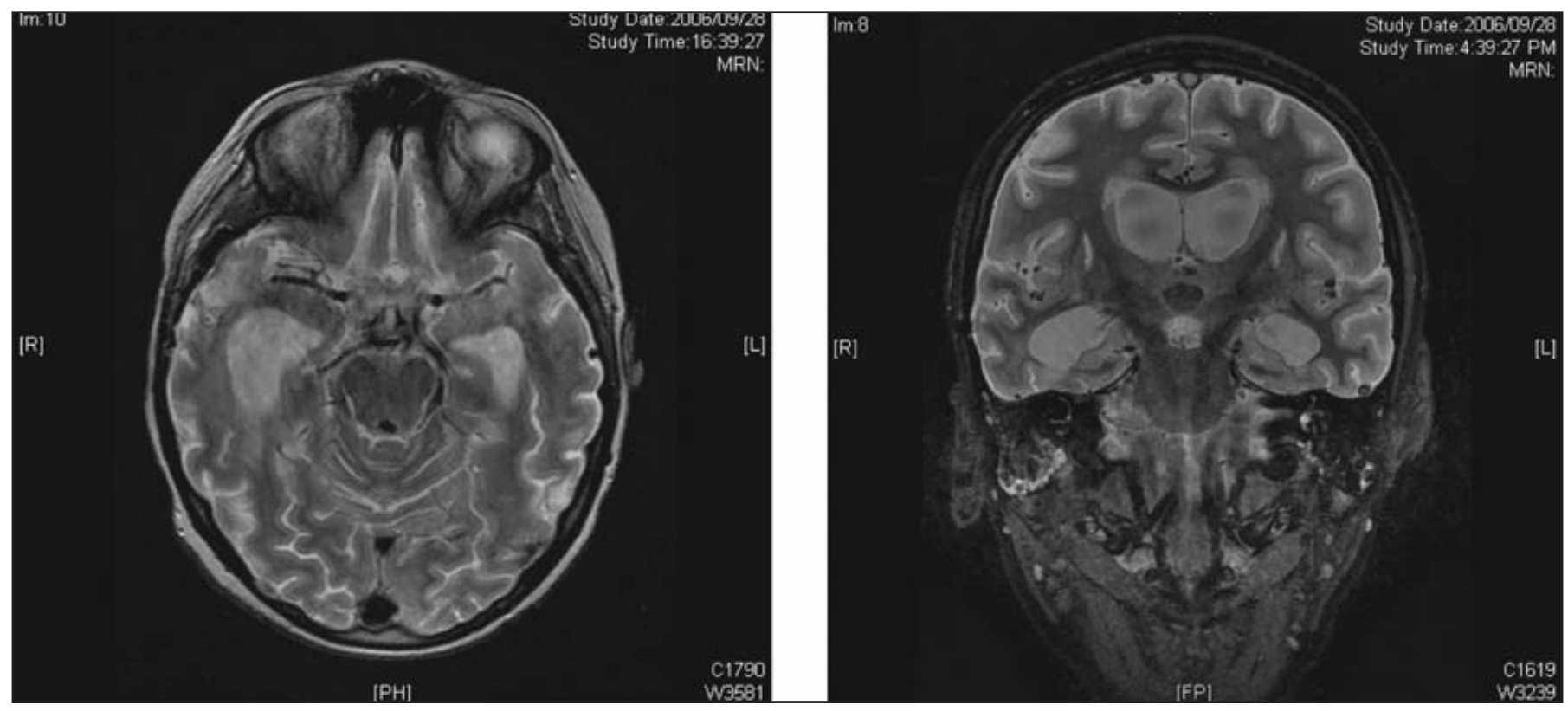

Figure 2: MRI images (axial and coronal T2 weighted sequences) in the survivor of intractable status epilepticus showing nonspecific but widespread cortical and hippocampal atrophy as a sequlae to the status epilepticus.

emphasize the importance of ascertaining accuracy in patient weight, and in drug prescribing practices in order to reduce the chances of under treatment. Both under treatment as well as overenthusiastic treatment have been found to be associated with an increase in the likelihood of admission to a PICU.

Status epilepticus is a refractory state, because it is characterized both by the inability of endogenous anticonvulsant systems to control seizure activity and self-reinforcement of the seizure process. In vitro studies demonstrate deterioration of GABAergic function over time during the course of self sustained status. Such decline of inhibition is often accompanied by loss of sensitivity to benzodiazepines ${ }^{28-30}$. The rapid internalization of GABA A receptor subunits accompanied by a simultaneous enhanced glutamatergic transmission provide the basis of our current understanding ${ }^{31}$. Other mechanisms may be involved in the development of pharmacoresistance: presynaptic processes (loss of phenytoin efficacy), translocation of calmodulin kinase from the membrane to cytosol enabling the release of neurotransmitter independent of $\mathrm{Na}+$ entry $^{32,33}$. Extrasynaptic mechanisms such as enhanced tonic GABA A inhibition may serve to limit focal discharges, but may result in negative consequences through effects on the corticothalamic oscillator system $^{34}$. Thus, a series of maladaptive changes ${ }^{35}$ at the cellular level underscore the development of treatment resistance. Understanding these mechanisms will be critical to the development of future treatment strategies.

\section{Treatment algorithms for $\mathrm{SE}$ in the ICU}

There is clear agreement amongst authorities in the field that prompt and aggressive administration of AED's to stop the evolution of the epileptic seizure into self-sustained status is essential. The rapid sequential use of short elimination half life AED such as a benzodiazepine (Midazolam) should be followed by a second agent (preferably phenytoin or fosphenytoin) in a timely manner. The time element, as pointed out in the initial discussion is critical. Epileptic seizures that last longer than seven minutes in duration carry a higher likelihood of becoming self-sustained. Furthermore early identification and treatment of refractory SE becomes a priority in the emergency department when the first line AED's have been administered.

The occurrence of breakthrough seizures, or continued seizure activity despite above measures can only be detected by close clinical and EEG monitoring. There is a critical role for continuous EEG monitoring in the detection of decoupling of electrical and clinical phenomenology of status epilepticus that often sets in when aggressive treatment measures are adopted. The challenges and opportunities presented by the ever improving technology are discussed elsewhere in this supplement. It is important to recognize that expert EEG interpretation often lags real time recording by several hours. Limitation of equipment, technologists and specialists probably influence outcome. Early studies point to the advantages in continuous EEG monitoring in patients with refractory and nonconvulsive status epilepticus in intensive care units ${ }^{36-38}$.

\section{Therapeutic options for refractory $S E$}

High dose suppression therapy (HDST) with agents such as propofol, pentobarbital, or midazolam should be used without delay once treatment refractoriness to conventional measures is noted. Such therapy will necessarily involve the need for 
continuous EEG monitoring, a service that is not consistently available across all tertiary pediatric intensive care units in Canada. The use of propofol in children has always been controversial on account of the risk of profound metabolic acidosis and myocardial failure that can occur. However, a recent study reports the use of a strict protocol where the dose of propofol (bolus of 1-2 mg/kg, followed by an infusion of 1-2 $\mathrm{mg} / \mathrm{kg} / \mathrm{hr}$ not exceeding an upper limit of $5 \mathrm{mg} / \mathrm{kg} / \mathrm{hr}$ ) with careful monitoring of blood lactate, triglyceride, acid base status and creatine kinase levels. The duration of treatment was controlled with favourable results in 14 of 22 episodes of refractory status treated in children. The authors ${ }^{39}$ point to the rapidity of therapeutic effect and the reversibility of side effects in this study as potential advantages favouring the careful use of propofol. The use of thiopentone remains an alternative. The depth of coma, the potential cardiac and respiratory complications of infection remain challenges to be overcome and likely influence mortality and morbidity.

The role of newer therapeutic alternatives to HDST remains an area for research. Several case series and open label trials have reported success with use of AED's such as intravenous valproic acid an,41, topiramate $^{42-44}$ and levetiracetam ${ }^{45,46}$. Increasing experience with these may provide additional options, prior to the consideration of HDST. Refractory status epilepticus is more prevalent in incident than in recurrent status epilepticus. In the pediatric age group, retrospective studies have reported high mortality rates $(32 \%)$ with use of $\mathrm{HDST}^{47}$. In studies that have included children, the outcome of patients treated with HDST is independent of the specific coma-inducing agents or the extent of EEG burst suppression, suggesting that the primary etiology may be a key determinant of outcome ${ }^{48}$. A role for surgery remains a consideration where there is evidence of focal epileptogenicity on the EEG and imaging studies. Finally, in the infant and the young child, treatment refractoriness may indicate rare inborn errors of metabolism, and treatment protocols have recommended the use of pyridoxine, folinic acid and pyridoxal phosphate supplementation. A recommended schema for treatment of status epilepticus is shown in Figure 3.

\section{Outcome of Status epilepticus in children in the ICU}

Short outcomes in the audit on patients admitted to the PICU in a tertiary children's hospital were good with a majority $(70 \%)$ recovering to neurological baseline, and high morbidity (nearly $25 \%$ ) left with fresh or additional neurological deficits. The mortality rate was about $6 \%$, similar to that reported (3-7\%) across different studies ${ }^{7,12,14}$. The risk of subsequent epilepsy (13-74\%), and of recurrent SE (ranging from 3-56\%) varies across published studies and meta-analysis ${ }^{49}$. The implications for behavioral and cognitive outcomes in clinical studies of children with prolonged seizures are complicated by the multiplicity of factors (neurobiological factors, genetic makeup, seizure duration, and recurrence, treatment choices and duration) that influence the developing brain. Evidence from the laboratory suggest that despite the lack of evidence of active neuronal injury following status epilepticus in the immature brain, there is uniformly a neurocognitive impairment in the longer term ${ }^{19}$. This age dependent vulnerability is seen irrespective of the nature of model of epileptogenesis studied. At a cellular level, cell loss, synaptic reorganization, changes in

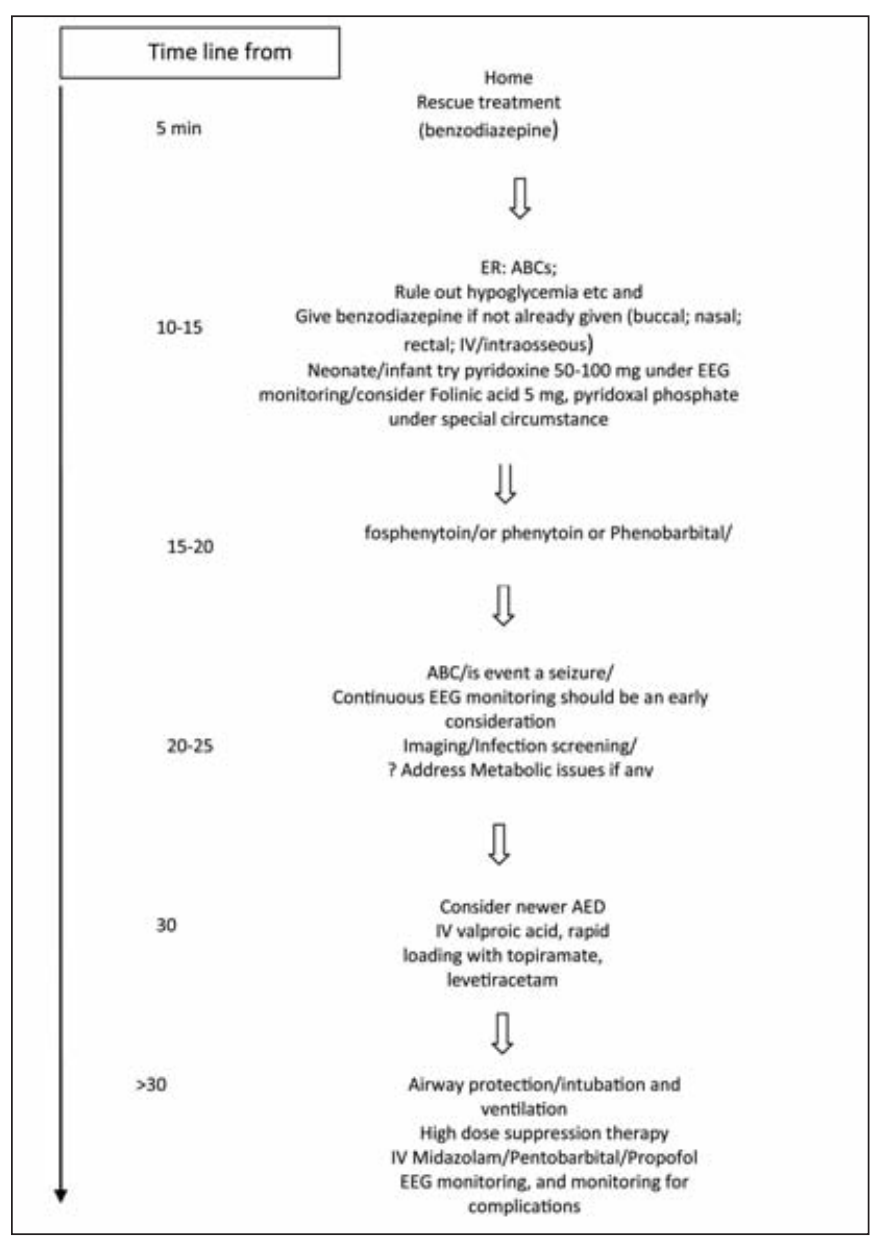

Figure 3: Proposed time locked sequence for treatment interventions in Status epilepticus.

dendritic morphology and in the expression of excitatory and inhibitory receptor subunits have been shown. The findings from both the laboratory and clinic impart a sense of urgent need to recognize the challenges in the management of status epilepticus in children to prevent the significant morbidity associate with a chronic illness (epilepsy) as well as the comorbidities in the long term in the form of behavioral and neurocognitive impairments.

\section{ACKNOWLEDGEMENTS}

The author thank Drs. S. Shah, and Dr. N. Shah, Department of Pediatrics, for their useful contributions and comments in the preparation of this manuscript.

\section{REFERENCES}

1. Working Group on Status Epilepticus. Treatment of convulsive status epilepticus. Recommendations of the Epilepsy Foundation of America's Working Group on Status Epilepticus. JAMA. 1993 Aug 18;270(7):854-9. 
2. Lowenstein DH, Bleck T, Macdonald RL. It's time to revise the definition of status epilepticus. Epilepsia. 1999 Jan;40(1):120-2.

3. Meldrum BS. The revised operational definition of generalised tonic-clonic (TC) status epilepticus in adults. Epilepsia. 1999 Jan:40(1):123-4.

4. DeLorenzo RJ, Hauser WA, Towne AR, Boggs JG, Pellock JM, Penberthy L, et al. A prospective, population-based epidemiologic study of status epilepticus in Richmond, Virginia. Neurology. 1996 Apr;46(4):1029-35.

5. Hesdorffer DC, Logroscino G, Cascino G, Annegers JF, Hauser WA. Incidence of status epilepticus in Rochester, Minnesota, 1965-1984. Neurology. 1998 Mar;50(3):735-41.

6. Sillanpaa M, Shinnar S. Status epilepticus in a population-based cohort with childhood-onset epilepsy in Finland. Ann Neurol. 2002 Sep;52(3):303-10.

7. Chin RF, Neville BG, Peckham C, Bedford H, Wade A, Scott RC. Incidence, cause, and short-term outcome of convulsive status epilepticus in childhood: prospective population-based study. Lancet. 2006 Jul 15;368(9531):222-9.

8. Shinnar S, Pellock JM, Moshe SL, Maytal J, O'Dell C, Driscoll SM, et al. In whom does status epilepticus occur: age-related differences in children. Epilepsia. 1997 Aug;38(8):907-14.

9. Corey LA, Pellock JM, Boggs JG, Miller LL, DeLorenzo RJ. Evidence for a genetic predisposition for status epilepticus. Neurology. 1998 Feb;50(2):558-60.

10. Corey LA, Pellock JM, DeLorenzo RJ. Status epilepticus in a population-based Virginia twin sample. Epilepsia. 2004 Feb; 45(2): 159-65.

11. Shinnar S, Berg AT, Moshe SL, Shinnar R. How long do new-onset seizures in children last? Ann Neurol. 2001 May;49(5):659-64.

12. Hussain N, Appleton R, Thorburn K. Aetiology, course and outcome of children admitted to paediatric intensive care with convulsive status epilepticus: a retrospective 5-year review. Seizure. 2007 Jun;16(4):305-12.

13. Shah N, Shah S, Prasad A, Johnson R, editors. Outcome variable of status epilepticus in a pediatric intensive care unit. International Child Neurology Congress; 2006; Montreal. ThiemeConnect.[Internet]:2006[ updated 2006, cited 2/1/2008] URL: http://www.thieme-connect.com/ejournals/abstract/ neuropediatrics/doi/10.1055/s-2006-945653

14. Neville BG, Chin RF, Scott RC. Childhood convulsive status epilepticus: epidemiology, management and outcome. Acta Neurol Scand. 2007 Apr;115(4):21-4.

15. Shinnar S, Pellock JM, Berg AT, O'Dell C, Driscoll SM, Maytal J, et al. Short-term outcomes of children with febrile status epilepticus. Epilepsia. 2001 Jan;42(1):47-53.

16. Scott RC, King MD, Gadian DG, Neville BG, Connelly A. Hippocampal abnormalities after prolonged febrile convulsion: a longitudinal MRI study. Brain. 2003 Nov;126(Pt 11):2551-7.

17. Shinnar S. Prolonged febrile seizures and mesial temporal sclerosis. Ann Neurol. 1998 Apr;43(4):411-2.

18. Maher J, McLachlan RS. Febrile convulsions. Is seizure duration the most important predictor of temporal lobe epilepsy? Brain. 1995 Dec;118 ( Pt 6):1521-8.

19. Sankar R, Rho JM. Do seizures affect the developing brain? Lessons from the laboratory. J Child Neurol. 2007 May;22 5 Suppl:21S-9S

20. Sloviter RS. Status epilepticus-induced neuronal injury and network reorganization. Epilepsia. 1999;40 Suppl 1:S34-9; discussion S40-1.

21. Toth Z, Yan XX, Haftoglou S, Ribak CE, Baram TZ. Seizureinduced neuronal injury: vulnerability to febrile seizures in an immature rat model. J Neurosci. 1998 Jun 1;18(11):4285-94.

22. Sutula TP. Experimental models of temporal lobe epilepsy: new insights from the study of kindling and synaptic reorganization. Epilepsia. 1990;31 Suppl 3:S45-54.

23. Barsi P, Kenez J, Solymosi D, Kulin A, Halasz P, Rasonyi G, et al. Hippocampal malrotation with normal corpus callosum: a new entity? Neuroradiology. 2000 May;42(5):339-45.
24. Lewis DV, Chan S, Bello J, Hesdorffer DC, Marmarou A, Moshe $\mathrm{SL}$, et al. HIMAL is a malformation that predisposes to prolonged febrile seizures: Data from the FEBSTAT study. [Internet]; 2006 [updated 2006; cited 2008 2/1/2008]; Available from: http://www.aesnet.org/go/publications/aesabstracts/abstract-search $/$ ? mode=display $\&$ st=FEBSTAT $\&$ sy $=2006 \& \mathrm{sb}=\mathrm{All} \&$ startrow $=1 \& \mathrm{id}=6101$.

25. Juntunen A, Herrgard E, Mannonen L, Korppi M, Linnavuori K, Vaheri A, et al. A major role of viruses in convulsive status epilepticus in children: a prospective study of 22 children. Eur J Pediatr. 2001 Jan;160(1):37-42.

26. Baxter P, Clarke A, Cross H, Harding B, Hicks E, Livingston J, et al. Idiopathic catastrophic epileptic encephalopathy presenting with acute onset intractable status. Seizure. 2003 Sep;12(6): 379-87.

27. Mikaeloff Y, Jambaque I, Hertz-Pannier L, Zamfirescu A, Adamsbaum C, Plouin P, et al. Devastating epileptic encephalopathy in school-aged children (DESC): a pseudo encephalitis. Epilepsy Res. 2006 Apr;69(1):67-79.

28. Goodkin HP, Kapur J. Responsiveness of Status Epilepticus to Treatment with Diazepan Decreases Rapidly as Seizure Duration Increases. Epilepsy Curr. 2003 Jan;3(1):11-2.

29. Goodkin HP, Sun C, Yeh JL, Mangan PS, Kapur J. GABA(A) receptor internalization during seizures. Epilepsia. 2007;48 Suppl 5:109-13.

30. Goodkin HP, Yeh JL, Kapur J. Status epilepticus increases the intracellular accumulation of GABAA receptors. J Neurosci. 2005 Jun 8;25(23):5511-20.

31. Naylor DE, Liu H, Wasterlain CG. Trafficking of GABA(A) receptors, loss of inhibition, and a mechanism for pharmacoresistance in status epilepticus. J Neurosci. 2005 Aug 24;25(34):7724-33.

32. Wasterlain CG, Bronstein JM, Morin AM, Dwyer BE, Sankar R. Translocation and autophosphorylation of brain calmodulin kinase II in status epilepticus. Epilepsy Res Suppl. 1992;9: 231-8

33. Wasterlain CG, Liu H, Mazarati AM, Baldwin RA, Shirasaka Y, Katsumori $\mathrm{H}$, et al. Self-sustaining status epilepticus: a condition maintained by potentiation of glutamate receptors and by plastic changes in substance $\mathrm{P}$ and other peptide neuromodulators. Epilepsia. 2000;41 Suppl 6:S134-43.

34. Cope DW, Hughes SW, Crunelli V. GABAA receptor-mediated tonic inhibition in thalamic neurons. J Neurosci. 2005 Dec 14; 25(50):11553-63.

35. Mazarati A, Sankar R. Status epilepticus: dance macabre in a ballet of subunits. Epilepsy Curr. 2006 May-Jun;6(3):102-5.

36. Hyllienmark L, Amark P. Continuous EEG monitoring in a paediatric intensive care unit. Eur J Paediatr Neurol. 2007 Mar; 11(2):70-5.

37. Trevathan E. Ellen R. Grass Lecture: Rapid EEG analysis for intensive care decisions in status epilepticus. Am J Electroneurodiagnostic Technol. 2006 Mar;46(1):4-17.

38. Ross C, Blake A, Whitehouse WP. Status epilepticus on the paediatric intensive care unit-the role of EEG monitoring. Seizure. 1999 Sep;8(6):335-8.

39. van Gestel JP, Blusse van Oud-Alblas HJ, Malingre M, Ververs FF, Braun KP, van Nieuwenhuizen O. Propofol and thiopental for refractory status epilepticus in children. Neurology. 2005 Aug 23;65(4):591-2.

40. Mehta V, Singhi P, Singhi S. Intravenous sodium valproate versus diazepam infusion for the control of refractory status epilepticus in children: a randomized controlled trial. J Child Neurol. 2007 Oct;22(10):1191-7.

41. Yu KT, Mills S, Thompson N, Cunanan C. Safety and efficacy of intravenous valproate in pediatric status epilepticus and acute repetitive seizures. Epilepsia. 2003 May;44(5):724-6.

42. Perry MS, Holt PJ, Sladky JT. Topiramate loading for refractory status epilepticus in children. Epilepsia. 2006 Jun;47(6):1070-1.

43. Blumkin L, Lerman-Sagie T, Houri T, Gilad E, Nissenkorn A, Ginsberg M, et al. Pediatric refractory partial status epilepticus responsive to topiramate. J Child Neurol. 2005 Mar;20(3): $239-41$. 
44. Kahriman M, Minecan D, Kutluay E, Selwa L, Beydoun A. Efficacy of topiramate in children with refractory status epilepticus. Epilepsia. 2003 Oct;44(10):1353-6.

45. Wheless JW, Clarke DF, Carpenter D. Treatment of pediatric epilepsy: expert opinion, 2005. J Child Neurol. 2005 Dec;20 Suppl 1:S1-56; quiz S9-60.

46. Misra UK, Kalita J, Patel R. Sodium valproate vs phenytoin in status epilepticus: a pilot study. Neurology. 2006 Jul 25;67(2): $340-2$.
47. Sahin M, Menache CC, Holmes GL, Riviello JJ. Outcome of severe refractory status epilepticus in children. Epilepsia. 2001 Nov;42(11):1461-7.

48. Rossetti AO, Logroscino G, Bromfield EB. Refractory status epilepticus: effect of treatment aggressiveness on prognosis. Arch Neurol. 2005 Nov;62(11):1698-702.

49. Chin RF, Neville BG, Scott RC. A systematic review of the epidemiology of status epilepticus. Eur J Neurol. 2004 Dec;11 (12):800-10 


\title{
Canadian League Against Epilepsy
}

\section{Abstracts}

\author{
CLAE 30th Anniversary Meeting, Vancouver 2-4 October 2007: Abstracts of Poster Presentations
}

Can. J. Neurol. Sci. 2009; 36: Suppl. 2 - S99-S106

\section{PEDIATRIC EPILEPSY ABSTRACTS}

\section{Hippocampal Volumes In Normal Children: An Age Dependent Analysis}

Blaire Anderson*, Xingchang Wei, Walid Abou Reslan, Martin Sherriff, Elaine Wirrell, Lorie Hamiwka

Department of Neurology and Diagnostic Imaging, Alberta Children's Hospital

Background: In Children, hippocampal sclerosis (HS) accounts for $17-40 \%$ of the pathology in operated patients with refractory temporal lobe epilepsy. The coexistence of HS with another epileptogenic substrate is common. It has been established in the adult population that quantitative measurement of hippocampal volume (HCV) can be used to augment qualitative visual inspection of hippocampal atrophy, the most reliable neuroimaging evidence of HS. Although normal HCV reference values have been established for adults, there is little data for children and it is unclear whether or not HCV is dependent on age in the pediatric population ${ }^{1-2}$. Our goal was to establish reference values of HCV for children aged 2-16 years.

Methods: High resolution 1-mm-thick isotropic 3D MPRAGE T1-weighted images (T1WI) and regular fast spin-echo T2-weighted images (T2WI) of the brain were acquired from subjects who underwent MR imaging for reasons other than epilepsy. Written informed consent was obtained. Patients with previous known cerebral abnormalities, abnormal neuroimaging and history of seizures of any reason were not included. The imaging data was uploaded to a personal computer and the volume measurement performed using 3D Slicer program. HCV was measured on the high resolution T1WI using the method of Watson et $\mathrm{al}^{3}$. The HCV of individual subjects was normalized with intracranial volume (ICV) measured on the T2WI using the analysis of covariance approach described by Jack et $\mathrm{al}^{4}$ : $\mathrm{HCV}$ corrected $=\mathrm{HCV}$ measured - gradient $(\mathrm{ICV}$ measured IVCmean), where gradient is the slope of the regression line of $\mathrm{HCV}$ versus ICV.

Results and Conclusion: 33 children participated (mean age 8.39 years; age distribution: 24\% 2-5 years, $42 \%$ 5-10 years,
$33 \%$ 10-16 years). No statistically significant difference was found between age and $\mathrm{HCV}$ uncorrected or corrected $(\mathrm{P}>0.05)$. The corrected reference values of hippocampal volume determined in our cohort of normal children were $3957 \pm$ $335 \mathrm{~mm}^{3}$ and $3948 \pm 362 \mathrm{~mm}^{3}$ for right and left side respectively. No difference was appreciated between gender or side $(\mathrm{P}>0.05)$. The lack of statistically significant correlation between age and $\mathrm{HCV}$ has allowed us to establish a single normal range for children aged 2-16 years.

\section{REFERENCES}

1. Mulani SJ, et al. Neuroradiology. 2005;47:552

2. Obenaus A, et al. Pediatr Res. 2001;50:124

3. Watson C, et al. Neurology. 1992;42:1743

4. Jack CR, Jr., et al. Radiology. 1989;172:549

\section{Surgical Results Of Corpus Callosotomy For Intractable} Epilepsy With West Syndrome

Hiroshi Baba, Tomonori Ono, Keisuke Toda, Kenji Ono, Shiro Baba

Department of Neurosurgery, National Nagasaki Medical Center, Nagasaki, Japan

Purpose: Infants and young children with refractory West syndrome are at high risk for developing severe mental retardation. Surgical results and prognostic factors in corpus callosotomy were analyzed in patients with West syndrome who were not candidate for resective surgery.

Methods: Callosotomy were performed in 35 patients under five years old. Age at seizure onset ranged from 0 to 1.8 years (mean 0.3). Nine patients were treated as EIEE during early stages of their illness. Normal developments were observed in 11 patients before the onset of epilepsy. ACTH and TRH therapy were used in 27 and 7 patients in addition to antiepileptic drugs, respectively. All patients had video-EEG monitoring, neuropsychological examination (Kinder Infant developmental scale, KIDS), MRI and inter-ictal ECD SPECT. 19 patients had only tonic spasm during video-EEG monitoring, but the other 16 
patients showed other seizure types such as tonic seizure and atypical absence in addition to tonic spasm. Patients with resectable lesion on MRI were excluded. Age at the surgery ranged from 0.4 to 4.6 years (mean 1.9). Anterior callosotomy was performed in 2 patients, staged or one-stage total callosotomy in 33 patients with a mean final follow-up of 2.6 years. Surgical outcome was categorized as free $(\mathrm{F})$ : seizure free, excellent (E) : greater than $80 \%$ reduction in seizure frequency, good $(\mathrm{G})$ : greater than $50 \%$ reduction in seizure frequency and poor $(\mathrm{P})$ : no significant change.

Results: Surgical outcome was F in 9 (26\%), E in 7 (20\%), G in $10(28 \%)$ and $\mathrm{P}$ in 9 patients (26\%). 26 of 35 patients $(74 \%)$ showed significant improvement after the surgery. Prognostic factors were analyzed between $\mathrm{F}+\mathrm{E}$ group and $\mathrm{G}+\mathrm{P}$ group. Age at seizure onset was significantly older in $\mathrm{F}+\mathrm{E}$ group ( 0.45 year) than in $\mathrm{G}+\mathrm{P}$ group $(0.22$ year) $(\mathrm{p}<0.05)$. Preoperative DQ was 28.3 in $\mathrm{F}+\mathrm{E}$ group and 12.7 in $\mathrm{G}+\mathrm{P}$ group $(\mathrm{p}<0.05) .11$ of 16 patients $(68 \%)$ in $\mathrm{F}+\mathrm{E}$ group showed normal development before the onset of epilepsy, but all patients in $\mathrm{G}+\mathrm{P}$ group had developmental delay before the onset of epilepsy $(\mathrm{p}<0.001)$. There were not significant differences on the age at surgery and duration of the epilepsy.

Conclusion: Corpus callosotomy was effective in patients with intractable West syndrome. Best results were obtained in patients who had late onset of epilepsy, higher in DQ and normal development before the onset of epilepsy.

\section{EEG coherence abnormalities in children with febrile}

Birca A, Carmant L, Lortie A, Vannasing P, Sauerwein $H$, Piper D, Lemay L, Wang X-P, Tamm N, Donici V, Lassonde M

Centre de recherche, Hôpital Sainte-Justine, Université de Montréal

Recent diffusion tensor imaging studies have shown that early onset epilepsy can interfere with the development of white matter connections between brain regions. It is not known whether benign conditions like febrile seizures (FS) are also characterized by brain connectivity abnormalities. Coherence of the EEG activity between two sites can provide information about the degree of functional connectivity between the structures underlying pairs of electrodes, but lacks anatomical precision, principally due to the smearing effect of the volume conduction in EEG. Recently developed source coherence analysis allows a better separation of activities of different brain regions and an estimation of coupling between them. The aim of this study was to compare source coherences between different brain regions in children with FS and their siblings.

EEG was recorded during rest and intermittent photic stimulation (IPS) in 12 FS patients and 5 siblings (mean age 20.3 \pm 9.5 and $17.6 \pm 4.8 \mathrm{mths}$ respectively). Original EEG data were transformed into source space using a multiple regional source model of steady-state visual evoked potentials generators. Source coherence values were calculated for interhemispheric (interfrontal, intertemporal and interoccipital) and intrahemispheric (intraoocipital, occipito-temporal and occipitofrontal) connections. Evoked source coherence at exactly the frequencies of stimulation and their low (less than $15 \mathrm{~Hz}$ ) and high gamma range harmonics $(30-50 \mathrm{~Hz})$, as well as the delta, theta, alpha and beta band source coherence during rest and IPS were retained for further analysis.

Children with FS showed significantly greater gamma range coherence evoked by IPS between the right and left frontal regions. They also had significantly greater coherence values across all the frequency bands during the rest and the IPS, the effect being again more pronounced between the frontal regions. However, these results should be interpreted cautiously given the small number of siblings.

Our data show a different pattern of brain connectivity in children with FS at the age of their maximal occurrence. We hypothesize that a stronger coupling, especially between the frontal lobes, predisposes to an easier propagation of seizure activity in FS patients. Future prospective studies should include normal control children and assess whether these abnormalities are permanent or have a prognostic value in the development of epilepsy following FSs.

Epileptic and developmental outcome of West syndrome: 6month follow-up of the ongoing Canadian multi-centre study

\section{CPEN IS study group}

\section{Canadian Pediatric Epilepsy Network}

Purpose: West syndrome is one of the 'catastrophic' childhood epilepsies which is associated with arrest or regression of cognitive development. We present here the epileptic and cognitive outcome in relation to the underlying aetiology.

Method: The series consisted of 69 infants with new onset of infantile spasms, of which 55 aged 3 to 16 months (mean age: 7 mo) had complete developmental data. The patients were given Vigabatrin as first choice, ACTH as second choice and Topamax when both drugs failed. Their developmental age was determined on the Mental Scales of the Bayleys at diagnosis (baseline) and 6 months after initiation of treatment. To explore the effect of aetiology on cognitive and clinical outcome, the infants were divided into three groups: cryptogenic, hypoxic ischemic encephalopathy (HIE) and divers other cerebral pathologies.

Results: The infants with cryptogenic aetiology were least delayed at diagnosis and had the best epileptic and cognitive outcome. The reverse was true for those with HIE. At 6 months, $96 \%$ of the patients were spasm free. Vigabatrin was effective in $66 \%$ of the children. Switch to ACTH was necessary in 34\%, and to Topamax in $4 \%$ of the cases, mostly HIE. Cognitive improvement again favoured the cryptogenic group.

Conclusion: Treatment outcome varies according to aetiology and cognitive gains follow the same pattern. Vigabatrin appears of limited efficacy in severe HIE cases. 
Comparing Quality of Life Measures in Childhood Epilepsy: What's in the measures?

\section{*Nora Fayed \& Elizabeth Kerr}

*Rehabilitation Science, McMaster University, Hamilton, Ontario, Canada, Psychology, Sick Kids Hospital, Toronto, Ontario, Canada

Introduction: An important step in selecting an epilepsyspecific quality of life (QOL) measure is an appraisal of its conceptual content. This process ensures the compatibility between areas of health contained in the QOL measure and the actual health intervention. Reviews assessing the psychometric properties of QOL measures in youth epilepsy (YE) have been previously completed, however, the measures have not been appraised with a focus on conceptual content.

Purpose: The purpose of our study was to 1) identify current disease-specific QOL outcome measures available for use in YE using systematic review, and 2) to compare those QOL measures based on a broadly defined, international standard of health using the International Classification of Functioning, Health, and Disability (ICF). Usefulness of the ICF for appraising the content of QOL outcome measures was also described.

Methods: A review of the literature was conducted to identify QOL measures that were specific to YE. Once an outcome measure was identified, two independent raters assigned an ICF code to each item on the QOL questionnaire using a modified form of Cieza et al.'s (2005) linking rules. ICF codes were then grouped under body functions, body structures, activities and participation, or environmental factors. A comparison of the percentage of ICF domains represented was performed between each measure. Inter-rater reliability of linking was analyzed using Cohen's kappa.

Results: Body functions was the most significantly represented domain of the ICF in 5 out of 8 QOL measures. Conversely, environmental factors was the least represented health domain included in the QOL measures. Reliability of coding was the highest between each rater and the final list of codes $(\mathrm{k}=0.66-0.74)$ as opposed to between raters $(\mathrm{k}=0.56)$.

Conclusion: Current QOL outcome measures in YE require expansion to reflect a broad definition of health according to the ICF. This is particularly true of items representing environmental factors influencing health. The ICF demonstrated usefulness for comparing the outcomes and identifying the need for the implementation of broader definitions of health in QOL measures.

\section{A Non Invasive Presurgical Investigation In A 10-Year-Old Epileptic Boy Using NIRS-EEG: Comparison With SPECT, PET, FMRI-EEG, MEG-EEG And Post Surgical Neuro- anatomical Assessments}

Gallagher* $A^{1,2}$, Lassonde $M^{1,2}$, Bastien $D^{1,2}$, Vannasing $P^{l}$, Lesage $F^{3}$, Grova $C^{2,6}$, Tyvaert $L^{6}$, Kobayashi $E^{6}$, Gotman $J^{6}$, Bouthillier $A^{5}$, Carmant $L^{1,4}$, Lepore $F^{1,2}$, Béland $R^{2}$, Nguyen $D^{5}$

1. Centre de Recherche du Centre Hospitalier Sainte-Justine, Montréal, QC, Canada 2. Centre de Recherche en Neuro- psychologie et Cognition, Département de Psychologie, Université de Montréal, Montréal, QC, Canada 3. Centre de recherches mathématiques, Université de Montréal, Montréal, QC, Canada 4. Neurology Service, Centre Hospitalier SainteJustine, Montréal, QC, Canada 5. Neurology Service, Hôpital Notre-Dame, Montreal, QC, Canada 6. Montreal Neurological Institute, Montreal, QC, Canada.

Near infrared spectroscopy (NIRS) and EEG videomonitoring have been combined as a part of a presurgical assessment in a young epileptic boy (LH) to evaluate the potential of this novel technique to improve the epileptogenic zone localization and assess language lateralization. This 10year-old boy with a nonlesional refractory MRI-negative right frontal epilepsy underwent a prolonged NIRS-EEG recording using 19 EEG electrodes and 128 NIRS channels (placed on right frontal, parasagital and rolandic bilateral areas) in order to record seizures. Results were then compared to those obtained with typical presurgical assessments (SPECT, PET, MRI, EEG, EcoG) as well as more recent techniques (simultaneous fMRIEEG and MEG-EEG). LH also performed a language task during a second NIRS recording over Broca and Wernicke's areas and analogous right hemisphere regions to investigate language lateralization. A control task was also performed to control the oro-motor aspect of the task. Two electroclinical and two electrical seizures were recorded over a three-hour NIRS-EEG session. Clinically, seizures consisted of an aura of fear lasting a few seconds. Electrically, ictal rhythmic spikes over the right frontocentral region were noted. Ictal NIRS mapping coregistered onto the MRI revealed a high increase of $\mathrm{rCBV}$ over the right frontal region during both electroclinical and electrical seizures. This was in good concordance with other functional techniques (PET, SPECT, fMRI-EEG, MEG-EEG). A milder bilateral rolandic activation was seen with both NIRS and fMRIEEG. Subsequent NIRS recording showed a left-hemisphere language lateralization during a category verbal fluency task compared to the control task. Intraoperative electrocorticography revealed continuous spiking over the suspected right frontal focus and a limited right frontal cortectomy was performed. The patient has remained seizure-free four months post surgery. Pathological analysis of the resection demonstrated the presence of an underlying cortical dysplasia. This case-report illustrates that continuous NIRS-EEG has the potential to contribute favorably to the localization of the epileptogenic zone and assessment of language lateralization. This recent technique can easily be performed in young patients. If replicated in a larger sample, continuous NIRS-EEG combined with classical and other novel noninvasive techniques may reduce the need for invasive monitoring in non-lesional patients.

\section{Anxiety and Depression in Children with Epilepsy}

\section{LD Hamiwka, CG Yu, EMS Sherman, EC Wirrell}

Alberta Children's Hospital Department of Pediatrics University of Calgary

Purpose: To determine the prevalence of anxiety and depression in children and teens with epilepsy. 
Methods: Children with epilepsy ages 8-16 were recruited from the Neurology Clinic at the Alberta Children's Hospital. Children were included if they had been diagnosed with epilepsy by a Pediatric Neurologist, on anti-convulsant therapy or had greater than 2 seizures with at least one in the preceding year. Children were excluded if they had another active nonneurological chronic disease or an estimated development quotient of less than 70. Families agreeing to participate were asked to complete the Children's Depression Inventory (CDI) and the Revised Children's Manifest Anxiety Scale (RCMAS). Epilepsy factors including age of seizure onset, seizure type (generalized, partial, and unclassified), seizure frequency, number of current medications, and number of previous medications/surgery were recorded.

Results: Fifty children $(\mathrm{F}=24, \mathrm{M}=26)$ completed the questionnaires. Children with epilepsy showed significantly lower total scores on the CDI than published normative data $(\mathrm{p}<$ $0.01)$. On subscale analysis they demonstrated significant interpersonal problems $(\mathrm{p}<0.01)$, felt negatively about their school performance $(\mathrm{p}<0.01)$, and had low self-esteem $(\mathrm{p}$ $<0.01)$. Although the overall RCMAS total scores were not significantly different than the published total scores, children with epilepsy did experience greater physiological anxiety ( $p$ $<0.01)$ and greater social concerns ( $p<0.01)$. Eight children (16\%) had clinically significant depression scores and 15 children (30\%) had clinically significant anxiety scores. Clinically significant depression and anxiety did not correlate with age of seizures onset, seizure type (partial vs generalized), or number of current or previous medications.

Conclusion: Children with epilepsy experience more depressive symptoms and show greater anxiety than the expected base rate according to published normative data. A significant proportion of these children experience clinically significant scores requiring further clinical assessment. Our data suggests that all children with epilepsy should be screened for these symptoms as part of their clinical evaluation.

\section{Risk factors for Valproic acid non response in patients with childhood absence epilepsy}

May Lissa Ollivier ${ }^{1}$, Marie-France Dubois ${ }^{2}$, Maja Krajinovic ${ }^{1}$, Patrick Cossette Chd Lionel Carmant $^{1}$

1. CHU Sainte Justine, Montreal; 2. Université de Sherbrooke, Sherbrooke; 3. CHUM (hôpital Notre Dame), Montreal; Canada

Childhood absence epilepsy (CAE) is one of the most common forms of epilepsy in young children. CAE accounts for $2-8 \%$ of patients with epilepsy. It arises in children with no prior illnesses and has a peak in incidence at around 5 or 6 years old. Worldwide statistics show that absence seizures can be controlled by Valproic Acid (VPA) in $75 \%$ of children with CAE. The remaining $25 \%$ will continue to have seizures or the side effects will limit its utilisation. Pharmacogenomic studies have been able to define mechanisms underlying drug-resistance. The aim of this study, prior to undertaking the pharmacogenomic study, is to determine the clinical and socio-demographic factors associated with a poor response to VPA in children with CAE.
Medical charts of 149 children diagnosed with CAE at Montreal's CHU Sainte-Justine and treated with VPA for at least 2 months were reviewed in order to extract their responsiveness to VPA and several factors potentially influential of its response. Factors associated with non response were identified through bivariate and multivariate logistic regression analyses. Treatment with VPA was successful in $88(59.1 \%)$ patients. Compared to patients which responded to VPA, more patients refractory to VPA experienced myoclonic or generalized tonic-clonic seizures (GTCS) (42.6\% vs. $19.3 \%$; $=0.002$ ) and $52.2 \%$ had a pretreatment seizure frequency greater than 10/day (vs. $26.8 \%$ for responders; $\mathrm{p}=0.005)$. Patients who had febrile convulsions responded better to VPA with $14.8 \%$ responding to treatment compared to only $9.8 \%$ not responding $(\mathrm{p}=0.047)$. Age at seizure onset also affected response to treatment by decreasing the risk of non response by 0.1 for every added year $(\mathrm{p}<0.002)$. Finally, the delay between the seizure onset and the start of the treatment also affected outcome by increasing the risk of non response by 0.02 for every month without treatment $(\mathrm{p}<0.001)$. When all factors where combined, only the treatment delay ceased to be significant $(\mathrm{p}=0.410)$ in the presence of other factors. VPA treatment outcome is therefore associated with certain variables which would allow us to know beforehand which types of patients might or might not respond to the treatment. Our results suggest that certain clinical phenotypes are associated with a reduced response rate to VPA. These children might have a distinct genetic and or pharmacogenomic profile than children without these clinical risk factors.

\section{The Spectrum of Occipital Lobe Epilepsy in Children}

Dewi V Schrader, Ruchika Shukla, Renee Gatrill, Kevin Farrell, Mary B Connolly

Division of Pediatric Neurology, Department of Pediatrics, University of British Columbia and BC Children's Hospital, Vancouver, British Columbia, Canada

Background: Occipital seizures can arise from brain lesions or may be part of an idiopathic, genetically determined syndrome. The purpose of this study was to determine the differences between idiopathic and symptomatic occipital epilepsy.

Methods: We reviewed the epilepsy and EEG database at the BC Children's Hospital from 1983-2007 to identify patients with occipital lobe epilepsy based on clinical, neuroimaging and EEG findings.

Results: We identified 66 patients with occipital epilepsy. 21 patients had symptomatic epilepsy with abnormal MR imaging (inflammatory or ischemic lesions $n=10$, malformations of cortical development $n=9$, tumours $n=2$ ). 14 patients were classified as probable symptomatic based on abnormal neurological exam findings, abnormal cognitive function or intractable seizures. 31 patients had normal neurological exams and imaging and were classified as idiopathic. Of these patients, 22 satisfied criteria for idiopathic occipital syndromes: Panayiotopoulos (12 patients), Gastaut (9 patients) and idiopathic photosensitive epilepsy (1 patient). 9 of the idiopathic 
patients had features that overlapped between the different syndromes and could not be classified. The symptomatic group had an earlier age of seizure onset: 1.5 years (range 0.2-5.5 years) vs. 6 years (range $3-9$ years) $(\mathrm{p}=0.0009)$ and tended to have more frequent seizures at presentation: 3.25 seizures per week vs. 0.75 seizures per week $(p=0.068)$. There was no significant difference in seizure semiology between the two groups. More patients in the idiopathic group had a family history of migraine than the symptomatic group (68\% vs. $37 \%$, $\mathrm{p}=0.013)$. The final rate of seizure remission was not significantly different between the 2 groups, although patients in the symptomatic group required a greater number of anti-seizure medications (median 1 vs. $2.5, \mathrm{p}=0.0539$ ).

Conclusions: Patients with abnormalities demonstrated on MR imaging were more likely to have an early age of seizure onset, tended to have more frequent seizures and required a greater number of anti-seizure medications. The most common syndrome in the idiopathic group was Panayiotopoulos syndrome. However, a significant proportion of the idiopathic patients exhibited overlapping clinical features and did not fit into the defined idiopathic syndromes, suggesting that these syndromes likely exist on a spectrum.

\section{Deterioration in Cognitive Function in Children with Benign Epilepsy of Childhood with Central Temporal Spikes Treated with Sulthiame}

\author{
*Elaine Wirrell MD, Elisabeth M.S. Sherman PhD, Bob \\ Vanmastrigt PhD, Lorie Hamiwka MD
}

Departments of Pediatrics and Clinical Neurosciences, University of Calgary

Purpose: To determine if reduction in spike frequency in children with benign epilepsy of centrotemporal spikes (BREC) treated with sulthiame correlates with improved neuropsychological function.

Methods: Six untreated children with BREC (5M:1F, mean age 9.1 years, SD 1.5 yrs) underwent baseline overnight ambulatory EEG recording and neuropsychological evaluation. Testing was repeated after 6 months of sulthiame monotherapy. Spike frequency was calculated during two periods of Stage 2 sleep, and compared between the two time points. The Reliable Change Index was used to determine whether a statistically reliable change in neuropsychological function occurred from baseline to retest.

Results: Mean seizure number prior to treatment was 7 (SD 7 , range 2-18). Five children had secondarily generalized seizures with or without partial seizures and one had partial seizures alone. All children continued on sulthiame monotherapy (dose range $8.0-9.3 \mathrm{mg} / \mathrm{kg} / \mathrm{d}$ ) for the six month study period with no further seizures. Spike frequency was reduced in all children, with three showing a decrease to less than $10 \%$ of baseline. However, all children demonstrated significant deterioration in their reading ability and 5/6 had significant declines in general memory. Over half had reduction in attention skills and mathematics ability.
Conclusions: Although sulthiame was effective at seizure control and significantly reduced spike frequency in children with BREC, it was also associated with deterioration in cognitive function. Given that BREC is a "benign" disorder with a favorable long-term outcome, treatment with sulthiame does not appear warranted in most cases.

\section{BASIC SCIENCE ABSTRACTS}

\section{Seizures Impede Dendritic Growth In Immature Neurons, Revealed By In Vivo Imaging Of The Intact Developing Brain - A Novel Experimental Model}

*D. Sesath Hewapathirane, Wesley Yen, Simon Chen, Derek Dunfield, Kurt Haas

Brain Research Centre, Graduate Program in Neuroscience and Dept. of Cellular and Physiological Sciences, University of British Columbia, Canada

The immature brain is exceptionally epileptogenic. While these seizures occur during critical periods of synaptogenesis and neuronal growth, little is known of the impact of neonatal seizures on neuronal circuit development. We have developed and characterized a novel model system designed specifically to examine effects of experimentally-induced seizures on the growth of neurons within the intact developing brain. This model system involves pentylenetetrazol (PTZ)-induced seizures in the albino Xenopus laevis tadpole and in vivo two-photon time-lapse imaging of individual immature neurons fluorescently labeled by single-cell electroporation. Bath application of PTZ elicits reproducible behavioural and electrographic seizures that cease upon washout of PTZ or by application of anticonvulsants. PTZinduced seizure activity is highly comparable to that observed in commonly utilized mammalian seizure models, as revealed by detailed analysis of behavioural seizures, extracellular electrophysiological recordings in vivo, and imaging of neuronal network dynamics in vivo using Calcium-sensitive fluorescent indicators. Rapid time-lapse imaging of fluorescently labeled individual developing neurons, within un-anaesthetized immobilized tadpoles during seizures, revealed that dendritic filopodia - dynamic ultrastructural processes involved in dendrite growth - are significantly less motile and have a significantly higher retraction rate as compared to controls. Imaging of the entire dendritic arbor of growing neurons over 8 hours revealed that prolonged seizures impede overall dendritic arbor growth, and that more sustained seizure activity eventually leads to retraction of existing dendritic branches. We next examined whether the observed short-term effects on dendritic growth during neuronal development led to a permanent change in the size and shape of the mature dendritic arbor. Neurons that experienced seizure activity (1 hr duration) during their development showed significantly reduced total dendritic size upon maturation, suggesting that seizure-induced effects are persistent. Collectively, these results demonstrate that seizures impede neuronal growth within the developing brain. These findings are particularly important given that the observed 
anatomical changes likely affect neuronal function and connectivity. Future directions include identifying molecular signals underlying the observed changes, and examining the effects of seizures on synapse formation.

\section{Does Early-Life Stress Play A Role In Epileptogenesis During Development?}

Lema P, *Levesque M, Bibeau K, Salas-Prato M, Brochu M, Carmant $L$

Ste-Justine Hospital Research Center

With our new experimental model of dual pathology, we have recently shown that a cortical dysplasia in rats at $\mathrm{P} 1$ increases the brain vulnerability to hyperthermic seizures at P10 and to chronic epilepsy, particularly, in males. Moreover, epileptic animals tend to have lower baseline temperature and to be smaller in size.

In this study, we hypothesize that perinatal stress is one of the mechanisms involved in epileptogenesis, and that this could be gender-dependent. We have thus compared corticosterone levels of male and female Sprague-Dawley pups at P1, before and two hours following the induction of a cortical freeze lesion. Similar measures were taken at P10 before and after the hypothermic seizure.

Only the lesioned male animal group showed a significant increase in corticosterone levels, compared to that of the females and the male naive and sham groups. We observed no significant differences between the sham and naive groups. At P10, all groups showed a mild yet significant rise of corticosterone levels following exposure to the hyperthermic seizure.

These results agree with previous studies in which we have shown that a cortical dysplasia and hyperthermic seizures render males more vulnerable to chronic epilepsy. We suggest that in rats, perinatal stress may play a critical role during epileptogenesis of the developing brain.

\section{Hypoxia-Induced Seizures In Aged Mice}

Marta Wais*, Chiping Wu, Jesse Gillis, Liang Zhang, Martin del Campo

Division of Fundamental Neurobiology, Toronto Western Research Institute

Epilepsy is most commonly thought of as a disease that begins to affect its sufferers in childhood. However, $60 \%$ of epilepsy cases in the elderly are stroke-related. In fact, seizures and epilepsy are frequent complications after a stroke. As common as this deadly combination is, the exact pathophysiology is not known, severely complicating treatment. Currently, there is no reliable model to study epileptic activity in the aged brain.

The purpose of this study was to determine whether episodes of hypoxia can induce seizures in aging mice. This may then lead to a more effective model for global hypoxia/ischemia and a framework for cellular and molecular studies to determine the exact mechanism of stroke- related epileptogenesis.

Eleven C57 black mice up to 20 months of age were used in this pilot study. Electrodes were implanted into the hippocampus and cerebral cortex to evaluate intra-cranial electroencephalographic (EEG) activity. Each mouse underwent two 15 minute episodes of hypoxia ( $96 \%$ nitrogen, $4 \%$ oxygen) 10 minutes apart. This was repeated 2-3 times, approximately seven to ten days apart.

Prior to the challenges, animals exhibited behavioural statedependent EEGs as previously described. Once challenged, all 11 mice showed motor convulsions and had clear episodes of cortical myoclonus and interictal spikes. In all cases, both the hippocampus and the cortex showed epileptic discharges.

With repeated hypoxia challenges, aged mice appeared susceptible to rhythmic epileptiform discharges. Our data shows for the first time that global hypoxia/ischemia can produce epileptic activity in older animals. We are currently examining the pharmaceutical features of these seizures and prevalence of recurrent spontaneous seizures.

\section{ADULT EPILEPSY ABSTRACTS}

\section{Impact of seizures in morbidity and mortality after stroke: a Canadian multi-centre cohort study}

JG Burneo*1, J Fang ${ }^{2}$, G Saposnik ${ }^{3}$

1. University of Western Ontario, Epilepsy Programme, London; 2. Institute for Clinical Evaluative Sciences, Toronto;3. Stroke Program, Department of Medicine, Division of Neurology, University of Toronto

Introduction: Limited information is available about the impact of seizures on stroke outcome. Our aims were to identify predictors of seizures after stroke, to determine whether the occurrence of seizures is an independent predictor of stroke outcome and to compare health resources utilization.

Material and Methods: We identified consecutive patients with acute stroke admitted to 11 hospitals in Ontario, from the Registry of the Canadian Stroke Network (2003-5). We compared patients with stroke and seizures and those without seizures (2 groups: seizures as part of the presentation and seizures after it). We analyzed stroke severity (Canadian neurological scale $=$ CNS $)$ and outcome measures: disability at discharge (modified-Rankin scale=mRS), mortality, length-ofstay, and resources utilization. Logistic regression modeled the presence of seizures in stroke, and identified predictors of seizures.

Results: Information in 5,027 patients was available. Seizures occurred as part of stroke presentation in 122 (2.4\%): mean age of 64.6 years and median CNS and mRS scores of 6 and 3; and during hospitalization after stroke in $138(2.7 \%)$ : mean age of 68.6 years and median CNS and mRS scores of 5 and 4 . Seizures 
at stroke presentation were associated with higher mortality at 30-day $(24.6 \%$ vs. $17.2 \%, \mathrm{p}=0.03)$ and 1 -year post-stroke $(39.3 \%$ vs. $28 \%, p<0.05)$, but did not influence in-hospital deaths $(\mathrm{p}=0.2)$. Hospitalization was longer and $\mathrm{mRS}$ higher in patients with seizures after stroke $(\mathrm{p}<0.05)$, but no differences were seen in those with seizures as part of the presentation $(\mathrm{p}=0.75)$. Multivariate analysis revealed that age $(<60)$, low CNS score, weakness, and non-lacunar infarcts were associated with seizures at the stroke presentation; while low CNS score, neglect, pneumonia, ICH, and seizures as stroke presentation, were associated to occurrence of seizures after stroke.

Conclusions: Seizures after stroke accounted for $2.4 \%$ of all cases. Hemorrhages were more likely to cause seizures. Patients with seizures after stroke had more disability, higher mortality, and longer hospital stay.

\section{Surgery For Temporal Lobe Epilepsy With Bilaterally Independent Ictal Onset Foci}

\section{*Tomonori Ono, Hiroshi Baba, Keisuke Toda, and Kenji Ono}

Department of Neurosurgery, National Nagasaki Medical Center, and Yokoo Hospital

Objective: Surgery for bilateral temporal lobe epilepsy (BiTLE), herein defined as seizures arising independently from both temporal lobes, has been demonstrated to have poor efficacy. However, lateralized MRI abnormality and a preponderance of interictal spikes on EEG have been identified as factors for good surgical outcome. Ictal EEG findings are also a decisive factor for determining the resection side. Predominant ictal onset side (PIOS) is considered to be a direct measure of laterality of ictogenisity, however, this has yet to be quantitatively analyzed. In this study, we reviewed our surgical series of Bi-TLE patients and determined the correlation between quantitatively assessed PIOS and postoperative outcome.

Methods: We analyzed data from 23 patients with Bi-TLE who had undergone anterior temporal lobectomy. Patients' ages at the time of the operation ranged from 14 to 55 years (mean 31.2 years). Diagnoses of Bi-TLE were confirmed using subdural electrode recordings, and the side of resection was determined by PIOS. Postoperative seizure outcome was assessed using Engel's outcome classification between 9 and 161 months (mean 80 months) after surgery. Percentages of ictal onset side calculated on the basis of all recorded seizures and other clinical characteristics were correlated with postoperative seizure outcome.

Results: Regarding postoperative seizure outcome, 9 patients $(39.1 \%)$ were class I, 8 patients $(34.8 \%)$ were class II, and 6 patients $(26.1 \%)$ were class III. The following items were found to be statistically significant factors for good surgical outcome: 1) no history of severe encephalitis $(p=0.03), 2)$ higher percentage of PIOS (class I vs. class II-III, $87.6 \pm 3.1 \%$ vs. $73.7 \pm 3.3 \%, p=0.009)$, and 3 ) lateralized lesion ( $p=0.01)$, or absence of bilateral abnormalities on MRI $(p=0.02)$. Furthermore, multivariate analyses showed that factors 1) and 2) were independent predictors of good outcome.
Conclusions: Surgery for Bi-TLE results in a greater reduction of seizures if preoperative evaluations show good predictive factors. In particular, when the percentage of PIOS is greater than $85 \%$, a more favorable outcome can be obtained.

\section{Electrical Stimulation Of The Insular Cortex}

Dong Bach Nguyen, Jean-Maxime Leroux, Ramez Malak, Lionel Carmant, Jean-Marc Saint-Hilaire, Normand Giard, Patrick Cossette, Alain Bouthillier, Dang Khoa Nguyen*.

Neurology service, Notre-Dame Hospital, 1560 Sherbrooke East, Montreal, Canada, H2L 4M1.

Introduction: In order to better define the characteristics of insular cortex seizures, we analyzed the results from cortical stimulation of the insula performed during the intracranial study of 9 patients with refractory epilepsy.

Methodology: A total of nine patients had an intracranial study which included electrodes sampling the insular region. The structures to be explored were defined on the basis of a comprehensive presurgical evaluation. The following stimulus parameters were used: stimulus frequency $50 \mathrm{~Hz}$; pulse width $100 \mathrm{~ms}$, stimulus intensity 1-10 mA; stimulus train duration five sec.

Results: A total of 96 intracortical insular stimulations were performed on 36 insular sites. The clinical responses were evoked in the absence of afterdischarges (AD) in 14 sites and with a brief localized AD in 21. Responses from one insular site were followed by a diffusing $\mathrm{AD}$ and excluded from the topographical analysis. Somatosensory symptoms were the most recurrent responses, representing $61 \%$ of the evoked responses. Sensations were reported as numbness, tingling, warmth, dizziness, prickle, airflow and electric current, were mainly contralateral but at times bilateral, and could affect restricted territories or larger areas. Sites evoking somatosensory symptoms were widely distributed but those involving the rhinolaryngeal region were all located in the anterior insula while those involving limbs were more posteriorly located. Viscerosensory symptoms (nausea, buzzing in abdomen, warmth in digestive system, metallic taste) were next in line (11\% of evoked responses), all located in the anterior insula. Four of the eight contacts involved ocular movements causing difficulty to focus or fixate an object when stimulating the anterior right insula, while the other half provoked the contralateral elevation of the right arm, when the posterior left insula was stimulated. Other evoked responses were auditory $(8 \%)$, vestibular $(3 \%)$ or linguistic (3\%). Heart rates prior to and during stimulation did not change significantly.

Discussion: The most frequently evoked responses in our series are coherent with data found in the literature on insular stimulation in that all previously reported responses, except for cardiac effects, have been reproduced. One should suspect insular cortex epilepsy in the presence of a combination of visceral, motor association and especially somatosensory symptoms due to the confluence of functions in a restricted region. 


\section{Selective Postictal Aphasia in Bilinguals: Two Cases with Implications for Cerebral Language Organization}

Yasser Aladdin, Thomas J. Snyder*, S. Nizam Ahmed

University of Alberta and Hospital, Department of Neurology, *Department of Psychiatry

Introduction: Ictal and postictal language dysfunction is common and strongly predictive of language laterality in monolinguals. For bilinguals, selective dysfunction has been reported for a single language with focal cerebral lesions, electrical brain stimulation, and intracarotid sodium amytal. Two Ukrainian-English right-handed bilingual patients with left perisylvian structual lesions, recent-onset complex-partial seizures, and postictal aphasia in English, are presented and discussed with regard to mechanisms of selective aphasia, factors contributory to language lateralization in bilinguals, and the development of intrahemispheric organization of language.

Cases: Ukrainian was the native language of both patients with English acquired at $\sim 7$ years of age. Regular/video-EEG showed left temporal epileptogenesis. A 56 year-old male, who had a left-sided hemorrhagic stroke at age 50 and had not spoken Ukrainian for 40 years, was unable to speak English for 20 minutes postictally but had global preservation of Ukrainian. A 71 year-old female, who had a left temporal arachnoid cyst and also had not spoken Ukrainian since childhood, had 10 to 15 minute postictal expressive aphasia but preservation of comprehension in English and preservation of speech and comprehension in Ukrainian.
Implications: These cases are instructive and consistent with the literature on cerebral organization of language in bilinguals. First, for both patients, postictal aphasia with preservation of Ukrainian is consistent with findings from clinical and experimental studies indicating that later age of second language acquisition ( $>6$ years) rather than language proficiency is a primary factor in language laterality. Second, global aphasia in the male patient with a late lesion vs. expressive aphasia with preservation of comprehension of English in the female patient with a prenatal/early lesion, is consistent with the atypical language laterality described for individuals with left-sided lesions sustained prior to age 5. Although IAP or fMRI were not done to assure left hemisphere laterality of Ukrainian and English, this is very probable, and the selective postictal aphasia observed for both patients is consistent with the differential intrahemispheric organization reported for the two languages of bilinguals. Possible mechanisms of selective postictal aphasia, e.g., active inhibition, and differences in language networks in bilinguals will be discussed. 


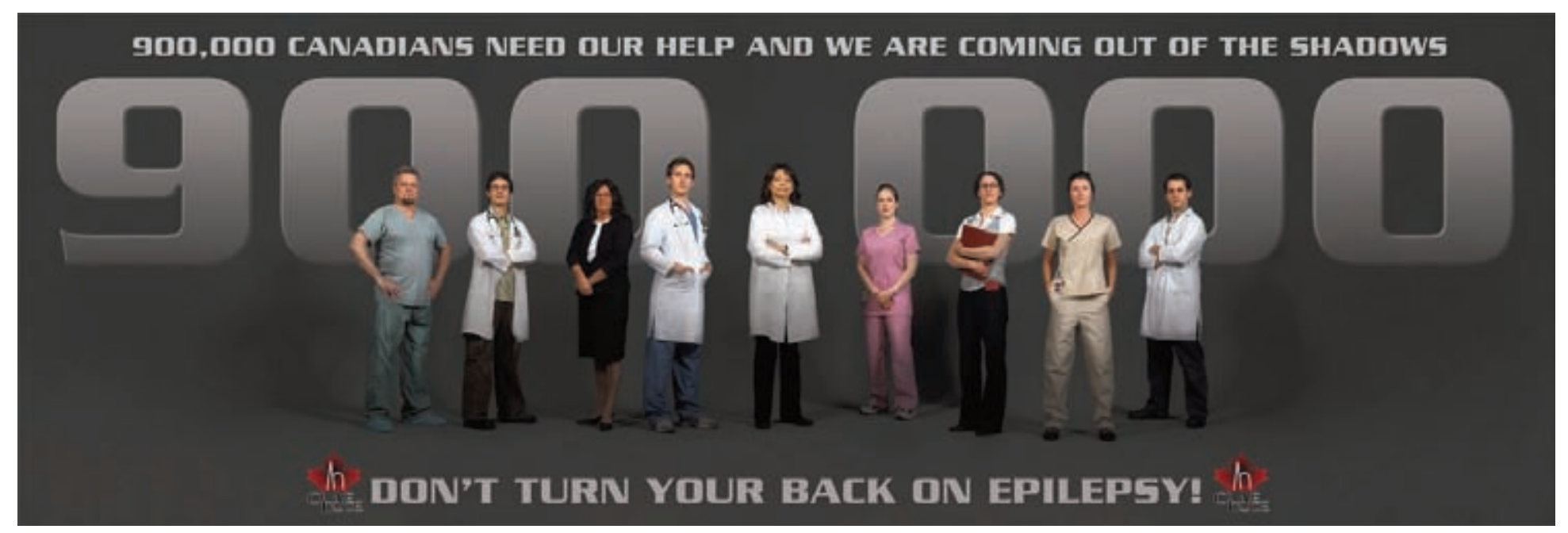

